\title{
Understanding the role of ascorbic acid and GDP-mannose pyrophosphorylase affecting ammonium sensitivity, genome stability and flowering time in Arabidopsis thaliana
}

Chase F. Kempinski

West Virginia University

Follow this and additional works at: https://researchrepository.wvu.edu/etd

\section{Recommended Citation}

Kempinski, Chase F., "Understanding the role of ascorbic acid and GDP-mannose pyrophosphorylase affecting ammonium sensitivity, genome stability and flowering time in Arabidopsis thaliana" (2011). Graduate Theses, Dissertations, and Problem Reports. 4740.

https://researchrepository.wvu.edu/etd/4740

This Thesis is protected by copyright and/or related rights. It has been brought to you by the The Research Repository @ WVU with permission from the rights-holder(s). You are free to use this Thesis in any way that is permitted by the copyright and related rights legislation that applies to your use. For other uses you must obtain permission from the rights-holder(s) directly, unless additional rights are indicated by a Creative Commons license in the record and/ or on the work itself. This Thesis has been accepted for inclusion in WVU Graduate Theses, Dissertations, and Problem Reports collection by an authorized administrator of The Research Repository @ WVU. For more information, please contact researchrepository@mail.wvu.edu. 


\title{
Understanding the role of ascorbic acid and GDP-mannose pyrophosphorylase affecting ammonium sensitivity, genome stability and flowering time in Arabidopsis thaliana
}

\author{
Chase F. Kempinski \\ Thesis submitted to the \\ Eberly College of Arts and Sciences \\ at West Virginia University \\ in partial fulfillment of the requirements \\ for the degree of \\ Master of Science \\ in \\ Biology \\ Dr. Carina Barth, PhD, Chair \\ Dr. Ashok Bidwai, PhD \\ Dr. Jed Doelling, PhD \\ Department of Biology \\ Morgantown, West Virginia \\ 2011
}

Key Words: ascorbic acid, Arabidopsis thaliana, GDP-mannose pyrophosphorylase, ammonium $\left(\mathrm{NH}_{4}{ }^{+}\right)$, genome stability, flowering time 


\section{ABSTRACT}

\section{Understanding the role of ascorbic acid and GDP-mannose pyrophosphorylase affecting ammonium sensitivity, genome stability and flowering time in Arabidopsis thaliana}

\section{Chase F. Kempinski}

L-ascorbic acid is an important antioxidant in both plants and animals. In plants, it is important for detoxifying reactive oxygen species that are produced during photosynthesis and cellular metabolism. It also contributes to several facets of plant growth as an enzyme cofactor, signaling molecule, and a precursor to several other metabolites. It has been implicated in the control of flowering time and senescence as well as several other growth processes largely through work with the ascorbic acid-deficient vtc mutants of Arabidopsis thaliana. Biochemical and genetic experiments have identified several pathways contributing to ascorbic acid biosynthesis, with the D-mannose/L-galactose pathway predominantly responsible for the accumulation of ascorbic acid in Arabidopsis. Key enzymes in this pathway include GDPmannose pyrophosphorylase (encoded by VTC1), GDP-galactose phosphorylase (encoded by VTC2/5), and galactose-1-P phosphatase VTC4 genes.

Nitrogen is one of the crucial minerals for plant growth and often one of the most limiting in nature. Ammonium is the favored form of nitrogen taken up by plants, but excess levels lead to toxicity since ammonia (the conjugate base) can diffuse across membranes and depolarize membrane potentials. Recent work has indicated that the enzyme GDP-mannose pyrophosphorylase (VTC1 in Arabidopsis thaliana), which generates the essential nucleotide sugar GDP-mannose, important for protein N-glycosylation, plays an important role in response to ammonium. Arabidopsis mutants with defective VTC1 have stunted growth when grown in tissue culture in the presence of ammonium. We demonstrate here that the response of VTC1 to ammonium is $\mathrm{pH}$-dependent and is not a result of ascorbic acid deficiency and is largely independent of the defects in protein $\mathrm{N}$-glycosylation. We speculate that VTC1 activity is regulated in a $\mathrm{pH}$-dependent manner and discuss our findings in the context of recent reports showing that GDP-mannose pyrophosphorylase forms oligomers necessary for optimal enzyme activity.

Currently, the Mendelian inheritance of genetic information is regarded as a core tenet in our understanding of how genetic information is passed from one generation to the next. However, recent experiments have shown that plants are able to produce progeny that are genetically unique from their parents. The genotypes of these progeny are not predictable given the laws of Mendelian inheritance and a decisive explanation as to how they arise is still not known. Often, these genetically unique progeny are disregarded as experimental errors or contaminants. However, we have isolated a novel Arabidopsis mutant, svt2, which is capable of producing genetically distinct progeny from self-pollinated plants at a persistent relatively high rate ( $10 \%$ of progeny exhibit a genotype different from the parent). The svt 2 mutant was 
isolated in a suppressor screen of the vtc1-1 mutant, which aimed to identify genes important for the ammonium sensitivity exhibited by vtc1-1. Further characterization of the isolated $M_{0}$ plant revealed a genotype that was different from vtc1-1 and the wild type (Columbia-0 [Col-0] accession), but was more similar to the genotype of Landsberg erecta-0 (Ler-0). Multiple experiments ruled out possible seed or pollen contamination. Furthermore, svt2 offspring with Col-like characteristics can produce plants with Ler-like features, suggesting genotypic and phenotypic instability in svt2. We speculate that the additive stress of the chemical mutagen used to generate svt2 and the elevated oxidative stress in the vtc1-1 mutant, trigged activation of a genome restructuring event that is an inherent capability present in plants. This is supported by other studies which show plants under intense abiotic stresses can produce genotypically different progeny.

The ascorbic acid deficiency in the vtc mutants causes several pleiotropic phenotypes beyond oxidative stress, including early flowering and senescence. In a study to identify the flowering pathway that ascorbic acid interacts in and causes this phenotype, a double mutant with a defect in the flowering time gene, FCA (fca-1, in the Ler-0 background), and vtc1-1 had partially recovered ascorbic acid but maintained a delayed flowering time. This suggested interaction of FCA or one of its interacting partners in ascorbic acid biosynthesis. Further analyses indicated that FCA does not act directly affect transcription of genes within the Dmannose/L-galactose pathway, but may act through post-transcriptional regulation. We speculate that the increased ascorbic acid in vtc1-1 fca-1 is most likely caused by the differing accession backgrounds of the two mutants. However, since vtc1-1 fca-9 and vtc4-1 fca-9 mutants ( $f c a-9$ is in the Col-0 background) exhibit significantly increased ascorbic acid compared to their respective single vtc mutants, FCA does indeed appear to play a role in ascorbic acid biosynthesis but does so through an unidentified mechanism in the D-mannose/Lgalactose pathway or possibly in another biosynthetic pathway. 


\section{TABLE OF CONTENTS}

LIST OF FIGURES

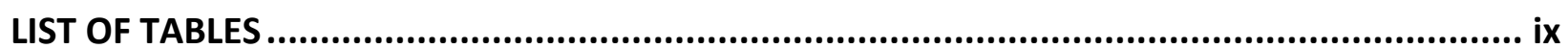

ACKNOWLEDGEMENTS........................................................................................................... $\mathrm{x}$

1 CHAPTER 1: Toward the mechanism of $\mathrm{NH}_{4}{ }^{+}$sensitivity mediated by Arabidopsis GDP-

mannose pyrophosphorylase .................................................................................

$1.1 \quad$ INTRODUCTION....................................................................................................... 1

1.1.1 Ascorbic acid as an antioxidant and enzyme cofactor in plants .................................... 1

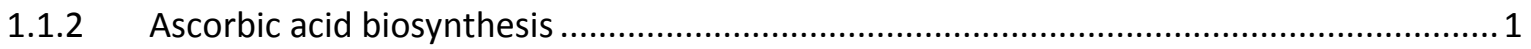

1.1.3 Ascorbic acid-deficient Arabidopsis thaliana vtc mutants.............................................. 3

1.1.4 GDP-mannose is an important molecule for ascorbic acid biosynthesis and protein $\mathrm{N}$ -

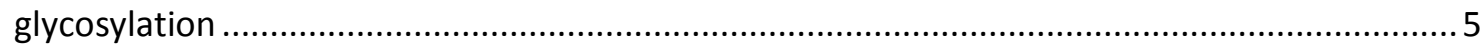

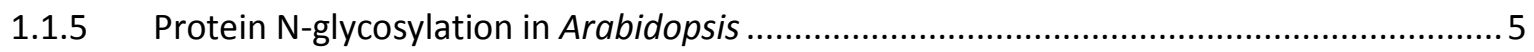

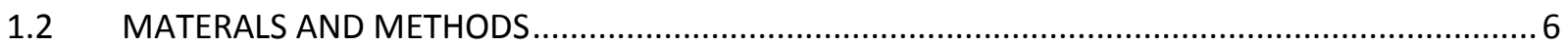

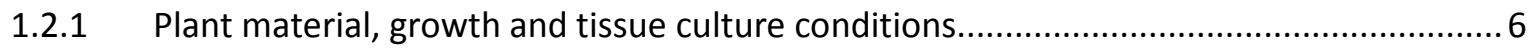

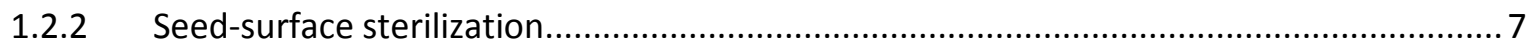

1.2.3 Generation of vtc1-1 VTC1 heterozygous mutants ................................................... 7

1.2.4 RNA isolation, cDNA synthesis and quantitative reverse transcriptase polymerase chain

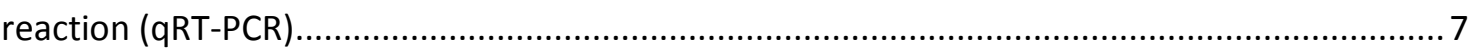

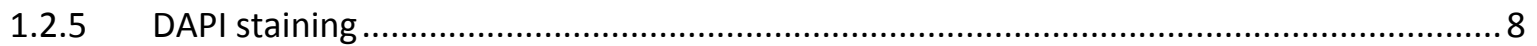

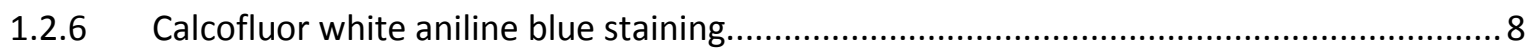

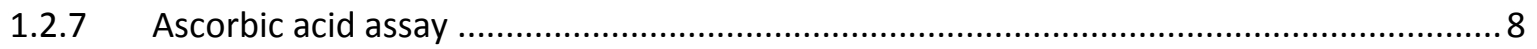

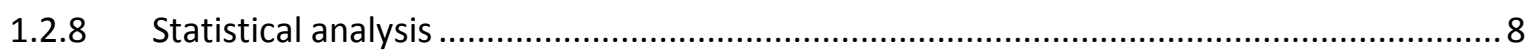

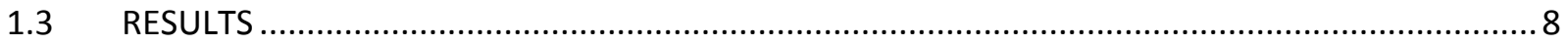

1.3.1 Transcript levels of ER stress genes are higher in $v t c 1-1$ in the presence of $\mathrm{NH}_{4}{ }^{+} \ldots \ldots \ldots \ldots . .8$

1.3.2 vtc1-1 exhibits PCD and some cell cycle defects in the presence of $\mathrm{NH}_{4}{ }^{+} \ldots \ldots \ldots \ldots \ldots \ldots \ldots . . . . . . .11$

1.3.3 vtc1-1 exhibits cell wall defects and accumulates callose in the presence of $\mathrm{NH}_{4}^{+} \ldots \ldots \ldots .11$

1.3.4 pmi and $\mathrm{pmm}$ mutants are not $\mathrm{NH}_{4}{ }^{+}$-sensitive ........................................................... 14

1.3.5 Primary root growth is recovered in vtc1-1 at pH 7.0 in the presence of $\mathrm{NH}_{4}{ }^{+} \ldots \ldots \ldots \ldots \ldots 17$

1.3.6 Root development in the presence of $\mathrm{NH}_{4}{ }^{+}$is fully recovered in vtc1-1 containing one

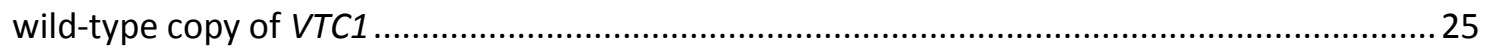

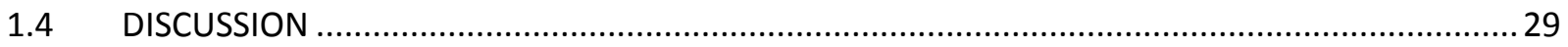

1.4.1 Impaired GDP-mannose biosynthesis, resulting in ER stress and defective protein Nglycosylation contributes to but is not the primary cause of $\mathrm{NH}_{4}{ }^{+}$sensitivity in $v t c 1-1 \ldots \ldots \ldots . .29$

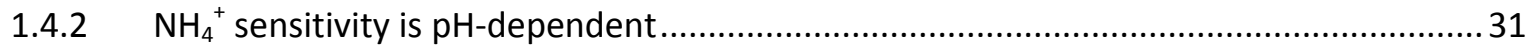

1.4.3 Understanding the biochemical properties of GMPase protein will enhance our

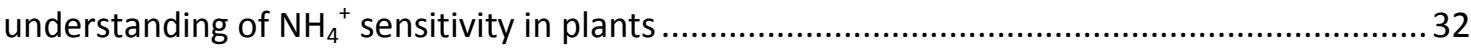

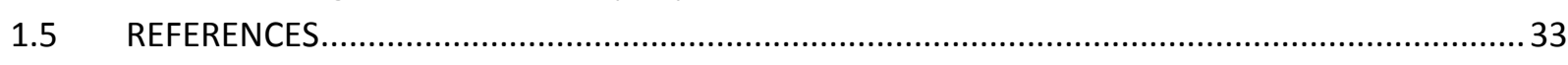

2 CHAPTER 2: The novel Arabidopsis thaliana svt2 suppressor of the ascorbic aciddeficient mutant vtc1-1 exhibits phenotypic and genotypic instability ....................... 38 


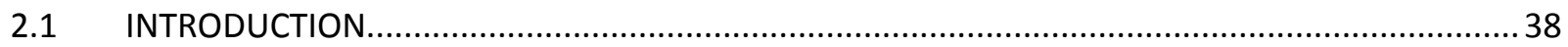

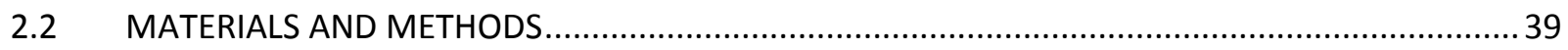

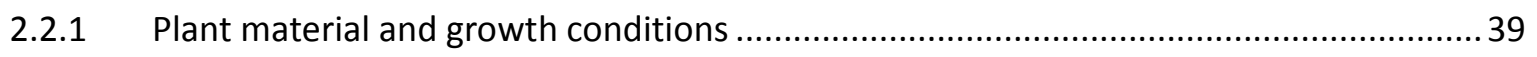

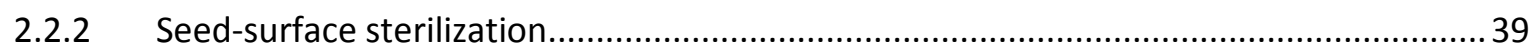

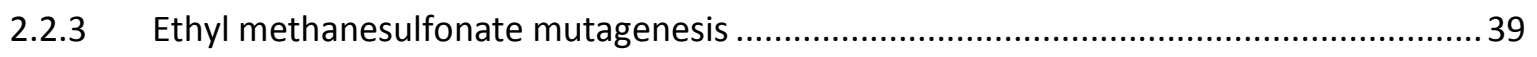

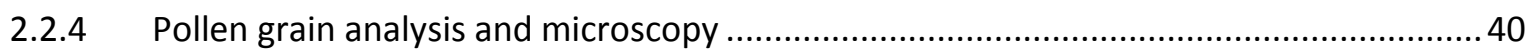

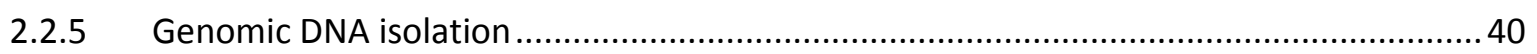

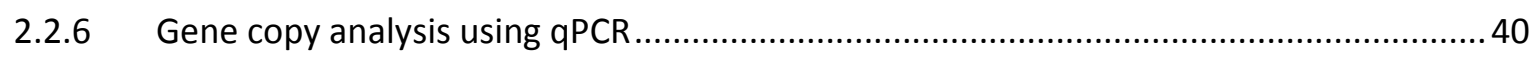

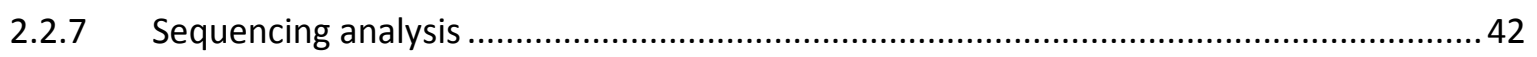

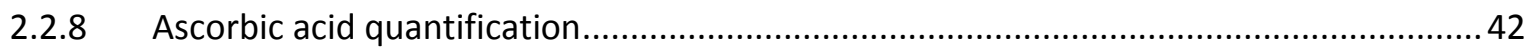

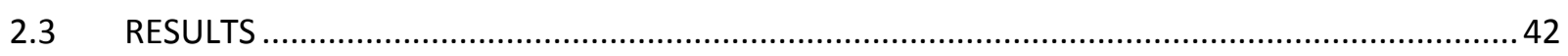

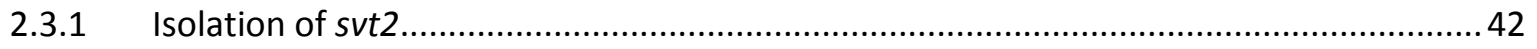

2.3.2 svt2 has similarities with the Ler phenotype, but has also phenotypic characteristics that

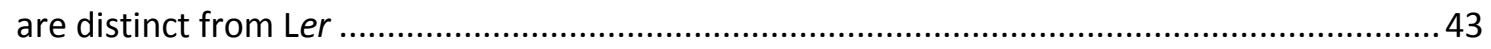

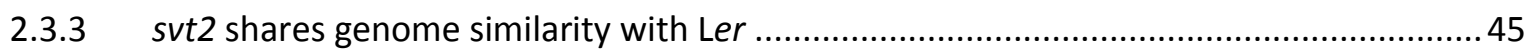

2.3.4 svt2 exhibits phenotypic and genotypic instability.......................................................51

2.3.5 Genome instability in svt2 does not appear to be triggered by a transgenerational

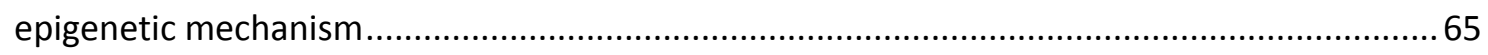

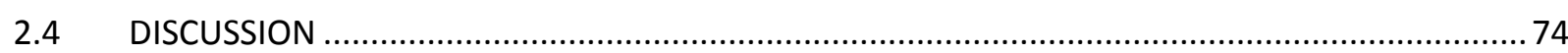

2.4.1 svt2 is a novel Arabidopsis mutant and not a result of an experimental artifact, seed

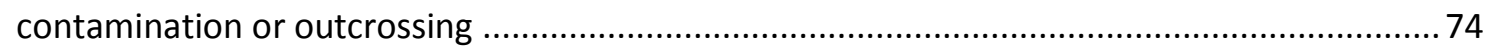

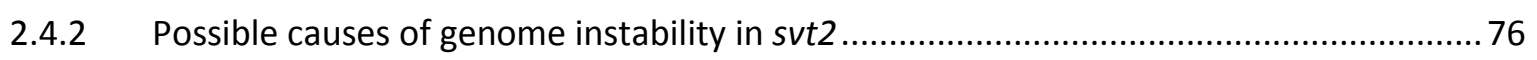

2.4.3 Possible mechanisms of genome restoration in svt2 ................................................ 77

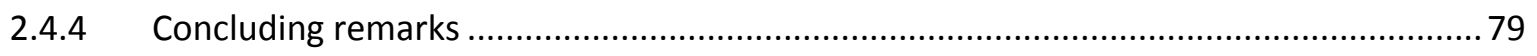

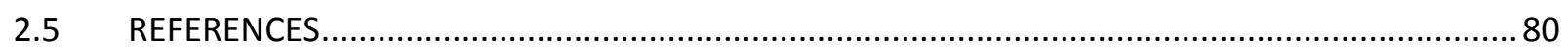

3 CHAPTER 3: Elucidating the role of the autonomous flowering pathway gene FCA in the regulation of ascorbic acid biosynthesis in Arabidopsis thaliana ............................... 83

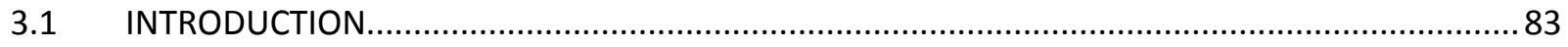

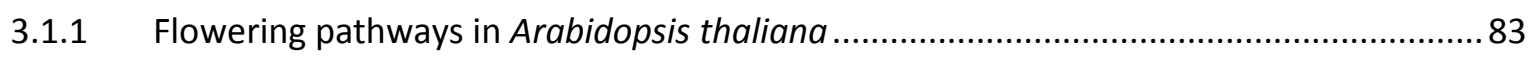

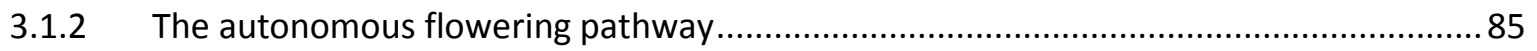

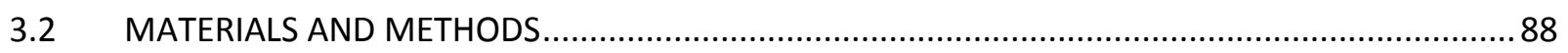

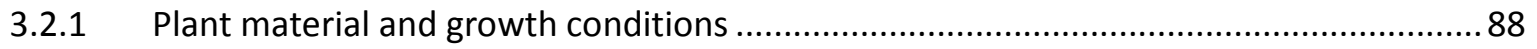

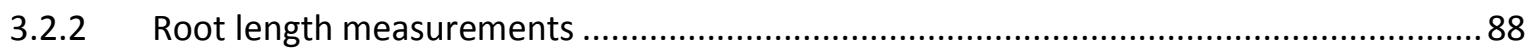

3.2.3 Generation and identification of $v t c$ and flowering time double mutants...................... 88

3.2.4 Qualitative AA content analysis in double mutants ..................................................90

3.2.5 RNA isolation, cDNA synthesis, and gene expression analysis ..................................... 90

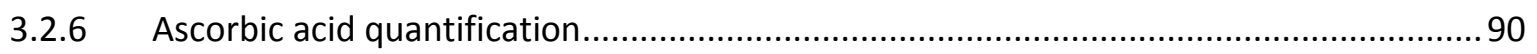

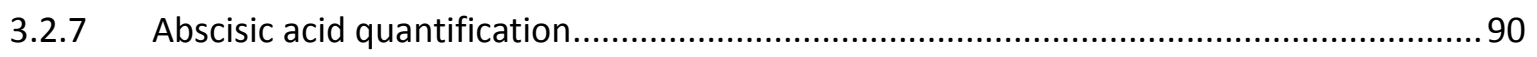

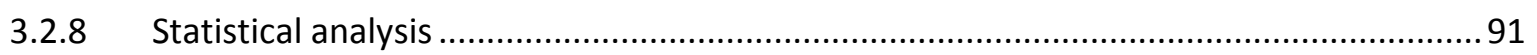

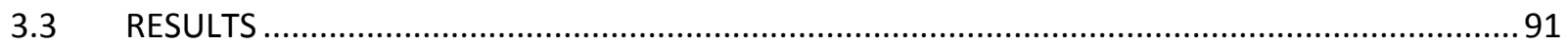


3.3.1 AA levels are partially recovered in vtc fca double mutants along with some but not all

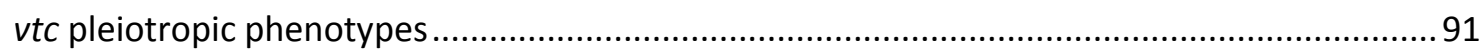

3.3.2 VTC transcripts are not altered in $v t c f c a$ double mutants............................................ 95

3.3.3 Ascorbic acid levels in autonomous pathway flowering time mutants fca-1, fca-9, fld-3,

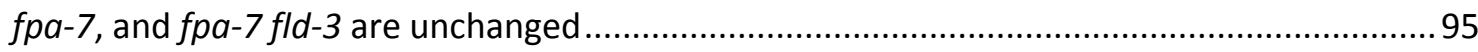

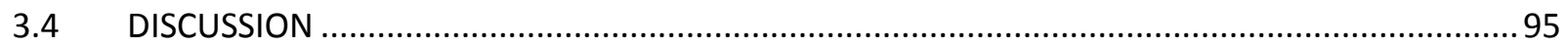

3.4.1 The autonomous flowering pathway protein, FCA, does not appear to be involved in

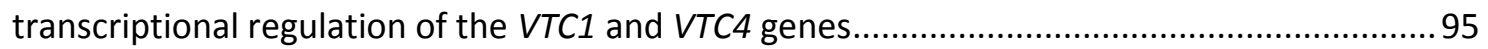

3.4.2 A wide variety of control mechanisms affect the autonomous and other flowering pathways in a combinatorial manner, making it difficult to elucidate the manner in which ascorbic acid biosynthesis is affected by flowering time .................................................... 100

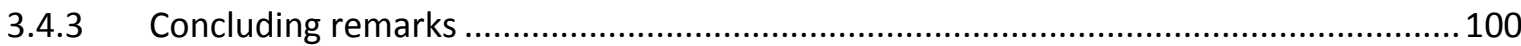

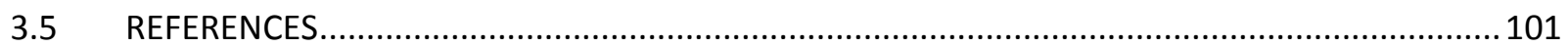




\section{LIST OF FIGURES}

Figure 1.1 Schematic of the known pathways contributing to AA biosynthesis in plants.

Figure 1.2 Transcript levels of the ER stress genes BIP (binding protein) and BII (BAX inhibitor-1) in the presence and absence of $\mathrm{NH}_{4}^{+}$. 10

Figure 1.3 Microscopic analysis of Col-0 wild-type and vtc1-1 roots in (a) the presence and (b) absence of $\mathrm{NH}_{4}{ }^{+}$and (c) mRNA levels of $\mathrm{H} 4$ (HISTONE H4) and (d) CyCB1 (CYCLIN B1) in the presence and absence of $\mathrm{NH}_{4}^{+}$.

Figure 1.4 Cellulose $(a, b)$ and callose $(c, d)$ staining in roots of seven-day-old Col-0 wild-type and vtc1-1 plants grown in the presence and absence of $\mathrm{NH}_{4}^{+}$. 13

Figure 1.5 Total ascorbic acid (AA) content in Col-0 wild-type plants and pmi-1, pmm-21, and vtc1-1 mutants grown on soil.

Figure 1.6 Primary root length of Col-0 wild type, pmi-1, pmm-12 and vtc1-1 mutants in the (a) presence and (b) absence of $\mathrm{NH}_{4}{ }^{+}$, (c) during heat stress, and (d) in the presence of $\mathrm{Cd}$. 16

Figure 1.7 Primary root lengths of seven-day-old Col-0 wild-type and vtc1-1 seedlings in the (a) absence and (b) presence of $\mathrm{NH}_{4}^{+}$in growth media ranging from acidic to alkaline $\mathrm{pH}$ values...... .18

Figure 1.8 Primary root length of seven-day-old Col-0 wild-type and vtc1-1 seedlings in the presence of $\mathrm{NH}_{4}{ }^{+}$and the buffering agent MES $(2.5 \mathrm{mM})$ in tissue culture media at $\mathrm{pH}$ 5.0, 5.7 and 7.0. 19

Figure 1.9 Primary root length of seven-day-old Col-0 wild type and vtc1-1 in the presence of increasing concentrations of $\mathrm{NH}_{4} \mathrm{Cl}$.

Figure 1.10 Primary root length of Col-0 wild-type plants and vtc1-1 mutants in the presence of $\mathrm{NH}_{4}{ }^{+}$and (a) $\mathrm{KCl}$ or (b) $\mathrm{CaCl}_{2}$ 24

Figure 1.11 Primary root length of Col-0 wild-type plants and ascorbic acid-deficient mutants grown in the absence of $\mathrm{NH}_{4}{ }^{+}$and in the presence of increasing concentrations of (a) $\mathrm{NaCl}$, (b) mannitol, (c) $\mathrm{KCl}$ or $(\mathrm{d}) \mathrm{LiCl}$.

Figure 1.12 Phenotypic and molecular characterization of Col-0 wild type, vtc1-1 homozygous and vtc1-1 VTC1 heterozygous mutants...

Figure 1.13 Total ascorbic acid (AA) content in Col-0 wild-type plants, vtc1-1 homozygous and vtc1-1 VTC1 heterozygous mutants grown in the presence of $\mathrm{NH}_{4}{ }^{+}$. .28

Figure 2.1 Schematic of the isolation of the $v t c 1-1$ suppressor mutant svt2 ..........................................4

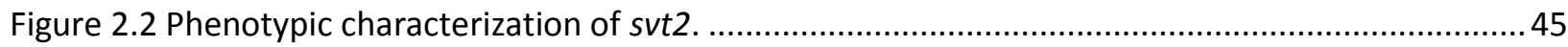

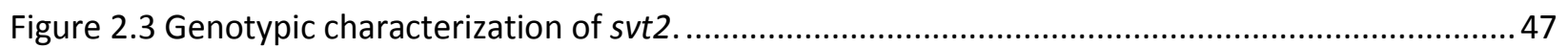

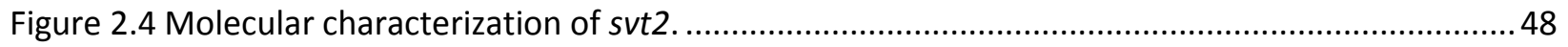

Figure 2.5 Insertion/Deletion polymorphism analysis in svt2, Col-0 and Ler-0..................................50

Figure 2.6 Sequence alignment of the VTC1 gene sequence of the Col-0 TAIR database, the vtc1-1, svt2

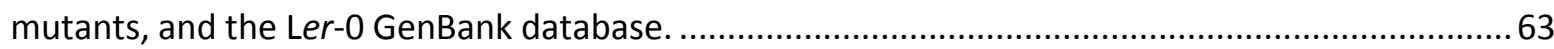

Figure 2.7 Photographs showing the phenotype of svt2 revertants...................................................67

Figure $2.8 \mathrm{Gel}$ imagine showing InDel polymorphisms in svt2, Col-0, Ler-0, and revertants. ....................68

Figure 2.9 Sequence alignment of the VTC1 promoter InDel polymorphism sequence of the Col-0 TAIR database, the Ler-0 Genbank database, the svt2 K1 Col R M (Col-like phenotype) and the svt2 K1

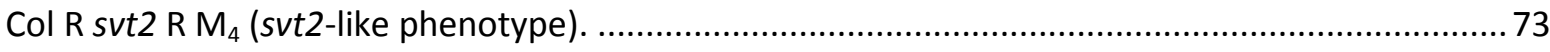


Figure 3.1 Diagram of flowering pathways in Arabidopsis and downstream genes cumulating in floral

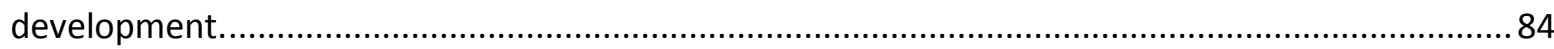

Figure 3.2 Diagram of the four alternative FCA transcripts after Macknight et al. (1997)...................... 87

Figure 3.3 Mean ascorbic acid (AA) content in three-week-old rosette leaves of vtc and fca single and double mutants compared to Col, Ler and Col/Ler wild-type controls.

Figure 3.4 Total abscisic acid (ABA) content in Col, Ler and Col/Ler wild-type controls compared to vtc1-1 and fca-1 single mutants and the vtc1-1 fca-1 double mutant.

Figure 3.5 Primary root length in seven-day-old Col, Ler, Col/Ler wild-type controls, vtc1-1, fca-1, fca-9 single and vtc1-1 fca-1 and vtc1-1 fca-9 double mutants grown on 1x MS medium.

Figure 3.6 Relative transcript levels of VTC1 (a) and VTC4 (b) in mutants and respective controls normalized to TUBULIN mRNA.

Figure 3.7 Total ascorbic acid (AA) content in three-week-old rosette leaves of autonomous flowering pathway mutants compared to Col wild type (Col WT).

Figure 3.8A hypothetical model of the interaction between VTC1 and FCA in the vtc1-1 fca-1 double mutant. 


\section{LIST OF TABLES}

Table 1.1 Pleiotropic phenotypes of Arabidopsis vtc mutants.

Table 1.2 Sequences of oligonucleotide primers used for qRT-PCR.

Table 1.3 Calculated molar concentrations of $\mathrm{NH}_{3}$ and $\mathrm{NH}_{4}{ }^{+}$in $1 \times \mathrm{MS}$ media from $\mathrm{pH} 1$ to $\mathrm{pH} 11$ using the Henderson-Hasselbalch equation.

Table 2.1 Forward (F) and reverse (R) sequences for primers used in analyzing the VTC1 gene and for amplifying five Col/Ler Insertion/Deletion (InDel) polymorphisms.

Table 2.2 Quantitative PCR to verify that VTC1 is a single copy gene in Col-0 and Ler-0 wild types and vtc1-1 and svt2 mutants.

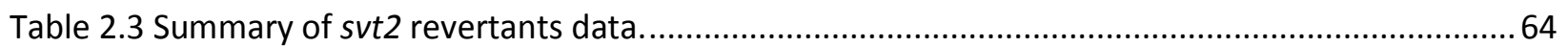

Table 2.4 Summary of PCR-based molecular genotypes in Col-0, vtc1-1, Ler-0, svt2, and revertants........66

Table 2.5 Summary of insertion/deletion polymorphism analysis of reciprocal crosses between svt2 and

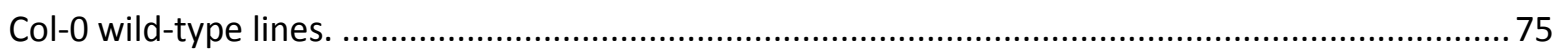

Table 3.1 Sequences of oligonucleotide primers used for qRT-PCR and sequencing.............................. 89 


\section{ACKNOWLEDGEMENTS}

I want to thank my adviser, Dr. Carina Barth for her patience, guidance, and time that she has given to help me further my abilities as a scientist. The amount I have learned from working with her has been invaluable to me in all aspects of my career. I know that many of the opportunities that I have been able to capitalize on would not have been possible without someone who genuinely cared about my future. I feel very fortunate that I was able to lay the foundation for my future with her help.

I also want to thank the other members who have worked in the lab: Madhumati Mukerjee for her help, motivation, and friendship; Rawaa Haffar; Sam Crowell ; Caleb Smeeth; Dr. Simeon Kotchoni; Zach Gouzd; Ryan Imperio; and Hilary Steele. Thanks must also be extended to Dr. Richard Macknight and his lab members at the University of Otago for their help, contributions, the great opportunity to work with them and to the National Science Foundation for the East Asia Pacific Sciences Institute Fellowship.

My committee members Dr. Ashok Bidwai and Dr. Jed Doelling have also given me their time and aided me in my progress to ensure that I received a well-rounded education. I also extend thanks to temporary members of my committee: Dr. Philip Keeting, Dr. Vagner Benedito, and Dr. Clifton Bishop. Thanks must also be addressed to Dr. Karen Weiler for her help, time, and allowing me to give input to her upper division undergraduate course. Thank you to the other faculty and graduate students within the biology department for their assistance, and for creating a positive atmosphere which helped to make my work easier.

Finally, thanks to my family for their eternal support. Their sacrifices made this possible for me and I owe them greatly for the innumerable ways they have helped, both large and small. 


\section{CHAPTER 1: Toward the mechanism of $\mathrm{NH}_{4}{ }^{+}$sensitivity mediated by Arabidopsis GDP-mannose pyrophosphorylase}

\subsection{INTRODUCTION}

\subsubsection{Ascorbic acid as an antioxidant and enzyme cofactor in plants}

L-ascorbic acid (AA) is an important antioxidant molecule in both plants and animals. Its main function is to detoxify reactive oxygen species (ROS) produced during respiration and photosynthesis (Noctor and Foyer, 1998; Conklin, 2001). In plants, it also functions as a cofactor for violaxanthin de-epoxidase and dioxygenase enzymes, which are important for the synthesis of the phytohormones ethylene and giberrellic acid (GA); hydroxyproline and hydroxylysine, which are important cell wall components (Conklin, 2001) as well as the synthesis of many other secondary metabolites (Arrigoni and De Tullio, 2000; Smirnoff, 2000; Arrigoni and De Tullio, 2002).

\subsubsection{Ascorbic acid biosynthesis}

Ascorbic acid is the most abundant antioxidant within plant cells with average values ranging from 2-25 $\mathrm{mM}$ and even higher amounts in the plastids (Smirnoff, 2000). There are three identified pathways in Arabidopsis thaliana that contribute to AA biosynthesis (Fig. 1.1): the L-galactose/D-mannose pathway, initially characterized by Wheeler et al. (1998), which contributes to the majority of the plant AA, the D-galacturonic acid pathway, and the myoinositol pathway (Lorence et al., 2004; Hancock and Viola, 2005). It should be noted that Wolucka and Van Montagu (2003) showed in vitro that GDP-mannose 3', 5' epimerase is capable of producing both GDP-L-galactose and GDP-L-gulose. They also demonstrated that plants incorporate L-gulose into $A A$, indicative of an alternative route to $A A$ that branches from the initially characterized D-mannose/L-galactose pathway. Using biochemical and genetic assays, Wheeler et al. (1998), described the L-galactose/D-mannose pathway (Fig. 1.1) after discovering that Arabidopsis plants fed with L-galactose had an increased AA content similar to plants fed with L-galactono-1,4-lactone. This provided evidence to demonstrate that plants can synthesize $A A$ without inversion of the hexose carbon skeleton, which is known not to occur in plant AA synthesis based on radiolabeled glucose experiments (Loewus, 1963; Wheeler et al., 1998). Ascorbic acid biosynthesis can also occur through D-galacturonic acid, but this pathway is believed to mainly serve as a salvage mechanism during the breakdown of pectin constituents: homogalacturonan and rhamnogalacturonan I. Lorence et al. (2004) demonstrated that myoinositol

is also

a

precursor

in

an 


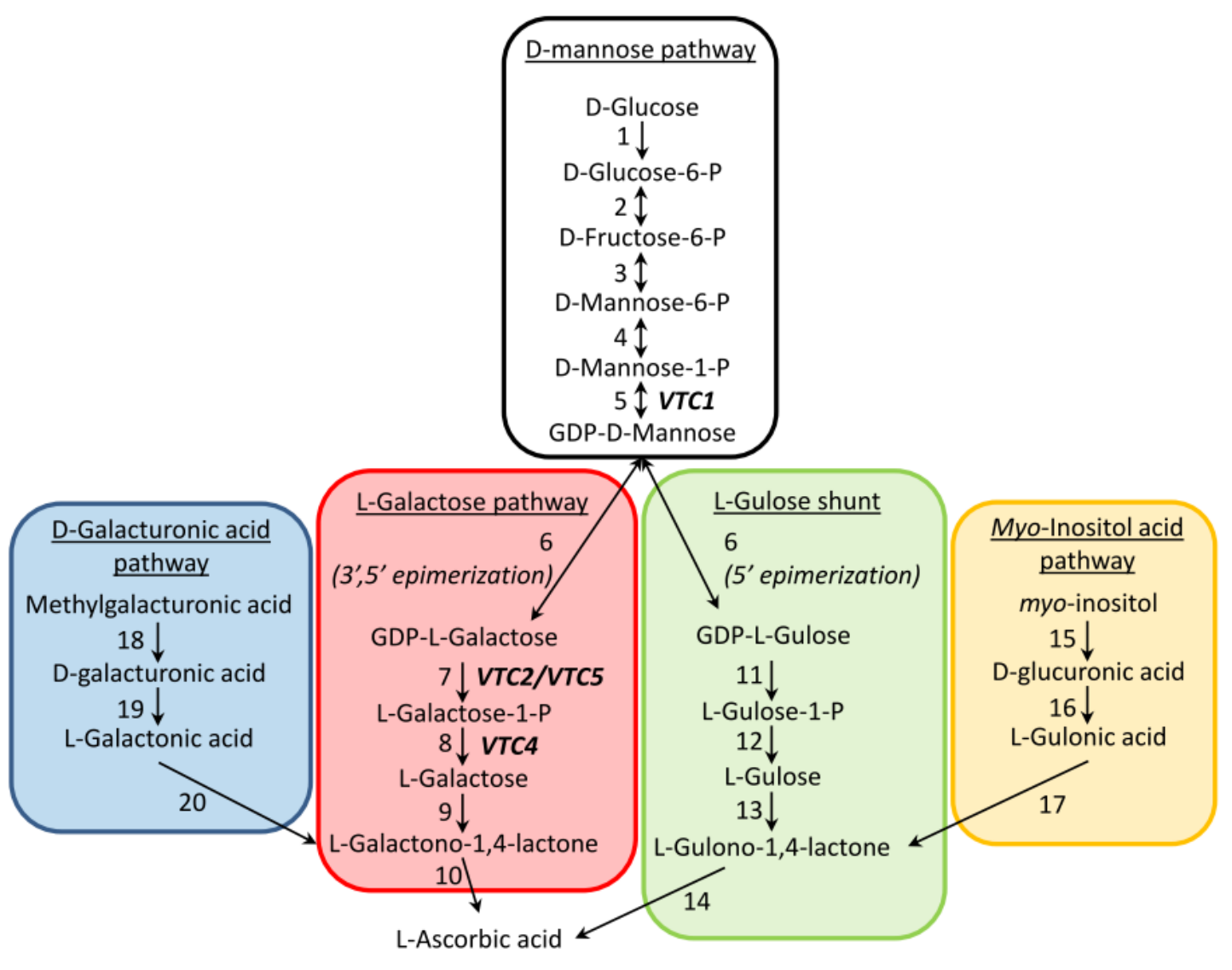

Figure 1.1 Schematic of the known pathways contributing to AA biosynthesis in plants.

After the production of D-mannose, catalyzed by hexokinase (1), phosphoglucose isomerase (2), phosphomannose isomerase (3), phosphomannose mutase (4), and GDP-D-mannose pyrophosphorylase (5) (VTC1) the product GDP-D-mannose can be funneled into the L-galactose pathway (red shaded rectangle) or the L-gulose shunt (green shaded rectangle), depending on the epimerization product of GDP-D-mannose-3,5-epimerase (6). For the L-galactose pathway, 3',5' epimerization occurs followed by catalysis involving GDP-L-galactose pyrophosphatase (7) (VTC2/VTC5), L-galactose-1-phosphate phosphatase (8) (VTC4), L-galactose dehydrogenase (9), and L-galactono-1,4-lactone dehydrogenase (10), which produces L-ascorbic acid. If 5' epimerization occurs at the GDP-D-mannose-3,5-epimerase (6) step, GDP-L-gulose is catalyzed by GDP-L-gulose pyrophosphatase (11), L-gulose-1-phosphate phosphatase (12), L-gulose dehydrogenase (13), and L-gulono-1,4-lactone dehydrogenase (14). Myoinositol can contribute to plant AA (yellow shaded rectangle) through myo-inositol oxidase (15), glucuronic acid reductase (16), and aldonolactonase (17), which produces L-gulono-1,4,-lactone. Dgalacturonic acid (salvage pathway, blue shaded box), is believed to occur through the activity of pectin methylesterase (18), galacturonic acid reductase (19), and aldonolactose producing L-galactono-1,4lactone (20). Adapted from Hancock et al. (2005). 
alternative path to AA biosynthesis. This pathway would require multiple inversions of the carbon skeleton of D-glucose. Such inversions have been previously observed, although in limited amounts. Substantial evidence for the role of the L-galactose/D-mannose pathway toward plant AA content came from the isolation of Arabidopsis mutants that accumulate low levels of AA (Conklin et al., 1999; Conklin et al., 2000).

\subsubsection{Ascorbic acid-deficient Arabidopsis thaliana vtc mutants}

Conklin and co-workers initially isolated four vitamin C deficient (vtc) mutants largely by virtue of their sensitivity to ozone, corresponding to four distinct loci (VTC1, VTC2, VTC3, and VTC4). The Arabidopsis vtc1-1 mutant was shown to encode a GDP-mannose pyrophosphorylase (Conklin et al., 1996; Conklin et al., 1997). This mutant contains approximately $30 \%$ of the wild-type AA content and has sensitivity to ROS. Further characterization of the vtc mutants has revealed four enzymes involved in AA biosynthesis (Fig. 1.1): VTC1, a GDP-mannose pyrophosphorylase (Conklin et al., 1999); VTC2, and its homolog, VTC5, which are both GDP-L-galactose phosphorylases (Dowdle et al., 2007; Linster et al., 2007; Linster et al., 2008); VTC4, an L-galactose-1-P-phosphatase (Conklin et al., 2006); the function of VTC3 remains unknown. vtc2-1 mutants contain approximately $30 \%$ of wild type AA and has a G to A point mutation at the predicted 3' splice site of intron 5 (Conklin et al., 2000; Jander et al., 2002). vtc4-1 mutants contain approximately $50 \%$ of wild type $A A$ and has a $C$ to $T$ point mutation changing a conserved proline residue to a leucine (Conklin et al., 2000; Conklin et al., 2006) . vtc3-1 mutant individuals contain approximately $30 \%$ of wild type AA (Conklin et al., 2000). vtc5-1 mutants contain a T-DNA insertion and have approximately $80 \%$ of wild type AA (Dowdle et al., 2007). Interestingly, the vtc mutants have varying pleiotropic phenotypes in addition to their AA-deficiencies (Table 1.1). These include altered flowering time and senescence (Barth et al., 2004; Conklin and Barth, 2004; Pavet et al., 2005; Kotchoni et al., 2009), increased resistance to pathogen attack (Pastori et al., 2003; Barth et al., 2004; Conklin and Barth, 2004; Pavet et al., 2005; Mukherjee et al., 2010), increased amounts of the phytohormones: abscisic acid (ABA; Pastori et al., 2003) and salicylic acid (SA; Mukherjee et al., 2010), and increased levels of hydrogen peroxide (Kotchoni et al., 2009; Barth et al., 2010). vtc1-1 mutants also exhibit a stunted root phenotype when grown in the presence of ammonium (Qin et al., 2008; Kotchoni et al., 2009; Barth et al., 2010; Kempinski et al., 2011). 
Table 1.1 Pleiotropic phenotypes of Arabidopsis vtc mutants.

Abbreviations: AmA, amino acid; ABA, abscisic acid; AA, ascorbic acid; N.D., not determined; SA, salicylic acid; WT, wild type (Kotchoni et al., 2009; Barth et al., 2004; Conklin et al., 2004; Mukherjee et al., 2010).

\begin{tabular}{|c|c|c|c|c|c|c|c|c|}
\hline Genotype & $\begin{array}{c}\text { Mutation } \\
\text { WT-AmA-vtc }\end{array}$ & $\begin{array}{c}\% \text { WT } \\
\text { AA }\end{array}$ & $\begin{array}{c}\% \text { WT } \\
\mathrm{H}_{2} \mathrm{O}_{2}\end{array}$ & $\begin{array}{c}\% \text { WT } \\
\text { SA }\end{array}$ & $\begin{array}{c}\% \text { WT } \\
\text { ABA }\end{array}$ & $\begin{array}{l}\text { Flowering, } \\
\text { senescence }\end{array}$ & $\begin{array}{l}\text { Resistance } \\
\text { to virulent } \\
\text { pathogens }\end{array}$ & $\begin{array}{l}\text { Root growth } \\
\text { in } \mathrm{NH}_{4}^{+}\end{array}$ \\
\hline vtc1-1 & Pro-22-Ser & 35 & 174 & 370 & 500 & Early & Increased & Stunted \\
\hline$v t c 2-1$ & Splice site & 30 & 165 & 370 & 300 & Early & Increased & Normal \\
\hline vtc3-1 & Unknown & 30 & 150 & 250 & N.D. & Early & Increased & Normal \\
\hline vtc4-1 & Pro-92-Leu & 50 & 101 & 110 & N.D. & Early & Increased & Normal \\
\hline vtc5-1 & Insertion & 80 & N.D. & N.D. & N.D. & N.D. & N.D. & N.D. \\
\hline
\end{tabular}




\subsubsection{GDP-mannose is an important molecule for ascorbic acid biosynthesis and protein $\mathrm{N}$ - glycosylation}

An important intermediate in AA biosynthesis is GDP-mannose, an activated sugar nucleotide. Biosynthesis of GDP-mannose requires three enzymes: phosphomannose isomerase (PMI), phosphomannose mutase (PMM), and GDP-mannose pyrophosphorylase (GMPase, VTC1; Fig. 1.1). GDP-mannose contributes to the biosynthesis of $A A$ and different structural carbohydrates in plant cell walls, and is essential for post-translational modifications, such as protein N-glycosylation and glycosylphosphatidylinositol (GPI)-anchoring (Qian et al., 2007). GDP-mannose provides mannose, a crucial building block of the core glycan chain attached to modified proteins (Lerouge et al., 1998; Spiro, 2002).

\subsubsection{Protein $\mathrm{N}$-glycosylation in Arabidopsis}

Disturbance of the protein $\mathrm{N}$-glycosylation process, which takes place in the endoplasmatic reticulum (ER) lumen and in the secretory system (Silberstein and Gilmore, 1996; Helenius and Aebi, 2001), leads to a buildup of misfolded proteins in the ER and triggers the unfolded protein response (UPR). UPR is a stress response that induces the expression of genes whose products ensure proper protein folding in the ER, including calnexin, calreticulin, binding protein (BiP), and peptide disulfide isomerase (Travers et al., 2000; Martinez and Chrispeels, 2003).

Upregulation of secretion-related genes was shown to be essential for the induction of systemic acquired resistance against bacterial pathogens in Arabidopsis (Wang et al., 2005). A mutation in the STT3a gene encoding an essential subunit of the oligosaccharyltransferase complex causes decreased protein glycosylation, resulting in improper protein folding, binding protein $(B i P)$ hyperexpression, reduced CYCLIN B1 expression and disturbed cell cycle progression. These results suggested that the STT3a subunit is necessary for cell cycle regulation during osmotic stress (Koiwa et al., 2003). The Arabidopsis BAX inhibitor-1 (BI1) plays a pivotal role as a highly conserved survival factor that is required to delay the onset of programmed cell death (PCD) upon ER stress signaling (Watanabe and Lam, 2008). Although there is strong evidence that genes encoding secretory and vacuolar proteins are induced by hypersaline conditions (Gong et al., 2001) and that mutations in components of the secretory machinery cause osmotic sensitivity and are important for ion homeostasis (Zhu et al., 2002; Shi et al., 2003), recent data suggest that protein $\mathrm{N}$-glycosylation functions beyond protein folding in the ER (Lerouxel et al., 2005; Kang et al., 2008).

It was reported previously that GMPase, encoded by VTC1, is a genetic determinant of $\mathrm{NH}_{4}{ }^{+}$sensitivity. Qin et al. demonstrated that GMPase activity was inhibited by $\mathrm{NH}_{4}{ }^{+}$and that defective protein $\mathrm{N}$-glycosylation, the unfolded protein response and cell death were 
downstream effects involved in the root growth inhibition in the hsn1 Arabidopsis mutant (Qin et al., 2008). These results were essentially confirmed by Barth and co-authors, whose data suggested that $\mathrm{NH}_{4}^{+}$hypersensitivity in vtc1-1 is caused by disturbed $\mathrm{N}$-glycosylation and associated with auxin and ethylene homeostasis and/or nitric oxide signaling (Barth et al., 2010). Finally, $\mathrm{Li}$ and co-authors recently presented data, indicating an association of $\mathrm{NH}_{4}{ }^{+}$ efflux at the elongation zone with the $\mathrm{NH}_{4}{ }^{+}$-mediated inhibition of primary root elongation, whereby GMPase directly or indirectly regulates this process (Li et al., 2010). Therefore, the primary cause of the stunted root growth in vtc1-1 as well as the underlying mechanism of the defective growth response is still unclear.

In order to better understand the cause and the mechanism of the growth defect in vtc1-1, we addressed the following questions: (i) Do vtc1-1 individuals suffer from cell wall or cell membrane defects per se or are these defects caused by the presence of $\mathrm{NH}_{4}{ }^{+}$? (ii) Are developing root cells in vtc1-1 mutants defective in cell cycle progression? (iii) If GDP-mannose deficiency is the primary cause of $\mathrm{NH}_{4}{ }^{+}$sensitivity, are other mutants with deficient GDPmannose also sensitive to $\mathrm{NH}_{4}{ }^{+}$? (iv) Since $\mathrm{NH}_{4}{ }^{+}$is known to alter cytosolic $\mathrm{pH}$, do vtc1-1 mutants respond to extracellular $\mathrm{pH}$ changes in the presence or absence of $\mathrm{NH}_{4}{ }^{+}$?

\subsection{MATERALS AND METHODS}

\subsubsection{Plant material, growth and tissue culture conditions}

Arabidopsis thaliana Col-0 wild type and previously described vtc1-1, vtc2-1, vtc4-1 mutants (all in the Col-0 background) were kindly provided by Patricia Conklin (Conklin et al., 1996; Conklin et al., 2000; Conklin, 2001). Additionally, a T-DNA insertion line (SALK_029748) was obtained for the previously described Arabidopsis PHOSPHOMANNOSE ISOMERASE 1 (PMI; AT3G02570) gene (Maruta et al., 2008) from the Arabidopsis Biological Resource Center. Mutant seed of PHOSPHOMANNOSE MUTATSE (PMM, AT2G45790), pmm-12, were kindly provided by Frank van Breusegem (Hoeberichts et al., 2008).

For assessment of root growth, seed of the wild type and mutant lines were surfacesterilized (see below) and grown on basal full strength 1x Murashige and Skoog (MS) medium without vitamins (Cat.\# MSP01, Caisson Laboratories, Inc., North Logan, UT) or full strength $1 \mathrm{x}$ MS without ammonium nitrate (but still containing potassium nitrate) also without vitamins (Cat.\# MSP05), containing 1\% Phytoblend (Cat.\# PTP01, Caisson Laboratories) in omni trays (Fisher Scientific, Pittsburgh, PA) as described (Barth et al. 2010). Additional experiments were performed in 1x MS without ammonium nitrate and vitamins (but still containing potassium nitrate) and with the addition of $\mathrm{KCl}, \mathrm{NaCl}, \mathrm{CaCl}_{2}, \mathrm{LiCl}$, mannitol, $\mathrm{CdCl}_{2}$ or $\mathrm{MES}$ at concentrations indicated in the figures and supplemental information. Note that sucrose was omitted from all 
growth media. Unless noted otherwise, the $\mathrm{pH}$ of the growth media was adjusted with $\mathrm{HCl}$ or $\mathrm{KOH}$ to 5.7 after making the indicated salt or buffer additions. Trays were sealed with two layers of $3 \mathrm{M}$ micropore tape (Fisher Scientific), put in vertical orientation, and placed in the growth chamber under long days ( $16 \mathrm{~h}$ light, $8 \mathrm{~h}$ dark) at $23^{\circ} \mathrm{C}$ day and night, and $160 \mu \mathrm{mol}$ photons $\mathrm{m}^{-2} \mathrm{~s}^{-1}$ (fluorescent bulbs) in a growth chamber (Percival Scientific, Inc., Perry, IA). Each plate contained wild-type and mutant seed. Primary root length was measured in seven-day-old seedlings using a ruler.

To assess AA content in leaf tissue, seeds of wild type and mutants were randomly sown on MetroMix 360 soil (BFG Supplies Co., Burton, $\mathrm{OH}$ ) in the same flat under the growth conditions described above. When plants were three weeks old, rosette leaves were harvested for the AA assay (see below). For AA measurements of plants grown on 1x MS, whole rosettes of two-week-old plants were collected.

\subsubsection{Seed-surface sterilization}

Seeds were soaked for $1 \mathrm{~min}$ in $50 \%$ ethanol, followed by washing the seeds in $50 \%$ bleach plus $0.01 \%$ sodium dodecyl sulphate for $6 \mathrm{~min}$. Finally, seeds were rinsed six times with sterile water and stored in $0.1 \%$ sterile phytoblend agar for $2 \mathrm{~d}$ at $4{ }^{\circ} \mathrm{C}$ (Weigel and Glazebrook, 2002).

\subsubsection{Generation of vtc1-1 VTC1 heterozygous mutants}

To generate heterozygous vtc1-1 VTC1 mutants, homozygous vtc1-1 mutant plants were crossed with Col- 0 wild-type plants. The resulting $F_{1}$ generation is heterozygous at the VTC1 locus.

\subsubsection{RNA isolation, cDNA synthesis and quantitative reverse transcriptase polymerase chain reaction (qRT-PCR)}

Total RNA was extracted from root tissue collected and pooled from seven- or 14-dayold seedlings using the Tri-Reagent protocol (Molecular Research Center, Inc., Cincinnati, $\mathrm{OH}$ ). One microliter of total RNA was treated with $1 \mu \mathrm{L}$ of DNasel (Invitrogen, Carlsbad, CA) and subsequently used for reverse transcription using $10 \mathrm{pg}$ of oligo(dT) primers using the firststrand cDNA synthesis kit (Invitrogen). Quantitative RT-PCR reactions were set up using 2.5 pmole of gene-specific primers and 1:10 dilutions of cDNA:DNase/RNase free water with the iQ SYBER Real-Time Master Mix (Bio-Rad, Hercules, CA) in a total volume of $10 \mu \mathrm{L}$. Negative controls contained water instead of reverse transciptase. In addition, reactions without template were set up to ensure that the master mix was not contaminated. Reactions were run in a Bio-Rad iCycler for 40 cycles. The threshold cycles $\left(C_{T}\right)$ were calculated using iQ software 
(Bio-Rad) and relative transcripts (RT) were calculated using the formula: $R T=1 / 2^{C T}$. The RT values of the genes assessed were normalized to TUBULIN2 and mean values of biological replicates were calculated. Experiments were performed at least three times. PCR fragments were separated on a $1 \%$ agarose gel stained with ethidium bromide to check for correct fragment amplification. Gene-specific primer sequences are listed in Table 1.2.

\subsubsection{DAPI staining}

Primary roots of seven-day-old seedlings were collected and immediately washed two times in phosphate buffered saline (PBS) buffer $\mathrm{pH}$ 7.4. Roots were then stained with $2.5 \mu \mathrm{g} / \mathrm{mL}$ DAPI (4',6-diamidino-2-phenylindole) for $20 \mathrm{~min}$, washed two times again in PBS buffer, and mounted in 50\% glycerol. DAPI staining was visualized with a standard UV fluorescence filter set and epifluorescence optics on a Nikon E800 microscope equipped with a CoolSNAP cf CCD camera (Photometrics, Tucson, AZ).

\subsubsection{Calcofluor white aniline blue staining}

Primary roots of seven-day-old seedlings were collected and immersed in $0.01 \%$ calcofluor white (Sigma-Aldrich Corp., St. Louis, MO) or $0.01 \%$ aniline blue (Sigma-Aldrich), respectively, and stained for $10 \mathrm{~min}$. Seedlings were washed two times in de-ionized water and mounted in $50 \%$ glycerol. Microscopy was performed as described above.

\subsubsection{Ascorbic acid assay}

Leaf AA content was quantified using the iron reduction assay as described (Dowdle et al., 2007; Mukherjee et al., 2010).

\subsubsection{Statistical analysis}

Experiments were performed at least three times. Figures represent individual experiments. Data were expressed as mean values \pm SE. $P$ values were determined by Student's $t$-test analysis.

\subsection{RESULTS}

\subsubsection{Transcript levels of ER stress genes are higher in vtc1-1 in the presence of $\mathrm{NH}_{4}{ }^{+}$}

Since GDP-mannose is involved in protein N-glycosylation, we would expect that GDPmannose deficiency is expected to result in an upregulation of ER stress genes, enhanced PCD, and defective cell cycle proliferation in vtc1-1 triggered by $\mathrm{NH}_{4}{ }^{+}$.

When grown in the presence of $\mathrm{NH}_{4}{ }^{+}, \mathrm{BIP}$ mRNA levels were more than twice as high in the vtc1-1 mutant as in the wild type (Fig. 1.2). BIP is an ER-localized chaperone, belonging to 
Table 1.2 Sequences of oligonucleotide primers used for qRT-PCR.

\begin{tabular}{|c|c|c|}
\hline Primer Name & $5^{\prime}$ & ATG Number \\
\hline BI1_CDS-F & CAGAAGCTGGAGCTATGATTC & \multirow{2}{*}{ AT5G47120 } \\
\hline BI1_CDS-R & CATAGTCCATGTCACCGAGGT & \\
\hline BIP_CDS-F & ATCGAGGTCACATTTGAAGTGGA & \multirow{2}{*}{ AT5G42020 } \\
\hline BIP_CDS-R & TAGAGCTCATCGTGAGACTCATCT & \\
\hline CYCLINB1_RT-PCR_CK-F & AGGCTGCTTGTGGTTTAGAGAA & \multirow{2}{*}{ AT4G37490 } \\
\hline CYCLINB1_RT-PCR_CK-R & TTGGCCGACATGAGAAGAGC & \\
\hline HISTONEH4_CDS-F & ATGTCTGGTCGTGGAAAGGGAG & \multirow{2}{*}{ AT5G59970 } \\
\hline HISTONEH4_CDS-R & ACCAAATTGCGTGTTTCCATTG & \\
\hline VTC1-F & TCGCTTGAGACCATTGACT & \multirow{2}{*}{ AT2G39770 } \\
\hline VTC1-R & TCGCTAGAGCCAGAGGAC & \\
\hline TUB2-RT-F2 & CTCAAGAGGTTCTCAGCAGTA & \multirow{2}{*}{ AT5G62690 } \\
\hline TUB2-RT-R2 & TCACCTTCTTCATCCGCAGTT & \\
\hline
\end{tabular}




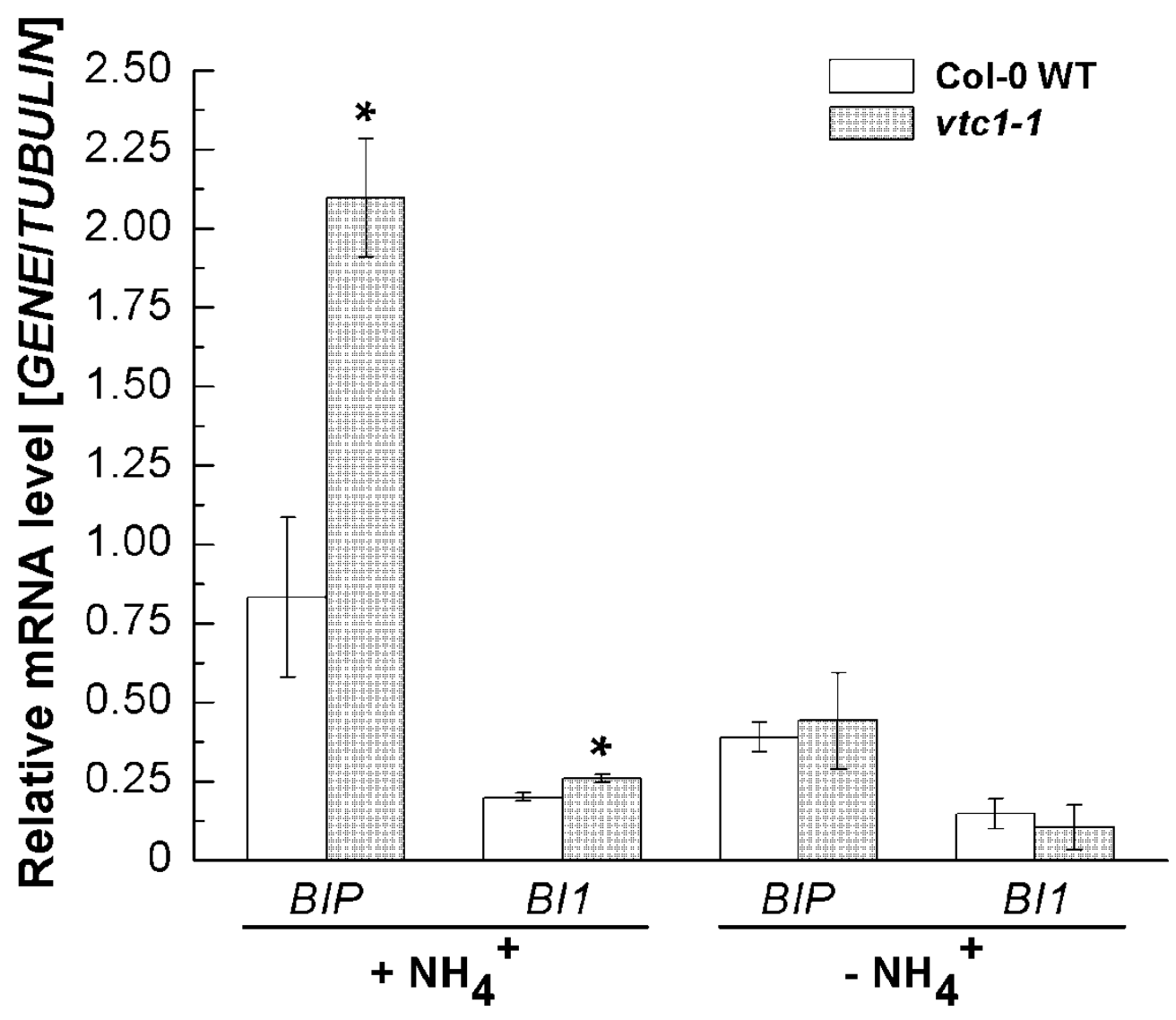

Figure 1.2 Transcript levels of the ER stress genes BIP (binding protein) and BI1 (BAX inhibitor-1) in the presence and absence of $\mathrm{NH}_{4}{ }^{+}$.

Relative mRNA levels were determined in root tissue from seven-day-old Col-0 wild-type and vtc1-1 seedlings and based on TUBULIN. Data indicate means \pm SE of three biological replicates of each genotype and treatment. Asterisks indicate significant differences between the mutant and the wild type. ${ }^{*} P<0.05$, Student's $t$-test. 
the HSP70 family, which is necessary for the transport and secretion of proteins in the ER. It has been used as a common marker for UPR activation in eukaryotes, including plants (Koizumi et al., 2001; Martinez and Chrispeels, 2003). Transcript levels of BI1 were also upregulated in vtc11 compared to the wild type, although only slightly. BI1 serves as a crucial cell survival factor that is important to delay the onset of PCD upon ER stress signaling (Watanabe and Lam, 2008). In contrast, mRNA levels of BIP and BII were the same in the wild type and vtc1-1 in the absence of $\mathrm{NH}_{4}{ }^{+}$(Fig. 1.2). This data suggests that the presence of $\mathrm{NH}_{4}{ }^{+}$activates ER stress and UPR to a greater extent in vtc1-1 than in the wild type.

\subsection{2 vtc1-1 exhibits PCD and some cell cycle defects in the presence of $\mathrm{NH}_{4}{ }^{+}$}

To further examine whether enhanced root cell death in the presence of $\mathrm{NH}_{4}{ }^{+}$occurs through necrosis or PCD, we visualized nuclei by staining wild type and vtc1-1 roots with DAPI when plants were grown in the presence or absence of $\mathrm{NH}_{4}^{+}$. PCD is characterized by morphological changes in the nucleus that are absent during necrosis. As shown in Fig. 1.3a, root nuclei in vtc1-1 plants grown in the presence of $\mathrm{NH}_{4}{ }^{+}$exhibited brighter fluorescence due to chromatin condensation (arrow heads in Fig. 1.3a). In contrast, nuclei of wild-type root cells and of both genotypes grown in the absence of $\mathrm{NH}_{4}{ }^{+}$(Fig. 1.3b) appeared more round in shape and had a uniform granular appearance throughout the root. Overall cell density was strongly diminished in vtc1-1 and abnormal nuclei were found throughout the elongation and differentiation zone (root hair zone) when the mutant was grown in the presence of $\mathrm{NH}_{4}{ }^{+}$, while the meristematic zone appeared normal. The elongation zone of the primary root was much shorter in vtc1-1, as root hairs were visualized within a short distance from the root tip (arrows in Fig. 1.3a).

To test whether cell cycle progression is affected in vtc1-1, we examined mRNA levels of the cell cycle genes HISTONE H4 and CYCLIN B1. The transcript level of HISTONE H4, which is specifically expressed during S-phase and into G2-phase of the cell cycle (Culligan et al., 2004), was almost double the amount in vtc1-1 compared to the wild type in the presence of $\mathrm{NH}_{4}{ }^{+}$, whereas no significant differences were found between the two genotypes in the absence of $\mathrm{NH}_{4}{ }^{+}$(Fig. 1.3c, d). In contrast, the wild type and vtc1-1 did not differ in the amount of CYCLIN B1 mRNA, which is expressed during G2-phase of the cell cycle, in either treatment.

Taken together, these data suggest that $\mathrm{NH}_{4}{ }^{+}$stress in combination with defective GMPase induces hallmarks of PCD and S-phase arrest.

\subsection{3 vtc1-1 exhibits cell wall defects and accumulates callose in the presence of $\mathrm{NH}_{4}{ }^{+}$}

To determine whether the $\mathrm{N}$-glycosylation defect in vtc1-1 causes weak cell walls or whether a cell wall defect is triggered by $\mathrm{NH}_{4}{ }^{+}$, we investigated cell wall integrity by staining 


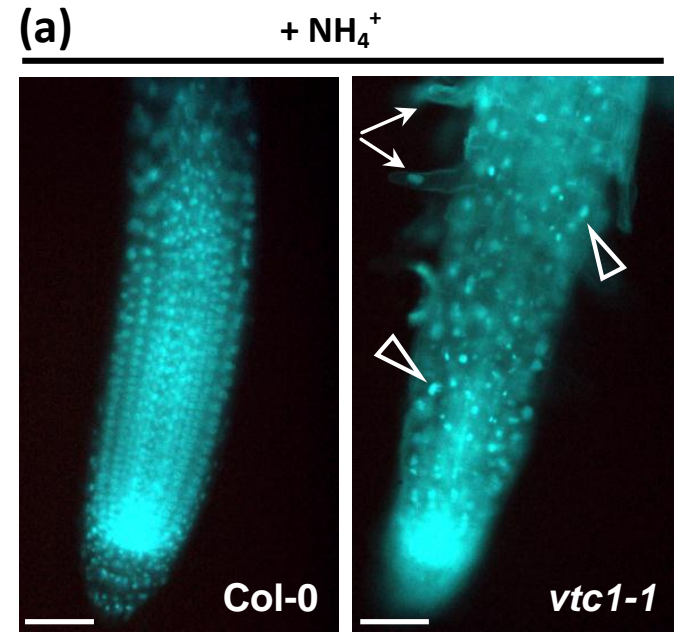

(b) $-\mathrm{NH}_{4}^{+}$
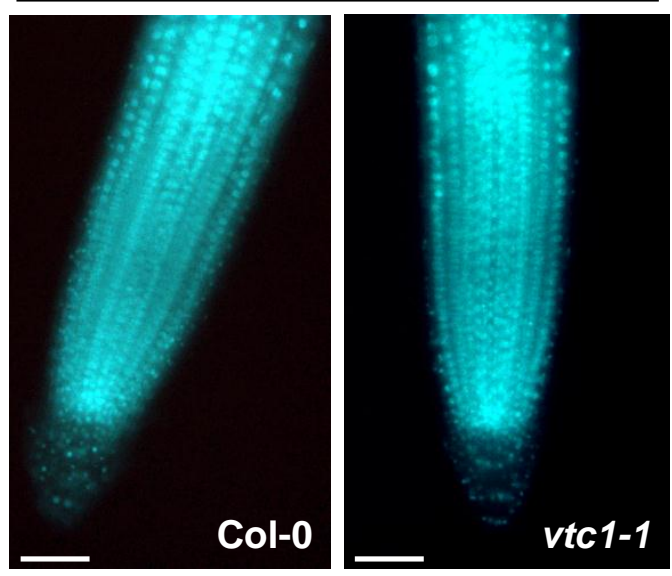

(c)

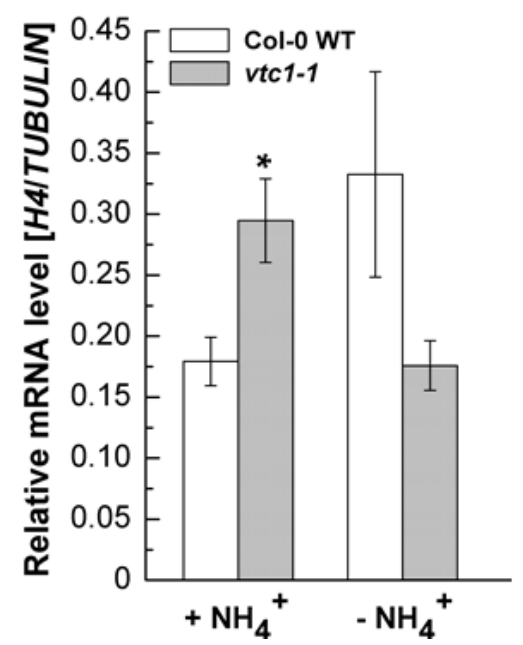

(d)

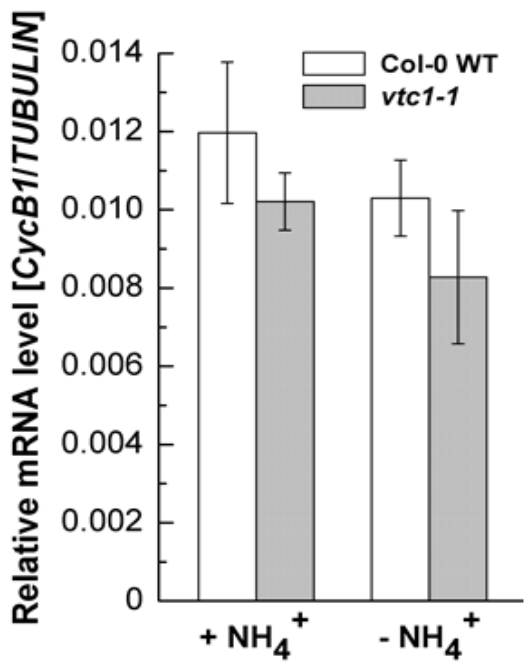

Figure 1.3 Microscopic analysis of Col-0 wild-type and vtc1-1 roots in (a) the presence and (b) absence of $\mathrm{NH}_{4}{ }^{+}$and (c) mRNA levels of $\mathrm{H4}$ (HISTONE H4) and (d) CyCB1 (CYCLIN B1) in the presence and absence of $\mathrm{NH}_{4}^{+}$.

(a) and (b) seven-day-old roots stained with $2.5 \mu \mathrm{g} / \mathrm{mL}$ DAPI. Bar $=50 \mu \mathrm{m}$. (c) and (d) relative transcript levels based on TUBULIN in root tissue from seven-day-old wild-type and vtc1-1 seedlings. Data represent means \pm SE of 8 to 11 biological replicates of each genotype and treatment. Asterisks indicate significant differences between the mutant and the wild type. ${ }^{*} P<0.05$, Student's $t$-test. 


\section{Cell wall integrity}

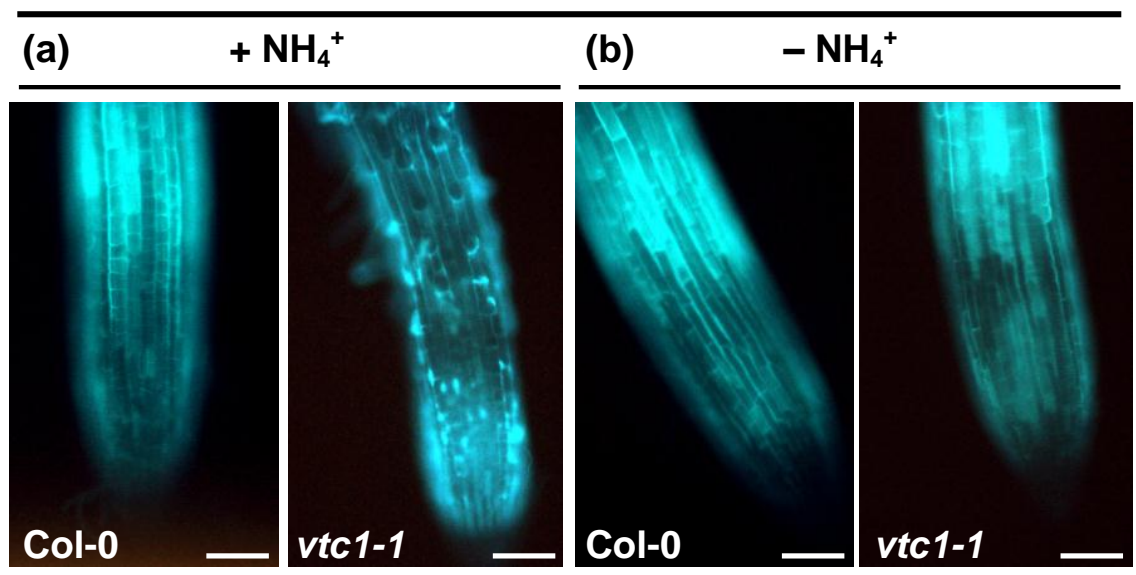

Callose accumulation

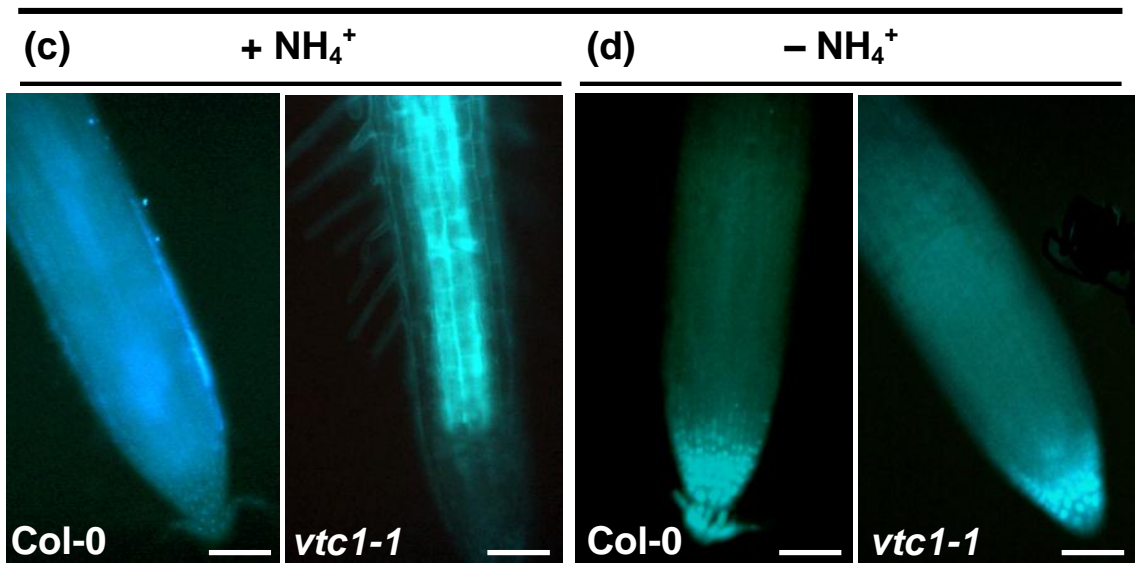

Figure 1.4 Cellulose $(a, b)$ and callose $(c, d)$ staining in roots of seven-day-old Col-0 wild-type and vtc1-1 plants grown in the presence and absence of $\mathrm{NH}_{4}{ }^{+}$.

Seven-day-old roots were stained with $0.01 \%$ calcofluor white and aniline blue, respectively. Bar $=50$ $\mu \mathrm{m}$ 
cellulose with calcofluor white and tested for callose deposition, a marker of cell wall and/or membrane defects, using aniline blue. Fig. 1.4a shows strongly reduced calcofluor white fluorescence in vtc1-1 grown in the presence of $\mathrm{NH}_{4}{ }^{+}$, whereas homogenous staining was observed in the wild type and in primary roots of both genotypes in the absence of $\mathrm{NH}_{4}^{+}$(Fig. 1.4b). Defective cell walls correlated with callose deposition particularly in the central cylinder of vtc1-1 in the presence of $\mathrm{NH}_{4}{ }^{+}$, while aniline blue staining was more diffuse in the wild type (Fig. 1.4c) and in both genotypes grown in the absence of $\mathrm{NH}_{4}^{+}$(Fig. 1.4d). Collectively, the data suggest that cell wall and membrane defects are triggered by $\mathrm{NH}_{4}{ }^{+}$stress in vtc1-1 rather than the mutant has weakened cell walls or membranes sensitive to $\mathrm{NH}_{4}{ }^{+}$.

\subsection{4 pmi and pmm mutants are not $\mathrm{NH}_{4}{ }^{+}$-sensitive}

If $\mathrm{NH}_{4}^{+}$sensitivity in vtc1-1 is caused by GDP-mannose deficiency, we would expect other mutants contributing to GDP-mannose biosynthesis to also show a stunted root phenotype in the presence of $\mathrm{NH}_{4}{ }^{+}$. The pmi-1 and pmm-12 mutants have defects in genes directly upstream of VTC1 in the D-mannose/L-galactose pathway. Genetic defects in VTC1, $P M I$ and $P M M$ have been shown to result in decreased activity of the respective enzymes, indirectly demonstrating a reduced accumulation of GDP-mannose (Fig. 1.1; Conklin et al., 1999; Hoeberichts et al., 2008; Maruta et al., 2008). When grown on soil, the pmi-1 and pmm12 mutants contain approximately $80 \%$ of the wild-type AA content (Fig. 1.5). When grown in the presence of $\mathrm{NH}_{4}{ }^{+}$, primary roots of pmi-1 and pmm-12 were similar or slightly longer than in the wild type, respectively, whereas root growth was strongly inhibited in vtc1-1, as expected (Fig. 1.6a). In the absence of $\mathrm{NH}_{4}{ }^{+}$, primary roots were slightly longer in pmi-1 and pmm-12 mutants compared to the wild type and vtc1-1 (Fig. 1.6b). The pmm-12 mutant is temperature-sensitive, although total PMM activity and protein levels were considerably reduced at the permissible temperature of $16^{\circ} \mathrm{C}$ (Hoeberichts et al., 2008). In the absence of $\mathrm{NH}_{4}{ }^{+}$but at the restrictive temperature of $28^{\circ} \mathrm{C}$ (compared to $23^{\circ} \mathrm{C}$ used in our experiments, see Materials and Methods), pmm-12 root and overall growth was strongly inhibited, as expected. However, this was not the case for pmi-1 and vtc1-1, which developed longer than wild-type primary roots or roots similar to the wild type, respectively (Fig. 1.6c). Finally, to test whether the defect in GDP-mannose/AA biosynthesis in these three mutants causes heightened susceptibility to oxidative stress, we grew pmi-1, pmm-12, and vtc1-1 in comparison to the wild type in the absence of $\mathrm{NH}_{4}{ }^{+}$but in the presence of Cd (Fig. 1.6d). In comparison to the control (Fig. 1.6b), all four genotypes exhibited root growth inhibition in the presence of $\mathrm{Cd}$ (Fig. 1.6d). However, none of the mutants was more susceptible than the wild type. In fact, pmm-12 developed somewhat longer roots than the other genotypes in the presence of $\mathrm{Cd}$ (Fig. 1.6d). In summary, these results suggest that the inferred low level of 


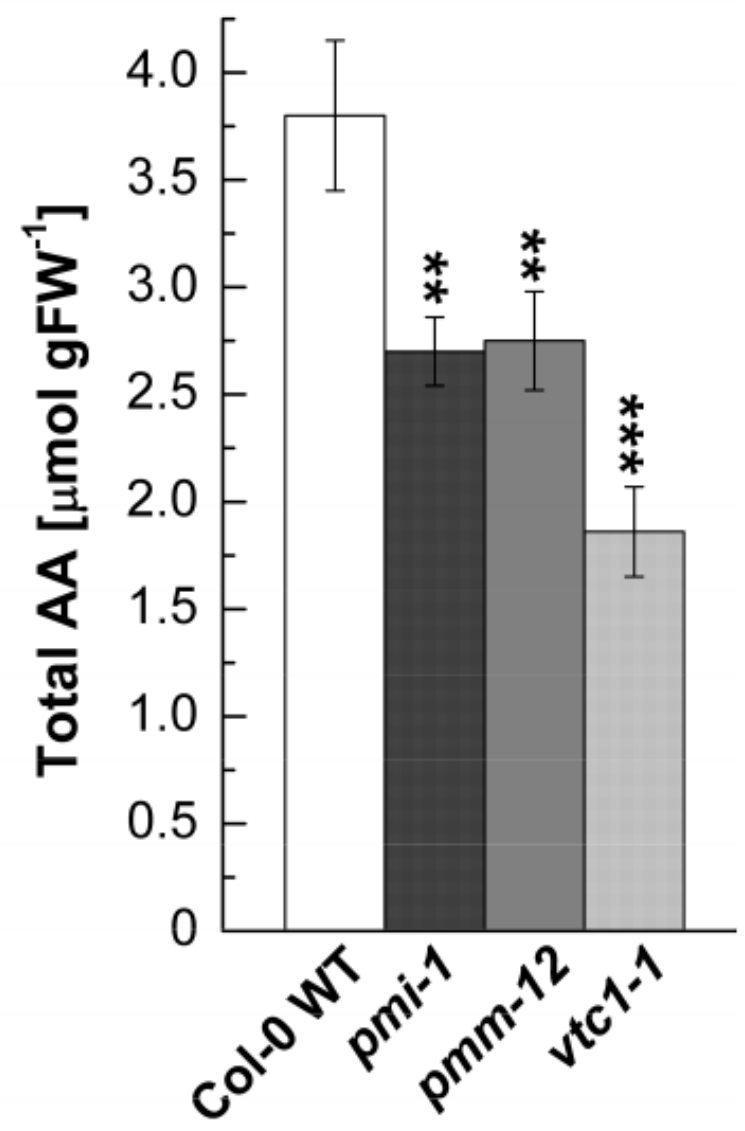

Figure 1.5 Total ascorbic acid (AA) content in Col-0 wild-type plants and pmi-1, pmm-21, and vtc1-1 mutants grown on soil.

Ascorbic acid content was measured in whole rosettes of three-week-old plants. Means \pm SE of seven individual plants are shown. Asterisks indicate significant differences between individual mutants and the wild type. ${ }^{* *} P<0.01,{ }^{* * *} P<0.001$, Student's $t$-test. 

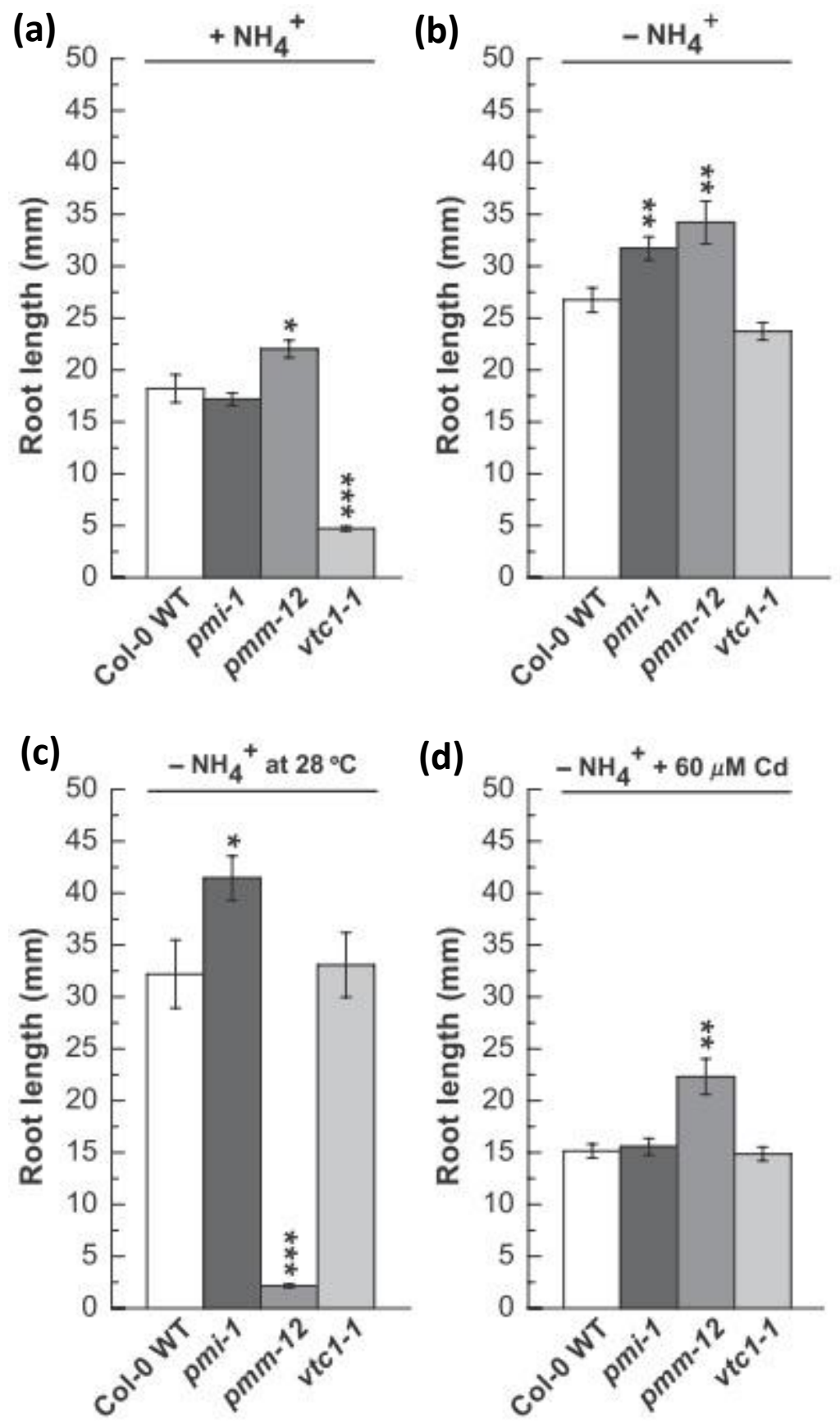

Figure 1.6 Primary root length of Col-0 wild type, pmi-1, pmm-12 and vtc1-1 mutants in the (a) presence and (b) absence of $\mathrm{NH}_{4}{ }^{+}$, (c) during heat stress, and (d) in the presence of $\mathrm{Cd}$.

Primary root length was measured when seedlings were seven days old. Results illustrate means \pm SE of 12 to 24 individual seedlings per genotype and treatment. Asterisks indicate significant differences between individual mutants and the wild type. ${ }^{*} P<0.05, * * P<0.01, * * * P<0.001$, Student's $t$-test. 
GDP-mannose does not cause general sensitivity to $\mathrm{NH}_{4}{ }^{+}$and that GDP-mannose deficiency and the resulting downstream effects (ER stress, UPR, cell wall, cell membrane defects, see above) are not the primary cause of the root growth inhibition in vtc1-1 in the presence of $\mathrm{NH}_{4}^{+}$. Since the pmi-1 and pmm-12 mutants behave differently from vtc1-1 when grown with $\mathrm{NH}_{4}{ }^{+}$, we hypothesize that the growth defect in vtc1-1 is inherent to the specific mutation in the GMPase enzyme.

\subsubsection{Primary root growth is recovered in vtc1-1 at pH 7.0 in the presence of $\mathrm{NH}_{4}^{+}$}

$\mathrm{NH}_{4}{ }^{+}$is known to cause alkalization of the cytosol (Britto, 2005) and, depending on the concentration and $\mathrm{pH}$ of the external medium, presumably alters proton and/or redox homeostasis within the cell. Therefore, we investigated whether the vtc1-1 mutant responds to $\mathrm{pH}$ changes in the growth medium in the absence and presence of $\mathrm{NH}_{4}{ }^{+}$. Thus, we would expect that root growth is the same in the wild type and vtc1-1 at various $\mathrm{pH}$ values in the absence of $\mathrm{NH}_{4}{ }^{+}$. However, we predict that root growth is different in vtc1-1 from the wild type in the presence of $\mathrm{NH}_{4}^{+}$.

When the wild type and vtc1-1 mutants were grown at $\mathrm{pH} 4.0,5.0,5.7,7.0,8.0$ and 9.0 in the absence of $\mathrm{NH}_{4}{ }^{+}$, root development was comparable between the two genotypes and only small changes in overall primary root length were detected (Fig. 1.7a). However, in the presence of $20.61 \mathrm{mM} \mathrm{NH}_{4} \mathrm{Cl}$ (the concentration of $\mathrm{NH}_{4}^{+}$present in $1 \times \mathrm{MS}$ ), primary root growth was strongly affected in both genotypes, but even more in vtc1-1. Primary root length was maximal in the wild type and vtc1-1 at $\mathrm{pH} 7.0$, which represents a remarkable recovery of root development in vtc1-1 compared to the low $\mathrm{pH}$ ranges. Note that we found similar results in the presence of the buffering agent MES (Fig. 1.8). However, root development is not fully complemented in the mutant compared to the wild type (Fig. 1.7b). When plants were grown on media with alkaline $\mathrm{pH}$ values (close to the $\mathrm{pK}_{\mathrm{a}}$ of $\mathrm{NH}_{4}^{+}$), primary root growth was strongly inhibited in both genotypes. The numbers above the $\mathrm{pH}$ values in Fig. $1.7 \mathrm{~b}$ indicate the calculated concentrations of $\mathrm{NH}_{3}$ present in the medium using the Henderson-Hasselbalch equation (Table 1.3). Note the drastic changes in free $\mathrm{NH}_{3}$ with increasing $\mathrm{pH}$. Similar calculations were performed for the growth of the wild type and vtc1-1 when grown in increasing concentrations of $\mathrm{NH}_{4} \mathrm{Cl}$ at pH 5.7 (Fig. 1.9). Finally, since it is known that $\mathrm{NH}_{4}{ }^{+}$and $\mathrm{K}^{+}$ ions compete during uptake via $\mathrm{K}^{+}$transporters and channels and that $\mathrm{NH}_{4}^{+}$toxicity may be alleviated by the addition of $\mathrm{K}^{+}$(Cao et al., 1993; ten Hoopen et al., 2010), we examined primary root development of the wild type and vtc1-1 in the presence of $\mathrm{NH}_{4}^{+}$and $\mathrm{KCl}$. We also investigated whether the addition of $\mathrm{CaCl}_{2}$ would suppress the root growth defect in vtc1-1 in the presence of $\mathrm{NH}_{4}{ }^{+}$, because $\mathrm{Ca}^{2+}$ has been shown to rescue salt-sensitive mutants (Liu and Zhu, 1997). As indicated in Fig. 1.10a, root development did not recover in vtc1-1 when grown 
(a)

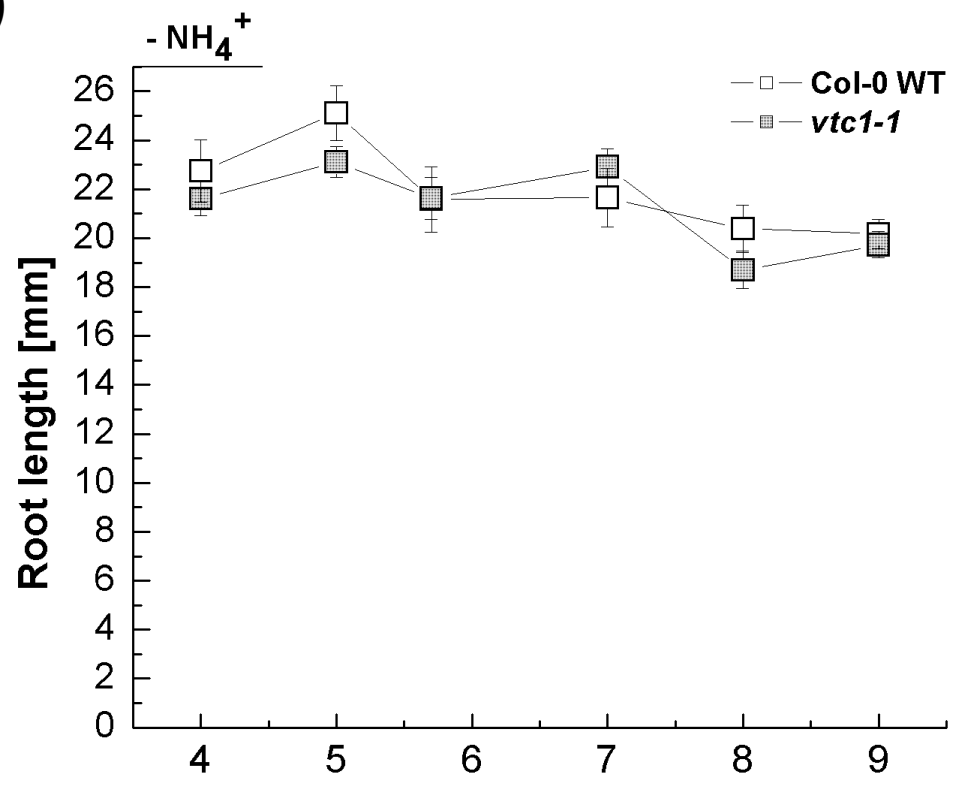

(b)

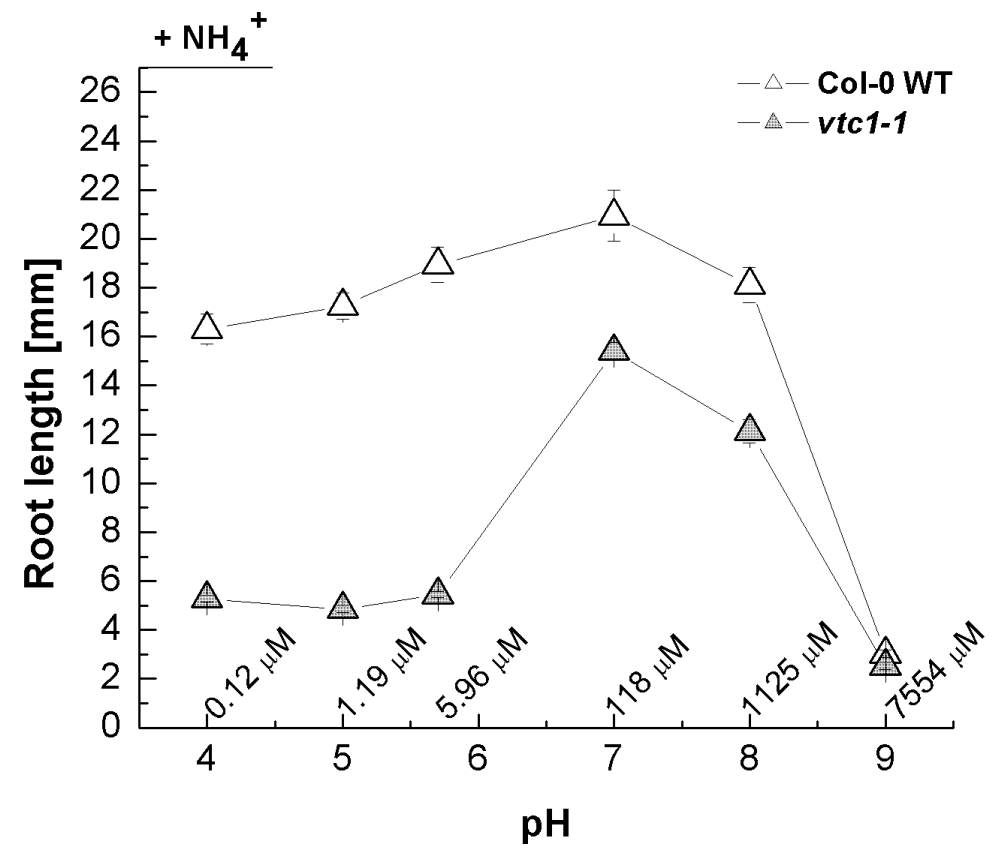

Figure 1.7 Primary root lengths of seven-day-old Col-0 wild-type and vtc1-1 seedlings in the (a) absence and (b) presence of $\mathrm{NH}_{4}{ }^{+}$in growth media ranging from acidic to alkaline $\mathrm{pH}$ values.

Data represent means \pm SE of 42 to 59 individual seedlings per genotype and treatment. Numbers along abscissa in (b) represent calculated $\mathrm{NH}_{3}$ concentrations at corresponding $\mathrm{pH}$ values (Table 1.3). 


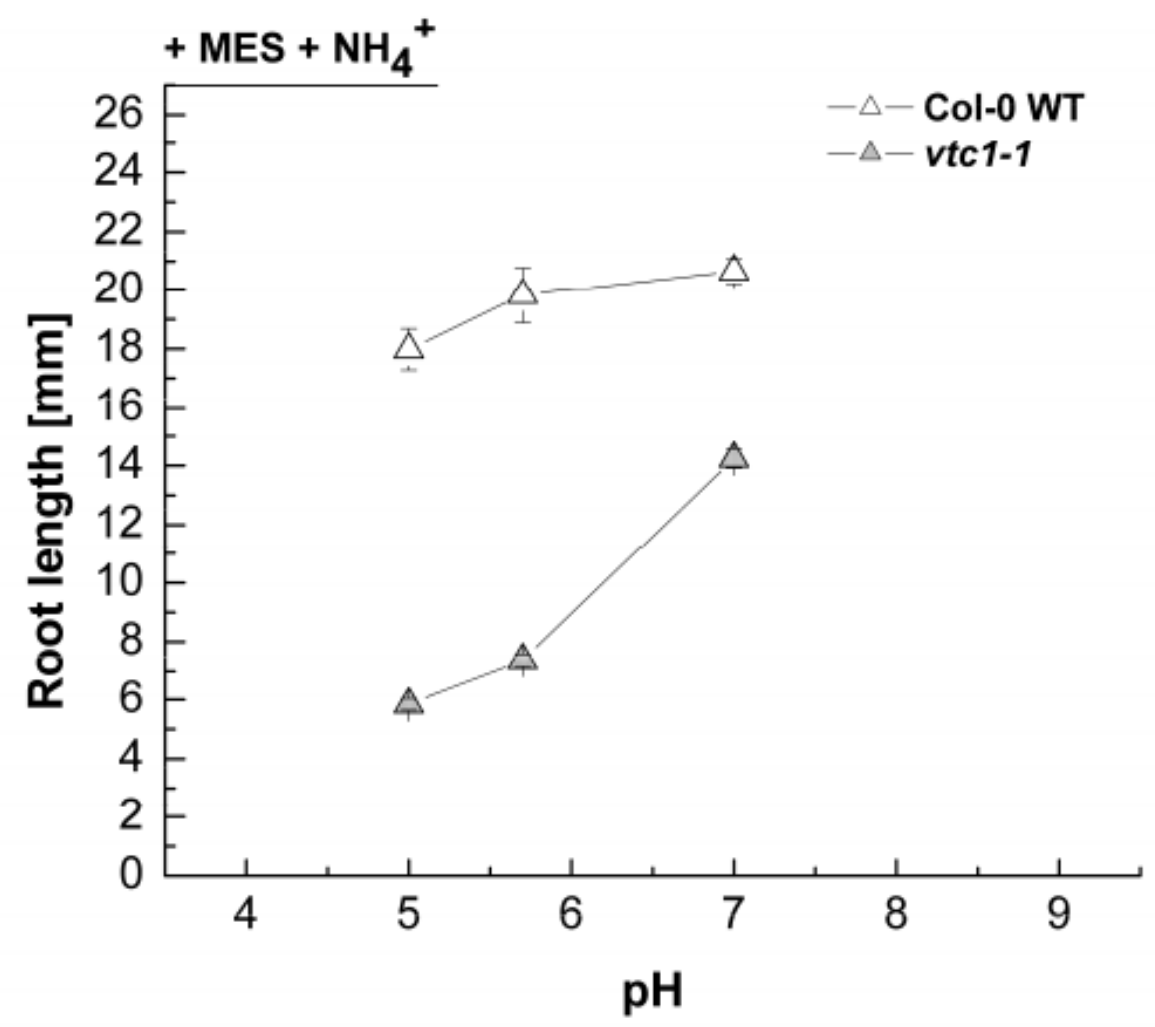

Figure 1.8 Primary root length of seven-day-old Col-0 wild-type and vtc1-1 seedlings in the presence of $\mathrm{NH}_{4}{ }^{+}$and the buffering agent MES (2.5 mM) in tissue culture media at pH 5.0, 5.7 and 7.0.

Data represent means \pm SE of 40 to 50 individual seedlings per genotype and treatment. 
Table 1.3 Calculated molar concentrations of $\mathrm{NH}_{3}$ and $\mathrm{NH}_{4}{ }^{+}$in $1 \times \mathrm{MS}$ media from $\mathrm{pH} 1$ to $\mathrm{pH} 11$ using the Henderson-Hasselbalch equation

$\left(\mathrm{pH}=\mathrm{pKa}+\log \left(\left[\mathrm{NH}_{3}\right] /\left[\mathrm{NH}_{4}{ }^{+}\right]\right)\right.$. The pKa of $\mathrm{NH}_{4}{ }^{+}$is 9.24.

\begin{tabular}{|c|c|c|c|c|c|}
\hline pH & pH-pKa & $\left(\mathrm{NH}_{3}\right) /\left(\mathrm{NH}_{4}^{+}\right)$ & {$\left[\mathrm{H}^{+}\right]$} & {$\left[\mathrm{NH}_{3}\right]$} & {$\left[\mathrm{NH}_{4}\right]$} \\
\hline 1 & -8.24 & 5.7544E-09 & 0.1 & $1.19 \mathrm{E}-10$ & 0.02061 \\
\hline 2 & -7.24 & $5.7544 \mathrm{E}-08$ & 0.01 & 1.19E-09 & 0.02061 \\
\hline 3 & -6.24 & $5.7544 \mathrm{E}-07$ & 0.001 & $1.19 \mathrm{E}-08$ & 0.02061 \\
\hline 4 & -5.24 & $5.7544 \mathrm{E}-06$ & 0.0001 & $1.19 \mathrm{E}-07$ & 0.02061 \\
\hline 5 & -4.24 & $5.7544 \mathrm{E}-05$ & 0.00001 & 1.19E-06 & 0.020609 \\
\hline 5.7 & -3.54 & 0.000288403 & $1.99526 \mathrm{E}-06$ & 5.962E-06 & 0.020604 \\
\hline 6 & -3.24 & 0.00057544 & 0.000001 & $1.189 \mathrm{E}-05$ & 0.020598 \\
\hline 6.05 & -3.19 & 0.000645654 & $8.91251 \mathrm{E}-07$ & $1.334 \mathrm{E}-05$ & 0.020597 \\
\hline 6.1 & -3.14 & 0.000724436 & $7.94328 \mathrm{E}-07$ & 1.497E-05 & 0.020595 \\
\hline 6.15 & -3.09 & 0.000812831 & $7.07946 \mathrm{E}-07$ & $1.68 \mathrm{E}-05$ & 0.020593 \\
\hline 6.2 & -3.04 & 0.000912011 & $6.30957 \mathrm{E}-07$ & $1.884 \mathrm{E}-05$ & 0.020591 \\
\hline 6.25 & -2.99 & 0.001023293 & $5.62341 \mathrm{E}-07$ & $2.114 \mathrm{E}-05$ & 0.020589 \\
\hline 6.3 & -2.94 & 0.001148154 & 5.01187E-07 & $2.372 \mathrm{E}-05$ & 0.020586 \\
\hline 6.35 & -2.89 & 0.00128825 & 4.46684E-07 & $2.661 \mathrm{E}-05$ & 0.020583 \\
\hline 6.4 & -2.84 & 0.00144544 & 3.98107E-07 & $2.985 \mathrm{E}-05$ & 0.02058 \\
\hline 6.45 & -2.79 & 0.00162181 & $3.54813 \mathrm{E}-07$ & $3.348 \mathrm{E}-05$ & 0.020577 \\
\hline 6.5 & -2.74 & 0.001819701 & $3.16228 \mathrm{E}-07$ & $3.756 \mathrm{E}-05$ & 0.020572 \\
\hline 6.55 & -2.69 & 0.002041738 & $2.81838 \mathrm{E}-07$ & $4.214 \mathrm{E}-05$ & 0.020568 \\
\hline 6.6 & -2.64 & 0.002290868 & $2.51189 \mathrm{E}-07$ & 4.727E-05 & 0.020563 \\
\hline 6.65 & -2.59 & 0.002570396 & $2.23872 \mathrm{E}-07$ & 5.302E-05 & 0.020557 \\
\hline 6.7 & -2.54 & 0.002884032 & $1.99526 \mathrm{E}-07$ & 5.947E-05 & 0.020551 \\
\hline 6.75 & -2.49 & 0.003235937 & $1.77828 \mathrm{E}-07$ & $6.67 \mathrm{E}-05$ & 0.020543 \\
\hline 6.8 & -2.44 & 0.003630781 & $1.58489 \mathrm{E}-07$ & 7.481E-05 & 0.020535 \\
\hline 6.85 & -2.39 & 0.004073803 & 1.41254E-07 & 8.39E-05 & 0.020526 \\
\hline 6.9 & -2.34 & 0.004570882 & $1.25893 \mathrm{E}-07$ & $9.409 \mathrm{E}-05$ & 0.020516 \\
\hline 6.95 & -2.29 & 0.005128614 & $1.12202 \mathrm{E}-07$ & 0.0001055 & 0.020504 \\
\hline 7 & -2.24 & 0.005754399 & 0.0000001 & 0.0001183 & 0.020492 \\
\hline 7.05 & -2.19 & 0.006456542 & $8.91251 \mathrm{E}-08$ & 0.0001327 & 0.020477 \\
\hline 7.1 & -2.14 & 0.00724436 & $7.94328 \mathrm{E}-08$ & 0.0001487 & 0.020461 \\
\hline 7.15 & -2.09 & 0.008128305 & $7.07946 \mathrm{E}-08$ & 0.0001667 & 0.020443 \\
\hline 7.2 & -2.04 & 0.009120108 & $6.30957 \mathrm{E}-08$ & 0.0001869 & 0.020423 \\
\hline 7.25 & -1.99 & 0.01023293 & $5.62341 \mathrm{E}-08$ & 0.0002095 & 0.020401 \\
\hline 7.3 & -1.94 & 0.011481536 & 5.01187E-08 & 0.0002347 & 0.020375 \\
\hline 7.35 & -1.89 & 0.012882496 & 4.46684E-08 & 0.000263 & 0.020347 \\
\hline 7.4 & -1.84 & 0.014454398 & 3.98107E-08 & 0.0002947 & 0.020315 \\
\hline 7.45 & -1.79 & 0.016218101 & 3.54813E-08 & 0.00033 & 0.02028 \\
\hline
\end{tabular}




\begin{tabular}{|c|c|c|c|c|c|}
\hline 7.5 & -1.74 & 0.018197009 & 3.16228E-08 & 0.0003696 & 0.02024 \\
\hline 7.55 & -1.69 & 0.020417379 & $2.81838 \mathrm{E}-08$ & 0.0004138 & 0.020196 \\
\hline 7.6 & -1.64 & 0.022908677 & $2.51189 \mathrm{E}-08$ & 0.0004631 & 0.020147 \\
\hline 7.65 & -1.59 & 0.025703958 & 2.23872E-08 & 0.0005182 & 0.020092 \\
\hline 7.7 & -1.54 & 0.028840315 & $1.99526 \mathrm{E}-08$ & 0.0005797 & 0.02003 \\
\hline 7.75 & -1.49 & 0.032359366 & $1.77828 \mathrm{E}-08$ & 0.0006482 & 0.019962 \\
\hline 7.8 & -1.44 & 0.036307805 & 1.58489E-08 & 0.0007245 & 0.019885 \\
\hline 7.85 & -1.39 & 0.040738028 & 1.41254E-08 & 0.0008095 & 0.019801 \\
\hline 7.9 & -1.34 & 0.045708819 & 1.25893E-08 & 0.0009039 & 0.019706 \\
\hline 7.95 & -1.29 & 0.051286138 & 1.12202E-08 & 0.0010089 & 0.019601 \\
\hline 8 & -1.24 & 0.057543994 & $1 \mathrm{E}-08$ & 0.0011253 & 0.019485 \\
\hline 8.05 & -1.19 & 0.064565423 & 8.91251E-09 & 0.0012542 & 0.019356 \\
\hline 8.1 & -1.14 & 0.072443596 & 7.94328E-09 & 0.0013969 & 0.019213 \\
\hline 8.15 & -1.09 & 0.081283052 & 7.07946E-09 & 0.0015546 & 0.019055 \\
\hline 8.2 & -1.04 & 0.091201084 & 6.30957E-09 & 0.0017284 & 0.018882 \\
\hline 8.25 & -0.99 & 0.102329299 & 5.62341E-09 & 0.0019197 & 0.01869 \\
\hline 8.3 & -0.94 & 0.114815362 & 5.01187E-09 & 0.0021298 & 0.01848 \\
\hline 8.35 & -0.89 & 0.128824955 & 4.46684E-09 & 0.0023601 & 0.01825 \\
\hline 8.4 & -0.84 & 0.144543977 & 3.98107E-09 & 0.0026117 & 0.017998 \\
\hline 8.45 & -0.79 & 0.16218101 & 3.54813E-09 & 0.0028859 & 0.017724 \\
\hline 8.5 & -0.74 & 0.181970086 & 3.16228E-09 & 0.0031838 & 0.017426 \\
\hline 8.55 & -0.69 & 0.204173794 & $2.81838 \mathrm{E}-09$ & 0.0035064 & 0.017104 \\
\hline 8.6 & -0.64 & 0.229086765 & 2.51189E-09 & 0.0038545 & 0.016755 \\
\hline 8.65 & -0.59 & 0.257039578 & 2.23872E-09 & 0.0042287 & 0.016381 \\
\hline 8.7 & -0.54 & 0.28840315 & $1.99526 \mathrm{E}-09$ & 0.0046292 & 0.015981 \\
\hline 8.75 & -0.49 & 0.323593657 & $1.77828 \mathrm{E}-09$ & 0.0050559 & 0.015554 \\
\hline 8.8 & -0.44 & 0.363078055 & 1.58489E-09 & 0.0055085 & 0.015101 \\
\hline 8.85 & -0.39 & 0.407380278 & $1.41254 \mathrm{E}-09$ & 0.0059861 & 0.014624 \\
\hline 8.9 & -0.34 & 0.45708819 & 1.25893E-09 & 0.0064874 & 0.014123 \\
\hline 8.95 & -0.29 & 0.512861384 & 1.12202E-09 & 0.0070106 & 0.013599 \\
\hline 9 & -0.24 & 0.575439937 & $1 \mathrm{E}-09$ & 0.0075536 & 0.013056 \\
\hline 9.05 & -0.19 & 0.645654229 & $8.91251 \mathrm{E}-10$ & 0.0081137 & 0.012496 \\
\hline 9.1 & -0.14 & 0.72443596 & $7.94328 \mathrm{E}-10$ & 0.0086879 & 0.011922 \\
\hline 9.15 & -0.09 & 0.812830516 & 7.07946E-10 & 0.0092726 & 0.011337 \\
\hline 9.2 & -0.04 & 0.912010839 & 6.30957E-10 & 0.0098644 & 0.010746 \\
\hline 9.25 & 0.01 & 1.023292992 & $5.62341 \mathrm{E}-10$ & 0.0104593 & 0.010151 \\
\hline 9.3 & 0.06 & 1.148153621 & $5.01187 \mathrm{E}-10$ & 0.0110534 & 0.009557 \\
\hline 9.35 & 0.11 & 1.288249552 & 4.46684E-10 & 0.0116429 & 0.008967 \\
\hline 9.4 & 0.16 & 1.445439771 & 3.98107E-10 & 0.0122238 & 0.008386 \\
\hline 9.45 & 0.21 & 1.621810097 & 3.54813E-10 & 0.0127928 & 0.007817 \\
\hline
\end{tabular}




\begin{tabular}{|c|c|c|c|c|c|}
\hline 9.5 & 0.26 & 1.819700859 & $3.16228 \mathrm{E}-10$ & 0.0133464 & 0.007264 \\
\hline 9.55 & 0.31 & 2.041737945 & $2.81838 \mathrm{E}-10$ & 0.0138818 & 0.006728 \\
\hline 9.6 & 0.36 & 2.290867653 & $2.51189 \mathrm{E}-10$ & 0.0143965 & 0.006213 \\
\hline 9.65 & 0.41 & 2.570395783 & $2.23872 \mathrm{E}-10$ & 0.0148885 & 0.005721 \\
\hline 9.7 & 0.46 & 2.884031503 & $1.99526 \mathrm{E}-10$ & 0.0153563 & 0.005254 \\
\hline 9.75 & 0.51 & 3.235936569 & $1.77828 \mathrm{E}-10$ & 0.0157987 & 0.004811 \\
\hline 9.8 & 0.56 & 3.630780548 & $1.58489 \mathrm{E}-10$ & 0.016215 & 0.004395 \\
\hline 9.85 & 0.61 & 4.073802778 & $1.41254 \mathrm{E}-10$ & 0.016605 & 0.004005 \\
\hline 9.9 & 0.66 & 4.570881896 & $1.25893 \mathrm{E}-10$ & 0.0169687 & 0.003641 \\
\hline 9.95 & 0.71 & 5.12861384 & $1.12202 \mathrm{E}-10$ & 0.0173065 & 0.003303 \\
\hline 10 & 0.76 & 5.754399373 & $1 \mathrm{E}-10$ & 0.0176192 & 0.002991 \\
\hline 10.05 & 0.81 & 6.45654229 & $8.91251 \mathrm{E}-11$ & 0.0179075 & 0.002702 \\
\hline 10.1 & 0.86 & 7.244359601 & $7.94328 \mathrm{E}-11$ & 0.0181726 & 0.002437 \\
\hline 10.15 & 0.91 & 8.128305162 & $7.07946 \mathrm{E}-11$ & 0.0184155 & 0.002194 \\
\hline 10.2 & 0.96 & 9.120108394 & $6.30957 \mathrm{E}-11$ & 0.0186376 & 0.001972 \\
\hline 10.25 & 1.01 & 10.23292992 & $5.62341 \mathrm{E}-11$ & 0.01884 & 0.00177 \\
\hline 10.3 & 1.06 & 11.48153621 & 5.01187E-11 & 0.0190242 & 0.001586 \\
\hline 10.35 & 1.11 & 12.88249552 & 4.46684E-11 & 0.0191914 & 0.001419 \\
\hline 10.4 & 1.16 & 14.45439771 & 3.98107E-11 & 0.019343 & 0.001267 \\
\hline 10.45 & 1.21 & 16.21810097 & $3.54813 \mathrm{E}-11$ & 0.0194801 & 0.00113 \\
\hline 10.5 & 1.26 & 18.19700859 & $3.16228 \mathrm{E}-11$ & 0.0196039 & 0.001006 \\
\hline 10.55 & 1.31 & 20.41737945 & $2.81838 \mathrm{E}-11$ & 0.0197156 & 0.000894 \\
\hline 10.6 & 1.36 & 22.90867653 & $2.51189 \mathrm{E}-11$ & 0.0198162 & 0.000794 \\
\hline 10.65 & 1.41 & 25.70395783 & $2.23872 \mathrm{E}-11$ & 0.0199067 & 0.000703 \\
\hline 10.7 & 1.46 & 28.84031503 & $1.99526 \mathrm{E}-11$ & 0.0199882 & 0.000622 \\
\hline 10.75 & 1.51 & 32.35936569 & $1.77828 \mathrm{E}-11$ & 0.0200613 & 0.000549 \\
\hline 10.8 & 1.56 & 36.30780548 & $1.58489 \mathrm{E}-11$ & 0.0201269 & 0.000483 \\
\hline 10.85 & 1.61 & 40.73802778 & $1.41254 \mathrm{E}-11$ & 0.0201857 & 0.000424 \\
\hline 10.9 & 1.66 & 45.70881896 & $1.25893 \mathrm{E}-11$ & 0.0202385 & 0.000372 \\
\hline 10.95 & 1.71 & 51.2861384 & $1.12202 \mathrm{E}-11$ & 0.0202857 & 0.000324 \\
\hline 11 & 1.76 & 57.54399373 & $1 \mathrm{E}-11$ & 0.020328 & 0.000282 \\
\hline
\end{tabular}




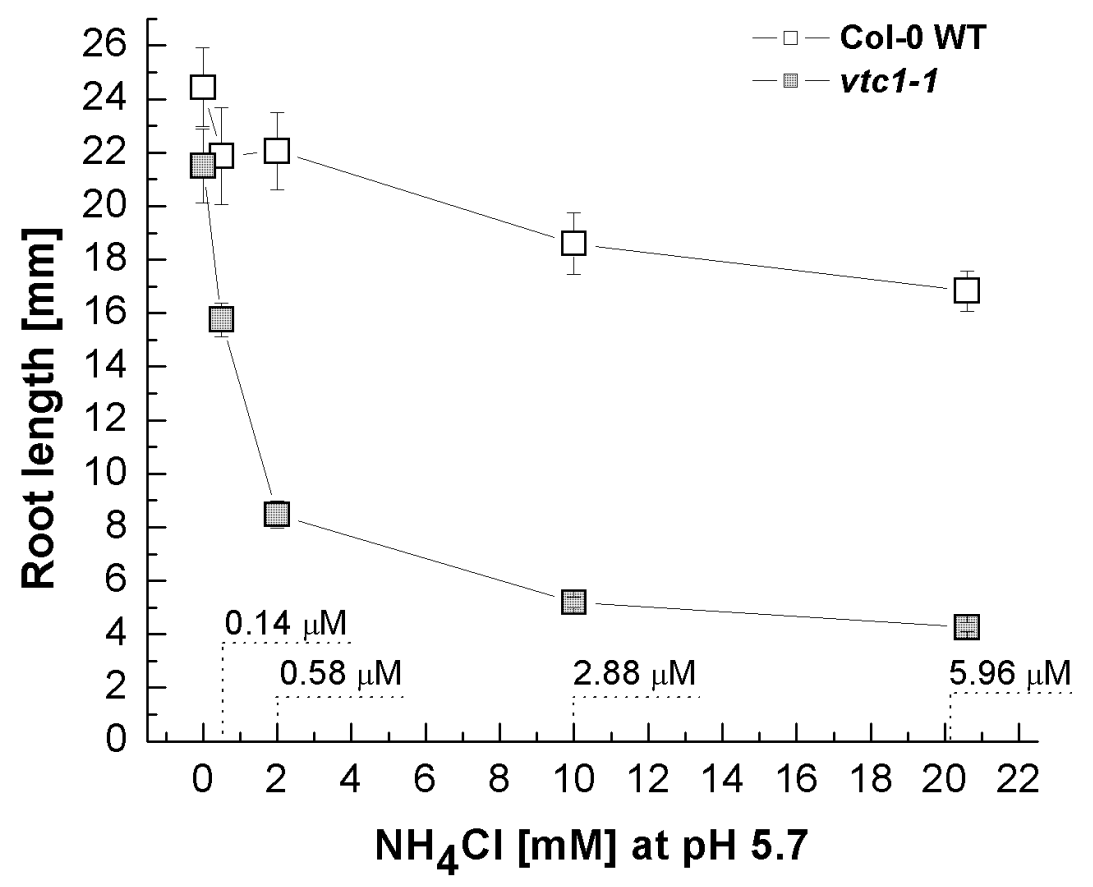

Figure 1.9 Primary root length of seven-day-old Col-0 wild type and vtc1-1 in the presence of increasing concentrations of $\mathrm{NH}_{4} \mathrm{Cl}$.

Data represent means \pm SE of 15 to 20 individual seedlings per genotype and concentration. Numbers on abscissa indicate calculated $\mathrm{NH}_{3}$ concentrations at corresponding $\mathrm{NH}_{4} \mathrm{Cl}$ concentrations. 


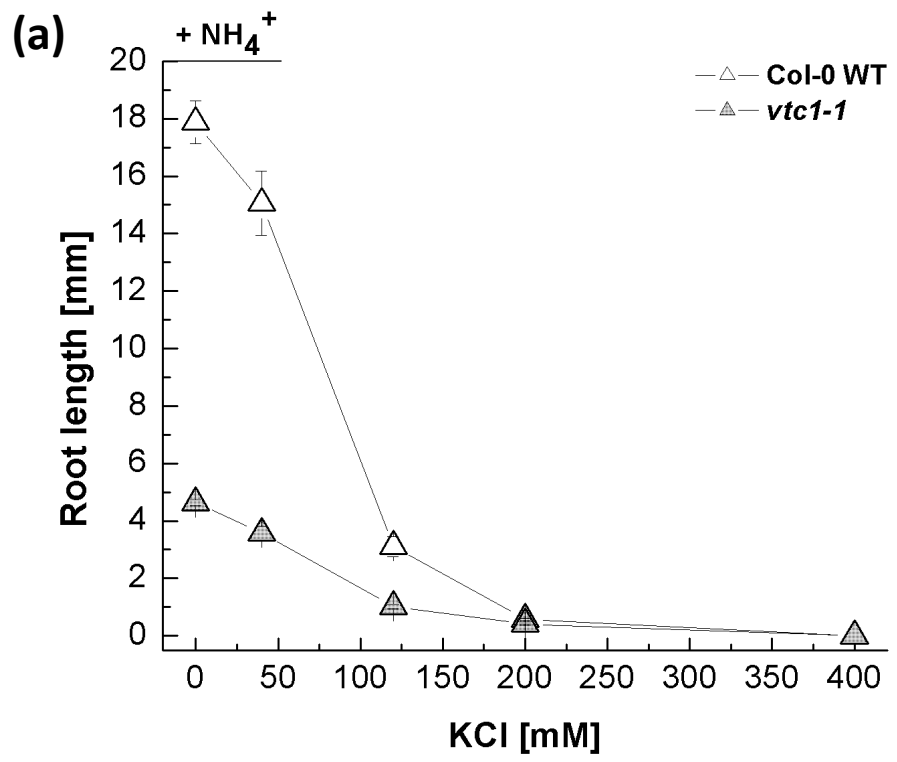

(b)

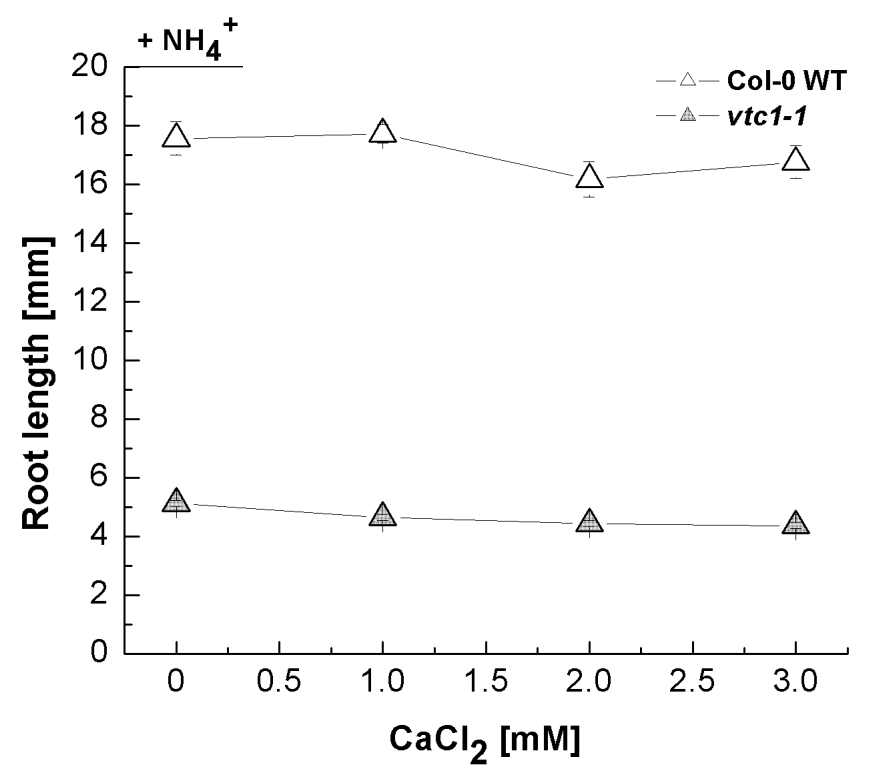

Figure 1.10 Primary root length of Col-0 wild-type plants and vtc1-1 mutants in the presence of $\mathrm{NH}_{4}{ }^{+}$ and (a) $\mathrm{KCl}$ or (b) $\mathrm{CaCl}_{2}$.

Data illustrate means \pm SE of 49 to 60 seven-day-old individual seedlings. 
in the presence of $\mathrm{NH}_{4}^{+}$and $\mathrm{KCl}$. Likewise, vtc1-1 exhibited stunted root growth compared to the wild type in the presence of both $\mathrm{NH}_{4}{ }^{+}$and $\mathrm{CaCl}_{2}$ (Fig. 1.10b). We also tested the response of vtc1-1, GDP-mannose-deficient and AA-deficient mutants compared to the wild type to salt and osmotic stress (Fig. 1.11). While vtc1-1, vtc2-1 and vtc4-1 were somewhat more susceptible to $\mathrm{NaCl}$ (Fig. 1.11a) and mannitol (Fig. 1.11b) than the wild type, this was not the case for pmm12 and pmm-21. None of the mutants were hypersensitive to $\mathrm{KCl}$ (Fig. 1.11c) or LiCl (Fig. 1.11d).

In conclusion, our data demonstrate that the short-root phenotype developed by vtc1-1 can be recovered to almost wild-type levels in the presence of $\mathrm{NH}_{4}{ }^{+}$when the $\mathrm{pH}$ of the growth medium is neutral. However, root growth cannot be restored by the addition of $\mathrm{K}^{+}$or $\mathrm{Ca}^{2+}$ cations. This suggests that in vtc1-1, $\mathrm{NH}_{4}^{+}$toxicity is $\mathrm{K}^{+}$- and $\mathrm{Ca}^{2+}$-independent but $\mathrm{pH}-$ dependent, presumably affecting $\mathrm{NH}_{4}{ }^{+}$and cellular properties (e.g. cell division and differentiation, PCD, metabolic enzymes; Foyer and Noctor, [2011]), and thus influencing growth and developmental properties.

\subsubsection{Root development in the presence of $\mathrm{NH}_{4}{ }^{+}$is fully recovered in vtc1-1 containing one wild-type copy of VTC1}

Our results presented in Fig. 1.8 suggest that the point mutation in GMPase in vtc1-1 makes the enzyme more susceptible to intracellular $\mathrm{pH}$ changes evoked by the presence of $\mathrm{NH}_{4}{ }^{+}$. In order to obtain first insights into the molecular properties of GMPase at the restrictive $\mathrm{pH}$ of 5.7, we examined a possible correlation between root development and VTC1 mRNA levels when vtc1-1 contains a wild-type copy of the VTC1 gene and is grown at pH of 5.7 in the presence of $\mathrm{NH}_{4}^{+}$.

As is shown in Fig. 1.12a, vtc1-1 VTC1 heterozygous mutants form primary roots similar to the wild type, while vtc1-1 homozygous mutants have strongly reduced root growth in the presence of $\mathrm{NH}_{4}{ }^{+}$, as expected. VTC1 mRNA was significantly lower by $40 \%$ in vtc1-1 homozygous mutants and was reduced by 70\% in vtc1-1 VTC1 heterozygotes compared to the wild type (Fig. 1.12b). No significant differences in VTC1 transcript levels were observed in the absence of $\mathrm{NH}_{4}{ }^{+}$(data not shown). Note that $\mathrm{AA}$ levels in rosettes of plants grown in the presence of $\mathrm{NH}_{4}{ }^{+}$were similar in the wild type and vtc1-1 VTC1 heterozygotes and were approximately $50 \%$ of the wild type in vtc1-1 mutants (Fig. 1.13). This is in contrast to plants grown on soil (no $\mathrm{NH}_{4}^{+}$stress), where vtc1-1 VTC1 heterozygotes have an AA content that is intermediate between the wild type and vtc1-1 (Conklin et al., 1996).

In sum, our results suggest that the introduction of one wild-type VTC1 copy into vtc1-1 is sufficient to fully recover root development in vtc1-1 at the restrictive $\mathrm{pH}$ in the presence of $\mathrm{NH}_{4}{ }^{+}$. Our data also suggest a regulatory mechanism at the VTC1 mRNA level in response to $\mathrm{NH}_{4}^{+} / \mathrm{pH}$ stress. 

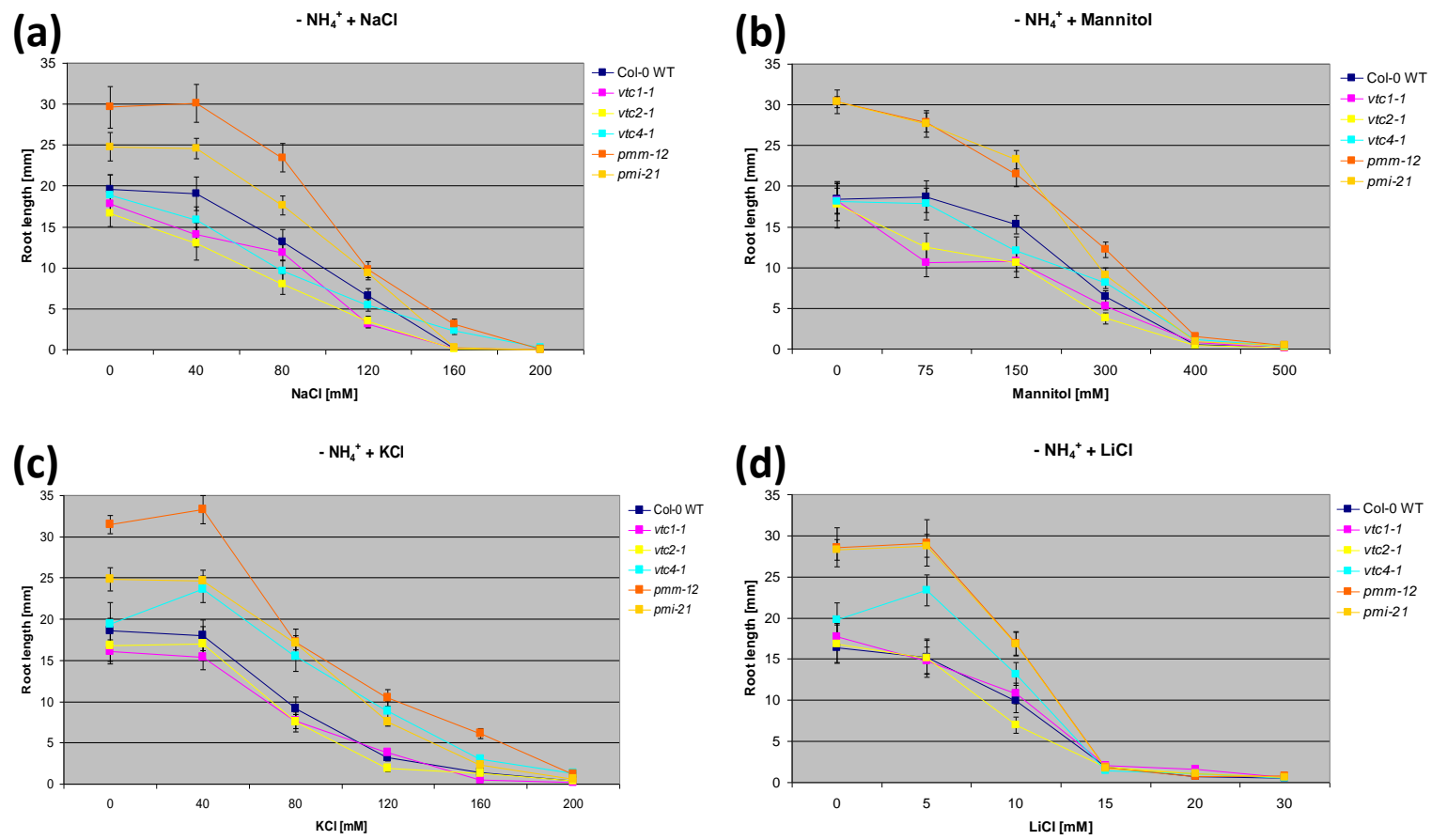

Figure 1.11 Primary root length of Col-0 wild-type plants and ascorbic acid-deficient mutants grown in the absence of $\mathrm{NH}_{4}{ }^{+}$and in the presence of increasing concentrations of (a) $\mathrm{NaCl}$, (b) mannitol, (c) $\mathrm{KCl}$ or (d) LiCl.

Results show means \pm SE of 21 to 26 seven-day-old individual seedlings. 
(a)

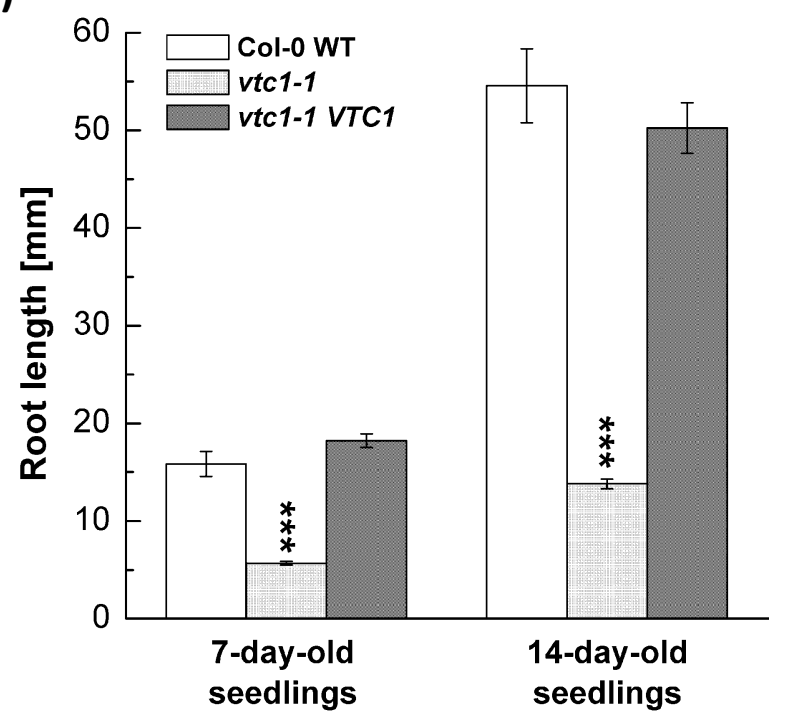

(b)

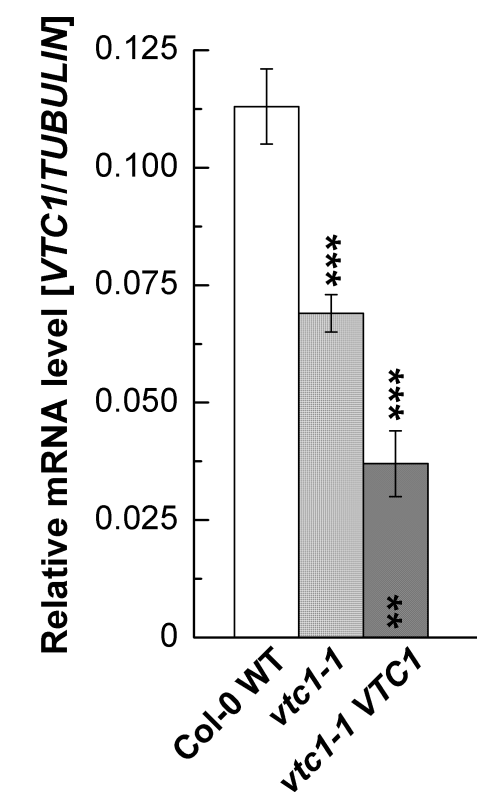

Figure 1.12 Phenotypic and molecular characterization of Col-0 wild type, vtc1-1 homozygous and vtc1-1 VTC1 heterozygous mutants.

(a) Primary root length of seven- and 14-day-old seedlings in the presence of $\mathrm{NH}_{4}{ }^{+}$. (b) Relative mRNA levels of VTC1 based on TUBULIN in 14-day-old seedlings grown in the presence of $\mathrm{NH}_{4}{ }^{+}$. Results display means \pm SE of 14 to 28 individual seedlings per genotype in (a) and of three to seven biological replicates in (b). Asterisks on top of bars indicate significant differences between mutants and the wild type. Asterisks on bottom of bar indicate significant difference between vtc1-1 and vtc1-1 VTC1. $* * P<0.01$, $* * * P<0.001$, Student's $t$-test. 


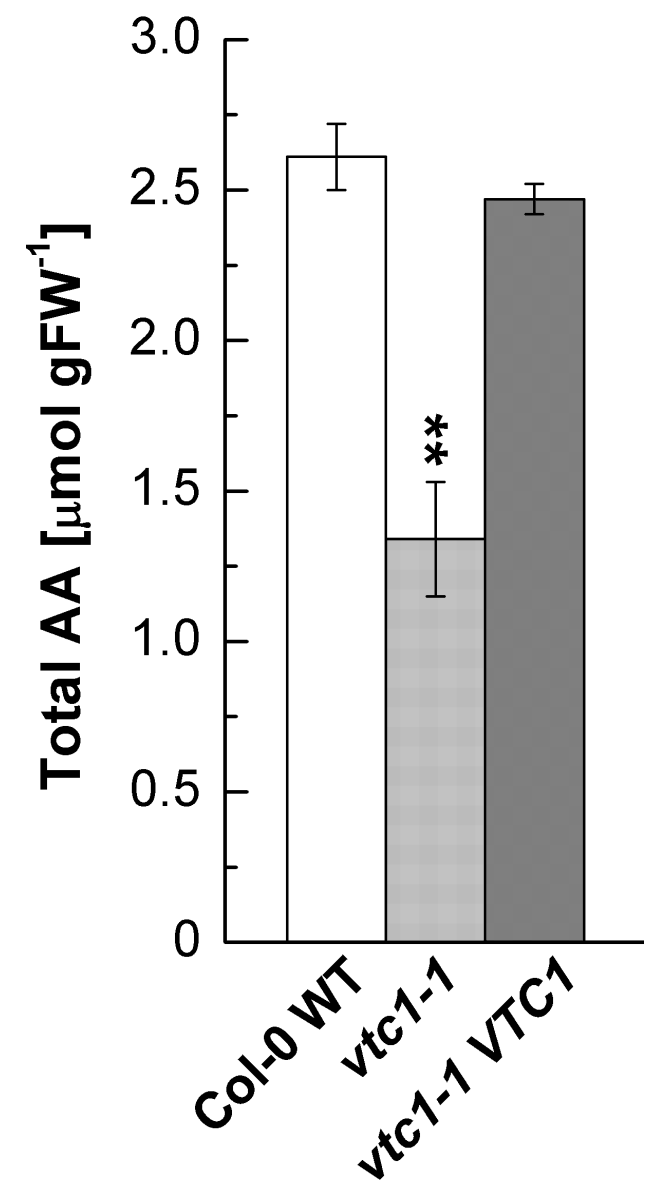

Figure 1.13 Total ascorbic acid (AA) content in Col-0 wild-type plants, vtc1-1 homozygous and vtc1-1 VTC1 heterozygous mutants grown in the presence of $\mathrm{NH}_{4}^{+}$.

Ascorbic acid content was measured in whole rosettes of two-week-old plants. Means \pm SE of four biological replicates are shown. Asterisks indicate significant differences between individual mutant and the wild type. ${ }^{* *} P<0.01$, Student's $t$-test. 


\subsection{DISCUSSION}

\subsubsection{Impaired GDP-mannose biosynthesis, resulting in ER stress and defective protein N- glycosylation contributes to but is not the primary cause of $\mathrm{NH}_{4}{ }^{+}$sensitivity in vtc1-1}

It has been suggested previously that GMPase is a genetic determinant of $\mathrm{NH}_{4}^{+}$ sensitivity in Arabidopsis, as has been demonstrated by the conditional hypersensitivity of two GMPase mutant alleles, hsn1 and vtc1-1 (Qin et al., 2008; Barth et al., 2010). Two additional GMPase mutant alleles, cyt1-1 and cyt2-1, were identified, displaying severe defects in protein $\mathrm{N}$-glycosylation, causing embryo lethality (Lukowitz et al., 2001). Initial investigations suggested that defective protein $\mathrm{N}$-glycosylation, caused by low levels of GDP-mannose (Fig. 1.1), in the hsn1 and vtc1-1 mutants are linked to the $\mathrm{NH}_{4}{ }^{+}$hypersensitivity in these mutants (Qin et al., 2008; Barth et al., 2010). Therefore, we asked whether other mutants impaired in GDPmannose biosynthesis also exhibit $\mathrm{NH}_{4}{ }^{+}$sensitivity. The pmi-1 and pmm-12 mutants act directly upstream of vtc1-1 and contribute to GDP-mannose biosynthesis (Fig. 1.1). Surprisingly, root growth was the same in pmi-1 and pmm-12 mutants and the wild type in the presence of $\mathrm{NH}_{4}^{+}$ (Fig. 1.6a), suggesting that GDP-mannose deficiency is not the sole cause of $\mathrm{NH}_{4}{ }^{+}$sensitivity. It should be noted, however, that defective protein $\mathrm{N}$-glycosylation in pmm-12 causes temperature sensitivity (Hoeberichts et al., 2008), while this is not the case in pmi-1 and vtc1-1 mutants (Fig. 1.6c). Nevertheless, pmm-12 mutants have decreased PMM activity and protein levels at permissible temperature (Hoeberichts et al., 2008), which is also evident in the significantly lower AA content in plants grown on soil in the absence of $\mathrm{NH}_{4}{ }^{+}$stress (Fig. 1.5).

However, we cannot rule out that GDP-mannose deficiency, and thus defective protein $\mathrm{N}$-glycosylation, contributes to the root growth defect in vtc1-1 in the presence of $\mathrm{NH}_{4}^{+}$. This is supported by the following facts: (i) ER stress genes are upregulated in vtc1-1 (Fig. 1.2), (ii) cell cycle progression is arrested in S-phase in vtc1-1 (Fig. 1.3c, d), and (iii) cell wall and cell membrane integrity is strongly impaired in vtc1-1 in the presence of $\mathrm{NH}_{4}{ }^{+}$(Fig. 1.4). The binding protein (BiP) and BAX-inhibitor 1 (BI1) are induced in response to treatment of Arabidopsis seedlings with tunicamycin, an inhibitor of $\mathrm{N}$-linked protein glycosylation and an inducer of ER stress. Tunicamycin causes strong inhibition of root growth in wild-type seedlings (Watanabe and Lam, 2008), resembling the vtc1-1 short-root phenotype in the presence of $\mathrm{NH}_{4}^{+}$(Barth et al., 2010). It has been previously proposed that BI1 is a critical survival factor for the suppression of PCD induced by ER stress (Watanabe and Lam, 2008). Note that BI1 is not markedly upregulated in vtc1-1 in the presence of $\mathrm{NH}_{4}^{+}$(Fig. 1.2), suggesting that the inability of vtc1-1 to substantially induce BI1 could promote the onset of PCD and compromise stress tolerance to $\mathrm{NH}_{4}{ }^{+}$(Fig. 1.3a). Although the exact chain of events is currently unclear, it is possible that these apoptotic regulatory mechanisms modulate the level of cell cycle- 
controlling proteins, thereby affecting DNA synthesis in vtc1-1 in the presence of $\mathrm{NH}_{4}^{+}$. This is supported by our data, which show that cell cycle progression is arrested in S-phase in vtc1-1 under $\mathrm{NH}_{4}{ }^{+}$stress (Fig. 1.3c, d) and by results by $\mathrm{Li}$ and co-workers who reported reduced meristematic cell division and/or meristem cell size in the wild type grown in the presence of $\mathrm{NH}_{4}{ }^{+}$(Li et al., 2010). Finally, GDP-mannose functions beyond protein $\mathrm{N}$-glycosylation and is important for cell wall polysaccharide biosynthesis (Fig. 1.1; Bonin et al., 1997). In fact, our data suggest that $\mathrm{NH}_{4}{ }^{+}$induces defects in cell wall formation, while vtc1-1 does not have weakened cell walls per se (Fig. 1.4a, b). Defective cell wall development in vtc1-1 in the presence of $\mathrm{NH}_{4}^{+}$ correlates with the accumulation of callose in vtc1-1 (Fig. 1.4c), suggesting that $\mathrm{NH}_{4}{ }^{+}$causes plasma membrane defects (see below). Callose is deposited outside the plasma membrane and may serve as a defense response to maintain structural integrity and osmotic conditions (Cresti and van Went, 1976). Since cell walls (and callose) are synthesized at the plasma membrane (Doblin et al., 2002; Saxena and Brown, 2005), altered membrane integrity in conjunction with a lack of complex $\mathrm{N}$-glycans is likely to result in insufficient structural polysaccharides and glycoproteins, thereby impacting cell wall formation and thus growth in vtc1-1 in the presence of $\mathrm{NH}_{4}{ }^{+}$. This is supported by the fact that GMPase is essential for cell wall integrity, morphogenesis and viability of Aspergillus fumigatus (Jiang et al., 2008). Furthermore, Arabidopsis mutants with defective N-glycosylation, such as stt3a-1 and stt3a-2 with defects in one of the subunits of an oligosaccharyltransferase complex, and cgl1, a mutant defective in $\mathrm{N}$ glycan maturation, suffer cell-wall biosynthesis defects in response to salt stress (Koiwa et al., 2003; Kang et al., 2008). Note, however, that cgl1 and stt3a single mutants do not exhibit any growth defects in the absence of stress and do not display stunted root growth in the presence of $\mathrm{NH}_{4}^{+}$(Frank et al., 2008). Interestingly, despite its $\mathrm{N}$-glycosylation defect, vtc1-1 is not hypersensitive to salt or osmotic stress (Fig. 1.11a, b). Although vtc1-1 is somewhat susceptible to salt and osmotic stress in comparison to the wild type, we reason that the reduced root growth in response to these two stresses is due to the AA deficiency in the mutant, because two other AA-deficient mutants, vtc2-1 and vtc4-1 show a similar response. Increased sensitivity of vtc1-1 to salt stress due to low endogenous $A A$ and impaired AA-glutathione cycle has been document previously (Huang et al., 2005).

Taken together, our data are consistent with previous reports that suggest a correlation between defective protein $\mathrm{N}$-glycosylation, ER stress, and cell wall formation, cumulating in root growth arrest in vtc1-1 in the presence of $\mathrm{NH}_{4}{ }^{+}$. However, we discovered distinct responses of vtc1-1, suggesting delineation between these secondary effects and yet unknown primary causes. 


\subsection{2 $\mathrm{NH}_{4}{ }^{+}$sensitivity is $\mathrm{pH}-$ dependent}

To obtain first insights into the primary cause of root growth inhibition in vtc1-1, we first tested the response of vtc1-1 in comparison to the wild type grown on acidic, neutral and alkaline growth media containing $\mathrm{NH}_{4}{ }^{+}$. This was important to investigate, because the external $\mathrm{pH}$ influences cation uptake (Marschner, 1995). While alterations in the $\mathrm{pH}$ of the growth medium in the absence of $\mathrm{NH}_{4}{ }^{+}$did neither have a significant effect on root growth in the wild type nor in vtc1-1 (Fig. 1.7a), primary root length increased slightly in the wild type and dramatically in vtc1-1 at neutral $\mathrm{pH}$ and decreased rapidly in both genotypes at alkaline $\mathrm{pH}$ in the presence of $\mathrm{NH}_{4}{ }^{+}$(Fig. 1.7b). While the $\mathrm{pH}$ in the medium was not monitored over time, our results with the buffering agent MES are consistent with those in the absence of MES (cf. Fig. 1.8 and Fig. 1.7b), suggesting that the $\mathrm{pH}$ in the medium is relatively stable over the growth period of seven days. Therefore, the results will have to be interpreted with caution and may be explained as follows. $\mathrm{NH}_{4}{ }^{+}$uptake by plant roots depends on its electrochemical gradient across the plasma membrane for passive transport through carriers or channels that regulate the transport. In addition, an electrochemical gradient of $\mathrm{H}^{+}$across the plasma membrane is maintained by $\mathrm{H}^{+}$-ATPases, which pump $\mathrm{H}^{+}$from the cytoplasm, generating the driving force for active transport of $\mathrm{NH}_{4}^{+}$across the plasma membrane. At low $\mathrm{pH}$, the efficiency of the $\mathrm{H}^{+}$ATPases or an increased re-entry of $\mathrm{H}^{+}$may decrease the electrochemical gradient across the plasma membrane, thereby reducing the driving force for $\mathrm{NH}_{4}{ }^{+}$uptake (Kleiner, 1985; Marschner, 1995; Dyhr-Jensen and Brix, 1996). At $\mathrm{NH}_{4}^{+}$concentrations greater than $1 \mathrm{mM}$, transport of $\mathrm{NH}_{4}^{+}$and/or $\mathrm{NH}_{3}$ is passive (Ullrich et al., 1984; Wang et al., 1993; Britto and Kronzucker, 2006). Thus, it appears more likely that the external pH affects $\mathrm{NH}_{4}^{+}$uptake by influencing the speciation of the ions. That is, with increasing $\mathrm{pH}$ the proportion of $\mathrm{NH}_{3}$ (and $\mathrm{NH}_{4} \mathrm{OH}$ ) increases (numbers on abscissa in Fig. 1.7b, Table 1.3), resulting in an increased uptake through diffusion, as the plasma membrane is more permeable to uncharged solutes (Kleiner, 1985; Marschner, 1995). Therefore, we suggest that low $\mathrm{pH}$ may have an adverse effect on $\mathrm{NH}_{4}{ }^{+}$uptake due to a combination of reduced $\mathrm{H}^{+}$-ATPase activity, re-entry of $\mathrm{H}^{+}$and a lower amount of $\mathrm{NH}_{3}$ that is liberated from $\mathrm{NH}_{4}^{+}$and presumably entering the cell where it is protonated again for assimilation and growth. At $\mathrm{pH} 7.0$, which is close to the $\mathrm{pH}$ of the cytosol, $\mathrm{H}^{+}$-ATPase activity is optimal, generating a sufficient gradient for $\mathrm{NH}_{4}^{+}$uptake and liberating a higher amount of $\mathrm{NH}_{3}$ that can penetrate the plasma membrane and assimilated as $\mathrm{NH}_{4}{ }^{+}$. Note that vtc1-1 root growth is dramatically enhanced at $\mathrm{pH} 7.0$ compared to the acidic $\mathrm{pH}$ values. However, primary roots are still shorter in vtc1-1 compared to the wild type (Fig. 1.7b). Finally, at alkaline $\mathrm{pH}$, overall net $\mathrm{NH}_{4}{ }^{+}$uptake is presumably decreased (Dyhr-Jensen and Brix, 1996), because larger amounts of $\mathrm{NH}_{3}$ are freed in the medium, permeating the plasma membrane, 
causing alkalinization of the cytosol, which in turn liberates $\mathrm{NH}_{3}$ that is diffusing back out into the surrounding medium. In fact, it has been reported recently that root growth inhibition by $\mathrm{NH}_{4}{ }^{+}$in Arabidopsis is mediated by enhanced $\mathrm{NH}_{4}{ }^{+}$efflux (Li et al., 2010).

We suggest that, under conditions when $\mathrm{NH}_{4}{ }^{+}$is the primary $\mathrm{N}$ source, the combination of lost $\mathrm{N}$ for assimilation and alkalization of the cytosol causes metabolic changes, leading to the drastic root growth defect in both genotypes (Fig. 1.7b). A more difficult question to answer is how the proline to serine mutation in vtc1-1 affects these processes and thereby influences growth homeostasis.

\subsubsection{Understanding the biochemical properties of GMPase protein will enhance our understanding of $\mathrm{NH}_{4}{ }^{+}$sensitivity in plants}

Arabidopsis GMPase has previously been suggested to localize to the cytosol (Wheeler et al., 1998; Conklin et al., 1999). Although we do not yet have protein biochemical data of the Arabidopsis GMPase in the presence and absence of $\mathrm{NH}_{4}{ }^{+}$in the wild type and vtc1-1 available, our results on VTC1 transcript levels in the wild type, vtc1-1 homozygous and vtc1-1 VTC1 heterozygous plants (Fig. 1.12b) suggest a regulatory mechanism at the transcription level that is possibly mediated by the VTC1 protein. This could be an autoregulatory mechanism or through interaction with a regulatory partner. This mechanism is disabled in the vtc1-1 homozygous mutant, while in the vtc1-1 VTC1 heterozygote, the vtc1-1 mutation exacerbates the defect. Thus, we propose that the vtc1-1 mutation acts as a dominant-negative mutation and the mutated VTC1 protein product acts antagonistically to the wild-type allele. Dominantnegative mutations usually result in an altered molecular function and are characterized by a dominant or semi-dominant phenotype. Genetic and phenotypic analysis of vtc1-1 demonstrated previously that vtc1-1 is conferred by a semi-dominant monogenic mutation with ozone sensitivity and AA levels of vtc1-1 VTC1 heterozygotes (grown on soil in the absence of $\mathrm{NH}_{4}{ }^{+}$stress) being intermediate between the wild type and vtc1-1 homozygous mutants (Conklin et al., 1996). Interestingly, root growth and AA levels are fully recovered to wild-type levels in the vtc1-1 VTC1 heterozygote in the presence of $\mathrm{NH}_{4}^{+}$(Fig. 1.12a, Fig. 1.13). We speculate that Arabidopsis VTC1 occurs in form of a multiprotein complex, in which substrate turnover from one protein to the next determines gene regulation of each monomer. This regulation could take place at the post-transcriptional level, mediated by mRNA degradation. One could argue that the pleiotropic responses exhibited by vtc1-1 homozygous mutants are compensatory mechanisms to increase VTC1 expression, while the presence of one wild type VTC1 copy in vtc1-1 mutants does not elicit pleiotropic effects and therefore VTC1 mRNA levels are low. Consequently, our data suggest possible protein-protein interactions (among VTC1 proteins and of VTC1 with other proteins). 
Structural information on plant GMPase is not currently available. However, the crystal structure of the thermophylic bacterium Thermotoga maritima has recently been solved (Pelissier et al., 2010). Bacterial GMPase appears to be dimeric, whereas eukaryotic GMPase can adopt oligomeric forms, as has been reported for Leishmania mexicana and Leishmania major (Davis et al., 2004; Perugini et al., 2005). Structural analysis of the T. maritima GMPase shows that two molecules associate into a dimer through a tail-to-tail arrangement of the Cterminal domains (Pelissier et al., 2010). The vtc1-1 mutation represents a point mutation of amino acid 22 from a conserved proline to a serine (Conklin et al., 1999). Similarly, the point mutation in the hsn 1 mutant constitutes a change of a conserved glycine into a serine at amino acid position 11 (Qin et al., 2008). Both mutations lie in the active site of the enzyme, which is highly conserved (Conklin et al., 1999) and situated in a deep pocket located in the N-terminal domain according to the T. maritima structure (Pelissier et al., 2010). Work on the L. mexicana GMPase suggested that oligomerization is driven by non-covalent interactions and that oligomers dissociate at low protein concentrations, at low ionic strength, and at alkaline $\mathrm{pH}$. In light of these published findings, we propose that Arabidopsis GMPase forms oligomers, which may be disrupted when the cytosolic $\mathrm{pH}$ changes from neutral to acidic or alkaline, a process that may be induced by the addition of $\mathrm{NH}_{4}{ }^{+}$. It is possible that the structural changes induced by the mutations in vtc1-1 and $h s n 1$ alter the predicted active site loop region such that the amount of active oligomers and thus enzyme activity is reduced. It also remains to be investigated whether GMPase interacts with other proteins.

In conclusion, our results demonstrate that GDP-mannose deficiency is not the primary cause of conditional $\mathrm{NH}_{4}{ }^{+}$sensitivity in vtc1-1. Instead, we propose that investigating the biochemical properties of GMPase will provide a full understanding of the $\mathrm{NH}_{4}{ }^{+}$sensitivity in plants.

\subsection{REFERENCES}

Arrigoni O, De Tullio MC (2000) The role of ascorbic acid in cell metabolism: between gene-directed functions and unpredictable chemical reactions. Journal of Plant Physiology 157: 481-488

Arrigoni O, De Tullio MC (2002) Ascorbic acid: much more than just an antioxidant. Biochimica Et Biophysica Acta 1569: 1-9

Barth C, Gouzd ZA, Steele HP, Imperio RM (2010) A mutation in GDP-mannose pyrophosphorylase causes conditional hypersensitivity to ammonium, resulting in Arabidopsis root growth inhibition, altered ammonium metabolism and hormone homeostasis. Journal of Experimental Botany 57: 1657-1665

Barth C, Gouzd ZA, Steele HP, Imperio RM (2010) A mutation in GDP-mannose pyrophosphorylase causes conditional hypersensitivity to ammonium, resulting in Arabidopsis root growth 
inhibition, altered ammonium metabolism, and hormone homeostasis. Journal of Experimental Botany 61: 379-394

Barth C, Moeder W, Klessig DF, Conklin PL (2004) The timing of senescence and response to pathogens is altered in the ascorbate-deficient Arabidopsis mutant vitamin c-1. Plant Physiology 134: 17841792

Bonin CP, Potter I, Vanzin GF, Reiter W-D (1997) The MUR1 gene of Arabidopsis thaliana encodes an isoform of GDP-D-mannose-4,6-dehydratase, catalyzing the first step in the de novo synthesis of GDP-L-fucose. Proc. Natl. Acad. Sci. USA 94: 2085-2090

Britto DT, Kronzucker HJ (2006) Futile cycling at the plasma membrane: a hallmark of low-affinity nutrient transport. Trends in Plant Science 11: 529-534

Britto DT, Kronzucker, H. J. (2005) Nitrogen acquistion, PEP carboxylase, and cellular pH homeostasis: new views on old paradigms. Plant, Cell and Environment 28: 1396-1409

Cao Y, Glass AD, Crawford NM (1993) Ammonium inhibition of Arabidopsis root growth can be reversed by potassium and by auxin resistance mutations aux1, axr1, and axr2. Plant Physiology 102: 983989

Conklin PL (2001) Recent advances in the role and biosynthesis of ascorbic acid in plants. Plant, Cell and Environment 24: 383-394

Conklin PL, Barth C (2004) Ascorbic acid, a familiar small molecule intertwined in the response of plants to ozone, pathogens, and the onset of senescence. Plant, Cell and Environment 27: 959-971

Conklin PL, Gatzek S, Wheeler GL, Dowdle J, Raymond MJ, Rolinski S, Isupov M, Littlechild JA, Smirnoff N (2006) Arabidopsis thaliana VTC4 encodes L-galactose-1-P phosphatase, a plant ascorbic acid biosynthetic enzyme. Journal of Biological Chemistry 281: 15662-15670

Conklin PL, Norris SR, Wheeler GL, Williams EH, Smirnoff N, Last RL (1999) Genetic evidence for the role of GDP-mannose in plant ascorbic acid (vitamin C) biosynthesis. Proceedings of the National Academy of Sciences of the United States of America 96: 4198-4203

Conklin PL, Pallanca JE, Last RL, Smirnoff N (1997) L-ascorbic acid metabolism in the ascorbate-deficient Arabidopsis mutant vtc1. Plant Physiology 115: 1277-1285

Conklin PL, Saracco SA, Norris SR, Last RL (2000) Identification of ascorbic acid-deficient Arabidopsis thaliana mutants. Genetics 154: 847-856

Conklin PL, Williams EH, Last RL (1996) Environmental stress sensitivity of an ascorbic acid-deficient Arabidopsis mutant. Proceedings of the National Academy of Sciences of the United States of America 93: 9970-9974

Cresti M, van Went JL (1976) Callose deposition and plug formation in Petunia pollen tubes in situ. Planta 133: $35-40$

Culligan K, Tissier A, Britt A (2004) ATR regulates a G2-phase cell-cycle checkpoint in Arabidopsis thaliana. The Plant Cell 16: 1091-1104

Davis AJ, Perugini MA, Smith BJ, Stewart JD, Ilg T, Hodder AN, Handman E (2004) Properties of GDPmannose pyrophosphorylase, a critical enzyme and drug target in Leishmania mexicana. Journal of Biological Chemistry 279: 12462-12468

Doblin MS, Kurek I, Jacob-Wilk D, Delmer DP (2002) Cellulose biosynthesis in plants: from genes to rosettes. Plant Cell Physiology 43: 1407-1420

Dowdle J, Ishikawa T, Gatzek S, Rolinski S, Smirnoff N (2007) Two genes in Arabidopsis thaliana encoding GDP-L-galactose phosphorylase are required for ascorbate biosynthesis and seedling viability. The Plant Journal 52: 673-689

Dyhr-Jensen K, Brix H (1996) Effects of pH on ammonium uptake by Typha latifolia L. Plant, Cell and Environment 19: 1431-1436 
Foyer CH, Noctor G (2011) Ascorbate and glutathione: the heart of the redox hub. Plant Physiology 155: 2-18

Frank J, Kaulfurst-Soboll H, Rips S, Koiwa H, von Schaewen A (2008) Comparative analyses of Arabidopsis complex glycan1 mutants and genetic interaction with staurosporin and temperature sensitive3a. Plant Physiology 148: 1354-1367

Gong Z, Koiwa H, Cushman MA, Ray A, Bufford D, Kore-eda S, Matsumoto TK, Zhu J, Cushman JC, Bressan RA, Hasegawa PM (2001) Genes that are uniquely stress regulated in salt overly sensitive (sos) mutants. Plant Physiology 126: 363-375

Hancock RD, Viola R (2005) Biosynthesis and catabolism of L-ascorbic acid in plants. Critical Reviews in Plant Sciences 24: 167-188

Helenius A, Aebi M (2001) Intracellular functions of N-linked glycans. Science 291: 2364-2369

Hoeberichts FA, Vaeck E, Kiddle G, Coppens E, van de Cotte B, Adamantidis A, Ormenese S, Foyer CH, Zabeau M, Inze D, Perilleux C, Van Breusegem F, Vuylsteke M (2008) A temperature-sensitive mutation in the Arabidopsis thaliana phosphomannomutase gene disrupts protein glycosylation and triggers cell death. Journal of Biological Chemistry 283: 5708-5718

Huang C, He W, Guo J, Chang X, Su P, Zhang L (2005) Increased sensitivity to salt stress in an ascorbatedeficient Arabidopsis mutant. Journal of Experimental Botany 56: 3041-3049

Jander G, Norris SR, Rounsley SD, Bush DF, Levin IM, Last RL (2002) Arabidopsis map-based cloning in the post-genome era. Plant Physiol 129: 440-450

Jiang $\mathbf{H}$, Ouyang $\mathbf{H}$, Zhou H, Jin C (2008) GDP-mannose pyrophosphorylase is essential for cell wall integrity, morphogenesis and viability of Aspergillus fumigatus. Microbiology 154: 2730-2739

Kang JS, Frank J, Kang CH, Kajiura H, Vikram M, Ueda A, Kim S, Bahk JD, Triplett B, Fujiyama K, Lee SY, von Schaewen A, Koiwa H (2008) Salt tolerance of Arabidopsis thaliana requires maturation of $\mathrm{N}$-glycosylated proteins in the Golgi apparatus. Proceedings of the National Academy of Sciences of the United States of America 105: 5933-5938

Kempinski CF, Haffar, R., Barth, C. (2011) Toward the mechanism of NH4+ sensitivity mediated by Arabidopsis GDP-mannose pyrophosphorylase. Plant, Cell \& Environment 34: 847-858

Kleiner $\mathbf{D}$ (1985) Energy expenditure for cyclic retention of $\mathrm{NH}_{3} / \mathrm{NH}_{4}{ }^{+}$during $\mathrm{N}_{2}$ fixation by Klebsiella pneumoniae. FEBS Letters 187: 237-239

Koiwa H, Li F, McCully MG, Mendoza I, Koizumi N, Manabe Y, Nakagawa Y, Zhu J, Rus A, Pardo JM, Bressan RA, Hasegawa PM (2003) The STT3a subunit isoform of the Arabidopsis oligosaccharyltransferase controls adaptive responses to salt/osmotic stress. The Plant Cell 15: 2273-2284

Koizumi N, Martinez IM, Kimata Y, Kohno K, Sano H, Chrispeels MJ (2001) Molecular characterization of two arabidopsis Ire1 homologs, endoplasmic reticulum-located transmembrane protein kinases. Plant Physiology 127: 949-962

Kotchoni SO, Larrimore KE, Mukherjee M, Kempinski CF, Barth C (2009) Alterations in the endogenous ascorbic acid content affect flowering time in Arabidopsis. Plant Physiology 149: 803-815

Lerouge P, Cabanes-Macheteau M, Rayon C, Fischette-Laine AC, Gomord V, Faye L (1998) Nglycoprotein biosynthesis in plants: recent developments and future trends. Plant Molecular Biology 38: 31-48

Lerouxel O, Mouille G, Andeme-Onzighi C, Bruyant MP, Seveno M, Loutelier-Bourhis C, Driouich A, Hofte $\mathbf{H}$, Lerouge $\mathbf{P}$ (2005) Mutants in DEFECTIVE GLYCOSYLATION, an Arabidopsis homolog of an oligosaccharyltransferase complex subunit, show protein underglycosylation and defects in cell differentiation and growth. The Plant Journal 42: 455-468 
Li Q, Li BH, Kronzucker HJ, Shi WM (2010) Root growth inhibition by $\mathrm{NH}_{4}{ }^{+}$in Arabidopsis is mediated by the root tip and is linked to $\mathrm{NH}_{4}{ }^{+}$efflux and GMPase activity. Plant, Cell and Environment 33: 1529-1542

Linster CL, Adler LN, Webb K, Christensen KC, Brenner C, Clarke SG (2008) A second GDP-L-galactose phosphorylase in Arabidopsis en route to vitamin C. Covalent intermediate and substrate requirements for the conserved reaction. Journal of Biological Chemistry 283: 18483-18492

Linster CL, Gomez TA, Christensen KC, Adler LN, Young BD, Brenner C, Clarke SG (2007) Arabidopsis VTC2 encodes a GDP-L-galactose phosphorylase, the last unknown enzyme in the SmirnoffWheeler pathway to ascorbic acid in plants. Journal of Biological Chemistry 282: 18879-18885

Liu J, Zhu JK (1997) An Arabidopsis mutant that requires increased calcium for potassium nutrition and salt tolerance. Proceedings of the National Academy of Sciences of the United States of America 94: 14960-14964

Loewus FA (1963) Tracer studies of ascorbic acid formation in plants. Phytochemistry 2: 109-128

Lorence A, Chevone BI, Mendes P, Nessler CL (2004) myo-inositol oxygenase offers a possible entry point into plant ascorbate biosynthesis. Plant Physiology 134: 1200-1205

Lukowitz W, Nickle TC, Meinke DW, Last RL, Conklin PL, Somerville CR (2001) Arabidopsis cyt1 mutants are deficient in a mannose-1-phosphate guanylyltransferase and point to a requirement of $\mathrm{N}$ linked glycosylation for cellulose biosynthesis. Proceedings of the National Academy of Sciences of the United States of America 98: 2262-2267

Marschner H (1995) Mineral Nutrition of Higher Plants. London: Academic Press

Martinez IM, Chrispeels MJ (2003) Genomic analysis of the unfolded protein response in Arabidopsis shows its connection to important cellular processes. The Plant Cell 15: 561-576

Maruta T, Yonemitsu M, Yabuta Y, Tamoi M, Ishikawa T, Shigeoka S (2008) Arabidopsis phosphomannose isomerase 1 , but not phosphomannose isomerase 2, is essential for ascorbic acid biosynthesis. Journal of Biological Chemistry 283: 28842-28851

Mukherjee M, Larrimore KE, Ahmed NJ, Bedick TS, Barghouthi NT, Traw MB, Barth C (2010) Ascorbic acid deficiency in Arabidopsis induces constitutive priming that is dependent on hydrogen peroxide, salicylic acid and the NPR1 gene. Molecular Plant-Microbe Interactions 23: 340-351

Noctor G, Foyer CH (1998) Ascorbate and glutathione: Keeping active oxygen under control. Annual Review of Plant Physiology and Plant Molecular Biology 49: 249-279

Pastori GM, Kiddle G, Antoniw J, Bernard S, Veljovic-Jovanovic S, Verrier PJ, Noctor G, Foyer CH (2003) Leaf vitamin $C$ contents modulate plant defense transcripts and regulate genes that control development through hormone signaling. The Plant Cell 15: 939-951

Pavet V, Olmos E, Kiddle G, Mowla S, Kumar S, Antoniw J, Alvarez ME, Foyer CH (2005) Ascorbic acid deficiency activates cell death and disease resistance responses in Arabidopsis. Plant Physiology 139: 1291-1303

Pelissier MC, Lesley SA, Kuhn P, Bourne Y (2010) Structural insights into the catalytic mechanism of bacterial guanosine-diphospho-D-mannose pyrophosphorylase and its regulation by divalent ions. Journal of Biological Chemistry 285: 27468-27476

Perugini MA, Griffin MD, Smith BJ, Webb LE, Davis AJ, Handman E, Gerrard JA (2005) Insight into the self-association of key enzymes from pathogenic species. European Biophysics Journal 34: 469476

Qian W, Yu C, Qin H, Liu X, Zhang A, Johansen IE, Wang D (2007) Molecular and functional analysis of phosphomannomutase (PMM) from higher plants and genetic evidence for the involvement of PMM in ascorbic acid biosynthesis in Arabidopsis and Nicotiana benthamiana. The Plant Journal 49: $399-413$ 
Qin C, Qian W, Wang W, Wu Y, Yu C, Jiang X, Wang D, Wu P (2008) GDP-mannose pyrophosphorylase is a genetic determinant of ammonium sensitivity in Arabidopsis thaliana. Proceedings of the National Academy of Sciences of the United States of America 105: 18308-18313

Saxena IM, Brown RM, Jr. (2005) Cellulose biosynthesis: current views and evolving concepts. Annals of Botany 96: 9-21

Shi H, Kim Y, Guo Y, Stevenson B, Zhu JK (2003) The Arabidopsis SOS5 locus encodes a putative cell surface adhesion protein and is required for normal cell expansion. The Plant Cell 15: 19-32

Silberstein S, Gilmore $\mathbf{R}$ (1996) Biochemistry, molecular biology, and genetics of the oligosaccharyltransferase. The FASEB journal: official publication of the Federation of American Societies for Experimental Biology 10: 849-858

Smirnoff N (2000) Ascorbic acid: metabolism and functions of a multi-faceted molecule. Current Opinion in Plant Biology 3: 229-235

Spiro RG (2002) Protein glycosylation: nature, distribution, enzymatic formation, and disease implications of glycopeptide bonds. Glycobiology 12: 43R-56R

ten Hoopen F, Cuin TA, Pedas P, Hegelund JN, Shabala S, Schjoerring JK, Jahn TP (2010) Competition between uptake of ammonium and potassium in barley and Arabidopsis roots: molecular mechanisms and physiological consequences. Journal of Experimental Botany 61: 2303-2315

Travers KJ, Patil CK, Wodicka L, Lockhart DJ, Weissman JS, Walter P (2000) Functional and genomic analyses reveal an essential coordination between the unfolded protein response and ERassociated degradation. Cell 101: 249-258

Ullrich WR, Larsson M, Larsson CM, Lesch S, Novacky A (1984) Ammonium uptake in Lemna gibba G-1, related membrane-potential changes, and inhibition of anion uptake. Physiologia Plantarum 61: 369-376

Wang D, Weaver ND, Kesarwani M, Dong X (2005) Induction of protein secretory pathway is required for systemic acquired resistance. Science 308: 1036-1040

Wang MY, Siddiqi MY, Ruth TJ, Glass A (1993) Ammonium uptake by rice roots (II. Kinetics of ${ }^{13} \mathrm{NH}_{4}{ }^{+}$ Influx across the plasmalemma). Plant Physiology 103: 1259-1267

Watanabe N, Lam E (2008) BAX inhibitor-1 modulates endoplasmic reticulum stress-mediated programmed cell death in Arabidopsis. Journal of Biological Chemistry 283: 3200-3210

Weigel D, Glazebrook J (2002) Arabidopsis: A Laboratory Manual. Cold Spring Harbor: Cold Spring Harbor Laboratory Press.

Wheeler GL, Jones MA, Smirnoff N (1998) The biosynthetic pathway of vitamin C in higher plants. Nature 393: 365-369

Wolucka BA, Van Montagu M (2003) GDP-mannose 3',5'-epimerase forms GDP-L-gulose, a putative intermediate for the de novo biosynthesis of vitamin $\mathrm{C}$ in plants. Journal of Biological Chemistry 278: 47483-47490

Zhu J, Gong Z, Zhang C, Song CP, Damsz B, Inan G, Koiwa H, Zhu JK, Hasegawa PM, Bressan RA (2002) OSM1/SYP61: A syntaxin protein in Arabidopsis controls abscisic acid-mediated and non-abscisic acid-mediated responses to abiotic stress. The Plant Cell 14: 3009-3028 


\section{CHAPTER 2: The novel Arabidopsis thaliana svt2 suppressor of the ascorbic acid-deficient mutant vtc1-1 exhibits phenotypic and genotypic instability}

\subsection{INTRODUCTION}

The VTC1 gene has recently been shown to be a determinant of ammonium sensitivity in plants. In the presence of ammonium, vtc1-1 mutants exhibit strongly reduced root growth in comparison to the wild type, a phenomenon that is independent of AA deficiency (Qin et al., 2008; Barth et al., 2010; Li et al., 2010; Kempinski et al., 2011). To better understand the mechanism through which VTC1 mediates conditional ammonium sensitivity, it is important to identify regulatory partners of VTC1. To accomplish this, we undertook a suppressor mutagenesis approach of vtc1-1 homozygous mutant seed in the hope to identify vtc1-1 suppressor mutants that could then be isolated and studied.

One of the suppressor mutants isolated in the $M_{0}$ generation, svt2 (suppressor of vtc1-1 2), contained wild-type AA levels and developed roots similar to the wild type in the presence of ammonium. However, while characterizing the mutant genotypically, we observed that it had lost the original vtc1-1 mutation (i.e., svt2 contained the homozygous wild-type allele). Furthermore, we determined that svt2, although generated through EMS mutagenesis of Col-0 vtc1-1 mutant seed, was phenotypically and genotypically similar to Ler. The most intriguing result was that a small percentage of svt2 $M_{1}$ plants would produce offspring that had phenotypic and genotypic similarities to $\mathrm{Col}$ in the $\mathrm{M}_{2}$ generation. Even more interesting was the fact that some of those Col revertants in the $\mathrm{M}_{2}$ generation would produce progeny that exhibited phenotypic and genotypic svt2 characteristics again in the $M_{3}$ generation.

Interestingly, phenotypic instability of Arabidopsis alleles affecting a disease resistance gene cluster has recently been reported (Yi and Richards, 2008). In their work, Yi and Richards reported that exposure to EMS or through the generation of different $F_{1}$ hybrids, phenotypic instability was induced in the bal and cpr1 mutant alleles. The authors later proposed that the high phenotypic instability is caused by a genetic mechanism (Yi and Richards, 2009).

The presented study focuses on describing and characterizing the Arabidopsis svt2 suppressor mutant and its phenotypic and genotypic behavior. After illustrating the phenotypic features of svt2, we investigate transgenerational changes in the phenome and genome of svt2 and provide evidence that svt 2 is a true mutant and not the result of an experimental artifact or contamination. Finally, we discuss our experimental findings in respect to the vtc1-1 mutant background and other reports that previously described similar phenomena of genome 
instability and restoration, and we briefly speculate on possible mechanisms of phenome and genome instability in svt2.

\subsection{MATERIALS AND METHODS}

\subsubsection{Plant material and growth conditions}

Arabidopsis thaliana Col-0 wild type and the previously described vtc1-1 mutant (in the Col-0 background) were kindly provided by Patricia Conklin. Ler-0 wild-type seed were obtained from The Arabidopsis Biological Resource Center. Plants were grown in Metromix 360 potting soil at $23^{\circ} \mathrm{C}$ at day and at night with a 16-hour photoperiod at $160 \mu \mathrm{mol}$ photons $\mathrm{m}^{-2} \mathrm{~s}^{-2}$ (fluorescent bulbs).

For assessment of root growth, seed of the wild types and mutant lines were surfacesterilized (see below) and grown on basal full strength 1x Murashige and Skoog (MS) medium without vitamins (Cat.\# MSP01, Caisson Laboratories, Inc., North Logan, UT), containing 1\% Phytoblend (Cat.\# PTP01, Caisson Laboratories) in omni trays (Fisher Scientific, Pittsburgh, PA) as described (Kempinski et al., 2011). Sucrose was omitted from the tissue culture medium. The $\mathrm{pH}$ of the medium was adjusted with $\mathrm{KOH}$ to 5.7. Trays were sealed with two layers of $3 \mathrm{M}$ micropore tape (Fisher Scientific), put in vertical orientation, and placed in the growth chamber

under long days ( $16 \mathrm{~h}$ light, $8 \mathrm{~h}$ dark) at $23^{\circ} \mathrm{C}$ day and night, and $160 \mu \mathrm{mol}$ photons $\mathrm{m}^{-2} \mathrm{~s}^{-1}$ in a growth chamber (Percival Scientific, Inc., Perry, IA). Each plate contained wild-type and mutant seed. Primary root length was measured in seven-day-old seedlings using a ruler.

To assess $A A$ content in leaf tissue, seeds of wild type and mutants were randomly sown on MetroMix 360 soil (BFG Supplies Co., Burton, $\mathrm{OH}$ ) in the same flat under the growth conditions described above. When plants were three weeks old, whole rosettes were harvested for the AA assay.

\subsubsection{Seed-surface sterilization}

Seeds were soaked for $1 \mathrm{~min}$ in $50 \%$ ethanol, followed by washing the seeds in $50 \%$ bleach plus $0.01 \%$ sodium dodecyl sulphate for $6 \mathrm{~min}$. Finally, seeds were rinsed six times with sterile water and stored in $0.1 \%$ sterile Phytoblend agar for $2 \mathrm{~d}$ at $4{ }^{\circ} \mathrm{C}$ (Weigel and Glazebrook, 2002).

\subsubsection{Ethyl methanesulfonate mutagenesis}

Seed of homozygous vtc1-1 Arabidopsis thaliana (Col-0 background) was mutagenized with ethyl methanesulfonate as described (Figure 2.1; Weigel and Glazebrook, 2002). Approximately, $1200 \mathrm{M}_{0}$ seed were stratified for 4 days at $4^{\circ} \mathrm{C}$ in $0.1 \%$ agar, sown on MetroMix 
soil and grown as above. Plants were screened for wild-type AA levels using the nitrobluetetrazoioum assay (Conklin et al., 2000). Additional suppressor mutants were isolated by pooling seeds generated from $\mathrm{M}_{1}$ plants. Putative mutants were isolated and allowed to selfpollinate to obtain seed.

\subsubsection{Pollen grain analysis and microscopy}

Pollen was taken from 4.5-week-old flowering plants of Col-0 and Ler wild type and vtc11 and svt2 $\mathrm{M}_{2}$ mutants, mounted in glycerol, and photographed using bright field settings on a Nikon E800 microscope equipped with a CoolSNAP of CCD camera (Photometrics, Tuscon, AZ, USA).

\subsubsection{Genomic DNA isolation}

Genomic DNA was isolated from rosette leaves following the protocol outlined in (Kotchoni et al., 2009). In case of genomic DNA isolation from vtc1-1 seeds, a small amount of dried seeds was crushed and the extraction procedure described previously (Kotchoni et al., 2009) was followed. Primers for the VTC1 gene and for the Insertion/Deletion (InDel) polymorphisms were designed using sequence data available on The Arabidopsis Information Resource (TAIR) database (www.arabidopsis.org). Polymerase chain reaction (PCR) was used to amplify fragments of the VTC1 gene for sequencing and to assess InDel polymorphisms. Sequences of primers used for sequencing and InDel analysis are summarized in Table 2.1. PCR reactions were run on $1.0 \%$ agarose gels stained with ethidium bromide.

\subsubsection{Gene copy analysis using qPCR}

Quantitative PCR reactions were set up to measure gene copy number using 2.5 pmole gene-specific primers, 300 ng of genomic DNA diluted in DNase/RNase free water, and iQ SYBR Green Supermix (Bio-Rad, Hercules, CA, USA) for a total volume of $10 \mu \mathrm{L}$. Reactions without template were used as negative controls. Each single copy reaction was set up in triplicate and run in a Bio-Rad iCycler for 40 cycles. Threshold cycles $\left(C_{T}\right)$ were calculated using iQ software (Bio-Rad).

Primer efficiencies (E) were calculated using cDNAs synthesized from RNA isolated from Col-0 plants (as previously described in Kempinski et al., 2011) which were serially diluted across three orders of magnitude. Serial dilutions were amplified in triplicate using the same protocol as for the copy number experiment. The $C_{T} S$ of each triplicate were averaged and plotted against dilution factor. A linear trend was fitted to the data and the slope of this trend was used to calculate $E$ for each primer with the formula: $E=10^{(1 / \text {-slope })}$. 
Table 2.1 Forward (F) and reverse (R) sequences for primers used in analyzing the VTC1 gene and for amplifying five Col/Ler Insertion/Deletion (InDel) polymorphisms

\begin{tabular}{|c|c|}
\hline Primer Name & $5^{\prime}$ \\
\hline VTC1 G1 F & AAA AAT TCG TTC TAG ATG GAT GCT \\
\hline VTC1 G1 R & ATG GCT GTA AAT TGG AAG AGA T \\
\hline VTC1 G2 F & GAA CCC TTG TCT CTA AAA TA \\
\hline VTC1 G2 R & CAA ATC CCA TAA TCT GTT CC \\
\hline VTC1 G3 F & CAA TTT TGC TTA CTT CTC T \\
\hline VTC1 G3 R & TGG ATG CAA CCG ACA CAA AAC AAT \\
\hline VTC1 G4 F & ACA TTT TTA GCA GCT GGT ATT GAG \\
\hline VTC1 G4 R & AGG TAA GAA CTG GCA GAC TAA AG \\
\hline VTC1 G5 F & TCG CTT GAG ACC ATT GAC T \\
\hline VTC1 G5 R & GAG GCT TCC CCA CCG TGA GAT TTG \\
\hline VTC1 G6 F & CAA GCT GGA AAT CAA AAT CAC T \\
\hline VTC1 G6 R & GCG CTG CTG CAA TCT TAG G \\
\hline VTC1 G7 F & ACA AAT CTC ACG GTG GGG AAG C \\
\hline VTC1 G7 R & TGG TTA ATT TGG CAG GAG A \\
\hline VTC1 G8 F & CAA GGG CTC TAT GCT ATG GTG \\
\hline VTC1 G8 R & GCG TTT TGA TTG ATG CTT ATT C \\
\hline VTC1 G9 F & GCG TGT ATC TCG AGC AGT ATC AT \\
\hline VTC1 G9 R & GTG GAG GGA AGT TAA GGG TAT TTT \\
\hline InDel $1450919 \mathrm{~F}$ & ATC GGT TTG TAA TCT CTG TCC A \\
\hline InDel 1450919 R & TAT GCG TTC CCA AAT TTG TTA TCT C \\
\hline Indel $2451470 \mathrm{~F}$ & GGA GAC CCA AAC TGC TAT TAC A \\
\hline Indel $2451470 \mathrm{R}$ & AAC CGC CTC CAT TTG CAC CTT ATC \\
\hline Indel $3469762 \mathrm{~F}$ & GTC ACC GAG TTT TGC TTT GTT CAT \\
\hline Indel 3469762 R & CTC GTT TCT TTT CTG GGC TTG TAG \\
\hline Indel $4449053 \mathrm{~F}$ & GAA AGA AAG CAG CGA AAG ACA \\
\hline Indel $4449053 \mathrm{R}$ & GCC CAT GCC CAT ACA CTG A \\
\hline Indel $5455100 \mathrm{~F}$ & ACT TGC TTA ATC GTT TCT TTG TA \\
\hline Indel 5455100 R & GCC CAC TCG TAT TCG CTT AG \\
\hline
\end{tabular}


Copy number of VTC1 (AT2G39770) was calculated using the formula: Reported Quantity $(R Q)=1 / E^{C T}$ normalized to the RQ of a known single copy gene (PAD4, AT3G52430; De Preter et al., 2002; Duarte et al., 2010). VTC1 RQ was calculated from the average VTC1 RQ of three biological replicates per genotype was normalized to the average RQ of PAD4 from three replicates of each respective genotype, all run in the same reaction plate.

\subsubsection{Sequencing analysis}

PCR products were purified using the Qiagen Miniprep Kit. Dye-terminator based DNA sequencing was performed at the Genomics Facility in the Department of Biology at West Virginia University. Sequence alignments were performed using the BioEdit program.

\subsubsection{Ascorbic acid quantification}

To screen mutants, AA levels were analyzed qualitatively in small pieces of 2-week-old rosette leaves using the nitroblue tetrazolium assay described in (Conklin et al., 2000). The AA content was determined in whole rosettes of 3-week-old plants using the iron reduction assay (Mukherjee et al., 2010).

\subsection{RESULTS}

\subsubsection{Isolation of svt2}

Our laboratory is interested in understanding how the VTC1 gene, which is essential for the biosynthesis of GDP-mannose and AA, is regulated. This would help to decipher the pleiotropic phenotypes displayed by vtc1-1, including its hypersensitivity to ammonium (Qin et al., 2008; Barth et al., 2010; Li et al., 2010; Kempinski et al., 2011). We employed a gene suppressor analysis with the goal to identify novel genes that interact or regulate VTC1. Seed of the vtc1-1 mutant, which is in the Col-0 genetic background (Conklin et al., 1996), were subjected to chemical mutagenesis using EMS (Weigel and Glazebrook, 2002). One thousand and one hundred mutagenized vtc1-1 seeds ( $M_{0}$ generation) were planted onto soil and screened for recovered (wild-type) leaf AA content using the qualitative nitroblue tetrazolium test (Conklin et al., 2000). One of the mutants exhibited wild-type AA levels in the $M_{0}$ generation. This mutant was named svt2 (suppressor of vtc1-1 2), isolated and further characterized. The mutant was allowed to self-fertilize and seeds from the plant were collected $\left(M_{1}\right.$ generation; Fig. 2.1). Note that we isolated additional suppressor mutants by pooling $M_{2}$ seed and screening for long roots on 1x Murashige and Skoog (MS) medium containing ammonium. Six suppressor mutants were identified among 2000 plants. $M_{3}$ seed were collected and screened for long roots again to test for segregation. $M_{4}$ progeny of one line all had long roots, whereas the other five lines segregated in a ratio of three plants producing long roots, one plant having short roots. All of these suppressor mutants had a Col-like phenotype 
and lacked the vtc1-1 mutation (Kempinski et al., unpublished results). Except for root development assessment, these suppressor mutants were not yet characterized further.

\subsection{2 svt2 has similarities with the Ler phenotype, but has also phenotypic characteristics that are distinct from Ler}

The first observation we made when characterizing svt2 $M_{1}$ plants was that svt2 exhibited a phenotype reminiscent of the Ler ecotype with the characteristic round leaves compared to Col. Yet, svt2 had features that were distinct from the Ler phenotype. The svt2 mutant displayed the characteristic erect morphology that is typical for Ler-0 (Fig. 2.2a). However, svt2 had an overall enlarged morphology as is evident in the larger rosettes (inset of 3-week-old rosettes in Fig. 2.2A) and flowers (inset, Fig. 2.2a). In addition, svt2 was strongly delayed in flowering compared to the Col-0 and Ler-0 wild types and the vtc1-1 mutant (Fig 2.2a). The flowering data are consistent with previous reports, with Ler-0 wild type entering the reproductive phase before Col-0 wild type. An early flowering phenotype of vtc1-1 has been reported previously (Kotchoni et al., 2009).

The enlarged morphology of svt2 raises the question as to whether svt2 is polyploid. In order to test this, we assessed the size of pollen grains from the Col-0 and Ler-0 wild-types and vtc1-1 and svt2 mutants. As is shown in Fig. 2.2B, pollen grains of the four genotypes are similar in size. In addition, using qPCR, we determined the number of VTC1 gene copies in the four genotypes. Our results revealed that VTC1 is present as a single copy gene in both the Col-0 and Ler-0 wild types and in the vtc1-1 and svt2 mutants (Table 2.1). Although an extensive chromosome analysis has not yet been performed in svt2, our results suggest that the mutant does not contain additional sets of chromosomes.

The AA content in svt2 was similar to levels quantified in Col-0 and Ler-0 wild types, whereas vtc1-1 contained only $30 \%$ of the AA content as expected (Fig. 2.2c; Conklin et al., 1996). Finally, we investigated whether svt2 also exhibits recovered root development in the presence of ammonium by growing the four genotypes in full strength 1x MS medium. The vtc1-1 mutant is conditionally hypersensitive to ammonium (Qin et al., 2008; Barth et al., 2010; Kempinski et al., 2011). Figure $2 \mathrm{~d}$ illustrates that root length in svt2 was the same as in Col-0 wild type, whereas root development was strongly inhibited in vtc1-1 as expected.

Taken together, based on the phenotypic observations, our data suggest that svt2 represents a novel vtc1-1 suppressor mutant with recovered AA content and root development. Next, we characterized svt2 genotypically in order to determine whether svt2 represents an intragenic or extragenic suppressor. 


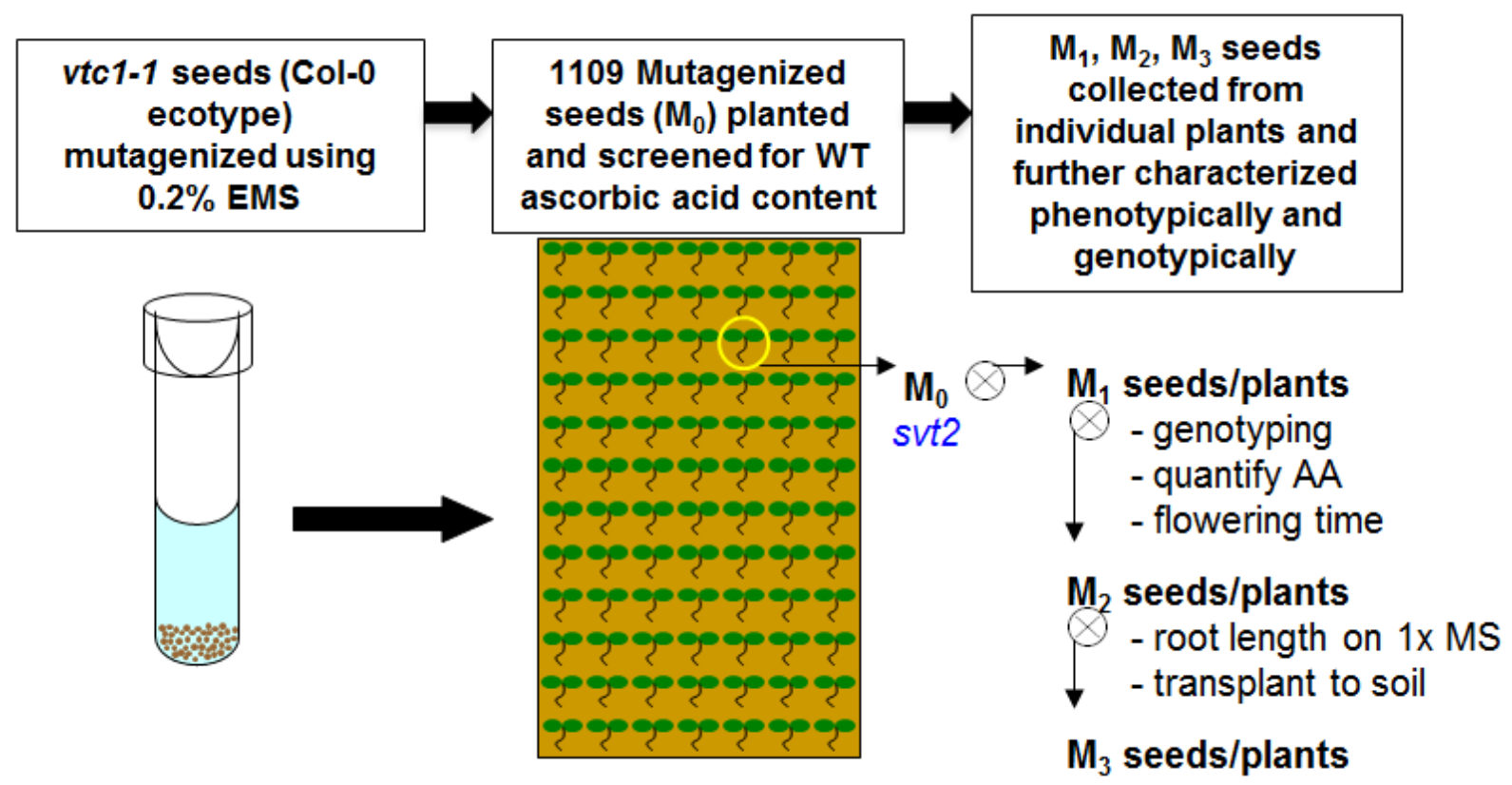

Figure 2.1 Schematic of the isolation of the vtc1-1 suppressor mutant svt2.

Homozygous vtc1-1 seed (in the Col-0 genetic background), were exposed to chemical mutagenesis using ethyl methanesulfonate (EMS). Over one thousand mutagenized seed $\left(M_{0}\right)$ were planted on soil and screened for wild-type levels of ascorbic acid. The only mutant isolated in the $\mathrm{M}_{0}$ generation containing recovered a ascorbic acid content was svt2. The mutant was allowed to self-fertilize and was characterized phenotypically and genotypically in subsequent generations. 
(a)

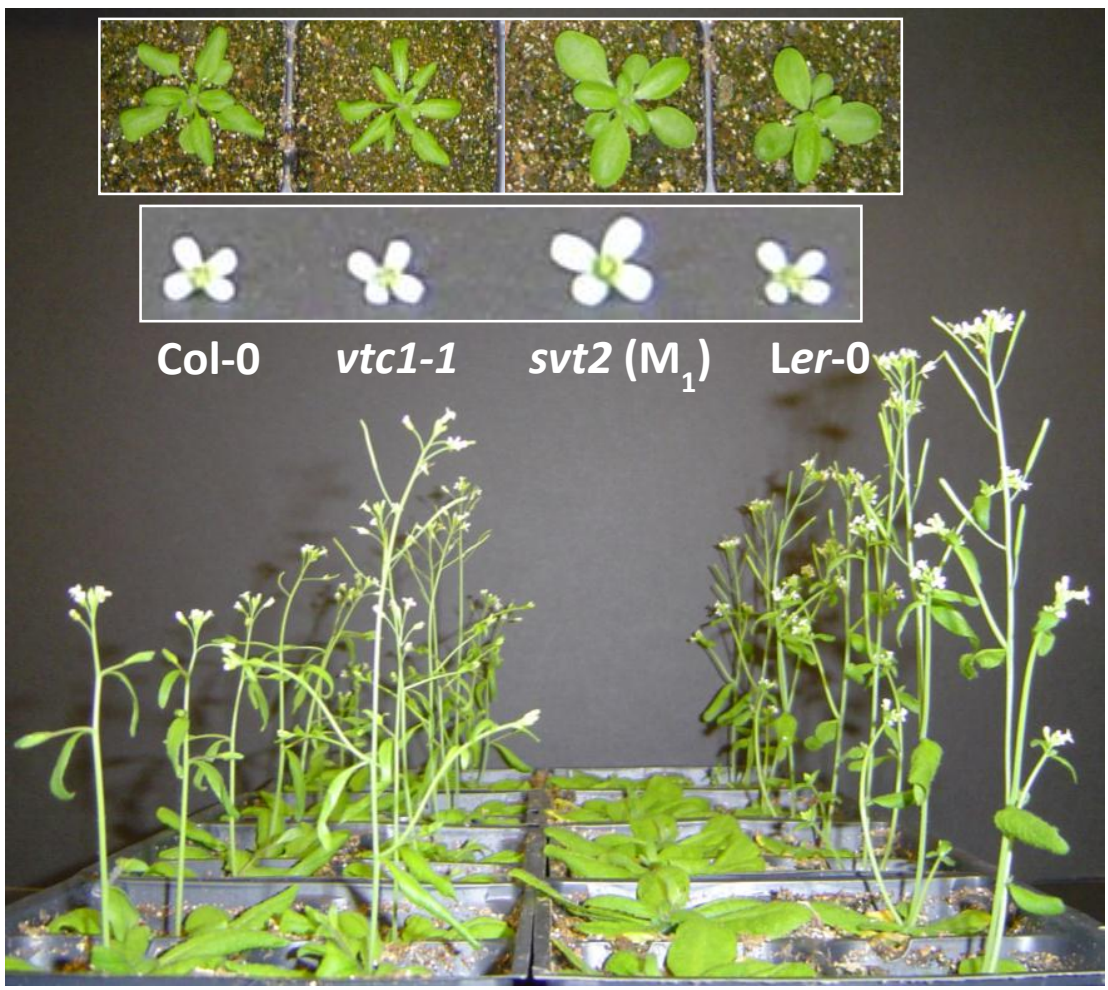

(b)

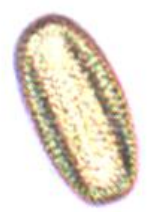

Col-0

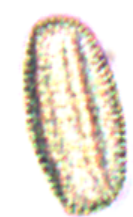

vtc1-1
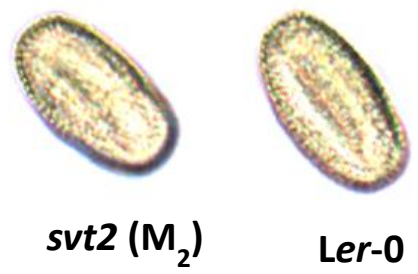

(c)

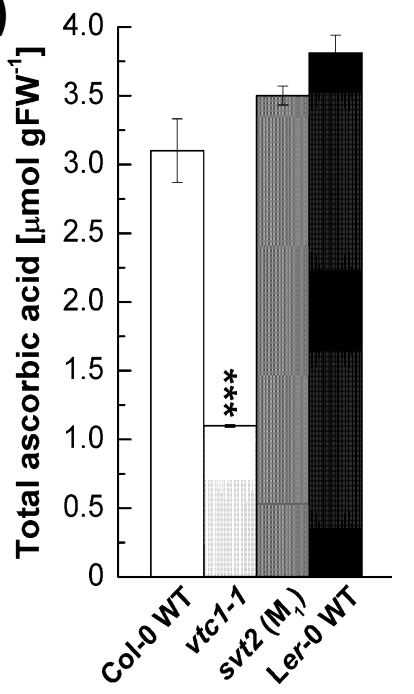

(d)

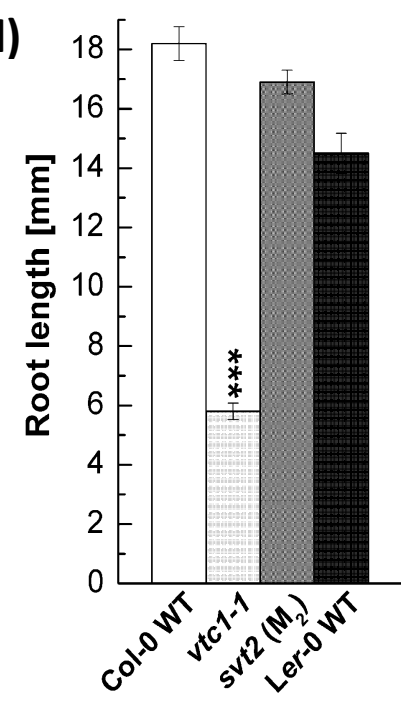

Figure 2.2 Phenotypic characterization of svt2.

(a) Flowering phenotype of four-week-old Col-0 wild type, the vtc1-1 and svt2 mutants and the Ler-0 wild type. Insets show rosette phenotypes of the four genotypes when plants were three weeks old and the flower phenotype of six-week-old plants, respectively. (b) Pollen phenotype of the four genotypes when plants were 4.5 weeks old. (c) Total ascorbic acid content per gram fresh weight in whole rosettes of three-week-old plants. Bars represent means $\pm S E$ of three individual replicates. (d) Root length in seven-day-old seedlings grown on $1 x$ MS. Bars represent mean \pm SE of 30-90 individuals. ${ }^{* * *} P<0.001$ by Student's $t$-test indicates significant differences. 


\subsection{3 svt2 shares genome similarity with Ler}

To determine whether svt2 represents an intragenic suppressor, i.e., to test whether the suppressor mutation is present within the VTC1 gene, we designed nine overlapping primer sets (Table 2.1) and PCR-amplified the entire VTC1 gene including approximately $500 \mathrm{bp}$ of the promoter region directly upstream of the first base in the $5^{\prime}$ UTR in genomic DNA extracted from Col-0 and Ler-0 wild types, and vtc1-1 and svt2 mutants (Fig. 2.3a). In eight of the nine primer pairs covering the entire VTC1 gene, the PCR products generated using svt2 genomic DNA had the same electrophoretic mobility as those generated using Col-0 wild-type genomic DNA. However, this was not the case for the first primer set (Fig. 2.4). The G1F/G1R primer set, used to amplify the VTC1 promoter region (Fig. 2.3a), generated a larger PCR product in svt2 than in the wild type. The PCR product in the wild type was $567 \mathrm{bp}$, whereas that in svt2 had a size of approximately $850 \mathrm{bp}$, suggesting that svt2 contained an approximately $300 \mathrm{bp}$ insertion in this region. We repeated the PCR analysis of the VTC1 promoter region using the G1F-G1R and the G1F-G2R primer sets that should generate a PCR product of $567 \mathrm{bp}$ and $751 \mathrm{bp}$, respectively (Fig. 2.3a). The expected size was obtained for the Col-0 wild type and the vtc1-1 mutant. However, approximately 300 bp larger PCR products were detected in the svt 2 mutant and the Ler-0 wild type (Fig. 2.3b), suggesting a Ler insertion polymorphism. Thus, these data imply that svt2 shares both phenotypic and genotypic similarities with Ler.

We therefore assessed five additional Insertion/Deletion (InDel) polymorphisms randomly chosen across the five Arabidopsis chromosomes (Table 2.1) in svt2 compared to the Col-0 and Ler- 0 wild types and sequenced the entire VTC1 gene and the promoter region tested. Our data show that the PCR products generated for those five InDels using svt2 genomic DNA had the same electrophoretic mobility as those produced from Ler-0 genomic DNA (Fig. 2.5). Moreover, sequence analysis of the VTC1 gene and promoter region revealed that svt2 contained a 280 bp insertion in the VTC1 promoter (Fig. 2.3c); DNA sequence highlighted in gray in Fig. 2.6) in addition to other single nucleotide polymorphisms (see examples indicated by upright arrows in Figs. 2.3c, 2.6). When we aligned the VTC1 gene sequence obtained from svt2 with that of the vtc1-1 mutant, the VTC1 Col-0 gene sequence deposited in the TAIR database and the VTC1 Ler GenBank sequence, the VTC1 gene sequence in svt2 shared sequence similarities with Ler (upright arrows in Figs. 2.3c, 2.6) and Col (see arrows pointing down in Fig. 2.6). However, note that there are sequences that are unique to svt2 and are not shared between Col, vtc1-1 or Ler (see arrow heads in Fig. 2.6). Finally, note the overlap in sequences between Col, vtc1-1, svt2 and Ler on the $5^{\prime}$ end of the sequence flanking the 
(a)

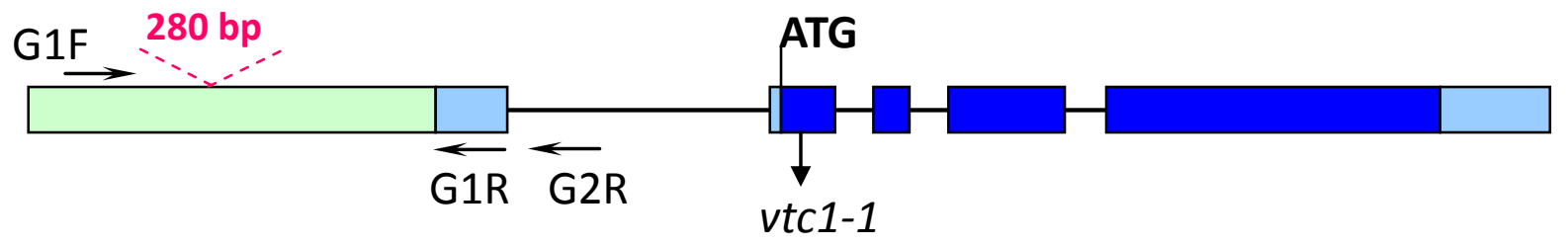

(b)

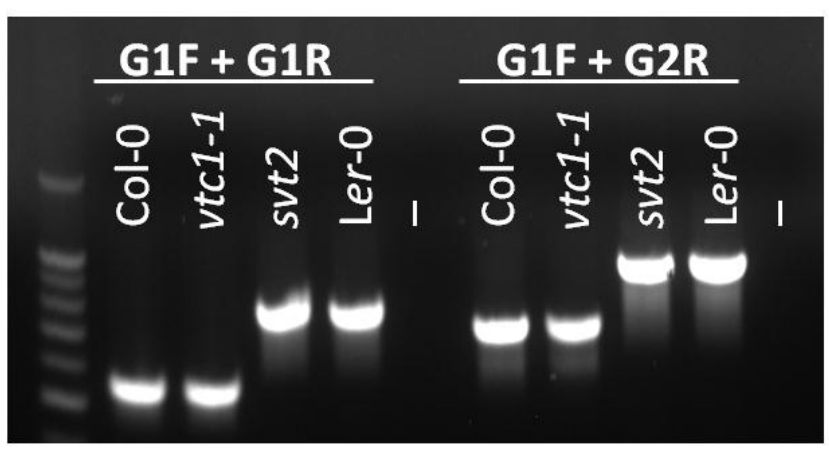

(d)

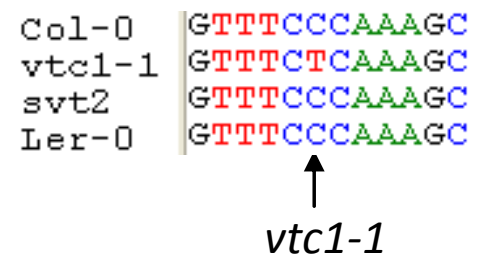

(c)

TAIR VTC1-gDNA

Col-0

$\mathrm{vtc1}-1$

svt2

ACATAATACCATCCCTTTAAAAACACAGAATTTTTTTTATCATCTCTGAA АCATAАTACCATCCCTTTAAAАACACAGAATTTTTTTTATCATCTCTGAA ACATAATACCATCCCTTTAA_A_ACACAGAATTTTTTTTATCATCTCTGAA AGTTTATGGGAGTATTTTTATACATAATACCATCCCTTTAAAAACACAGAATTTTCTTTATCATCTCCGAA GenBank AJ275979.1 AGTTTATGGGAGTATGTTTTATACATA_TACCATCCCTTTA_A_ACACAGAATTTTCTTTATCATCTCCGAA

\section{Figure 2.3 Genotypic characterization of svt2.}

(a) VTC1 Col-0 gene model. Light green box indicates VTC1 gene promoter region, light blue rectangles indicate 5' and 3' UTRs, dark blue rectangles indicate exons, and lines indicate introns. Shown is the location of the vtc1-1 mutation within the first exon, primer locations, and polymorphism insertion of $280 \mathrm{bp}$ in Ler-0 VTC1. (b) PCR amplification of the VTC1 promoter region in the Col-0 wild type, vtc1-1 and svt2 mutants and Ler-0 wild type. (-) indicates negative control, no DNA. (c) Partial sequence alignment of the VTC1 promoter region from the TAIR database (Col-0), sequenced Col-0 wild type, vtc11 and svt 2 mutants, sequenced Ler- 0 wild type and the Ler- 0 sequence obtained from GenBank. The alignment shows the sequence insertion in the svt2 mutant, the Ler-0 wild type and the GenBank sequence. Arrows indicate single nucleotide polymorphisms between the Ler-0 and Col-0 sequence. (d) Point mutation in vtc1-1, a conversion from a cytosine to a thymine. 


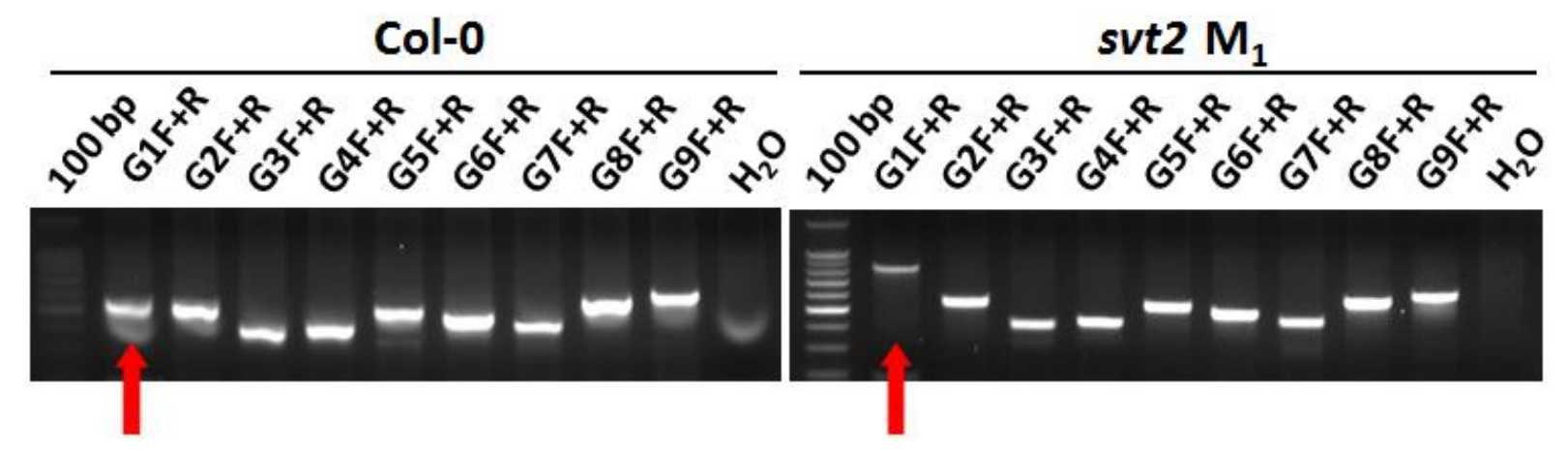

Figure 2.4 Molecular characterization of svt2.

Amplification of the VTC1 gene including approximately $500 \mathrm{bp}$ of the promoter region using a series of nine, overlapping primers ( $\mathrm{G} 1 \mathrm{~F}+\mathrm{R}$ through $\mathrm{G} 9 \mathrm{~F}+\mathrm{R}$ ) in both Col-0 wild type and svt2 $\mathrm{M}_{1}$ mutant genomic DNA. The last lane in each gel contained a negative control (water instead of DNA). Red arrows indicate the different sized PCR products using the same primer set. 
Table 2.2 Quantitative PCR to verify that VTC1 is a single copy gene in Col-0 and Ler-0 wild types and vtc1-1 and svt2 mutants.

Quantitative PCR was performed as described in Materials and Methods. The PAD4 gene is a known single copy gene. Therefore, an $\mathrm{RQ} / \mathrm{RQ}$ ratio of approximately 1 indicates that $V T C 1$ is present in similar quantity as $P A D 4$, and therefore a single-copy gene.

\begin{tabular}{|c|c|c|}
\hline & RQ/RQ & \multirow{2}{*}{} \\
\cline { 2 - 2 } & VTC1/PAD4 & \\
\hline Col-0 WT & 0.3796 & \\
\hline vtc1-1 & 0.5843 & \multirow{2}{*}{ VTC1 } \\
\hline svt2 & 0.5504 & E=1.8 \\
\hline Ler-0 WT & 0.6329 & \\
\hline Col-0 & 0.3153 & \multirow{2}{*}{ VTC1 } \\
\hline vtc1-1 & 0.5292 & \multirow{2}{*}{ E=2 } \\
\hline svt2 & 0.4946 & \\
\hline Ler-0 WT & 0.5807 & \\
\hline
\end{tabular}




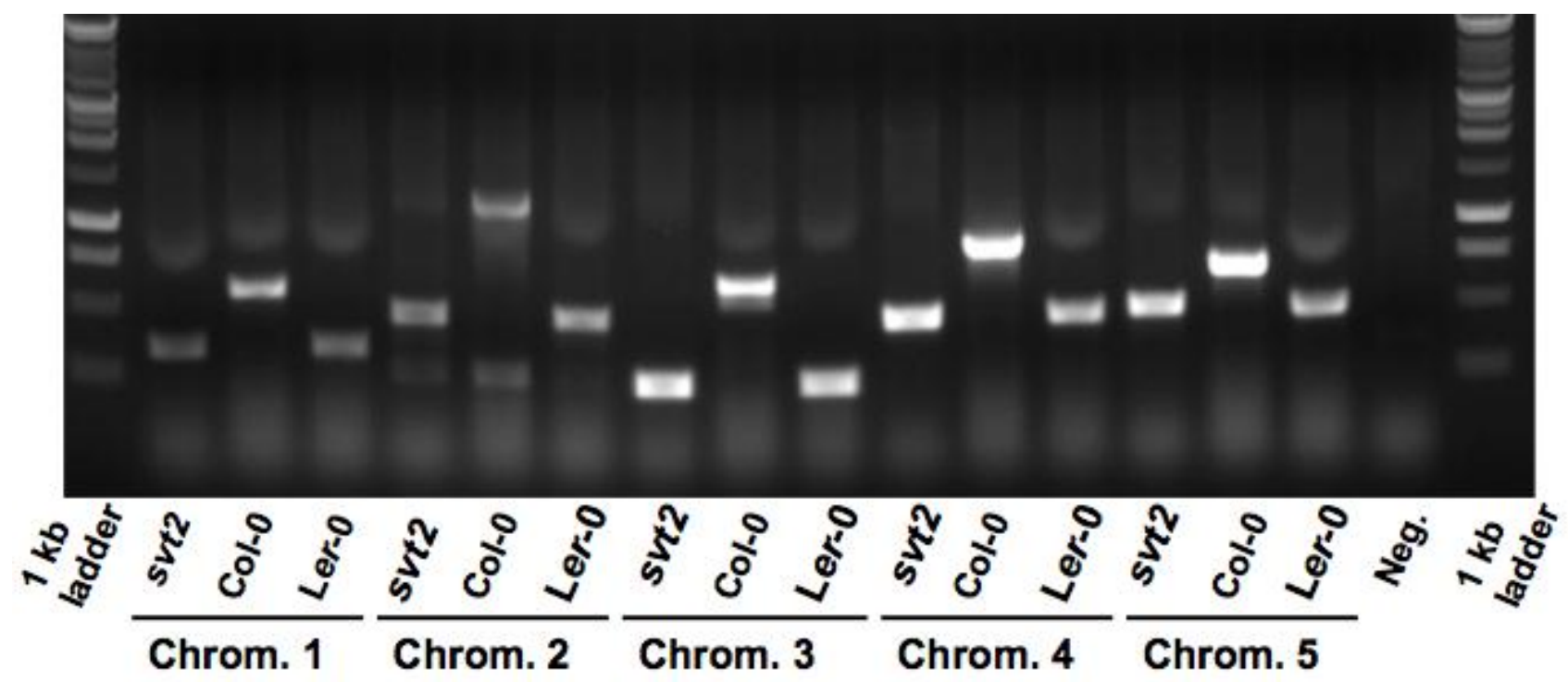

Figure 2.5 Insertion/Deletion polymorphism analysis in svt2, Col-0 and Ler-0.

Primers were designed for five randomly selected InDel polymorphisms across the five Arabidopsis chromosomes. The polymorphisms represent insertions in Col-0 and deletions in Ler. 
insertion (at approximately base pair 1902; see horizontal black arrows in Fig. 2.6) compared to the sequence flanking the $3^{\prime}$ end of the DNA sequence insertion (starting at base pair 2273; see horizontal black arrows in Fig. 2.6).

Finally, most intragenic suppressor mutants still contain the original mutation in addition to the suppressor mutation. Therefore, we expected that the vtc1-1 mutation is still present in svt2. However, our sequencing analysis demonstrated that svt2 did not contain the vtc1-1 mutation anymore and that the mutation reverted back to the homozygous wild-type allele (Figs. 2.3d, 2.6).

In summary, our data demonstrate that svt2 shares DNA sequence similarity with Col and Ler, but also contains DNA sequences that are unique to this mutant. This is particularly remarkable because svt 2 was generated in the vtc1-1 Col-0 background. Also, svt 2 did not contain the original vtc1-1 mutation anymore. Although our data already argue against svt2 being a result of an artifact of the experiment or a contamination with Ler, we analyzed subsequent svt2 generations and discovered additional characteristics that are unique to svt2.

\subsection{4 svt2 exhibits phenotypic and genotypic instability}

Our initial observations revealed that approximately $10 \%$ of svt2 $\mathrm{M}_{2}$ plants displayed a Col-like phenotype. Therefore, we planted svt2 $M_{1}, M_{2}$, and $M_{3}$ progeny to check whether this result can be repeated and to determine the segregation ratio (Table 2.3). Additionally, we investigated whether phenotypic Col-like revertants would produce svt2 (Ler-like) offspring in the next generation.

As summarized in Table 2.3, revertants could only be detected when a relatively large population was planted. In the svt2 $\mathrm{M}_{1}$ generation, only $1 \%$ of Col-like revertants were detected. In contrast, $8 \%-10 \%$ of svt2 $\mathrm{M}_{2}$ plants displayed a Col-like phenotype, whereas no revertants were detected in the svt2 $\mathrm{M}_{3}$ generation. These Col-like revertants were isolated and seeds were collected from individual plants and the phenotype of the progeny in the $\mathrm{M}_{3}$ generation was assessed in some examples. In most cases, reversion appeared to be stable, i.e., once svt2 plants reverted, displaying a Col-like phenotype in the $M_{2}$ generation, their $M_{3}$ progeny continued to appear as Col-like plants. This was the case for the $\mathrm{M}_{3}$ progeny of the $A 8$ and G7 plants listed in Table 2.4 However, out of 63 progeny from the K1 revertant plant, one reverted back to a svt2-like phenotype (Table 2.3). The $\mathrm{K} 1$ double revertant switched from svt2 phenotype in the $M_{1}$ generation to a Col-like phenotype in the $M_{2}$ generation, and then back to a svt2-like phenotype in the $\mathrm{M}_{3}$ generation. Note that only a small number of progeny was planted. In case of the svt2 Col R1 revertant, 20 individuals displaying a svt2-like phenotype were observed (Table 2.3). 
Col-0 VTC1 TAIR GDNA

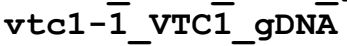
svt2 VTC1 gDNA

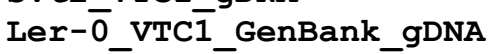

Col-0_VTC1_TAIR_gDNA

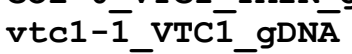

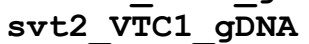
Ler-0_VTC $\overline{1}$ _GenBank_gDNA

Col-0_VTC1_TAIR_gDNA

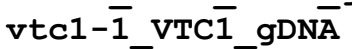
svt2_VTTC1_gDNA

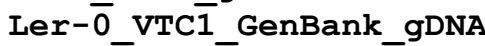

Col-0 VTC1 TAIR gDNA vtc1- $\overline{1}$ VTC $\overline{1}$ gDNA svt2 VTC1 gDNA

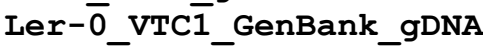

Col-0_VTC1_TAIR_gDNA

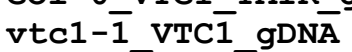
svt2_VTC1_gDNA

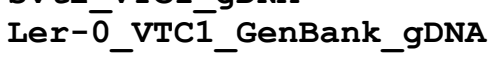

Col-0_VTC1_TAIR_gDNA

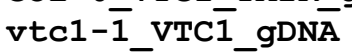
svt2 VTTC1 gDNA

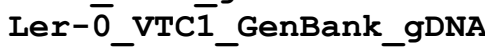

COI-0 VTC1 TAIR gDNA

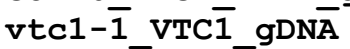
svt2 VTC1_g $\overline{\mathrm{DNA}}$

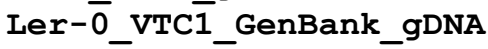

Col-0 VTC1 TAIR gDNA

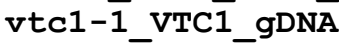
svt2 VTTC1 gDNA Ler-ōVTC $\overline{1}$ _GenBank_gDNA

Col-0_VTC1_TAIR_gDNA
10

20

30

40

50

60

$\ldots|\ldots| \ldots|\ldots| \ldots|\ldots| \ldots|\ldots| \ldots|\ldots| \ldots|\ldots| \ldots \mid$ ACGTCGCTATATATTGAAAGCATGTTTGACTATGTTACGTTAGCTATCATTTTATAAATG ACGTCGCTATATATTGAAAGCATGTTTGACTATGTTACGTTAGCTATCATTTTATAAATG
70

80

90

100

110

120 ACGTGATGATTACGAATTTACGATATACGTACTGCTTAAAGAAGAAGAATGTAAGAAGAA ACGTGATGATTACGAATTTACGATATACGTACTGCTTAAAGAAGAAGAATGTAAGAAGAA
130
140
150
160
170
180

$\ldots|\ldots| \ldots|\ldots| \ldots|\ldots| \ldots|\ldots| \ldots|\ldots| \ldots|\ldots| \ldots|\ldots|$ AAATCTATTGGCGCAAAACGTCGGTGAGTCAAAGCTGAAATCAAGGTGCTGCCTAACTAC AAATCTATTGGCGCAAAACGTCGGTGAGTCAAAGCTGAAATCAAGGTGCTGCCTAACTAC
190
200
210
220
230
240

$\ldots|\ldots| \ldots|\ldots| \ldots|\ldots| \ldots|\ldots| \ldots|\ldots| \ldots|\ldots| \ldots|\ldots|$ GATGTTGCTTTGGTATCTTTCCATAACTTTCTCTTTTTGTGACTTTTTTTTTTTTTTTTT GATGTTGCTTTGGTATCTTTCCATAACTTTCTCTTTTTGTGACTTTTTTTTTTTTTTTTT
250
260
270
280
290
300

$\ldots . \ldots|\ldots| \ldots|\ldots| \ldots|\ldots| \ldots|\ldots| \ldots|\ldots| \ldots|\ldots| \ldots \mid$ TTTCATTTCTAAATTCCTTCATTTAACTTTTCTAAAGTATTGTAGTATTACTTTAAAATC TTTCATTTCTAAATTCCTTCATTTAACTTTTCTAAAGTATTGTAGTATTACTTTAAAATC

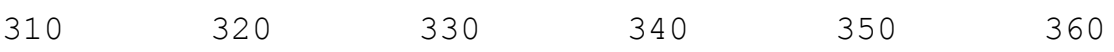
$\ldots|\ldots| \ldots|\ldots| \ldots|\ldots| \ldots|\ldots| \ldots|\ldots| \ldots|\ldots| \ldots|\ldots| \ldots \mid$ AACCAAAATTATACAGTATTGTTACTATGATGTGTGTATGCATATGGGGTCACCGCGTT AACCAAAАTTTATACAGTATTGTTACTATGATGTGTGTATGCATATGGGGTCACCGCGTT
370
380
390
400
410
420

$\ldots|\ldots| \ldots|\ldots| \ldots|\ldots| \ldots|\ldots| \ldots|\ldots| \ldots|\ldots| \ldots|\ldots|$ TGATGGTGGCGTGTATTTGTCAAAATGGACTATGCTTTTAATTAAACGTTAGATCTGGGG TGATGGTGGCGTGTATTTGTCAAAATGGACTATGCTTTTAATTAAACGTTAGATCTGGGG
430
440
450
460
470
480

$\ldots|\ldots| \ldots|\ldots| \ldots|\ldots| \ldots|\ldots| \ldots|\ldots| \ldots|\ldots| \ldots|\ldots| \ldots \mid$ TTCTCTATTCTTCTTTTTTAGTCATAAATCATAATATATACGTTATGATATAATATTGTA TTCTCTATTCTTCTTTTTTAGTCATAAATCATAATATATACGTTATGATATAATATTGTA

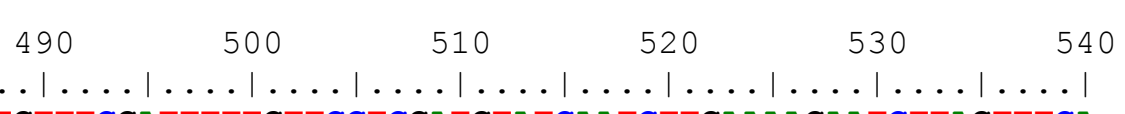

$\ldots \ldots|\ldots| \ldots|\ldots| \ldots|\ldots| \ldots|\ldots| \ldots|\ldots| \ldots|\ldots| \ldots|\ldots| \ldots|\ldots| \ldots \mid$ 
vtc1-1_VTC1_gDNA svt2 VTC1 gDNA

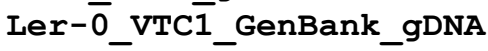

Col-0_VTC1_TAIR_gDNA

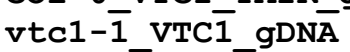
svt2_vT̄C1_gDNA

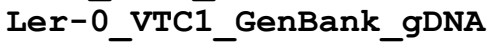

Col-0 VTC1 TAIR gDNA

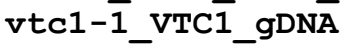
svt2_VT̄C1_gDNA

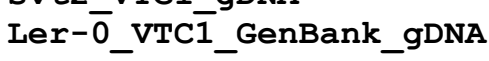

Col-0_VTC1_TAIR_gDNA

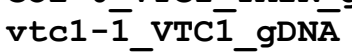
svt2 VTC1 gDNA

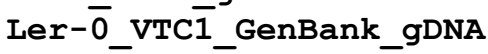

Col-0_VTC1_TAIR_gDNA

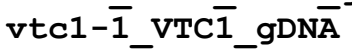
svt2 VTC1 gDNA

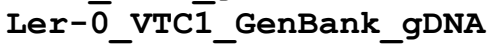

Col-0_VTC1_TAIR gDNA

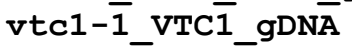

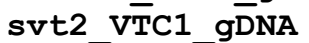

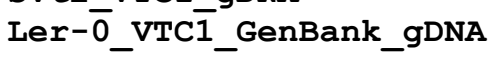

Col-0_VTC1_TAIR_gDNA

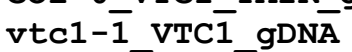
svt2_VT̄C1_gD̄NA Ler-0_VTC $\overline{1}$ _GenBank_gDNA

Col-0_VTC1_TAIR_gDNA

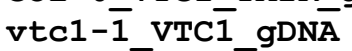
svt2 VTC1 gDNA

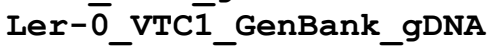

Col-0 VTC1 TAIR gDNA vtc1- $\overline{1}$ VTC $\overline{1}$ gDNA svt2 VTC1 gDNA

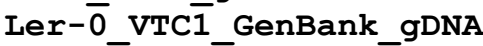

GCCTCTATGTTTCGATTTTTGTTCCTCGATGTATCAATCTTGAAAAGAATCTTAGTTTCA

$550 \quad 560 \quad 570 \quad 580 \quad 590 \quad 600$

$\ldots|\ldots| \ldots|\ldots| \ldots|\ldots| \ldots|\ldots| \ldots|\ldots| \ldots|\ldots| \ldots|\ldots| \ldots \mid$ TTCTAGGTAATCTCAAGGTGTGAAAATCCTATGTACATAAATATGTAAAGAATTCTCAAC TTCTAGGTAATCTCAAGGTGTGAAAATCCTATGTACATAAATATGTAAAGAATTCTCAAC
610
620
630
640
650
660

$\ldots|\ldots| \ldots|\ldots| \ldots|\ldots| \ldots|\ldots| \ldots|\ldots| \ldots|\ldots| \ldots|\ldots| \ldots|\ldots|$

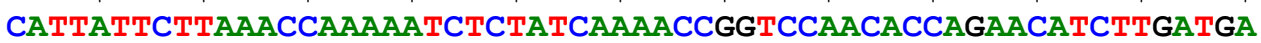
САТTАТTСТTАААССАААААТСТСТАТСАААACCGGTCCAACACCAGAАCATCTTGATGA

$\begin{array}{lllll}670 & 680 & 690 & 700 & 710\end{array}$ $\ldots|\ldots| \ldots|\ldots| \ldots|\ldots| \ldots|\ldots| \ldots|\ldots| \ldots|\ldots| \ldots|\ldots| \ldots|\ldots|$ TCTAGACAAATCAGTTTCTTAAAAAAATTATTGATATGCACCACTTTACTAAGAAGGAGA TCTAGACAAATCAGTTTCTTAAAAAAATTATTGATATGCACCACTTTACTAAGAAGGAGA
730
740
750
760
770
780

$\ldots|\ldots| \ldots|\ldots| \ldots|\ldots| \ldots|\ldots| \ldots|\ldots| \ldots|\ldots| \ldots|\ldots| \ldots \mid$ АTAАCAAАAАAAACAAAATGAAGGTACCTTGTCGGTGTCACGTGGGGAAGAACATGTGAA ATAACAAAAAAAACAAAATGAAGGTACCTTGTCGGTGTCACGTGGGGAAGAACATGTGAA
790
800
810
820
830
840

$\ldots|\ldots| \ldots|\ldots| \ldots|\ldots| \ldots|\ldots| \ldots|\ldots| \ldots|\ldots| \ldots \mid$ AACAAACGAACAATAATTGGAAGAAAAAAAAATGTGAATCTTGTGATGGATCAAATTAGG AACAAACGAACAATAATTGGAAGAAAAAAAAATGTGAATCTTGTGATGGATCAAATTAGG

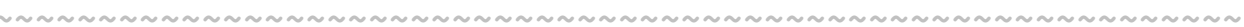
850
860
870
880
890
900

$\ldots|\ldots| \ldots|\ldots| \ldots|\ldots| \ldots|\ldots| \ldots|\ldots| \ldots|\ldots| \ldots|\ldots|$ TATATTCTTTGTAGCTCTTTAGTGTTCGTTCACTCACAGCCTCAGGCCCTCAGCTTTGGT TATATTCTTTGTAGCTCTTTAGTGTTCGTTCACTCACAGCCTCAGGCCCTCAGCTTTGGT
910
920
930
940
950
960

$\ldots|\ldots| \ldots|\ldots| \ldots|\ldots| \ldots|\ldots| \ldots|\ldots| \ldots|\ldots| \ldots|\ldots| \ldots|\ldots|$ СTTATCCAAACGACTGGCCCGCATAACAGAGACATTACACAATACGAATGCGTTTCTATA СTTATCCAAACGACTGGCCCGCATAACAGAGACATTACACAATACGAATGCGTTTCTATA
970
980
990
1000
1010
1020

$\ldots|\ldots| \ldots|\ldots| \ldots|\ldots| \ldots|\ldots| \ldots|\ldots| \ldots|\ldots| \ldots|\ldots| \ldots \mid$ TTACTGCTCCATACTCAAATCGAATCCTGGAGACAGATTCTTATTTTTTTTGTTATATTC TTACTGCTCCATACTCAAATCGAATCCTGGAGACAGATTCTTATTTTTTTTGTTATATTC 
Col-0_VTC1_TAIR_gDNA vtc1- $\overline{1}$ VTC $\overline{1}$ gDNA svt2_VTC1_gDNA

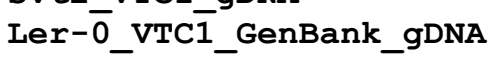

Col-0_VTC1_TAIR gDNA vtc $1-\overline{1}$ VTC $\overline{1}$ gDNA svt2_VTC1_gDNA Ler- $\overline{0}$ _VTC $\overline{1}$ _GenBank_gDNA

Col-0 VTC1 TAIR gDNA

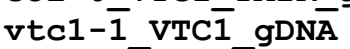
svt2_vTC1_g- $\overline{\mathrm{DNA}}$

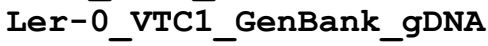

Col-0_VTC1_TAIR_gDNA

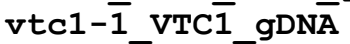
svt2 VTTC1 gDNA

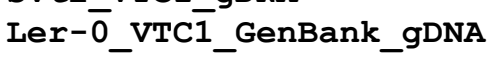

Col-0_VTC1_TAIR_gDNA

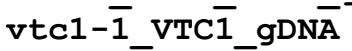
svt2 VTC1 g $\overline{\mathrm{DNA}}$

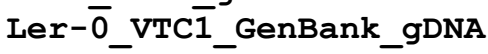

Col-0_VTC1_TAIR gDNA

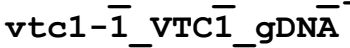
svt2 VTC1 gDNA

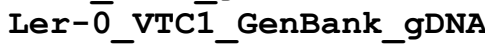

Col-0 VTC1 TAIR gDNA

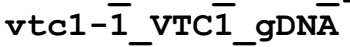
svt2 VTTC1_gDNA

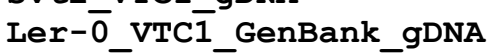

Col-0_VTC1_TAIR_gDNA

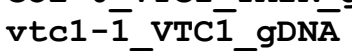
svt2 VT̄C1_gDNA

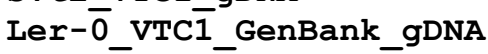
1030
1040
1050
1060
1070
1080

$\ldots|\ldots| \ldots|\ldots| \ldots|\ldots| \ldots|\ldots| \ldots|\ldots| \ldots|\ldots| \ldots|\ldots|$ AATTGTTTAGATTACTAAAAGCCAAAATCATAAAAACTTTAAACGATTTGATTATTATAT AATTGTTTAGATTACTAAAAGCCAAAATCATAAAAACTTTAAACGATTTGATTATTATAT
1090
1100
1110
1120
1130
1140

$\ldots|\ldots| \ldots|\ldots| \ldots|\ldots| \ldots|\ldots| \ldots|\ldots| \ldots|\ldots| \ldots|\ldots| \ldots \mid$ CACCAAAATATTGGCTTTAATCCATGTTAATACTGATTAACTTGAAATATACTTATATT

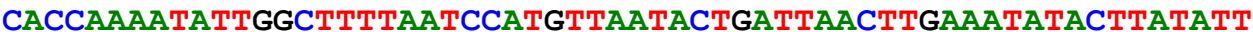
1150
1160
1170
1180
1190
1200

$\ldots|\ldots| \ldots|\ldots| \ldots|\ldots| \ldots|\ldots| \ldots|\ldots| \ldots|\ldots| \ldots|\ldots|$ TTTGGTTATTGGGGAGGAAGGAATACAAATAATCTTTTTCGACACTGAATAGTTTCCTTT TTTGGTTATTGGGGAGGAAGGAATACAAATAATCTTTTTCGACACTGAATAGTTTCCTTT
1210
1220
1230
1240
1250
1260

$\ldots|\ldots| \ldots|\ldots| \ldots|\ldots| \ldots|\ldots| \ldots|\ldots| \ldots|\ldots| \ldots|\ldots| \ldots \mid$

GAATGAAAGCTGATAAAATAGTGTATAAGTTCATTTTTTTATAACGTAATTTTTTTTTTG GAATGAAAGCTGATAAAATAGTGTATAAGTTCATTTTTTTATAACGTAATTTTTTTTTTG
1270
1280
1290
1300
1310
1320

$\ldots \ldots|\ldots| \ldots|\ldots| \ldots|\ldots| \ldots|\ldots| \ldots|\ldots| \ldots|\ldots| \ldots|\ldots| \ldots \mid$ GTAATGTGAACACССTAAAAAGATCTCСTTCTGATGTAGAAАTATTATACCCATACACAT GTAATGTGAACACCCTAAAAAGATCTCCTTCTGATGTAGAAATATTATACCCATACACAT
1330
1340
1350
1360
1370
1380

$\ldots|\ldots| \ldots|\ldots| \ldots|\ldots| \ldots|\ldots| \ldots|\ldots| \ldots|\ldots| \ldots|\ldots| \ldots \mid$ CGATAAGTTAGTTTGTGGAAAGAAAAACTAACTAACAAAATAACACCTTCAATTCGACAA CGATAAGTTAGTTTGTGGAAAGAAAAАCTAАCTAACAАAАTAACACCTTCAATTCGACAA
1390
1400
1410
1420
1430
1440

$\ldots|\ldots| \ldots|\ldots| \ldots|\ldots| \ldots|\ldots| \ldots|\ldots| \ldots|\ldots| \ldots|\ldots| \ldots \mid$ AAGAGCATAAGTTTAATAAAATACCTACAGAAATTTTTGACGATGATACCACTACCATTC AAGAGCATAAGTTTAATAAAATACCTACAGAAATTTTTGACGATGATACCACTACCATTC

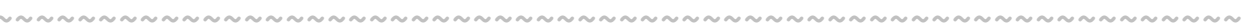
1450
1460
1470
1480
1490
1500

$\ldots|\ldots| \ldots|\ldots| \ldots|\ldots| \ldots|\ldots| \ldots|\ldots| \ldots|\ldots| \ldots|\ldots| \ldots|\ldots|$ GCCAАAАCCACAАTAАTTCAАTTСTTCTAАATGTAGATTCTATTAАTATGGTCGATTGTC GCCAAAACCACAATAATTCAATTCTTCTAAATGTAGATTCTATTAATATGGTCGATTGTC

$\ldots|\ldots| \ldots|\ldots| \ldots|\ldots| \ldots|\ldots| \ldots|\ldots| \ldots|\ldots| \ldots|\ldots| \ldots|\ldots|$


Col-0_VTC1_TAIR_gDNA vtc1-1﹎VTC $\overline{1}$ gDN $\bar{A}$ svt2 vTC1 gDNA Ler-0_VTC $\overline{1}$ _GenBank_gDNA

Col-0 VTC1 TAIR gDNA

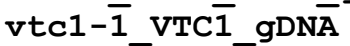

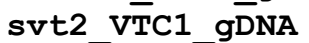

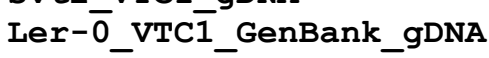

Col-0_VTC1_TAIR_gDNA

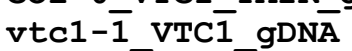
svt2 VTC1_ḡNA

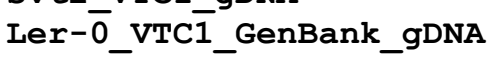

Col-0_VTC1_TAIR_gDNA

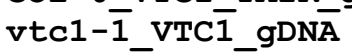

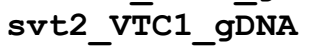

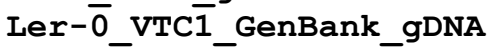

Col-0 VTC1 TAIR gDNA

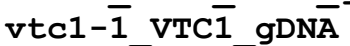
svt2 VTTC1 gDNA

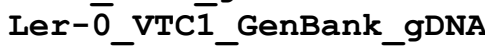

Col-0 VTC1 TAIR gDNA

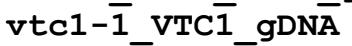
svt2 VTC1 gDNA

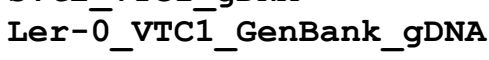

Col-0_VTC1_TAIR_gDNA

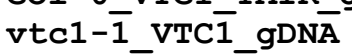
svt2 VTC1 gDNA

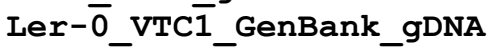

Col-0 VTC1 TAIR gDNA

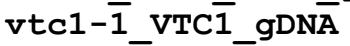
svt2_vTC1_g $\overline{\mathrm{DNA}}$

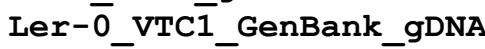

Col-0 VTC1 TAIR gDNA

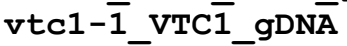
svt2_vT̄C1_gDNA

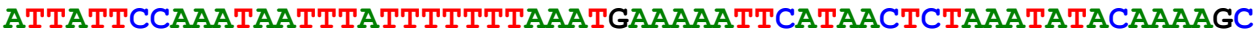
АТTАТTССАААТААТTТАТTTTTTТАААТGАААААТТСАТААСТСТАААТАТАСААААGC
1570
1580
1590
1600
1610
1620

$\ldots|\ldots| \ldots|\ldots| \ldots|\ldots| \ldots|\ldots| \ldots|\ldots| \ldots|\ldots| \ldots|\ldots| \ldots \mid$ AATTGCTGATTTGGATTCAAATTTTCAAAGAGAACTTGTAGTTATGCATATACATAAAAA AATTGCTGATTTGGATTCAAATTTCAAAGAGAACTTGTAGTTATGCATATACATAAAAA

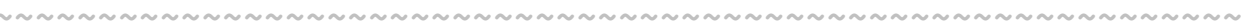
1630
1640
1650
1660
1670
1680

$\ldots|\ldots| \ldots|\ldots| \ldots|\ldots| \ldots|\ldots| \ldots|\ldots| \ldots|\ldots| \ldots|\ldots| \ldots \mid$ GGTAAGTCAGTTTTTTTTTTTGGCTAATAAAAACGGTAAAATCATGTTATTGATAAAAAA GGTAAGTCAGTTTTTTTTTTTGGCTAATAAAAACGGTAAAATCATGTTATTGATAAAAAA
1690
1700
1710
1720
1730
1740

$\ldots|\ldots| \ldots|\ldots| \ldots|\ldots| \ldots|\ldots| \ldots|\ldots| \ldots|\ldots| \ldots|\ldots| \ldots \mid$ TTTGAAAACAGTAAAAGAAATATGACCATATTTGAAAATTTACCTAAAAACTATAАTGAT TTTGAAAACAGTAAAAGAAATATGACCATATTTGAAAATTTACCTAAAAАCTATAATGAT
1750
1760
1770
1780
1790
1800

$\ldots|\ldots| \ldots|\ldots| \ldots|\ldots| \ldots|\ldots| \ldots|\ldots| \ldots|\ldots| \ldots|\ldots| \ldots \mid$ GTAATAGTTTGATTTACTTACATTTAACTAATTTTAAGGTCTGTTGATCGAACTCGTTA GTAATAGTTTGATTTACTTACATTTAACTAATTTTTAAGGTCTGTTGATCGAACTCGTTA TCT
1810
1820
1830
1840
1850
1860

$\ldots \ldots|\ldots| \ldots|\ldots| \ldots|\ldots| \ldots|\ldots| \ldots|\ldots| \ldots|\ldots| \ldots|\ldots|$ CCTTGAACAATTAGTAGGACAACTCAAACCACTAAACCATTATACTTTAAGGATTTATGT

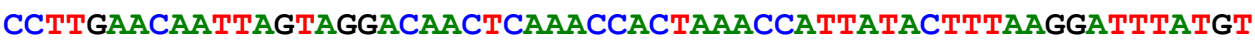
1870
1880
1890
1900
1910
1920

$\ldots|\ldots| \ldots|\ldots| \ldots|\ldots| \ldots|\ldots| \ldots|\ldots| \ldots|\ldots| \ldots|\ldots|$ AАААTTTCAААTATATATAGTTTAGTAGATGCACTTATCATCACACTCACCAATTGGATG AAAATTTCAAАTATATATAGTTTAGTAGATGCACTTATCATCACACTCACCAATTGGATG
1930
1940
1950
1960
1970
1980

$\ldots|\ldots| \ldots|\ldots| \ldots|\ldots| \ldots|\ldots| \ldots|\ldots| \ldots|\ldots| \ldots|\ldots|$ TCAACACCTGGTTCTAGCTTTTTAATTACCAAAGTGAAAAAACTGACTTTTTCTAAAAAA TCAACACCTGGTTCTAGCTTTTTAATTACCAAAGTGAAAAAACTGACTTTTTCTAAAAAA

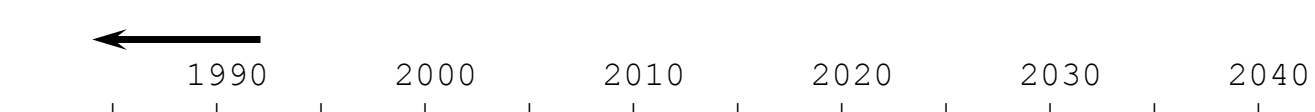
$\ldots|\ldots| \ldots|\ldots| \ldots|\ldots| \ldots|\ldots| \ldots|\ldots| \ldots|\ldots| \ldots|\ldots| \ldots \mid$ AATTCGTTCTAGATGGATGCTCTTCAAATTCGTTC TAAAAAAAACTG AATTCGTTCTAGATGGATGCTCTTCAAATTCGTTC TAAAAAAAACTG ATGGATGCTCTTTAAAT C TTCGATATTTTTTATCCGTTTCGATAAT 
CO1-0_VTC1_TAIR_gDNA vtc1-1̄_VTC $\overline{1} \_g D N \bar{A}$ svt2 VT̄C1 gDNA

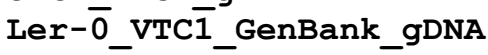

COI-0 VTC1 TAIR GDNA vtc1-1̄ VTC $\overline{1} \_g D N \bar{A}$ svt2 VTC1 gDNA

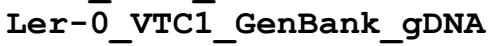

Col-0_VTC1_TAIR_gDNA vtc1-1̄ VTC $\overline{1} \_g D N \bar{A}$ svt2 VTC1 gDNA Ler-̄o_VTC1̄_GenBank_gDNA

Col-0_VTC1_TAIR_gDNA vtc1-1̄ VTC $\overline{1}$ gDN $\bar{A}$ svt2 VTC1 gDNA Ler-̄o_VTC1̄_GenBank_gDNA

Col-0_VTC1_TAIR_gDNA vtc1-1̄_VTC $\overline{1}$ _gDNA $\bar{A}$ svt2_VTC1_gDNA

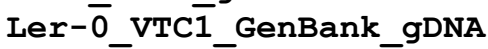

Col-0 VTC1 TAIR gDNA vtc1- $\overline{1}$ VTC $\overline{1}$ gDNA $\bar{A}$ svt2 VTC1 gDNA Ler- $\overline{0}$ VTC $\overline{1}$ _GenBank_gDNA

Col-0_VTC1_TAIR_gDNA

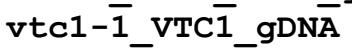
svt2_VTC1_gDNA Ler-0_VTC1̄_GenBank_gDNA

Col-0_VTC1_TAIR_gDNA

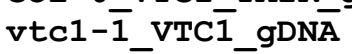
svt2_vTC1_gDNA

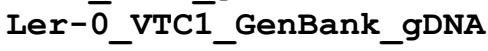

$20502060 \quad 2070 \quad 2080 \quad 2090 \quad 2100$

$\ldots|\ldots| \ldots|\ldots| \ldots|\ldots| \ldots|\ldots| \ldots|\ldots| \ldots|\ldots| \ldots|\ldots| \ldots \mid$

ATGGTAAGAATGAATGACGAATCGGTCAAGCTAATCTGTATATTAATCATTGTACTCATC

ATGGTAAGAATGAATGACGAATCGGTCAAGCTAATCTGTATATTAA CATTGTACTCATC
2110
2120
2130
2140
2150
2160

$\ldots|\ldots| \ldots|\ldots| \ldots|\ldots| \ldots|\ldots| \ldots|\ldots| \ldots|\ldots| \ldots|\ldots| \ldots \mid$

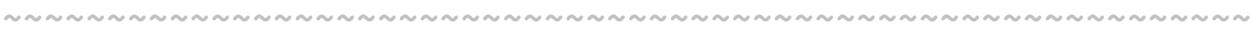

AACGTAAAGTCСTATTCGTCTATACATATGTGAACTTATATATGTCTATCAACTAGTTCA AACGTAAAGTCCTATTCGTCTATACATATGTGAACTTATATATGTCTATCAACTAGTTCA

$$
\begin{array}{llll}
2170 & 2180 & 2190 \quad 2200 & 2210
\end{array} 220
$$

$\ldots|\ldots| \ldots|\ldots| \ldots|\ldots| \ldots|\ldots| \ldots|\ldots| \ldots|\ldots| \ldots|\ldots| \ldots \mid$

СTAСССТАTATATAAAGTTCATCAGAGTTGTCGATCAGCAGTGACCACTACACATTCTTC СTAСССТАT AAAGTTCATCAGAGTTGTCGATCAGCAGTGACCACTACACATTCTTC

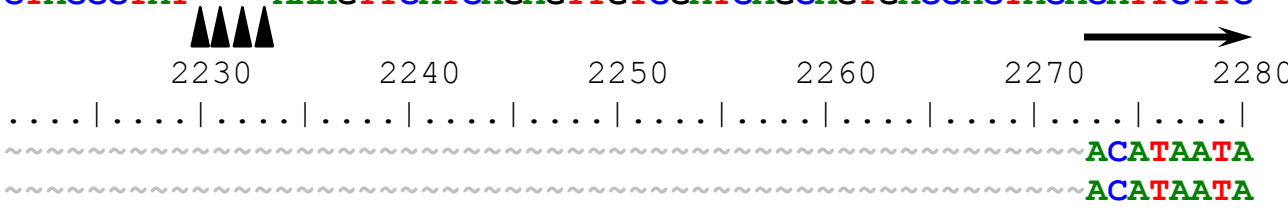

ATACAGCTGAGTTAGGAATGTTAACAAAATAGTTTATGGGAGTATGTTTTATACATAATA ATACAGCTGAGTTAGGAATGTTAACAAAATAGTTTATGGGAGTATGTTTTATACATAATA
2290
2300
2310
2320
2330
2340

$\ldots|\ldots| \ldots|\ldots| \ldots|\ldots| \ldots|\ldots| \ldots|\ldots| \ldots|\ldots| \ldots|\ldots|$ ССАТСССТTTAАAАACACAGAАTTTTTTTATCATСTCTGAAACAAATCATTTACAGTAG ССАТСССТTТАААААСАСАGАТТTTTTTАТСАТСТСТGАААСАААТСАТTTAСАGTAG ССАТСССТTTAАAАACACAGAАTTTTСTTTATCATCTCCGAAACAAАTCATTTACAGTAG

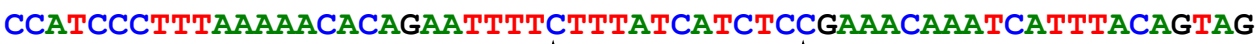
2350
2360
2370
$\uparrow$
2380
2390
2400

$\ldots|\ldots| \ldots|\ldots| \ldots|\ldots| \ldots|\ldots| \ldots|\ldots| \ldots|\ldots| \ldots|\ldots| \ldots \mid$ TAAATGT CAACACAACATTAATTCTGTTTGTTGTTGGCATTTACAATTGCAAAATCAT TAAATGT CAACACAACATTAATTCTGTTTGTGTTGGCATTTACAATTGCAAAATCAT TAAATGTAAAAACACAACATTAАTTCTGTTTGTTGTTGGCATTTACAАTTGCAAАATСAT TAAATGTAAAAACACAACATTAATTCTGTTTGTTGTTGGCATTTACAATTGCAAAATCAT

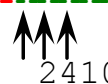

2420

2430

2440

2450

2460

$\ldots|\ldots| \ldots|\ldots| \ldots|\ldots| \ldots|\ldots| \ldots|\ldots| \ldots|\ldots| \ldots|\ldots| \ldots \mid$ TTTСTСАTTTATTATTCGTATTTATTTTGTCAAGAАСССTTGTСTСTAAAATATTCATAG TTTCTCATTTATTATTCGTATTTATTTTGTCAAGAACCCTTGTCTCTAAAATATTCATAG TTTCTCATTTATTATTCGTATTTATTTTGTCAAGAACССTTGTCTCTAAAATATTCATAG TTTCTCATTTATTATTCGTATTTATTTTGTCAAGAACCCTTGTCTCTAAAATATTCATAG
2470
2480
2490
2500
2510
2520

$\ldots|\ldots| \ldots|\ldots| \ldots|\ldots| \ldots|\ldots| \ldots|\ldots| \ldots|\ldots| \ldots|\ldots| \ldots|\ldots|$ AAAAAGAAAAGAGCCATTAATTATGGCTTGAAGAAAGATTGGTGTATAAGCGTCTACGT AAAAAGAAAAGAGCCATTAATTAATGGCTTGAAGAAAGATTGGTGTATAAGCGTCTACGT AAAAA AAAAGAGCCATTAATTAATGGCTTGAAGAAAGATTGGTGTATAAGCGTCTACGT AAAAA AAAAGAGCCATTAATTAATGGCTTGAAGAAAGATTGGTGTATAAGCGTCTACGT $\uparrow$

$$
2530 \quad 2540 \quad 2550 \quad 2560 \quad 2570 \quad \downarrow 2580
$$


Col-0 VTC1 TAIR gDNA

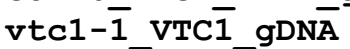

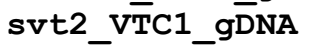

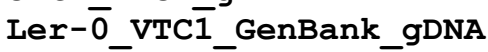

Col-0 VTC1_TAIR_gDNA

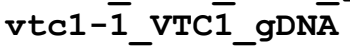
svt2 VTC1 gDNA

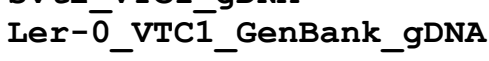

Col-0_VTC1 TAIR_gDNA

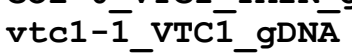
svt2_vT $\mathrm{T} 1$ gDNA

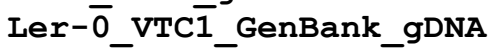

Col-0_VTC1_TAIR_gDNA

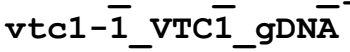
svt2 VTC1 gDNA

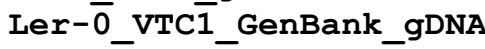

Col-0_VTC1_TAIR_gDNA

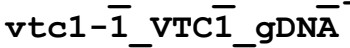
svt2_VTTC1_gDNA

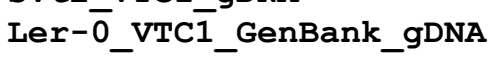

Col-0_VTC1_TAIR_gDNA

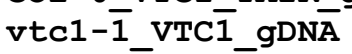
svt2_VTC1_gDNA

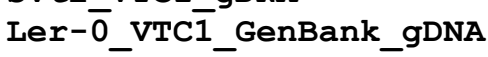

Col-0_VTC1_TAIR_gDNA

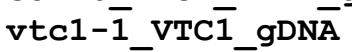
svt2 VTTC1 gDNA

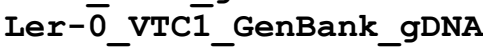

Col-0_VTC1_TAIR_gDNA

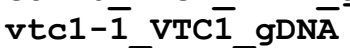
svt2 VTTC1 gDNA

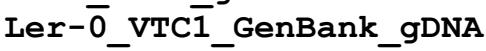

Col-0_VTC1_TAIR_gDNA

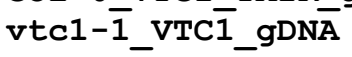

$\ldots|\ldots| \ldots|\ldots| \ldots|\ldots| \ldots|\ldots| \ldots|\ldots| \ldots|\ldots| \ldots|\ldots| \ldots \mid$

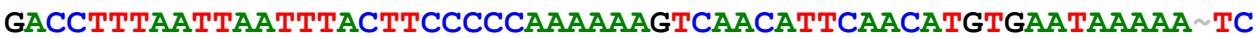
GACСTTTAАTTAАTTTACTTCCCCCAAAAAAGTCAACATTCAACATGTGAATAAAAA TC GACСTTTAАTTAАTTTACTTCCCCAAAAAAAGTCAACATTCAACATGTGAATAAAAA TC GACСTTTAАTTAАTTTACTTCCCCAAAAAAAGTCAАCATTCAACATGTGAATAAAAAATC

$$
25902600 \text { 个 } 2610 \quad 2620 \quad 2630 \quad 2640
$$

$\ldots|\ldots| \ldots|\ldots| \ldots|\ldots| \ldots|\ldots| \ldots|\ldots| \ldots|\ldots| \ldots|\ldots| \ldots \mid$

ААTATTGGTTTCTAAGTAAGTAAGTACCATATTATTAAATTATTTATTTTGGTAAATACG АATATTGGTTTCTAAGTAAGTAAGTACCATATTATTAAATTATTTATTTTGGTAAATACG AATATTGGTTTCTAAGTAAGTAAGTACCATATTATTAAATTATTTATTTTGGTAAATACG ААTATTGGTTTCTAAGTAAGTAAGTACCATATTATTAAАTTATTTATTTTGGTAAATACG

$$
\begin{array}{lllll}
2650 & 2660 & 2670 & 2680 & 2690
\end{array}
$$

$\ldots|\ldots| \ldots|\ldots| \ldots|\ldots| \ldots|\ldots| \ldots|\ldots| \ldots|\ldots| \ldots|\ldots| \ldots \mid$ САСТСААTTTTСTCTCAACGGTG TATATAAACAAAAGGAGTCTCCTTTGGAAAAA САСТСААТTTTСТTССАACGGTG TATATAAACAAAAGGAGTCTCСTTTGGAAAAA САСТСААTTTTTСTСTCAACGGTGGGTGTATATAAACAAAAGGAGTCTCСTTTGGAAAAA САСTСААTTTTTСTСTCAACGGTGGGTGTATATAAACAAAAGGAGTCTCСTTTGGAAAAA

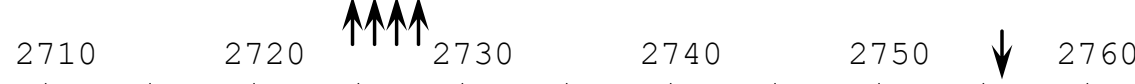

$\ldots|\ldots| \ldots|\ldots| \ldots|\ldots| \ldots|\ldots| \ldots|\ldots| \ldots|\ldots| \ldots|\ldots| \ldots|\ldots|$ АСTTGCCTATCATTTTGCCAACGAACGTTCTTTCTTCTTAATCACAGCTCAGCCTGACGC АСTTGCСTATCATTTTGCCAACGAACGTTCTTTCTTCTTAATCACAGCTCAGCCTGACGC ACTTGCCTATCATTTTGCCAACGAACGTTCTTTCTTCTTAATCACAGCTCAGCCTGACGC АСTTGССTATCATTTTGCCAACGAACGTTCTTTCTTCTTAATCACAGCTCAGCCT ACGC

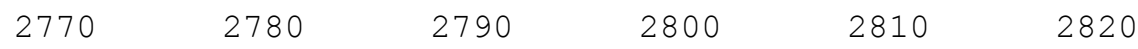

$\ldots|\ldots| \ldots|\ldots| \ldots|\ldots| \ldots|\ldots| \ldots|\ldots| \ldots|\ldots| \ldots|\ldots| \ldots|\ldots|$ AACCGCTCAGGCTGATCTCTTCCAATTACAGCCATTTCCCAGCTCAGATCTCTGATCCG AACCGCTCAGGCTGATCTCTTCCAATTTACAGCCATTTCCCAGCTCAGATCTCTGATCCG AACCGCTCAGGCTGATCTCTTCCAАTTTACAGCCATTTCCCAGCTCAGATCTCTGATCCG AACCGCTCAGGCTGATCTCTTCCAATTACAGCCATTTCCCAGCTCAGATCTCTGATCCG
2830
2840
2850
2860
2870
2880

$\ldots|\ldots| \ldots|\ldots| \ldots|\ldots| \ldots|\ldots| \ldots|\ldots| \ldots|\ldots| \ldots|\ldots| \ldots \mid$ GTGAGATCTCTCTCAAGGTAATGCCCCTGCAATTTTGCTTACTTCTCTGGTTGTGATATG GTGAGATCTCTCTCAAGGTAATGCCCCTGCAATTTTGCTTACTTCTCTGGTTGTGATATG GTGAGATCTCTCTCAAGGTAATGCCСCTGCAATTTTGCTTACTTCTCTGGTTGTGATATG GTGAGATCTCTCTCAAGGTAATGCCCCTGCAATTTTGCTTACTTCTCTGGTTGTGATATG
2890
2900
2910
2920
$293 p$
2940

$\ldots|\ldots| \ldots|\ldots| \ldots|\ldots| \ldots|\ldots| \ldots|\ldots| \ldots|\ldots| \ldots|\ldots| \ldots \mid$ CATGTTCTTCGAATTTCATCGTTTGTGATTGAATCTCATTTTGTATTTGCTGTTGTT CATGTTCTTCGAATTTCATCGTTTGTGATTTGAATCTCATTTTGTATTTGCTGTTGTT CATGTTCTTCGAATTTTCATCGTTTGTGATTTGAATTCTCATTTTGTATTTGCTGTTGTT САTGTTCTTCGAATTTCATCGTTTGTGATTTGAATCTCATTTTGTATTT CTGTTGTT

$$
2950 \quad 2960 \quad 2970 \quad 2980 \downarrow \quad 2990 \quad 3000
$$

$\ldots|\ldots| \ldots|\ldots| \ldots|\ldots| \ldots|\ldots| \ldots|\ldots| \ldots|\ldots| \ldots|\ldots| \ldots \mid$ GGTTTTTAATTCGATTTTCCGGAACAGATTATGGGATTT GTATTCGAATCTTCGATTTG GGTTTTTAATTCGATTTTCCGGAACAGATTATGGGATTT GTATTCGAATCTTCGATTTG GGTTTTTAATTCGATTTTCCGGAACAGGTTATGGGGATTTGTATTCGAATCTTCGATTTG GGTTTTTAATTCGATTTTCCGGAACAGGTTATGGGGATTTGTAT CGAATCTTCGATTTG

$$
\begin{array}{llllll} 
& & & & & \\
3010 & \uparrow_{3030} & \uparrow_{3040} & 3050 & 3060
\end{array}
$$

$\ldots|\ldots| \ldots|\ldots| \ldots|\ldots| \ldots|\ldots| \ldots|\ldots| \ldots|\ldots| \ldots|\ldots| \ldots \mid$ ATGACATAATGTCCCAGCCTTTTATGTTTAATCTTGAAATGATGGACTTTTATCCGATCT ATGACATAATGTCCCAGCCTTTTATGTTTAATCTTGAAATGATGGACTTTTATCCGATCT 
svt2_VTC1_gDNA

Ler-̄o_VTC1̄_GenBank_gDNA

Col-0_VTC1_TAIR_gDNA vtc1-1̄_VTC $\overline{1}$ gDN $\bar{A}$ svt2_VTC1_gDNA

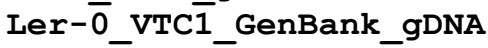

Col-0 VTC1 TAIR gDNA

vtc1- $\overline{1}$ VTC $\overline{1}$ gDNA

svt2 VTC1 gDNA

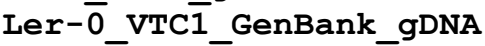

Col-0_VTC1_TAIR_gDNA

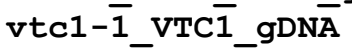

svt2 VTC1 gDNA

Ler-o_VTC1'_GenBank_gDNA

Col-0_VTC1_TAIR_gDNA

vtc1-1̄_VTC $\overline{1}$ gDN $\bar{A}$

svt2 VTC1_gDNA

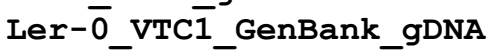

Col-0_VTC1_TAIR_gDNA

vtc $1-\overline{1}$ VTC $\overline{1}$ gDN $\bar{A}$

svt2_VTC1_gDNA

Ler- $\overline{0}$ _VTC $\overline{1}$ _GenBank_gDNA

Col-0_VTC1 TAIR gDNA

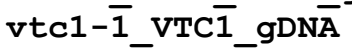

svt2_VTC1_gDNA

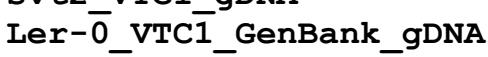

Col-0_VTC1_TAIR_gDNA

vtc $1-\overline{1}$ VTC $\overline{1} \_g D N \bar{A}$

svt2_VTC1_gDNA

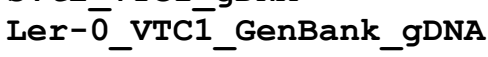

Col-0_VTC1_TAIR_gDNA

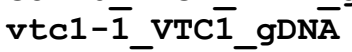

svt2 vTC1 gDNA

Ler- $\overline{0}$ _VTC $\overline{1}$ _GenBank_gDNA
ATGACATAATGTCCCAGCCATTTATGTTTAATCTTGAAATGATGGACTTTAATCCGATCT ATGACATAATGTCCCAGCCATTTATGTTTAATCTTGAAATGATGGACTTTAATCCGATCT

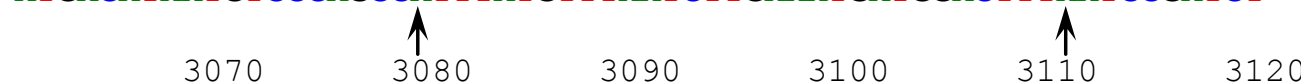

$\ldots|\ldots| \ldots|\ldots| \ldots|\ldots| \ldots|\ldots| \ldots|\ldots| \ldots|\ldots| \ldots|\ldots|$ GGGTTTAAAGCTGGAATTTTGATTGTGGGTACTATTAGGTTTCATTGATTTATTGCTTGG GGGTTTAAAGCTGGAATTTTGATTGTGGGTACTATTAGGTTTCATTGATTTATTGCTTGG GGGTTTAAAGCTGGAATTTTGATTGTGGGTACTATTAGGTTTCATTGATTTATTGCTTGG GGGTTTAAAGCTGGAATTTTGATTGTGGGTACTATTAGGTTTCATTGATTTATTGCTTGG

$$
\begin{array}{lllll}
3130 & 3140 & 3150 & 3160 & 3170
\end{array}
$$

$\ldots|\ldots| \ldots|\ldots| \ldots|\ldots| \ldots|\ldots| \ldots|\ldots| \ldots|\ldots| \ldots|\ldots|$ TCCAACATTTTTAGCAGCTGGTATTGAGCTCTTGTTGTCTGAATTTTGGAAAGAACTATT TCCAACATTTTTAGCAGCTGGTATTGAGCTCTTGTTGTCTGAATTTTGGAAAGAACTATT TCCAACATTTTTAGCAGCTGGTATTGAGCTCTTGTTGTCTGAATTTTGGAAAGAACTATT TCCAACATTTTTAGCAGCTGGTATTGAGCTCTTGTTGTCTGAATTTTGGAAAGAACTATT
3190
3200
3210
3220
3230
3240

$\ldots . \ldots|\ldots| \ldots|\ldots| \ldots|\ldots| \ldots|\ldots| \ldots|\ldots| \ldots|\ldots| \ldots|\ldots$. TTTGTTGTATCGTTTTGATTTATTTGGATCTGAATTCATTCACCTTTTTCTCTGATTATT TTTGTTGTATCGTTTTGATTTATTTGGATCTGAATTCATTCACCTTTTTCTCTGATTATT TTTGTTGTATCGTTTTGATTTATTTGGATCTGAATTCATTCACCTTTTTCTCTGATTATT TTTGTTGTATCGTTTTGATTTATTTGGATCTGAATTCATTCACCTTTTTCTCTGATTATT
3250
3260
3270
3280
3290
3300

$\ldots|\ldots| \ldots|\ldots| \ldots|\ldots| \ldots|\ldots| \ldots|\ldots| \ldots|\ldots| \ldots|\ldots| \ldots \mid$ GTTTTGTGTCGGTTGCATCCACTTTGATTAGATCTGAATGAATCATTTTTTTATGTGCTC GTTTTGTGTCGGTTGCATCCACTTTGATTAGATCTGAATGAATCATTTTTTTATGTGCTC GTTTTGTGTCGGTTGCATCCACTTTGATTAGATCTGAATGAATCATTTTTTTATGTGCTC GTTTTGTGTCGGTTGCATCCACTTTGATTAGATCTGAATGAATCATTTTTTTATGTGCTC
3310
3320
3330
3340
3350
3360

$\ldots|\ldots| \ldots|\ldots| \ldots|\ldots| \ldots|\ldots| \ldots|\ldots| \ldots|\ldots| \ldots|\ldots| \ldots \mid$ AAGTTATTGTATGGATTGTTCTGTTTCTAGCATGTTTTGGTTAGACATTGTTAAGATCTG AAGTTATTGTATGGATTGTTCTGTTTCTAGCATGTTTTGGTTAGACATTGTTAAGATCTG AAGTTATTGTATGGATTGTTCTGTTTCTAGCATGTTTTGGTTAGACATTGTTAAGATCTG AAGTTATTGTATGGATTGTTCTGTTTCTAGCATGTTTTGGTTAGACATTGTTAAGATCTG

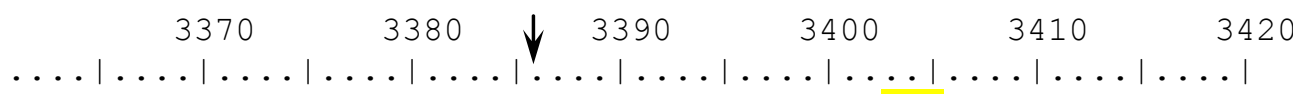

ACGTTTGCATTTTCAGGAAAAGGAG TTAGAGCATCATCAAGATGAAGGCACTCATTCTT ACGTTTGCATTTTCAGGAAAAGGAG TTAGAGCATCATCAAGATGAAGGCACTCATTCTT ACGTTTGCATTTTCAGGAAAAGGAG TTAGAGCATCATCAAGATGAAGGCACTCATTCTT ACGTTTGCATTTTCAGGAAAAGGAGCTTAGAGCATCATCAAGATGAAGGCACTCATTCTT

$$
\begin{array}{lllll}
3430 & 3440 & 3450 & 3460 & 3470
\end{array}
$$

$\ldots|\ldots| \ldots|\ldots| \ldots|\ldots| \ldots|\ldots| \ldots|\ldots| \ldots|\ldots| \ldots|\ldots|$ GTTGGAGGCTTCGGCACTCGCTTGAGACCATTGACTCTCAGTTTCCCAAAGCCССTTGTT GTTGGAGGCTTCGGCACTCGCTTGAGACCATTGACTCTCAGTTTCTCAAAGCCCCTTGTT GTTGGAGGCTTCGGCACTCGCTTGAGACCATTGACTCTCAGTTTCCCAAAGCCCCTTGTT GTTGGAGGCTTCGGCACTCGCTTGAGACCATTGACTCTCAGTTTCCCAAAGCCCCTTGTT
3490
3500
3510
3520
3530
3540

$\ldots|\ldots| \ldots|\ldots| \ldots|\ldots| \ldots|\ldots| \ldots|\ldots| \ldots|\ldots| \ldots|\ldots|$ GATTTTGCTAATAAACCCATGATCCTTCATCAGGTAATCTATCTTAAATTTGCCGCTTTA GATTTTGCTAATAAACCCATGATCCTTCATCAGGTAATCTATCTTAAATTTGCCGCTTTA GATTTTGCTAATAAACCCATGATCCTTCATCAGGTAATCTATCTTAAATTTGCCGCTTTA GATTTTGCTAATAAACCCATGATCCTTCATCAGGTAATCTATCTTAAATTTGCCGCTTTA 
Col-0 VTC1 TAIR gDNA

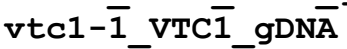
svt2 VTTC1 gDNA

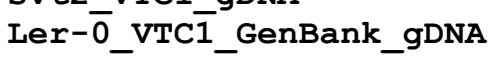

Col-0_VTC1_TAIR_gDNA

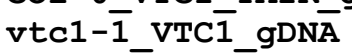
svt2_VT̄C1_gDNA

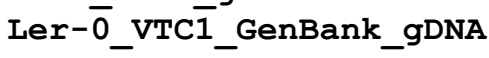

Col-0_VTC1_TAIR_gDNA

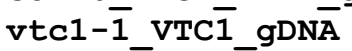
svt2_VTTC1_gDNA

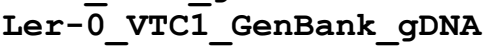

Col-0_VTC1 TAIR_gDNA vtc1- $\overline{1}$ VTC $\overline{1}$ gDNA svt2 VTC1 gDNA

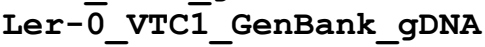

Col-0_VTC1_TAIR_gDNA

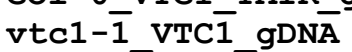
svt2_VTC1_gDNA

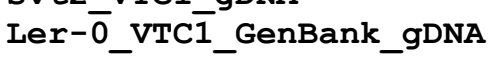

Col-0_VTC1_TAIR_gDNA

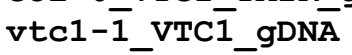
svt2_vT̄C1_gDNA

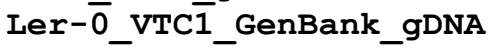

Col-0_VTC1_TAIR_gDNA

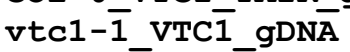
svt2_VTC1_gDNA

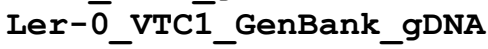

Col-0_VTC1_TAIR_gDNA

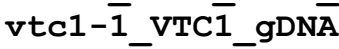
svt2 VTC1 gDNA

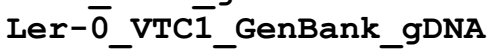

Col-0_VTC1_TAIR_gDNA

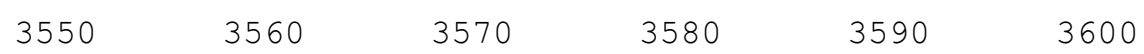
$\ldots|\ldots| \ldots|\ldots| \ldots|\ldots| \ldots|\ldots| \ldots|\ldots| \ldots|\ldots| \ldots|\ldots|$ GTCTGCCAGTTCTTACCTATGCCTATGTTTGAACCGAGGCATGTTTTCTTGTAGATAGAG GTCTGCCAGTTCTTACCTATGCCTATGTTTGAACCGAGGCATGTTTTCTTGTAGATAGAG GTCTGCCAGTTCTTACCTATGCCTATGTTTGAACCGAGGCATGTTTTCTTGTAGATAGAG GTCTGCCAGTTCTTACCTATGCCTATGTTTGAACCGAGGCATGTTTTCTTGTAGATAGAG

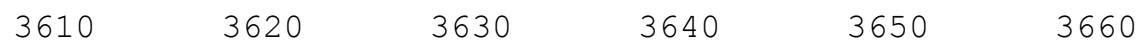

$\ldots|\ldots| \ldots|\ldots| \ldots|\ldots| \ldots|\ldots| \ldots|\ldots| \ldots|\ldots| \ldots|\ldots| \ldots \mid$ GCTCTTAAGGCAGTTGGAGTTGATGAAGTGGTTTTGGCCATCAATTATCAGCCAGAGGTA GCTCTTAAGGCAGTTGGAGTTGATGAAGTGGTTTTGGCCATCAATTATCAGCCAGAGGTA GCTCTTAAGGCAGTTGGAGTTGATGAAGTGGTTTTGGCCATCAATTATCAGCCAGAGGTA GСTCTTAAGGCAGTTGGAGTTGATGAAGTGGTTTTGGCCATCAATTATCAGCCAGAGGTA

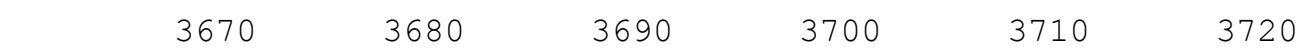

$\ldots|\ldots| \ldots|\ldots| \ldots|\ldots| \ldots|\ldots| \ldots|\ldots| \ldots|\ldots| \ldots|\ldots| \ldots \mid$ AGATACTAATCTCTCTTAACTTTTTTTTTCAGCTATTTTCTGTTTACATATGTTTGTA AGATACTAАTСTСTСTTAАСTTTTTTTTTGCAGCTATTTTCTGTTTACATATGTTTGTA AGATACTAАTСTСTСTTAАСTTTTTTTTGCAGCTATTTTCTTTTACATATGTTTGTA AGATACTAАTСTСTСTTAАСTTTTTTTTTGCAGCTATTTTCTGTTTACATATGTTTGTA

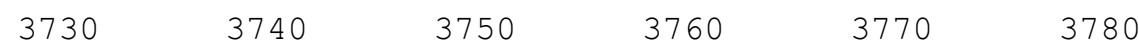

$\ldots . \ldots|\ldots| \ldots|\ldots| \ldots|\ldots| \ldots|\ldots| \ldots|\ldots| \ldots|\ldots| \ldots|\ldots|$ TTTACCATTTGCTCTGTTTCGACAGGTGATGCTGAACTTCTTGAAGGACTTTGAGACCAA TTTACCATTTGCTCTGTTTCGACAGGTGATGCTGAACTTCTTGAAGGACTTTGAGACCAA TTTACCATTTGCTCTGTTTCGACAGGTGATGCTGAACTTCTTGAAGGACTTTGAAACCAA TTTACCATTTGCTCTGTTTCGACAGGTGATGCTGAACTTCTTGAAGGACTTTGAGACCAA

$$
\begin{array}{llllll}
3790 & 3800 & 3810 & 3820 & 3830 & 3840
\end{array}
$$

$\ldots|\ldots| \ldots|\ldots| \ldots|\ldots| \ldots|\ldots| \ldots|\ldots| \ldots|\ldots| \ldots|\ldots| \ldots \mid$ GCTGGAAATCAAAATCACTTGCTCACAAGAGACCGAGCCACTAGGTACCGCTGGTCCTCT GCTGGAAATCAAAATCACTTGCTCACAAGAGACCGAGCCACTAGGTACCGCTGGTCCTCT GCTGGAAATCAAAATCACTTGCTCACAAAAAACCGAGCCACTAGGTACCGCTGGTCCTCT GCTGGAAATCAAAATCACTTGCTCACAAGAGACCGAGCCACTAGGTACCGCTGGTCCTCT

\section{$\Lambda$}

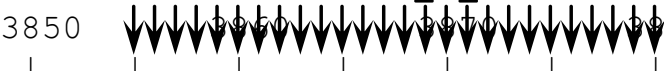
$\ldots|\ldots| \ldots \mid$ GGCTCTAGCGAGAG 3890 3900 GGCTCTAGCGAGAG ACAAATTGCTTGATGGATCT

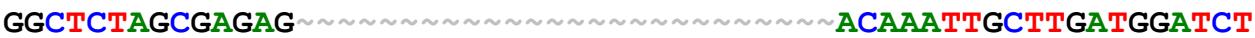
GGCTCTAGCGAGAGGTTGGCGTAATCATGGTCATAGCTAGACAAATTGCTTGATGGATCT
3910
3920
3930
3940
3950

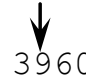

$\ldots \ldots|\ldots| \ldots|\ldots| \ldots|\ldots| \ldots|\ldots| \ldots|\ldots| \ldots|\ldots| \ldots|\ldots| \ldots \mid$ GGAGAGCCСTTCTTTGTTCTTAACAGTGATGTGATTAGTGAGTACCCTCTTAAAGAAATG GGAGAGCCСTTCTTTGTTCTTAACAGTGATGTGATTAGTGAGTACCСTCTTAAAGAAATG GGAAAGCССTTCTTTGTTCTTAACAGTGATGTGATTAGTGAGTACССTCTTAAAGAAATG GGAGAGCCСTTCTTTGTTCTTAACAGTGATGTGATTAGTGAGTACСCTCTTAAAGAAATC

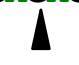

$$
\begin{array}{lllll}
3970 & 3980 & 3990 & 4000 & 4010
\end{array} \quad 4020
$$

$\ldots|\ldots| \ldots|\ldots| \ldots|\ldots| \ldots|\ldots| \ldots|\ldots| \ldots|\ldots| \ldots|\ldots| \ldots \mid$ СTTGAGTTTCACAAATCTCACGGTGGGGAAGCCTCCATAATGGTAACAAAGGTGAGATTA СTTGAGTTTCACAAATCTCACGGTGGGGAAGCCTCCATAATGGTAACAAAGGTGAGATTA CTTGAGTTTCACAAATCTCACGGTGGGGAAGCCTCCATAATGGTAACAAAGGTGAGATTA CTTGAGTTTCACAAATCTCACGGTGGGGAAGCCTCCATAATGGTAACAAAGGTG GATTA
4030
4040
4050
4060
4070
4080

$\ldots|\ldots| \ldots|\ldots| \ldots|\ldots| \ldots|\ldots| \ldots|\ldots| \ldots|\ldots| \ldots|\ldots| \ldots|\ldots|$ TCGAAACATAATACTCTCCAGTTACGAGATAAGTACGTTATTCATCTAATGTGGACTTGC 
vtc1-1_VTC1_gDNA svt2 vT $\mathrm{T} 1$ g $\overline{\mathrm{DNA}}$

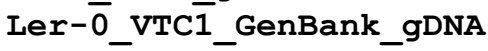

Col-0_VTC1_TAIR_gDNA

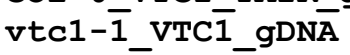
svt2 VT̄C1_gDNA

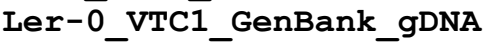

Col-0 VTC1 TAIR gDNA

vtc1- $\overline{1}$ VTC $\overline{1}$ gDNA

svt2_VTC1_gDNA

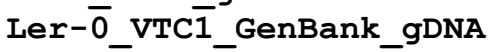

Col-0_VTC1_TAIR_gDNA

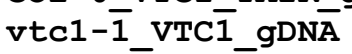

svt2_vTC1_gDNA

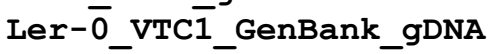

Col-0_VTC1_TAIR_gDNA

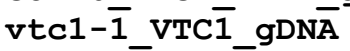

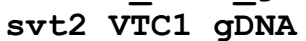

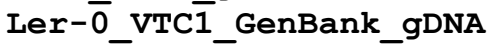

Col-0_VTC1_TAIR gDNA

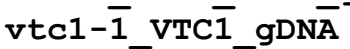

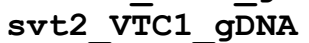

Ler-ōVTC $\overline{1}$ _GenBank_gDNA

Col-0_VTC1_TAIR_gDNA

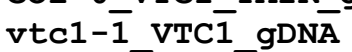

svt2 VTC1 gDNA

Ler-0_VTC $\overline{1}$ _GenBank_gDNA

Col-0_VTC1_TAIR_gDNA

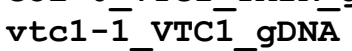

svt2_VT̄C1_gDNA

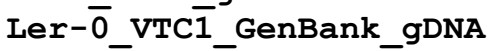

Col-0 VTC1 TAIR gDNA

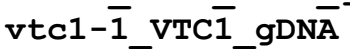

svt2_vT̄C1_gDNA

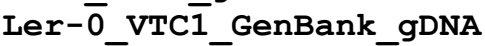

TCGAAACATAATACTCTCCAGTTACGAGATAAGTACGTTATTCATCTAATGTGGACTTGC TCGAAACATAATACTCTCCAGTTACGAGATAAGTACGTTATTCATCTAATGTGGACTTGC TCGAAACATAATACTCTCCAGTTACGAGATAAGTACGTTATTCATCTAATCTGGACTTGC
4090
4100
4110
4120
4130
4140

$\ldots \ldots|\ldots| \ldots|\ldots| \ldots|\ldots| \ldots|\ldots| \ldots|\ldots| \ldots|\ldots| \ldots|\ldots|$ ATGTATTGGTTATATAGGTGGATGAACCGTCGAAATATGGAGTGGTTGTTATGGAAGAAA ATGTATTGGTTATATAGGTGGATGAACCGTCGAAATATGGAGTGGTTGTTATGGAAGAAA ATGTATTGGTTATATAGGTGGATGAACCGTCGAAATATGGAGTGGTTGTTATGGAAGAAA ATGTATTGGTTATATAGGTGGATGAACCGTCGAAATATGGAGTGGTTGTTATGGAAGAAA
4150
4160
4170
4180
4190
4200

$\ldots|\ldots| \ldots|\ldots| \ldots|\ldots| \ldots|\ldots| \ldots|\ldots| \ldots|\ldots| \ldots|\ldots| \ldots \mid$ GCACTGGAAGAGTGGAGAAGTTTGTGGAAAAGCCAAAACTGTATGTAGGTAACAAGATCA GCACTGGAAGAGTGGAGAAGTTTGTGGAAAAGCCAAAACTGTATGTAGGTAACAAGATCA GCACTGGAAGAGTGGAGAAGTTTGTGGAAAAGCCAAAACTGTATGTAGGTAACAAGATCA GCACTGGAAGAGTGGAGAAGTTTGTGGAAAAGCCAAAACTGTATGTAGGTAACAAGATCA
4210
4220
4230
4240
4250
4260

$\ldots|\ldots| \ldots|\ldots| \ldots|\ldots| \ldots|\ldots| \ldots|\ldots| \ldots|\ldots| \ldots|\ldots| \ldots \mid$ ACGCTGGGATTTATCTTCTGAACCCATCTGTTCTTGATAAGATTGAGCTAAGACCGACTT ACGCTGGGATTTATCTTCTGAACCCATCTGTTCTTGATAAGATTGAGCTAAGACCGACTT ACGCTGGGATTTATCTTCTGAACCCATCTGTTCTTGATAAGATTGAGCTAAGACCGACTT ACGCTGGGATTTATCTTCTGAACCСАTCTGTTCTTGATAAGATTGAGCTAAGACCGACTT

$\ldots|\ldots| \ldots|\ldots| \ldots|\ldots| \ldots|\ldots| \ldots|\ldots| \ldots|\ldots| \ldots|\ldots| \ldots|\ldots|$ CAATCGAAAAAGAGACTTTCCCTAAGATTGCAGCAGCGCAAGGGCTCTATGCTATGGTGC САATCGAAAAAGAGACTTTCССTAAGATTGCAGCAGCGCAAGGGCTCTATGCTATGGTGC CAATCGAAAAAGAGACTTTCССTAAGATTGCAGCAGCGCAAGGGCTСTATGCTATGGTGC CAATCGAAAAAGAGACTTTCCCTAAGATTGCAGCAGCGCAAGGGCACTATGCTATGGTGC

$$
4330 \quad 4340 \quad 4350 \quad 4360 \quad 4370 \quad 4380
$$

$\ldots|\ldots| \ldots|\ldots| \ldots|\ldots| \ldots|\ldots| \ldots|\ldots| \ldots|\ldots| \ldots|\ldots| \ldots \mid$ TACCAGGGTTTTGGATGGACATTGGGCAACCCCGTGACTACATAACGGGTTTGAGACTCT TACCAGGGTTTTGGATGGACATTGGGCAACCCCGTGACTACATAACGGGTTTGAGACTCT TACCAGGGTTTTGGATGGACATTGGGCAACCCCGTGACTACATAACGGGTTTGAGACTCT TACCAGGGTTTTGGATGGACATTGGGCAACCCCGTGACTACATAACGGGTTTGAGACTCT
4390
4400
4410
4420
4430
4440

$\ldots|\ldots| \ldots|\ldots| \ldots|\ldots| \ldots|\ldots| \ldots|\ldots| \ldots|\ldots| \ldots|\ldots| \ldots|\ldots|$ ACTTAGACTCССTTAGGAAGAAATCTCCTGCCAAATTAACCAGTGGGCCACACATAGTTG ACTTAGACTСССTAGGAAGAAATCTCСTGCCAAATTAACCAGTGGGCCACACATAGTTG AСTTAGACTСССTAAGAAGAAATCTCСTGCCAAATTAACCAGTGGGCCACACATAGTTG ACTTAGACTCССTTAGGAAGAAATСTCСTGCCAAАTTAACCAGTGGGCCACACATAGTTG
4450
4460
4470
4480
4490
4500

$\ldots \ldots|\ldots| \ldots|\ldots| \ldots|\ldots| \ldots|\ldots| \ldots|\ldots| \ldots|\ldots| \ldots|\ldots| \ldots \mid$ GGAATGTTCTTGTTGACGAAACCGCTACAATTGGGGAAGGATGTTTGATTGGACCAGACG GGAATGTTCTTGTTGACGAAACCGCTACAATTGGGGAAGGATGTTTGATTGGACCAGACG GGAATGTTCTTGTTGACGAAACCGCTACAATTGGGGAAGGATGTTTGATTGGACCAGACG GGAATGTTCTTGTTGACGAAACCGCTACAATTGGGGAAGGATGTTTGATTGGACCAGACG
4510
4520
4530
4540
4550
4560

$\ldots|\ldots| \ldots|\ldots| \ldots|\ldots| \ldots|\ldots| \ldots|\ldots| \ldots|\ldots| \ldots|\ldots| \ldots \mid$ TTGCCATTGGTCCAGGCTGCATTGTTGAGTCAGGAGTCAGACTCTCCCGATGCACGGTCA TTGCCATTGGTCCAGGCTGCATTGTTGAGTCAGGAGTCAGACTCTCCCGATGCACGGTCA TTGCCATTGGTCCAGGCTGCATTGTTGAGTCAGGAGTCAGACTCTCCCGATGCACGGTCA TTGCCATTGGTCCAGGCTGCATTGTTGAGTCAGGAGTCAGACTCTCCCGATGCACGGTCA 
Col-0_VTC1_TAIR_gDNA vtc1- $\overline{1}$ VTC $\overline{1}$ gDNA svt2_VTC1_gDNA Ler-̄o_VTC1̄_GenBank_gDNA

Col-0_VTC1_TAIR_gDNA vtc $1-\overline{1} \_$VTC $\overline{1} \_g D N \bar{A}$ svt2_VTC1_gDNA

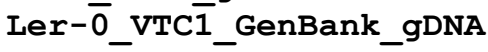

Col-0 VTC1_TAIR_gDNA vtc1-1 1 VTC $\overline{1}$ gDNA svt2 VTC1 gDNA Ler-0_VTC1'_GenBank_gDNA

Col-0_VTC1_TAIR_gDNA

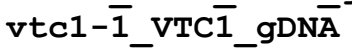
svt2_vTC1_gDNA

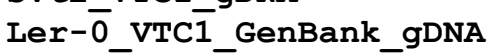

Col-0_VTC1_TAIR_gDNA vtc1-1̄_VTC $\overline{1} \_g D N \bar{A}$ svt2 vTC1 gDNA

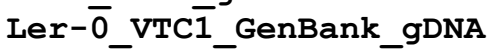

Col-0_VTC1_TAIR_gDNA vtc $1-\overline{1}$ VTC $\overline{1}$ gDN $\bar{A}$ svt2 VTC1 gDNA Ler- $\overline{0}$ _VTC $\overline{1}$ _GenBank_gDNA

Col-0_VTC1_TAIR_gDNA vtc1-1﹎VTC $\overline{1}$ _gDNA svt2_vTC1_gDNA Ler-0_VTC1̄_GenBank_gDNA

Col-0_VTC1_TAIR_gDNA vtc1-1̄_VTC $\overline{1}$ gDN $\bar{A}$ svt2_VTC1_gDNA

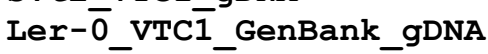

$4570 \quad 4580 \quad 4590 \quad 4600 \quad 4610 \quad 4620$ $\ldots \ldots|\ldots| \ldots|\ldots| \ldots|\ldots| \ldots|\ldots| \ldots|\ldots| \ldots|\ldots| \ldots|\ldots|$ TGCGTGGAGTCCGCATCAAGAAGCATGCGTGTATCTCGAGCAGTATCATCGGGTGGCACT TGCGTGGAGTCCGCATCAAGAAGCATGCGTGTATCTCGAGCAGTATCATCGGGTGGCACT TGCGTGGAGTCCGCATCAAGAAGCATGCGTGTATCTCGAGCAGTATCATCGGGTGGCACT TGCGTGGAGTCCGCATCAAGAAGCATGCGTGTATCTCGAGCAGTATCATCGGGTGGCACT

$$
\begin{array}{lllll}
4630 & 4640 & 4650 & 4660 & 4670
\end{array} 680
$$

$\ldots|\ldots| \ldots|\ldots| \ldots|\ldots| \ldots|\ldots| \ldots|\ldots| \ldots|\ldots| \ldots|\ldots| \ldots \mid$ CAACGGTTGGTCAATGGGCCAGGATCGAGAACATGACGATCCTCGGTGAGGATGTTCATG CAACGGTTGGTCAATGGGCCAGGATCGAGAACATGACGATCCTCGGTGAGGATGTTCATG CAACGGTTGGTCAATGGGCCAGGATCGAGAACATGACGATCCTCGGTGAGGATGTTCATG CAACGGTTGGTCAATGGGCCAGGATCGAGAACATGACGATCCTCGGTGAGGATGTTCATG
4690
4700
4710
4720
4730
4740

$\ldots|\ldots| \ldots|\ldots| \ldots|\ldots| \ldots|\ldots| \ldots|\ldots| \ldots|\ldots| \ldots|\ldots| \ldots \mid$ TGAGCGATGAGATCTATAGCAATGGAGGAGTTGTTTTGCCACACAAGGAGATCAAATCAA TGAGCGATGAGATCTATAGCAATGGAGGAGTTGTTTTGCCACACAAGGAGATCAAATCAA TGAGCGATGAGATCTATAGCAATGGAGGAGTTGTTTTGCCACACAAGGAGATCAAATCAA TGAGCGATGAGATCTATAGCAATGGAGGAGTTGTTTTGCCACACAAGGAGATCAAATCAA
4750
4760
4770
$4780 \downarrow \downarrow 4790$
4800

$\ldots|\ldots| \ldots|\ldots| \ldots|\ldots| \ldots|\ldots| \ldots|\ldots| \ldots|\ldots| \ldots|\ldots| \ldots \mid$ ACATCTTGAAGCCAGAGATAGTGATGTGAAAATGAGATATTATA TGTGCAACTTTTTT ACATCTTGAAGCCAGAGATAGTGATGTGAAAATGAGATATTATA TGTGCAACTTTTTT ACATCTTGAAGCCAGAGATAGTGATGTGAAAATGAGATATTATA TGTGCAACTTTTTT ACATCTTGAAGCCAGAGATAGTGATGTGAAAATGAGATATTATATATGTGCAACTTTTTT
4810
4820
4830
4840
4850
4860

$\ldots|\ldots| \ldots|\ldots| \ldots|\ldots| \ldots|\ldots| \ldots|\ldots| \ldots|\ldots| \ldots|\ldots| \ldots|\ldots|$ TTTTTTTTT GTGTCCTTTCTTCAACTTTGAAATCGCTTTCGTAATTCTTAATGGCTTT TTTTTTTTT GTGTCCTTTCTTCAACTTTGAAATCGCTTTCGTAATTCTTAATGGCTTT TTTтTтTтT

TTTTTTTTTTGTGTCCTTTCTTCAACTTTGAAATCGCTTTCGTAATTCTTAATGGCTTT

$$
\begin{aligned}
& \begin{array}{lllll}
4870 & 4880 \quad 4890 \quad 4900 & 4910 & 4920
\end{array} \\
& \ldots|\ldots| \ldots|\ldots| \ldots|\ldots| \ldots|\ldots| \ldots|\ldots| \ldots|\ldots| \ldots|\ldots|
\end{aligned}
$$

TGAАTAАTСАTСААTСАAАACGCTGTATATCTTGTTAGGGTCGTTTGCTGTTTTGTCTCT

$$
\begin{array}{lllll}
4930 & 4940 & 4950 & 4960 & 4970
\end{array} 980
$$$$
\ldots|\ldots| \ldots|\ldots| \ldots|\ldots| \ldots|\ldots| \ldots|\ldots| \ldots|\ldots| \ldots|\ldots| \ldots|\ldots|
$$
TTTTTTGTTTTGAATTTATAAAAAAATTATTCTCATTTTATGTGAGATACTTTTGAAT TTTTTTGTTTTGTAАTTTATAAAАAАATTATTCTCATTTTATGTGAGATACTTTTGAAT

TTTTTTGTTTTGTAАTTTATAАAАAАAАTTATTCTСАTTTATGTGAGATACTTTTGAAT

$$
4990 \quad 5000 \quad 5010 \quad 5020 \quad 5030 \quad 5040
$$

$\ldots|\ldots| \ldots|\ldots| \ldots|\ldots| \ldots|\ldots| \ldots|\ldots| \ldots|\ldots| \ldots|\ldots| \ldots \mid$ АTTCATTAАTTATAAAGCTTTTTTTTTGTAAGTAACATTCAAAАTTCAАTAGTAGTCAT ATTCATTAATTATAAAGCTTTTTTTTTGGAAGTAACATTCAAAATTCAATAGTAGTCAT

АTTCATTAАTTATAAAGCTTTTTTTTGTGAAGTAACATTCAAAATTGAATAGTAGTCAT

$\ldots|\ldots| \ldots|\ldots| \ldots|\ldots| \ldots|\ldots| \ldots|\ldots| \ldots|\ldots| \ldots|\ldots| \ldots|\ldots| \ldots \mid$


Col-0_VTC1_TAIR_gDNA

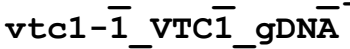
svt2 VTC1 gDNA

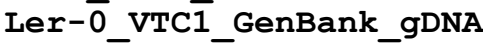

Col-0 VTC1 TAIR gDNA

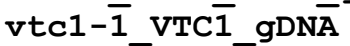
svt2 VTC1 gDNA

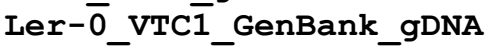

Col-0_VTC1_TAIR_gDNA

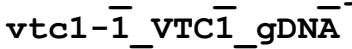

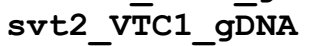

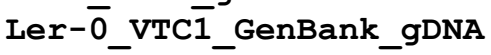

Col-0_VTC1_TAIR_gDNA

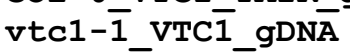
svt2 VT̄C1_gDNA

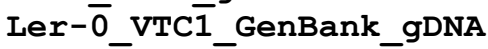

Col-0 VTC1 TAIR gDNA

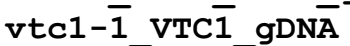

svt2 VTTC1 gD̄NA

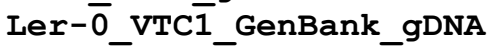

COI-0_VTC1_TAIR_gDNA

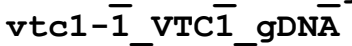

svt2_VTC1_gDNA

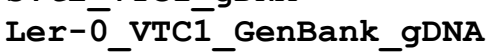

TGTAAAAAAACTTGAAAATAGCATGTATAATGCAGATAAAАTTTTTTAACATGACCATTG TGTAAAAAАACTTGAAAATAGCATGTATAATGCAGATAAАATTTTTTAACATGACCATTG

TATAAAAAAACTTGAAAATAGAATGTATAATGCAGATAAAATTTTTTAACATGACCATTG

$$
\begin{array}{llll}
5110 & 5120 \quad 5130 \quad 5140 \quad 5150 \quad 5160
\end{array}
$$

$\ldots \ldots|\ldots| \ldots|\ldots| \ldots|\ldots| \ldots|\ldots| \ldots|\ldots| \ldots|\ldots| \ldots|\ldots| \ldots|\ldots|$ АTAATCCAAAAAGGTTTTAAAAATTAGAAGCAACAAATATCCATTGGGGTTTCTCCAAAT АТААTCCAАAАAGGTTTTAAAAАTTAGAAGCAACAАATATCCATTGGGGTTTCTCCAАAT

АTAАTCCAAAAAGGTTTTAAAAATTAGAAGCAACAAATATCCATTGGGGTTTCTCCAAAT

$$
\begin{array}{lllll}
5170 & 5180 & 5190 & 5200 & 5210
\end{array} 220
$$

$\ldots|\ldots| \ldots|\ldots| \ldots|\ldots| \ldots|\ldots| \ldots|\ldots| \ldots|\ldots| \ldots|\ldots| \ldots \mid$ CCAAGGCATAGAGGAATATTCGTTAGCGTGGAAAGACTAAAATACCCTTAACTTCCCTCC CCAAGGCATAGAGGAATATTCGTTAGCGTGGAAAGACTAAAATACССTTAАСTTCССTCC

CCAAGGCATAGAGGAATATTCGTTAGCGTGGAAAGACTAAAАTACССTTAАСTTCССTCC

$5230 \quad 5240 \quad 5250 \quad 5260 \quad 5270 \quad 5280$

$\ldots|\ldots| \ldots|\ldots| \ldots|\ldots| \ldots|\ldots| \ldots|\ldots| \ldots|\ldots| \ldots|\ldots| \ldots|\ldots|$

ACATAATGTATACAGTGACCCGATCTGAATTC

ACATAATGTATACAGTGACCCGATCTGAATTC

ACATAATGTATACAGTGACCCGATCTGAATCGGAGCTAAAAACGGTTTCAATCGAАTTA

$\ldots|\ldots| \ldots|\ldots| \ldots|\ldots| \ldots|\ldots| \ldots|\ldots| \ldots|\ldots| \ldots|\ldots| \ldots|\ldots| \ldots|\ldots|$

AAGTCAATGGCGTCACGTTTATGTCTTCTCCTTCTCGTTGCGTGTATCGCCGGAGCATTT

$$
\begin{aligned}
& \begin{array}{lllll}
5350 & 5360 & 5370 & 5380 & 5390
\end{array} \\
& \ldots|\ldots| \ldots|\ldots| \ldots|\ldots| \ldots|\ldots| \ldots|\ldots| \ldots|\ldots| \ldots|\ldots| \ldots|\ldots| \ldots \mid
\end{aligned}
$$

GCCGGAGACGTCATCGAACTCAATCGATCTCAGAGGGAGTTCGATTATTTCGCTСTATCT 
Figure 2.6 Sequence alignment of the VTC1 gene sequence of the Col-0 TAIR database, the vtc1-1, svt2 mutants, and the Ler-0 GenBank database.

Horizontal arrows denote $5^{\prime}$ respectively 3' flanking regions of the sequence insertion, which is highlighted in grey, in the VTC1 promoter region (between base pairs 1902 and 2273). Upright arrows indicate sequences shared between svt2 and Ler. Arrows pointing down denote sequences shared between svt2 and Col. Arrow heads point to sequences unique to svt2. Highlighted in yellow are the start and stop codons, respectively. Highlighted in green is the vtc1-1 mutation. 
Table 2.3 Summary of svt2 revertants data.

The table summarizes the number of plants screened in each of three svt2 generations $\left(M_{1}, M_{2}\right.$ and $\left.M_{3}\right)$, screens of revertant progeny from Col-like revertants ( $A 8, G 7, K 1)$, and the revertant progeny of a Lerlike line ( $\mathrm{K} 1 \mathrm{Col} \mathrm{R}$ svt2 R). The percent reversion is shown in the last column. Although the number of progeny plants tested is relatively large, some lines did not give rise to revertant progeny. $R$ denotes revertant. * indicates mutant plants that were also analyzed genotypically (see Table 2 ).

\begin{tabular}{|c|c|c|c|}
\hline Generation & $\begin{array}{l}\text { Total \# of } \\
\text { plants }\end{array}$ & $\begin{array}{l}\text { \# of phenotypic } \\
\text { revertants }\end{array}$ & $\begin{array}{l}\% \\
\text { reversion }\end{array}$ \\
\hline svt2 $\mathrm{M}_{1}$ (experiment 1 ) & 63 & 0 & 0 \\
\hline svt2 $\mathrm{M}_{1}$ (experiment 2) & 96 & 1 (Col phenotype) & 1.04 \\
\hline $\begin{array}{l}\text { svt2 } \mathrm{M}_{2} \text { (experiment } 1 \text { ), } 3 \text { of } 7 \text { revertants } \\
\text { tested further: }\end{array}$ & 78 & 7 (Col phenotype) & 8.97 \\
\hline$\hookrightarrow$ svt2 A8 Col R M 3 & 64 & 0 & 0 \\
\hline$\longrightarrow$ svt2 G7 Col R M 3 & 64 & 0 & 0 \\
\hline$\longrightarrow$ svt2 K1 Col R M ${ }^{*}$ & 63 & 1 (svt2 phenotype) & 1.58 \\
\hline$\longrightarrow$ svt2 K1 Col R svt2 $\mathrm{R} \mathrm{M}_{4}^{*}$ & 96 & 0 & \\
\hline $\begin{array}{l}\text { svt2 } \mathrm{M}_{2} \text { (experiment 2), } 2 \text { of } 5 \text { revertants } \\
\text { tested further: }\end{array}$ & 62 & 5 (Col phenotype) & 8.06 \\
\hline$\longrightarrow$ svt2 Col R1 M ${ }_{3}^{*}$ & 88 & 20 (svt2 phenotype) & 22.73 \\
\hline$\longrightarrow$ svt2 Col R4 M ${ }^{*}$ & 96 & 0 & \\
\hline svt2 $\mathrm{M}_{2}$ (experiment 3) & 96 & 10 (Col phenotype) & 10.42 \\
\hline svt2 $\mathrm{M}_{3}$ (experiment 1) & 96 & 0 & 0 \\
\hline
\end{tabular}


This represents a larger reversion percentage than in the K1 double revertant $(22.7 \%$ vs. $1.6 \%)$. This may be explained by the genotypic make-up of the Col-like reverted parents and will be presented in the next section. Fig. 2.7) illustrates the phenotypic appearance of three examples of svt2 $\rightarrow$ Col single revertants (Col R1, Col R2, K1 Col R) and an svt2 $\rightarrow$ Col $\rightarrow$ svt2 double revertant (K1 Col $\mathrm{R}$ svt2 R).

Next we tested whether a Col-like revertant phenotype correlated with a Col-like genotype. Likewise, we would expect that a svt $\rightarrow$ Col $\rightarrow$ svt2 double revertant phenotype corresponds with svt2-like genomic markers. To check this we isolated genomic DNA from Col-0 and Ler-0 wild types, svt2, vtc1-1, and revertant mutants, and PCR-amplified the five randomly selected InDel polymorphisms plus the InDel polymorphism in the VTC1 promoter. In all cases but the svt2 $\mathrm{M}_{2}$ Col R1 revertant, the svt2-like revertant plants (labeled svt2 $\mathrm{M}_{2}$ Col revertants 1 through 5) produced PCR products that were of the same electrophoretic mobility as the PCR products generated using Col-0 wild-type genomic DNA. In contrast, svt2 $\mathrm{M}_{1}$ plants and svt2 $\mathrm{M}_{2}$ plants that displayed a svt2 phenotype, gave rise to PCR products that were of the same electrophoretic mobility as those of the Ler wild type (Table 2.4, Fig. 2.8). In addition, the double revertant plant $\mathrm{K} 1$ (labeled svt2 $\mathrm{M}_{2} \mathrm{~K} 1 \mathrm{Col} R$ ) was genotyped in both its $\mathrm{M}_{2}$ and $\mathrm{M}_{3}$ generations. The K1 plant produced InDel PCR products similar to those of the Col-0 wild type in the $M_{2}$ generation. However, the $M_{3}$ generation that displayed svt2-like morphology produced PCR products that were comparable to the InDel PCR products generated using Ler genomic DNA (Table 2.4). The svt2 $\mathrm{M}_{2}$ Col R1 (highlighted in red in Table 2.4) is intriguing, because it appears to contain DNA that is similar to both Col and Ler genomic DNA. This suggests the presence of chimeric genome sectors, which may explain the higher percentage of Col-like revertants compared to svt2 $\mathrm{M}_{2} \mathrm{~K} 1 \mathrm{Col} \mathrm{R}$. Note that the PCR results are in line with the sequencing analysis of the revertants. That is, Col-like revertants and svt2-like revertants share sequence similarity with Col-0 and Ler wild-type, respectively (Fig. 2.9).

Taken together, these data suggest (i) transgenerational phenotypic and genotypic instability in svt2, and that (ii) svt2 offspring do not segregate in a Mendelian fashion. In an attempt to obtain first insights toward a mechanism that is causing this genotypic instability, we investigated whether transgenerational epigenetic inheritance could play a role.

\subsubsection{Genome instability in svt2 does not appear to be triggered by a transgenerational epigenetic mechanism}

To investigate whether genome instability is caused by transgenerational epigenetic inheritance in the svt2 mutant, we performed reciprocal crosses between svt2 mutants and Col0 wild-type plants. It is possible that through the EMS mutagenesis of vtc1-1 seeds, genes involved in the regulation of epigenetic alterations were altered, whereby their activity was 
Table 2.4 Summary of PCR-based molecular genotypes in Col-0, vtc1-1, Ler-0, svt2, and revertants.

With the exception of svt2 Col R1 $\mathrm{M}_{2}$, where Col and Ler markers and one heterozygous marker were found (highlighted in red), phenotype matched genotype. That is, a Col-like phenotype correlated with the presence of Col polymorphisms, while a Ler-like phenotype correlated with Ler polymorphisms. C, L, and $\mathrm{H}$ refer to $\mathrm{Col}$, Ler, or heterozygous, respectively. $\mathrm{R}$ denotes revertant.

\begin{tabular}{|c|c|c|c|c|c|c|}
\hline Genotype & $\begin{array}{l}\text { InDel } 1 \\
450919\end{array}$ & $\begin{array}{l}\text { InDel } 2 \\
451470\end{array}$ & $\begin{array}{l}\text { InDel } 3 \\
469762\end{array}$ & $\begin{array}{l}\text { InDel } 4 \\
449053\end{array}$ & $\begin{array}{l}\text { InDel } 5 \\
455100\end{array}$ & $\begin{array}{c}\text { G1F + G2R } \\
\text { VTC1 }\end{array}$ \\
\hline Col-0 WT & $\mathrm{C}$ & C & C & C & $\mathrm{C}$ & C \\
\hline vtc1-1 & C & C & C & C & C & C \\
\hline Ler-0 WT & $\mathrm{L}$ & $\mathrm{L}$ & $\mathrm{L}$ & $\mathrm{L}$ & $\mathrm{L}$ & $\mathrm{L}$ \\
\hline svt2 $\mathrm{M}_{1}$ & $\mathrm{~L}$ & L & L & L & $L$ & $L$ \\
\hline svt2 $\mathrm{M}_{2}$ & $\mathrm{~L}$ & $L$ & $\mathrm{~L}$ & $L$ & $L$ & $L$ \\
\hline svt2 Col R1 $\mathrm{M}_{2}$ & C & $\mathrm{L}$ & $\mathrm{C}$ & $\mathrm{H}$ & $\mathrm{C}$ & $\mathrm{C}$ \\
\hline svt2 Col R2 $\mathrm{M}_{2}$ & $\mathrm{C}$ & $\mathrm{C}$ & $\mathrm{C}$ & $\mathrm{C}$ & $\mathrm{C}$ & $\mathrm{C}$ \\
\hline svt2 Col R3 $\mathrm{M}_{2}$ & $\mathrm{C}$ & $\mathrm{C}$ & $\mathrm{C}$ & $\mathrm{C}$ & $\mathrm{C}$ & $\mathrm{C}$ \\
\hline svt2 Col R4 $\mathrm{M}_{2}$ & $\mathrm{C}$ & $\mathrm{C}$ & $\mathrm{C}$ & $\mathrm{C}$ & $\mathrm{C}$ & C \\
\hline svt2 Col R5 $\mathrm{M}_{2}$ & $\mathrm{C}$ & C & C & C & $\mathrm{C}$ & C \\
\hline svt2 K1 Col R M & $\mathrm{C}$ & $\mathrm{C}$ & $\mathrm{C}$ & $\mathrm{C}$ & $\mathrm{C}$ & $\mathrm{C}$ \\
\hline svt2 K1 Col R svt2 R M & $\mathrm{L}$ & L & $\mathrm{L}$ & $L$ & $L$ & $L$ \\
\hline
\end{tabular}



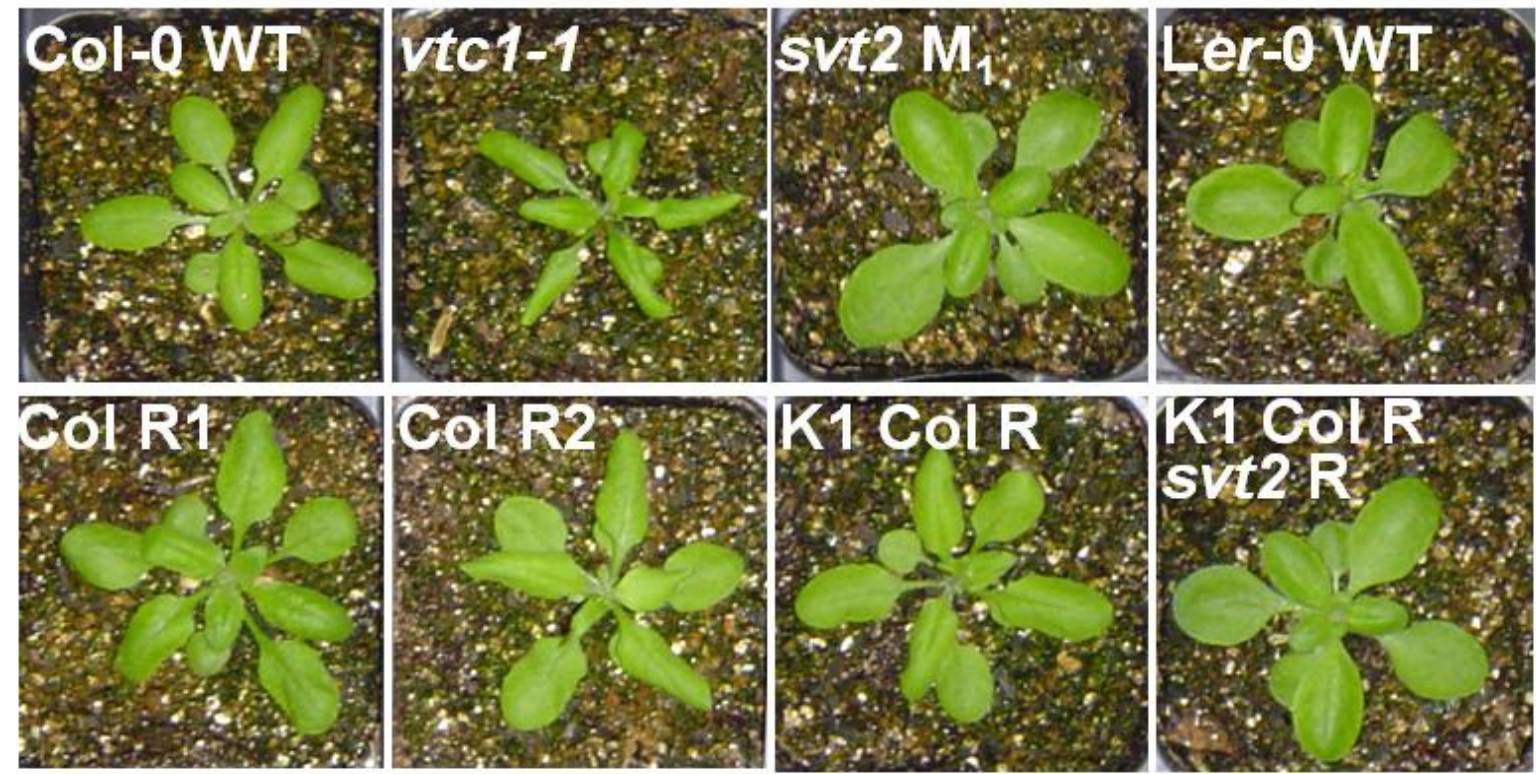

Figure 2.7 Photographs showing the phenotype of svt2 revertants.

Plants were three weeks old when photographs were taken. Top row represents controls, Col-0 wild type, vtc1-1 and svt2 mutants, and Ler-0 wild type. Bottom row represents three Col-like revertants, svt2 Col R1 $\mathrm{M}_{3}$, svt2 Col R2 $\mathrm{M}_{3}$, svt2 $\mathrm{K} 1 \mathrm{Col} \mathrm{R} \mathrm{M}_{3}$, and a double revertant, svt2 $\mathrm{K} 1 \mathrm{Col} \mathrm{R}$ svt2 R $\mathrm{M}_{4}$. R stands for revertant. 


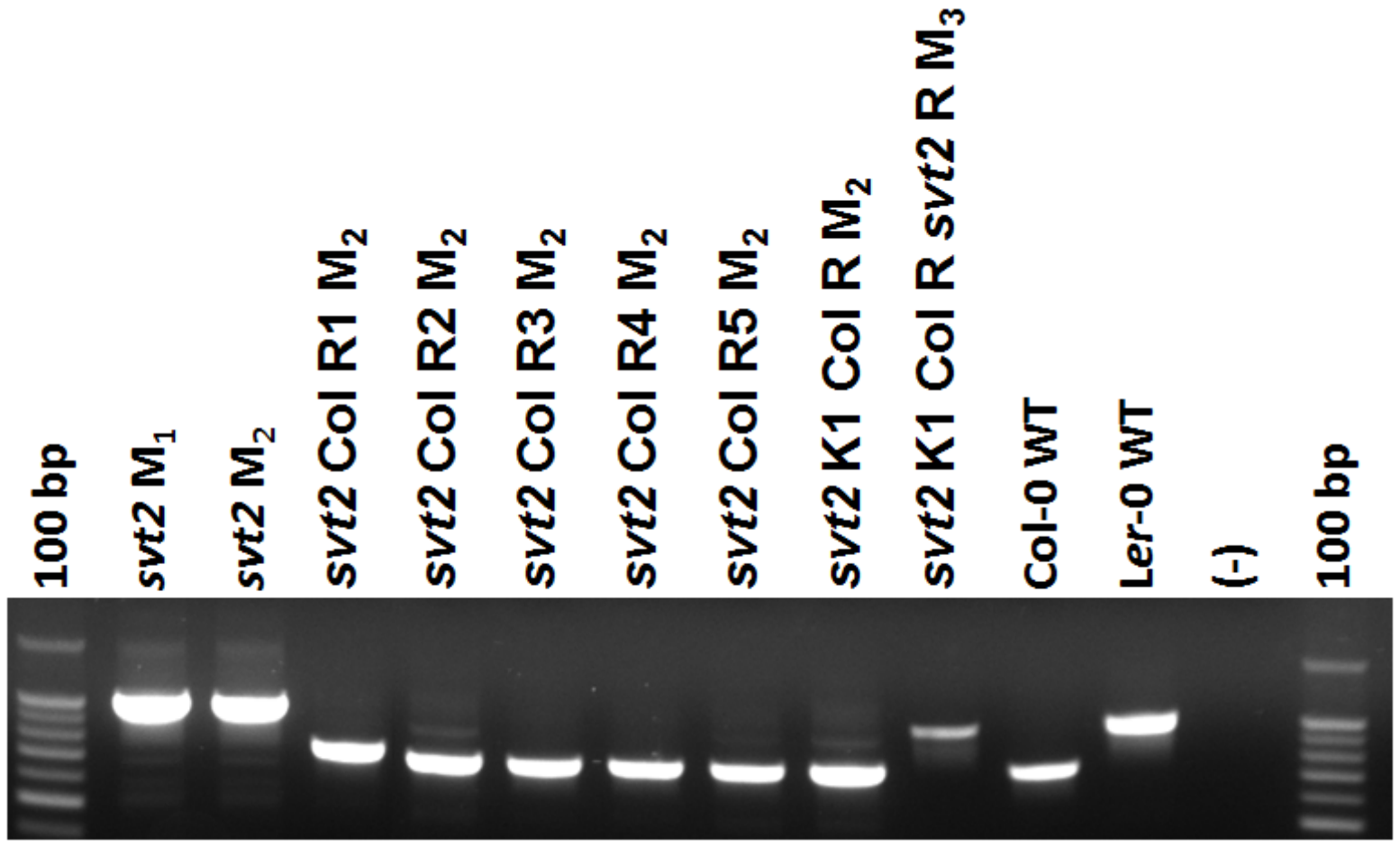

Figure 2.8 Gel imagine showing InDel polymorphisms in svt2, Col-0, Ler-0, and revertants.

PCR amplification of the Col/Ler VTC1 promoter polymorphism in svt2 plants and svt2 revertant (R) plants, amplified with the VTC1 G1F and G2R primers. (-) indicates negative control, no DNA. 
Col-0_VTC1_gDNA_TAIR

Ler-0_VTC1_gDNA_Genbank

svt2 $\overline{\mathrm{K}} 1$ Col $\mathrm{R}$ M3_G1F

svt2 K1 Col $R$ svt2 R M4_G1F

Col-0_VTC1_gDNA_TAIR

Ler-0_VTC1_gDNA_Genbank

svt2 $\bar{K} 1$ Col $R$ M3 G1F

svt2 $\mathrm{K} 1$ Col $R$ svt2 R M4_G1F

Col-0_VTC1_gDNA_TAIR

Ler-0_VTC1_gDNA_Genbank

svt2 $\bar{K} 1$ Col $R$ M3 G1F

svt2 K1 Col $R$ svt2 R M4_G1F

Col-0_VTC1_gDNA TAIR

Ler-0_VTC1_gDNA_Genbank

svt2 $\overline{\mathrm{K}} 1$ Col $\mathrm{R}$ M3 $\mathrm{G} 1 \mathrm{~F}$

svt2 K1 Col $R$ svt2 R M4_G1F

Col-0_VTC1_gDNA_TAIR

Ler-0_VTC1_gDNA_Genbank

svt2 $\overline{\mathrm{K}} 1 \mathrm{Col} R \mathrm{M} \overline{3} \mathrm{G} 1 \mathrm{~F}$

svt2 K1 Col $R$ svt2 R M4_G1F

Col-0_VTC1_gDNA_TAIR

Ler-0_VTC1_gDNA_Genbank

svt2 $\bar{K} 1$ Col $R$ M3_G1F

svt2 K1 Col $R$ svt2 R M4_G1F

Col-0_VTC1_gDNA_TAIR

Ler-0_VTC1_gDNA_Genbank

svt2 $\overline{\mathrm{K}} 1 \mathrm{Co} \overline{\mathrm{l}} \mathrm{R} \overline{3} \mathrm{G} 1 \mathrm{~F}$

svt2 K1 Col $R$ svt2 R M4_G1F
GATTTACTTAСАTTTAАСTAАTTTTAAGGTCTGTTGATCGAАCTCGTTA

$\begin{array}{llll}1810 & 1820 & 1830 & 1840\end{array}$

$\ldots|\ldots| \ldots|\ldots| \ldots|\ldots| \ldots|\ldots| \ldots|\ldots| \ldots|\ldots|$

ССТTGAACAATTAGTAGGACAАCTCAAACCACTAAACСАTTATAСTTTAA

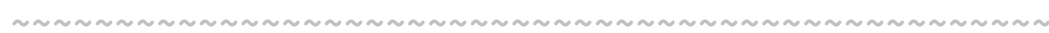

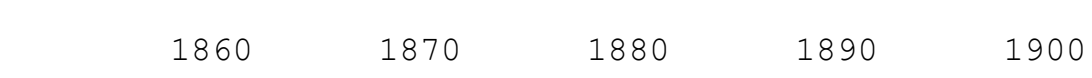

$\ldots|\ldots| \ldots|\ldots| \ldots|\ldots| \ldots|\ldots| \ldots|\ldots| \ldots|\ldots| \ldots \mid$

GGATTTATGTAAAАTTTCAAATATATATAGTTTAGTAGATGCACTTATCA

$\begin{array}{lllll}1910 & 1920 & 1930 & 1940 & 1950\end{array}$

$\ldots|\ldots| \ldots|\ldots| \ldots|\ldots| \ldots|\ldots| \ldots|\ldots| \ldots|\ldots|$

TCACACTCACCAATTGGATGTCAACACCTGGTTCTAGCTTTTTAATTACC
1960
1970
1980
1990
2000

$\ldots|\ldots| \ldots|\ldots| \ldots|\ldots| \ldots|\ldots| \ldots|\ldots| \ldots|\ldots| \ldots \mid$ AAAGTGAAAAAACTGACTTTTTCTAAAAAAAATTCGTTCTAGATGGATGC TCGNATCTAGATGGATGC

\section{西}

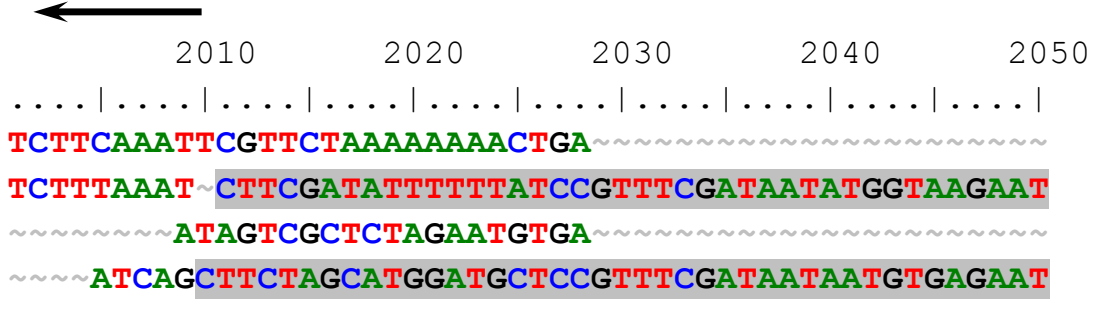

$2060 \quad 2070 \quad 2080 \quad 2090 \quad 2100$

$\ldots|\ldots| \ldots|\ldots| \ldots|\ldots| \ldots|\ldots| \ldots|\ldots| \ldots|\ldots|$

GAATGACGAATCGGTCAAGCTAATCTGTATATTAA CATTGTACTCATCA

GAATGACGAATCGGTCAAGCTAATCTGTATATTAATCATTGTACTCATCA

$\begin{array}{llll}2110 & 2120 & 2130 & 2140\end{array}$


Col-0_VTC1_gDNA_TAIR

Ler-0_VTC1_gDNA_Genbank

svt2 K1 Col R M3 G1F

svt2 K1 Col R svt2 R M4_G1F

Col-0_VTC1_gDNA_TAIR

Ler-0_VTC1_gDNA_Genbank

svt2 K1 Col R M3_G1F

svt2 K1 Col R svt2 R M4_G1F

Col-0_VTC1_gDNA_TAIR

Ler-0_VTC1_gDNA_Genbank

svt2 K1 Col R M3_G1F

svt2 K1 Col R svt2 R M4_G1F

Col-0_VTC1_gDNA_TAIR

Ler-0_VTC1_gDNA_Genbank

svt2 K1 Col R M3_G1F

svt2 K1 Col $R$ svt2 R M4_G1F

Col-0_VTC1_gDNA_TAIR

Ler-0_VTC1_gDNA_Genbank

svt2 K1 Col R M 3 G1F

svt2 K1 Col $R$ svt2 R M4_G1F

Col-0_VTC1_gDNA_TAIR

Ler-0_VTC1_gDNA_Genbank

svt2 K1 Col R M3_G1F

svt2 K1 Col R svt2 R M4_G1F

Col-0_VTC1_gDNA_TAIR

Ler-0_VTC1_gDNA_Genbank

svt2 K1 Col R M3 G1F

svt2 K1 Col R svt2 R M4_G1F

Col-0_VTC1_gDNA_TAIR

Ler-0_VTC1_gDNA_Genbank $\ldots \ldots|\ldots| \ldots|\ldots| \ldots|\ldots| \ldots|\ldots| \ldots|\ldots| \ldots \mid$

ACGTAAAGTCCTATTCGTCTATACATATGTGAACTTATATATGTCTATCA

ACGTAAAGTCCTATTCGTCTATACATATGTGAАCTTATATATGTCTATCA

2160
$\ldots \ldots|\ldots| \ldots|\ldots| \ldots|\ldots| \ldots|\ldots| \ldots|\ldots| \ldots|\ldots| \ldots \mid$

ACTAGTT CACTACCCTATAAAGTTCATCAGAGTTGTCGATCAGCAGTG

ACTAGTTCACACTACCCTATAAAGTTCATCAGAGTTGTCGATCAGCAGTG

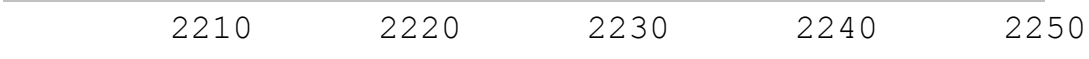

$\ldots|\ldots| \ldots|\ldots| \ldots|\ldots| \ldots|\ldots| \ldots|\ldots| \ldots|\ldots|$

ACCACTACACATTCTTCATACAGCTGAGTTAGGAATGTTAACAAAATAGT

ACCACTACACATTCTTCATACAGCTGAGTTAGGAATGTTAACAAAATAGT

$$
\begin{gathered}
2260 \\
2270 \\
\ldots \ldots|\ldots| \ldots|\ldots| \ldots|\ldots| \ldots|\ldots| \ldots|\ldots| \ldots|\ldots| \ldots \mid \\
\sim \sim \sim \sim \sim \sim \sim \sim \sim \sim
\end{gathered}
$$

TTATGGGAGTATGTTTTATACATAATACCATCCCTTTAAAAACACAGAAT

CATAATACCATCCCTTTAAAA-CACAGAAT

TTATGGGAGTATGTTTTATACATAATACCATCCCTTTAAAAACACAGAAT

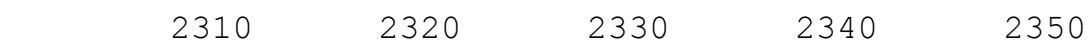

$\ldots|\ldots| \ldots|\ldots| \ldots|\ldots| \ldots|\ldots| \ldots|\ldots| \ldots \mid$

TTTTTTTATCATCTCTGAAACAAATCATTTACAGTAGTAAATGTCAA--C

TTTCTTTATCATCTCCGAAACAAATCATTTACAGTAGTAAATGTAAAAAC TTTTTTTATCATCTCTGAAACAAATCATTTACAGTAGTAAATGTCAA--C

TTTCTTTATCATCTCCGAAACAAATCATTTACAGTAGTAAATGTAAAAAC

$\begin{array}{rrrr}2360 & 2370 \quad 2380 & 2390 & 2400\end{array}$ $\ldots|\ldots| \ldots|\ldots| \ldots|\ldots| \ldots|\ldots| \ldots|\ldots| \ldots|\ldots| \ldots \mid$ ACAACATTAATTCTGTTT-GTTGTTGGCATTTACAATTGCAAAATCATTT ACAACATTAATTCTGTTT-GTTGTTGGCATTTACAATTGCAAAATCATTT ACAACATTAATTTGGTTTTGTTGTTGGCATTTACAATTGCAAAATCATTT ACAACATTAATTCTGTTT-GTTGTTGGCATTTACAATTGCAAAATCATTT

$2410 \quad 2420 \quad 2430 \quad 2440 \quad 2450$

$\ldots|\ldots| \ldots|\ldots| \ldots|\ldots| \ldots|\ldots| \ldots|\ldots| \ldots|\ldots|$

TCTCATTTATTATTCGTATTTATTTTGTCAAGAACССTTGTCTCTAAAAT TСTСАTTTATTATTCGTATTTATTTTGCAAGAАСССTTGTСTСTAАAАT TCTCATTTATTATTCGTATTTATTTTGTCAAGAACССTTGTCTCTAAAАT TCTCATTTATTATTCGTATTTATTTTGCAAGAACCСTTGTCTCTAAAAT

$\begin{array}{llll}2460 & 2470 & 2480 & 2490 \\ \ldots & 2500\end{array}$

$\ldots|\ldots| \ldots|\ldots| \ldots|\ldots| \ldots|\ldots| \ldots|\ldots| \ldots|\ldots|$ АTTCATAGAAAAAGAAAAGAGCCATTAATTAATGGCTTGAAGAAAGA-TT ATTCATAGAAAAA-AAAAGAGCCATTAATTAATGGCTTGAAGAAAGA-TT 
svt2 K1 Col R M3_G1F svt2 $\mathrm{K} 1 \mathrm{Col} R$ svt2 $\mathrm{R}$ M4_G1F

Col-0_VTC1_gDNA_TAIR

Ler-0_VTC1_gDNA_Genbank

svt2 K 1 Col $R$ M 3 G1F

svt2 K1 Col R svt2 R M4_G1F

Col-0_VTC1_gDNA_TAIR

Ler-0_VTC1_gDNA_Genbank

svt2 K1 Co1 R M3_G1F

svt2 K1 Col R svt2 R M4_G1F

Col-0_VTC1_gDNA_TAIR

Ler-0 VTC1 gDNA Genbank

svt2 $\bar{K} 1$ Col $R$ M3 $G 1 F$

svt2 K1 Col $R$ svt2 R M4_G1F

Col-0_VTC1_gDNA_TAIR

Ler-0_VTC1_gDNA_Genbank

svt2 K1 Col R M3_G1F

svt2 K1 Col R svt2 R M4_G1F

Col-0_VTC1_gDNA_TAIR

Ler-0_VTC1_gDNA_Genbank

svt2 K1 Col $R$ M3_G1F

svt2 K1 Col R svt2 R M4_G1F

Col-0_VTC1_gDNA_TAIR

Ler-0_VTC1_gDNA_Genbank

svt2 K1 Col R M3_G1F

svt2 K1 Col R svt2 R M4_G1F
ATTCATAGAAAAAGAAAAGAGCCATTAATTAATGGCTTGAAGAAAGA-TT ATTCATAGAAAAA-AAAAGAGCCATTAATTAATGGCTTGAAGAAAGAATT
GGTGTATAAACCGTCTACCTGACCTTTAAATTTAATTTACTTTCCCCCCA

$\begin{array}{llll}2560 & 2570 & 2580 & 2590\end{array}$

$\ldots|\ldots| \ldots|\ldots| \ldots|\ldots| \ldots|\ldots| \ldots|\ldots| \ldots|\ldots|$

AAAAAAGTCAAC-ATTCAA-CATGTG-AATAAAAA-TCAATATTGG-TTT

AAAAAAGTCAAC-ATTCAA-CATGTG-AATAAAAAATCAATATTGG-TTT AAAAAAGTCAAC-ATTCAA-CATGTG-AATAAAAA-TCAATATTGG-TTT CAAAAAGTCAACCATTCAAACATGGGGAGTAAAAAATCAATATTGGGTTG

$2610 \quad 2620 \quad 2630 \quad 2640 \quad 2650$

$\ldots|\ldots| \ldots|\ldots| \ldots|\ldots| \ldots|\ldots| \ldots|\ldots| \ldots|\ldots|$

CTAAGTAA-GTAAGTACCATATTATTAAATTATTTATTTT-GGTAAATAC

CTAAGTAA-GTAAGTACCATATTATTAAATTATTT-ATTTTGGTAAATAC

CTAAGTAA-GTAAGTACCATATTATTAAATTATTTATTTT-GGTAAATAC

CTAAGTAAAGTAAGTACCATATTATTAAATTATTTTATTTTGGTAAAAGA

$26602670 \quad 2680 \quad 2690 \quad 2700$

$\ldots|\ldots| \ldots|\ldots| \ldots|\ldots| \ldots|\ldots| \ldots|\ldots| \ldots|\ldots|$

-GCACTCAATTTTTCTC--TCAACG----GTGTATATAAACAAAAGGAG

-GCACTCAATTTTTCTC--TCAACGGTGGGTGTATATAAACAAAAGGAG

--GCACTCAATTTTTCTC--TCAACG----GTGTATATAAACAAAAGGAG

CAACAСTCAАTTTTTTCTCTTCACCGGGGGGGGATGTAAAAAAAAAGAG

$\begin{array}{llll}2710 & 2720 & 2730 & 2740\end{array} 2750$

$\ldots|\ldots| \ldots|\ldots| \ldots|\ldots| \ldots|\ldots| \ldots|\ldots| \ldots|\ldots|$

TCTCCTTTGGAAAAAACTTGCCTATCATTTTGCCAACGAAC-GTTCTTTC TCTCCTTTGGAAAAAACTTGCCTATCATTTTGCCAACGAAC-GTTCTTTC TCTCСTTTGGAAAAAACTTGCCTATCATTTTGCCAACGAAC-GTTCTTTC TCTСCTTTGGAAAAAAAAAAC-TATC-TTTTGCCGCC-AAC-АTTTTTTT

$\begin{array}{llll}2760 & 2770 & 2780 & 2790\end{array}$

$\ldots|\ldots| \ldots|\ldots| \ldots|\ldots| \ldots|\ldots| \ldots|\ldots| \ldots|\ldots|$ TTCTTAATCAC-AGCTCAGCCTGACGCAACCGCTCAGGCTGATCTCTTCC TTCTTAATCAC-AGCTCAGC-CTACGCAACCGCTCAGGCTGATCTCTTCC TTCTTAATCAC-AGCTCAGCCTGACGCAACCGCTCAGGCTGATTGATTCT TCTTTATTCA---GCTCAGC-CTGAGGAACCCCCAGTGGGCATTTTTTAA

$\begin{array}{lll}2810 & 2820 \quad 2830 \quad 2840 \quad 2850\end{array}$ $\ldots|\ldots| \ldots|\ldots| \ldots|\ldots| \ldots|\ldots| \ldots|\ldots| \ldots|\ldots|$ ААTTTACAGCCATTTCCCAGCTCAGATCTCTGATCCGGTGAGATCTCTCT ААTTTACAGCCATTTCCCAGCTCAGATCTCTGATCCGGTGAGATСTCTCT СTTTTTT--TCCCCGAAAAAAAAAAAACAGAAACTGGGGGCAАTTTTTTT AAAAG
2860
2870
2880
2890
2900 
Col-0_VTC1_gDNA_TAIR

Ler-0_VTC1_gDNA_Genbank

svt2 $\mathrm{K} 1$ Col $R$ M3_G1F

svt2 K1 Col $R$ svt2 R M4_G1F

Col-0 VTC1 gDNA TAIR

Ler-0_VTC1_gDNA_Genbank

svt2 $\bar{K} 1$ Col $R$ M3 G1F

svt2 $\mathrm{K} 1$ Col $R$ svt2 R M4 G1F

svt2 $\mathrm{K} 1$ Col $R$ svt2 $R$ M4 G1R $\ldots|\ldots| \ldots|\ldots| \ldots|\ldots| \ldots|\ldots| \ldots|\ldots| \ldots|\ldots|$ CAAGGTAATGCCССTGCAATTTTGCTTACTTCTCTGGTTGTGATATGCAT CAAGGTAATGCCCСTGCAATTTTGCTACTTCTCTGGTTGTGATATGCAT

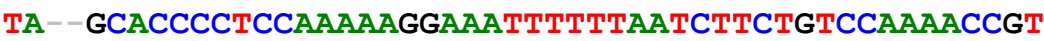

$$
2910
$$$$
2920
$$

2930

2940

2950

$\ldots|\ldots| \ldots|\ldots| \ldots|\ldots| \ldots|\ldots| \ldots|\ldots| \ldots|\ldots|$ GTTCTTCGAATTTTCATCGTTTGTGATTTGAATTCTCATTTTGTATTTGC GTTCTTCGAATTTTCATCGTTTGTGATTTGAATCTCATTTTGTATTT-C ATTTTTTTAAGCCCССTTT- 
Figure 2.9 Sequence alignment of the VTC1 promoter InDel polymorphism sequence of the Col-0 TAIR database, the Ler-0 Genbank database, the svt2 $\mathrm{K} 1 \mathrm{Col} \mathrm{R} \mathrm{M}_{3}$ (Col-like phenotype) and the svt2 $\mathrm{K} 1 \mathrm{Col} \mathrm{R}$ svt2 $\mathrm{R} \mathrm{M}_{\mathbf{4}}$ (svt2-like phenotype).

Horizontal arrows denote $5^{\prime}$ respectively $3^{\prime}$ flanking regions of the sequence insertion, which is highlighted in grey, in the VTC1 promoter region in Ler-0 and svt2 K1 Col R svt2 R M svt2-like phenotype. The svt2 $\mathrm{K} 1 \mathrm{Col} \mathrm{R} \mathrm{M}_{3}$ mutant has a Col-like phenotype and share sequence similarities with the Col-0 sequence. $\mathrm{R}$ denotes revertant. 
affected. There is increasing evidence in both plants and animals that epigenetic marks are not always cleared between generations. Incomplete erasure at genes associated with a measurable phenotype results in unusual patterns of inheritance from one generation to the next, termed transgenerational epigenetic inheritance (Molinier et al., 2006; Jablonka and Raz, 2009). Therefore, analysis of the progeny of the reciprocal crosses is expected to provide some first insights on the possibility of transgenerational epigenetic inheritance that is transmitted maternally. If this were the case, only progeny of crosses with a maternal svt2 donor should have an svt2-like phenotype. Generally, $F_{1}$ plants were much larger than svt2, but appeared to have a "mixed" Col/svt2 phenotype (data not shown). To determine the genotypes of the $F_{1}$ progeny of the reciprocal crosses, we performed another InDel polymorphism assay as described above. In addition, progeny were also screened using the VTC1 InDel promoter polymorphism. Table 2.5 contains a summary of the InDel screen for progeny from each reciprocal cross. In all but six of the progeny from the reciprocal crosses, PCR products similar to those obtained using Col and Ler genomic DNA, respectively, were generated, suggesting that the $F_{1}$ of the reciprocal crosses were heterozygous. A similar result was obtained for the VTC1 promoter polymorphism marker in all reciprocal crosses. Note, however, that for some polymorphisms and irrespective of whether svt2 or Col-0 served as female or male donor, respectively, PCR products comparable to those obtained using Ler-0 wild-type DNA were prevalent (highlighted in red in Table 2.5). This is surprising because heterozygosity was expected at all loci. This suggests that some parts of the genome were not inherited equally from both parents. Taken together, these results suggest that maternal epigenetic inheritance may not be the cause of genome instability in svt2. However, at some loci svt2-like alleles dominate over Col-0.

\subsection{DISCUSSION}

Although this study aimed to isolate novel suppressor mutants of the AA-deficient Arabidopsis mutant vtc1-1, we identified svt2, which indeed has wild-type levels of AA (Fig. 2.2c) and recovered root development in the presence of ammonium (Fig. 2.2d). However, svt2 manifests genotypic and phenotypic instability, making it unsuitable for the identification of VTC1 interacting partners. Instead, svt2 harbors unique characteristics that will aid in our understanding of the mechanism of genome instability and restoration.

\subsection{1 svt2 is a novel Arabidopsis mutant and not a result of an experimental artifact, seed contamination or outcrossing}

Several lines of evidence support our findings that svt2 is a novel mutant. First, svt2 was the only suppressor mutant that was isolated among over 1000 EMS-mutagenized $M_{0}$ seeds, showing unique phenotypic characteristics. Our genetic analysis revealed that astonishingly 
Table 2.5 Summary of insertion/deletion polymorphism analysis of reciprocal crosses between svt2 and Col-0 wild-type lines.

Molecular analysis of the InDel polymorphism markers showed evidence of cryptic but persistent homozygosity, irrespective of the direction of the sexual cross (highlighted in red). However, heterozygosity was expected at all loci.

\begin{tabular}{|l|c|c|c|c|c|c|}
\hline Female $x$ Male crosses & $\begin{array}{c}\text { InDel 1 } \\
\mathbf{4 5 0 9 1 9}\end{array}$ & $\begin{array}{c}\text { InDel 2 } \\
\mathbf{4 5 1 4 7 0}\end{array}$ & $\begin{array}{c}\text { InDel 3 } \\
\mathbf{4 6 9 7 6 2}\end{array}$ & $\begin{array}{c}\text { InDel 4 } \\
\mathbf{4 4 9 0 5 3}\end{array}$ & $\begin{array}{c}\text { InDel 5 } \\
\mathbf{4 5 5 1 0 0}\end{array}$ & $\begin{array}{c}\text { G1F + G2R } \\
\text { VTC1 }\end{array}$ \\
\hline svt2 $\times$ Col-0 $\mathrm{F}_{1} 1$ & $\mathrm{H}$ & $\mathrm{H}$ & $\mathrm{L}$ & $\mathrm{H}$ & $\mathrm{H}$ & $\mathrm{H}$ \\
\hline svt2 $\times$ Col-0 $\mathrm{F}_{1} 2$ & $\mathrm{H}$ & $\mathrm{H}$ & $\mathrm{L}$ & $\mathrm{H}$ & $\mathrm{H}$ & $\mathrm{H}$ \\
\hline svt2 $\times$ Col-0 $\mathrm{F}_{1} 3$ & $\mathrm{H}$ & $\mathrm{H}$ & $\mathrm{H}$ & $\mathrm{H}$ & $\mathrm{H}$ & $\mathrm{H}$ \\
\hline svt2 $\times$ Col-0 $\mathrm{F}_{1} 4$ & $\mathrm{H}$ & $\mathrm{H}$ & $\mathrm{H}$ & $\mathrm{H}$ & $\mathrm{H}$ & $\mathrm{H}$ \\
\hline Col-0 0 svt2 $\mathrm{F}_{1} 1$ & $\mathrm{H}$ & $\mathrm{H}$ & $\mathrm{H}$ & $\mathrm{L}$ & $\mathrm{H}$ & $\mathrm{H}$ \\
\hline Col-0 0 svt $2 \mathrm{~F}_{1} 2$ & $\mathrm{H}$ & $\mathrm{H}$ & $\mathrm{L}$ & $\mathrm{H}$ & $\mathrm{H}$ & $\mathrm{H}$ \\
\hline Col-0 0 svt $2 \mathrm{~F}_{1} 3$ & $\mathrm{H}$ & $\mathrm{H}$ & $\mathrm{H}$ & $\mathrm{L}$ & $\mathrm{H}$ & $\mathrm{H}$ \\
\hline Col-0 0 svt $2 \mathrm{~F}_{1} 4$ & $\mathrm{H}$ & $\mathrm{H}$ & $\mathrm{L}$ & $\mathrm{H}$ & $\mathrm{H}$ & $\mathrm{H}$ \\
\hline
\end{tabular}


both maternal and paternal alleles were affected in five randomly selected InDel polymporphism loci, the newly discovered InDel polymporphism in the VTC1 promoter, and additional SNPs (Figs. 2.3b, c, d, 2.4, 2.5, 2.6). These data demonstrate that svt2 has acquired new characteristics, presumably in response to EMS mutagenesis, and that svt2 is neither Col nor Ler. The data also argue against svt2 being an experiment or PCR artifact.

Second, a number of data provide strong arguments against seed contamination. (1) Descendents of the original svt2 mutant produce with high reproducibility offspring revertants with Col-like features (Tables 2.3, 2.4; Figs. 2.7, 2.8). (2) One of the Col-like revertants, svt2 Col R1 $\mathrm{M}_{3}$, exhibited heterozygosity at some of the InDels tested (Table 2.4). (3) One of those Collike revertant, svt2 $\mathrm{K} 1 \mathrm{Col} \mathrm{R} \mathrm{M}_{3}$, produced progeny that reverted back to svt2-like plants (Tables $2.3,2.4$, Figs. 2.7, 2.8). (4) We were unable to obtain true $F_{1}$ heterozygotes in svt2/Col-0 reciprocal crosses (Table 2.5). (5) The delayed flowering phenotype and enlarged morphology argue against the fact that svt 2 is a result of a Ler-0 wild-type seed landing on the flat during the initial planting of the vtc1-1 $M_{0}$ mutagenized population. There is the possibility of a Ler seed contamination of the vtc1-1 seed stock used for EMS mutagenesis. Although, we have sequenced the vtc1-1 seed stock used for this experiment and confirmed that it is homozygous for the vtc1-1 mutation, one could argue that sequencing the seed stock may not be a sensitive enough method to rule out contamination with a few Ler seed. We performed many other experiments using this very same seed stock and never observed Ler-like plants among the vtc1 population. However, arguments (1) through (4) above are most compelling against seed contamination.

Third, the following experimental evidence argues against the possibility that svt2 was generated by cross pollination of vtc1-1 mutant plants with Ler wild-type plants. (1) If svt 2 were generated by Ler cross-pollination, the InDel polymorphism markers tested using svt2 genomic DNA should have indicated heterozygosity. This, however, was not the case (Table 2.4). (2) While svt2 shares phenotypic and genotypic characteristics with Ler and Col, it also has unique features (Figs. 2.2a, 2.6). (3) svt2 exhibits phenotypic and genotypic instability, causing the appearance of revertants with persistent reproducibility. (4) Ler plants were not grown in our growth chambers at the time of the mutagenesis experiment. Furthermore, svt2 was isolated by placing Aracons over the mutant plant to allow self-fertilization and seed production.

\subsubsection{Possible causes of genome instability in svt2}

Our results are indicative of genome instability in svt2. Genome instability may be a result of polyploidy (Wang et al., 2010). Polyploids can arise by genome duplication (autopolyploids) or interspecific hybridization (allopolyploids). Our data suggest that svt2 does 
not contain multiple sets of chromosomes, because VTC1 occurs as a single copy gene in svt2 and vtc1-1 mutants as well as the Col-0 and Ler-0 wild-type controls (Table 2.2). Furthermore, extra DNA must be replicated with each cell division. Therefore, enlarged cell size is often associated with polyploids (Ranney, 2006). The chemical mutagenesis of vtc1-1 seed may have resulted in mutations, which may have led to increased ploidy levels in one, two, or all three meristem layers, L1, L2, L3. However, only mutations in the L2 layer, which gives rise to the reproductive organs, are inherited. Polyploidy in the $\mathrm{L} 2$ layer are reflected in pollen size. While svt2 has an overall enlarged morphology (Fig. 2.2a), its pollen size is comparable to that of the other three genotypes (Fig. 2.2b). This suggests that svt2 anthers are not polyploid. Finally, allopolyploids often display a greater degree of heterozygosity (Ranney, 2006), low fertility, and low embryonic viability (Soltis and Soltis, 1995; Comai et al., 2000; Schranz and Osborn, 2000). This, however, is not the case in svt2. The fact that svt 2 is fertile and that svt 2 offspring with enlarged morphology are being produced suggests that svt2 is neither a somatic nor a gamete polyploid. Thus, it is therefore unlikely that polyploidy in svt2 contributes to genome instability. This is supported by a study by Ruffio-Chable and co-workers who reported between $5 \%$ and $21 \%$ of aberrant plants in $F_{1}$ hybrids of Brassica oleracea, which was not correlated with abnormal ploidy levels (Ruffio-Chable et al., 2000).

Instead, we hypothesize that genome instability of svt2 was further aggravated by exposing the already instable genome of vtc1-1 mutants to EMS. It has recently been shown that plants impaired in certain aspects of protection against reactive oxygen species have a higher incidence of spontaneous double-strand breaks (Filkowski et al., 2004). The AA-deficient vtc1-1 mutant has a three-fold higher spontaneous homologous recombination frequency and has a higher incidence of double-strand breaks (see below). Similar results were reported for the Arabidopsis thaliana flavonoid-deficient mutants tt4 and tt5 (Filkowski et al., 2004). One may speculate that through the high level of stress induced by EMS a yet unknown mechanism of genome restoration was turned on. In fact, genome alterations in soybean and flax in response to environmental stress have been reported previously (Roth et al., 1989; Chen et al., 2009). In the process of soybean cell culture, massive specific changes of genomic loci spread throughout the genome were observed (Roth et al., 1989). It was suggested that this genetic variation is a consequence of specific recombinational events. Similarly, a single-copy 5.7 kilobase DNA fragment that was not present in the parent line, appeared in genotrophs in flax in response to particular growth conditions (Chen et al., 2009).

\subsubsection{Possible mechanisms of genome restoration in svt2}

The experimental evidence described in this work raises the question as to what mechanism is responsible for the loss or reintroduction of genomic DNA sequences in the original svt2 mutant and its revertant offspring. Several mechanisms may be considered: 
activity of transposable elements, random mutations, unequal crossing over, gene conversion, double-strand breaks and recombination, and activity of an RNA cache.

Transposons are DNA elements capable of moving around the genome, which is often associated with chromosome breaks and causes unstable mutations that revert frequently but often give rise to new phenotypes. Movement of transposable elements often occurs during meiosis and mitosis and is accelerated by genome damage (Lisch, 2009). These represent conditions that are present in svt2. However, transposons have a variety of molecular features that do not apply to svt2. Transposons exist as multiple copies in the genome. A BLAST search of the VTC1 promoter insertion in svt2 did not return any other hits, indicating that the DNA sequence is present in its entirety somewhere else in the genome. Transposon termini represent inverted repeats. This, however, is not the case in svt2 (Fig. 2.6). A short, direct repeat of genomic DNA often flanks the transposon, leaving a "footprint". Our sequencing analysis of the VTC1 promoter region in svt2 did not reveal any footprints, arguing against the activity of transposons, thereby causing the insertion or loss of novel sequences in svt2 (Fig. 2.6).

Random mutations caused by EMS mutagenesis may have activated an unknown mechanism in vtc1-1 seeds, giving rise to the phenome and genome instability in svt2. This may explain the novel SNPs we detected in svt2 that are distinct from the vtc1-1 mutant and Col-0 and Ler-0 wild types (Fig. 2.6). The disappearance of the vtc1-1 mutation in svt2 (Figs. 2.3d, 2.6) may also be explained by the introduction of a random mutation. Exposure of vtc1-1 seeds to EMS could have reversed the original vtc1-1 mutation, which was initially generated by EMS (Conklin et al., 1999), to the wild-type sequence. Interestingly, Conklin and co-workers (1999) previously isolated two vtc1 alleles, vtc1-1 and vtc1-2, containing the exact same single cytosine to thymine point mutation at position 64 relative to the start codon, despite the fact that vtc1-1 and vtc1-2 mutants were isolated independently from different EMS-mutagenized pools (Conklin et al., 1999). The authors suggested that a limited number of mutations are tolerable in the VTC1 enzyme GDP-D-mannose pyrophosphorylase without causing embryo lethality. This is supported by the fact that several independently isolated cyt mutant alleles containing different amino acid mutations in VTC1 are embryo lethal (Lukowitz et al., 2001). To date, only the vtc1-1 (Conklin et al., 1999) and hsn1 mutations (Qin et al., 2008) have been isolated and reportedly do not cause embryo lethality. This suggests some form of allelic constraint that has been reported in Arabidopsis previously (Kreps et al., 1996; Li and Last, 1996). Furthermore, in the EMS screen in which the svt2 mutant was isolated, several other vtc1-1 suppressor mutants with restored root development in the presence of ammonium were identified. Sequencing analysis revealed that in all of these mutants the vtc1-1 mutation was restored to the wild-type 
allele, while the suppressor mutants neither exhibited a svt2-like phenotype nor did they produce revertants in the subsequent generation (Kempinski et al., unpublished data).

Exposure to EMS or $\mathrm{y}$-radiation, was reported to induce high frequency phenotypic instability in the Arabidopsis disease resistance genes, CPR1 and BAL, mapping to the RPP5 locus (Yi and Richards, 2008). Yi and Richards reported destabilization of phenotypes in both the $b a l$ and $c p r 1$ mutants in more than $10 \%$ of EMS-treated plants in the $\mathrm{M}_{1}$ generation. They also identified exceptions to simple Mendelian inheritance in the $M_{2}$ generation. Phenotypic instability was also observed in bal $\times c p r 1 \mathrm{~F}_{1}$ hybrids. The authors suggested that the high degree of phenotypic instability in bal and cpr1 mutants is due to the fact that the RPR5 locus can adopt different metastable genetic or epigenetic states, whose stability is highly susceptible to mutagenesis and pairing of different alleles. $\mathrm{Yi}$ and Richards later reported that the phenotypic instability of bal mutants is caused mainly by gene duplication and hypermutation of the SNC1 gene (Yi and Richards, 2009).

Finally, a combination of unequal crossing over, gene conversion, double-strand breaks, DNA recombination, in conjunction of an RNA cache template may explain the loss and reappearance of DNA sequences in svt2. Genome-wide non-Medelian inheritance of extragenomic information in Arabidopsis was reported in the hothead (hth) Arabidopsis mutant (Lolle et al., 2005). Self-fertilization of homozygous mutant plants resulted in approximately $10 \%$ hth revertants, which were $h t h / H T H$ heterozygous, suggesting that the HTH gene was altered in the progeny. However, the authors also detected rare homozygous revertants HTH/HTH embryos, which must have inherited one of their two wild-type HTH genes from the maternal parent and could not have been a result of outcrossing. Inheritable genome-wide high-frequency gene homozygosity in early generations in rice has also been reported (Xu et al., 2007). Lolle et al. postulated that these genetic restoration events are the result of a templatedirected process that utilizes an ancestral RNA-sequence cache (Lolle et al., 2005). This hypothesis is supported by observations reported by $\mathrm{Xu}$ and co-workers (Xu et al., 2007). Therefore, our genetic and phenotypic svt2 data in conjunction with the observed higher occurrence of double-strand breaks and spontaneous homologous recombination frequency in vtc1-1 are in support of the RNA cache theory. Additional studies are underway to provide experimental support for this hypothesis.

\subsubsection{Concluding remarks}

We have isolated a novel Arabidopsis mutant that is capable of restoring genetic information that was not present in the chromosomal genome of the parents. However, we suggest that this ancestral information is present in some cryptic form, allowing plants to access this information under stress conditions. How this genome restoration process is triggered and 
accomplished mechanistically remains to be determined. Double strand breaks, DNA recombination, and the activity of an RNA cache may be contributing factors. It is clear that genome restoration could be advantages to plants to survive environmental changes for which the ancestral genes were better adapted. This could also lead to the identification and utilization of new traits in crops. Understanding svt2 could also provide new knowledge on how Arabidopsis ecotypes evolved and diversified, and serve as a model to study non-Mendelian inheritance.

\subsection{REFERENCES}

Barth C, Gouzd ZA, Steele HP,Imperio RM (2010) A mutation in GDP-mannose pyrophosphorylase causes conditional hypersensitivity to ammonium, resulting in Arabidopsis root growth inhibition, altered ammonium metabolism and hormone homeostasis. Journal of Experimental Botany 57: 1657-1665

Chen Y, Lowenfeld R,Cullis CA (2009) An environmentally induced adaptive (?) insetion event in flax. International Journal of Genetics and Molecular Biology 1: 038-047

Comai L, Tyagi AP, Winter K, Holmes-Davis R, Reynolds SH, Stevens Y,Byers B (2000) Phenotypic instability and rapid gene silencing in newly formed Arabidopsis allotetraploids. The Plant Cell 12: 1551-1568

Conklin PL, Williams EH,Last RL (1996) Environmental stress sensitivity of an ascorbic acid-deficient Arabidopsis mutant. Proceedings of the National Academy of Sciences of the United States of America 93: 9970-9974

Conklin PL, Norris SR, Wheeler GL, Williams EH, Smirnoff N,Last RL (1999) Genetic evidence for the role of GDP-mannose in plant ascorbic acid (vitamin C) biosynthesis. Proceedings of the National Academy of Sciences of the United States of America 96: 4198-4203

Conklin PL, Saracco SA, Norris SR,Last RL (2000) Identification of ascorbic acid-deficient Arabidopsis thaliana mutants. Genetics 154: 847-856

De Preter K, Speleman F, Combaret V, Lunec J, Laureys G, Eussen BH, Francotte N, Board J, Pearson AD, De Paepe A, Van Roy N,Vandesompele J (2002) Quantification of MYCN, DDX1, and NAG gene copy number in neuroblastoma using a real-time quantitative PCR assay. Mod Pathol 15: 159-166

Duarte JM, Wall PK, Edger PP, Landherr LL, Ma H, Pires JC, Leebens-Mack J,dePamphilis CW (2010) Identification of shared single copy nuclear genes in Arabidopsis, Populus, Vitis and Oryza and their phylogenetic utility across various taxonomic levels. BMC Evol Biol 10: 61

Filkowski J, Kovalchuk O,Kovalchuk I (2004) Genome stability of vtc1, tt4, and tt5 Arabidopsis thaliana mutants impaired in protection against oxidative stress. The Plant Journal 38: 60-69

Jablonka E,Raz G (2009) Transgenerational epigenetic inheritance: prevalence, mechanisms, and implications for the study of heredity and evolution. Q Rev Biol 84: 131-176

Kempinski CF, Haffar R,Barth C (2011) Toward the mechanism of $\mathrm{NH}_{4}{ }^{+}$sensitivity mediated by Arabidopsis GDP-mannose pyrophosphorylase. Plant, Cell \& Environment 34: 847-858

Kotchoni SO, Larrimore KE, Mukherjee M, Kempinski CF,Barth C (2009) Alterations in the endogenous ascorbic acid content affect flowering time in Arabidopsis. Plant Physiology 149: 803-815 
Kreps JA, Ponappa T, Dong W,Town CD (1996) Molecular basis of alpha-methyltryptophan resistance in amt-1 a mutant of Arabidopsis thaliana with altered tryptophan metabolism. Plant Physiology 110: $1159-1165$

Li J,Last RL (1996) The Arabidopsis thaliana trp5 mutant has a feedback-resistant anthranilate synthase and elevated soluble tryptophan. Plant Physiology 110: 51-59

Li Q, Li BH, Kronzucker HJ,Shi WM (2010) Root growth inhibition by $\mathrm{NH}_{4}{ }^{+}$in Arabidopsis is mediated by the root tip and is linked to $\mathrm{NH}_{4}{ }^{+}$efflux and GMPase activity. Plant, Cell and Environment 33: 1529-1542

Lisch D (2009) Epigenetic Regulation of Transposable Elements in Plants. Annual review of plant biology 60: $43-66$

Lolle SJ, Victor JL, Young JM,Pruitt RE (2005) Genome-wide non-mendelian inheritance of extragenomic information in Arabidopsis. Nature 434: 505-509

Lukowitz W, Nickle TC, Meinke DW, Last RL, Conklin PL,Somerville CR (2001) Arabidopsis cyt1 mutants are deficient in a mannose-1-phosphate guanylyltransferase and point to a requirement of $\mathrm{N}$ linked glycosylation for cellulose biosynthesis. Proceedings of the National Academy of Sciences of the United States of America 98: 2262-2267

Molinier J, Ries G, Zipfel C,Hohn B (2006) Transgeneration memory of stress in plants. Nature 442: 1046-1049

Mukherjee M, Larrimore KE, Ahmed NJ, Bedick TS, Barghouthi NT, Traw MB,Barth C (2010) Ascorbic Acid Deficiency in Arabidopsis Induces Constitutive Priming That is Dependent on Hydrogen Peroxide, Salicylic Acid, and the NPR1 Gene. Molecular Plant-Microbe Interactions 23: 340-351

Qin C, Qian W, Wang W, Wu Y, Yu C, Jiang X, Wang D,Wu P (2008) GDP-mannose pyrophosphorylase is a genetic determinant of ammonium sensitivity in Arabidopsis thaliana. Proceedings of the National Academy of Sciences of the United States of America 105: 18308-18313

Ranney TG (2006) Polyplooid: From Evolution to New Plant Development. Combined Proceedings International Plant Propagators' Society 56: 137-142

Roth EJ, Frazier BL, Apuya NR,Lark KG (1989) Genetic variation in an inbred plant: variation in tissue cultures of soybean [Glycine max (L.) Merrill]. Genetics 121: 359-368

Roudier F, Fernandez AG, Fujita M, Himmelspach R, Borner GH, Schindelman G, Song S, Baskin TI, Dupree P, Wasteneys GO,Benfey PN (2005) COBRA, an Arabidopsis extracellular glycosylphosphatidyl inositol-anchored protein, specifically controls highly anisotropic expansion through its involvement in cellulose microfibril orientation. The Plant Cell 17: 1749-1763

Ruffio-Chable V, Chatelet P,Thomas G (2000) Developmentally "aberrant" plants in F1 hybrids of Brassica oleracea. Acta Hort. 539: 89-94

Schmelz EA, Engelberth J, Alborn HT, O'Donnell P, Sammons M, Toshima H,Tumlinson JH, 3rd (2003) Simultaneous analysis of phytohormones, phytotoxins, and volatile organic compounds in plants. Proceedings of the National Academy of Sciences of the United States of America 100: 10552-10557

Schranz ME,Osborn TC (2000) Novel flowering time variation in the resynthesized polyploid Brassica napus. Journal of Heredity 91: 242-246

Soltis DE,Soltis PS (1995) The dynamic nature of polyploid genomes. Proceedings of the National Academy of Sciences of the United States of America 92: 8089-8091

Wang Y, Jha AK, Chen R, Doonan JH,Yang M (2010) Polyploidy-associated genomic instability in Arabidopsis thaliana. Genesis 48: 254-263

Weigel D,Glazebrook J (2002) Arabidopsis: A Laboratory Manual. Cold Spring Harbor Press, Cold Spring Harbor 
Xu PZ, Yuan S, Li Y, Zhang HY, Wang XD, Lin HH,Wu XJ (2007) Genome-wide high-frequency nonMendelian loss of heterozygosity in rice. Genome 50: 297-302

Yi H,Richards EJ (2008) Phenotypic instability of Arabidopsis alleles affecting a disease Resistance gene cluster. BMC Plant Biology 8: 36

Yi H,Richards EJ (2009) Gene duplication and hypermutation of the pathogen Resistance gene SNC1 in the Arabidopsis bal variant. Genetics 183: 1227-1234 


\section{CHAPTER 3: Elucidating the role of the autonomous flowering pathway gene $F C A$ in the regulation of ascorbic acid biosynthesis in Arabidopsis thaliana}

\subsection{INTRODUCTION}

\subsubsection{Flowering pathways in Arabidopsis thaliana}

In higher plants, the timing of the transition from the vegetative to the reproductive phase is essential to ensure reproductive success. Flowering time is controlled by external and internal factors that are integrated in a complex gene regulatory network that ensures the expression of flowering genes, resulting in flower formation (Corbesier and Coupland, 2005; Jack, 2004). Flowering cues include changes in photoperiod, light, temperature, and internal changes in GA (Koornneef et al., 1998). There are four, partially overlapping pathways which lead to the development of floral tissue: the long-day photoperiodic, gibberellic/phytohormone, vernalization, and autonomous pathways (Fig. 3.1; Boss et al. 2004; Jack 2004). Boss et al. divides these pathways into two groups: those that promote the transition to the floral meristem and those that enable this transition. The photoperiodic and gibberllic/phytohormone pathways act as floral promoters, while the vernalization and autonomous pathways enable floral development. This categorization is helpful in understanding the epistatic relationships between flowering pathway genes. The floral promotion pathways function to increase levels of floral integrators; but as long as levels of floral repressors (e.g. FLC) remain elevated, floral promotion stimuli are blocked from triggering floral development (Boss et al., 2004; Hepworth et al., 2002).

These flowering pathways incorporate environmental and internal cues in a combinatorial manner to cause flowering at an appropriate time. In the facultative long day plant, Arabidopsis, the photoperiodic pathway is activated when peak expression of the transcription factor, $\mathrm{CO}$, in the leaves coincides with exposure to far red and blue light which stabilize and cause CO to promote expression of the floral integrators FT and SOC1 (Blazquez, 2005; Hepworth et al., 2002; Huang et al., 2005; Putterill et al., 1995; Valverde et al., 2004). FT protein moves through the phloem to the shoot apex, where it interacts with the transcription factor FD to activate AP1, SOC1, and other floral identity genes (Fig. 3.1; Abe et al., 2005; Blazquez, 2005; Huang et al., 2005; Wigge et al., 2005). Phytohormones can also affect flowering time, with the giberellins being the most thoroughly characterized (Davis, 2009). Gibberellins promote flowering 


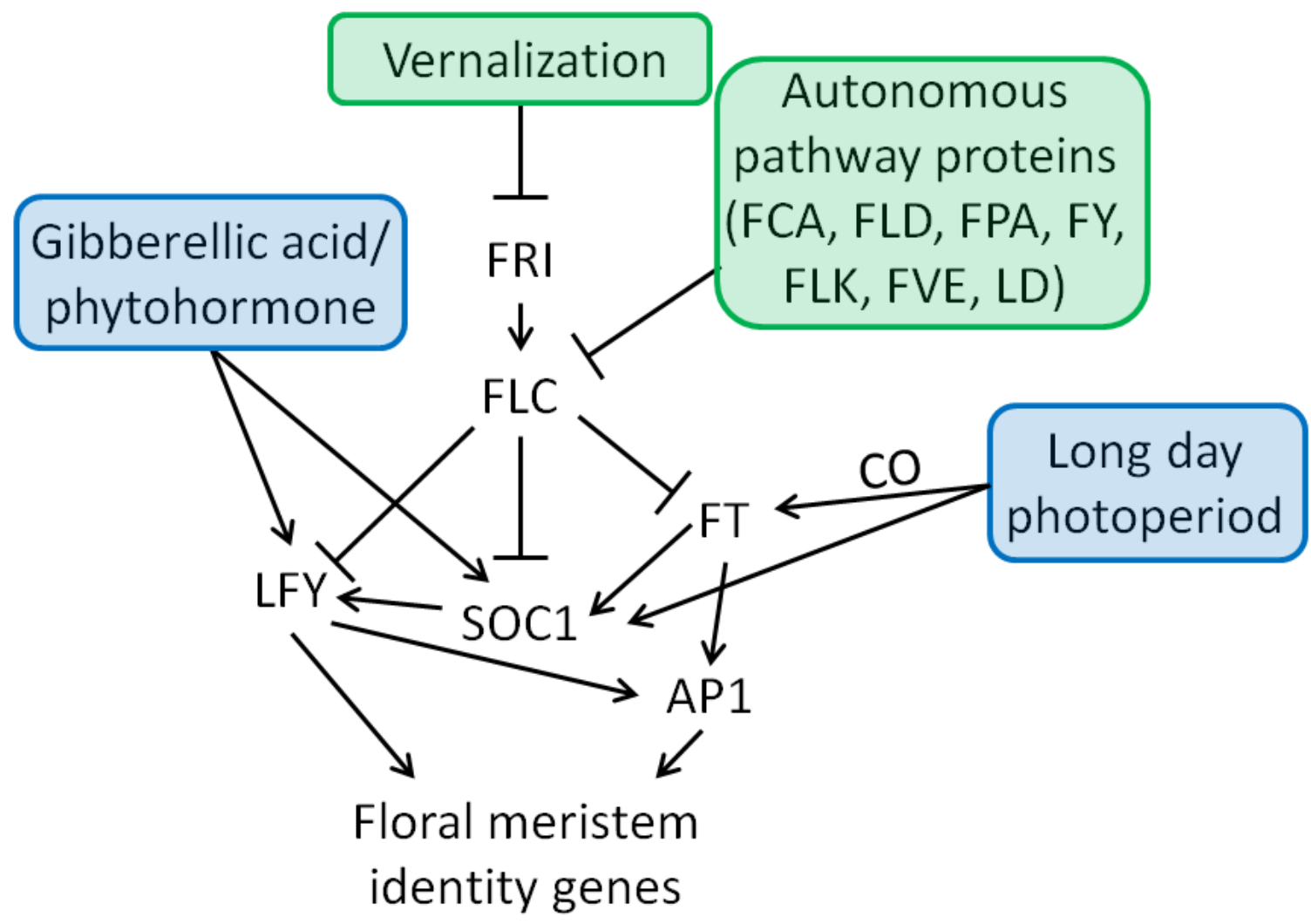

Figure 3.1 Diagram of flowering pathways in Arabidopsis and downstream genes cumulating in floral development.

Pathways promoting floral development are shaded in blue, those that enable floral development are shaded in green. Adapated from Jack (2004) and Blazquez (2005). 
through stimulation of the floral meristem identify genes SOC1, LFY, and AGL24; this pathway appears to be important for promotion of flowering during short days, but during long days, its contribution is negligible (Boss et al., 2004; Davis, 2009; Michaels and Amasino, 1999b). Interestingly, it appears that after initial floral promoters are expressed, they then can activate other floral promoters to amplify the transition signal, e.g. a positive feedback mechanism to increase expression exists between SOC1 and AGL24 and the ability of $L F Y$ to directly increase AP1 expression (Fig. 3.1; Jack, 2004; Lee and Lee, 2010; Liu et al., 2008; Michaels et al., 2003). Together, day length and phytohormone production function to upregulate floral meristem identity genes, but these processes rely on the downregulation of floral integrator suppressors TFL1, SVP, TOE1/2, and FLC (Boss et al., 2004). In winter annual Arabidopsis plants, FLC expression is maintained by $F R I$ (Michaels and Amasino, 1999a). However, following a vernalization period (i.e. the promotion of flowering by low-temperature treatment), FLC expression is suppressed through various chromatin modifications (He et al., 2003; Noh and Noh, 2006; Veley and Michaels, 2008) Signals from these pathways work towards regulating FLC, SOC1, FT, AP1 and LFY (Koorneef et al. 1998; Jack 2004). The floral meristem identity genes direct the conversion from a vegetative to floral meristem and direct formation of lateral floral meristems on the primary inflorescence (Fig. 3.1; Jack, 2004; Kobayashi and Weigel, 2007).

As introduced above, vtc mutants exhibit early flowering independent of the photoperiod (Kotchoni et al., 2009). Kotchoni and co-workers undertook a study to identify the flowering pathway that promotes the early flowering phenotype. Through the generation of double mutants with defects in AA biosynthesis and flowering, they identified vtc1-1 fca-1 that was still delayed in flowering but had substantially recovered AA levels. FCA acts in the autonomous flowering pathway and was therefore hypothesized to possibly contribute to the regulation of AA biosynthesis in Arabidopsis.

\subsubsection{The autonomous flowering pathway}

The autonomous flowering pathway enables flowering independently of environmental cues (Boss et al., 2004; Quesada et al., 2003). It consists of seven genes which promote floral induction through suppressing FLC expression independent of $F R I$ and vernalization (Veley and Michaels, 2008). The effect of $F R I$ on FLC is epistatic to the autonomous pathway genes. Thus, mutations in $F R I$ or FLC promote flowering, while mutations in the autonomous pathway genes suppress flowering (Veley et al. 2008). It is important to note that while stimuli which promote floral development may be present, the expression of floral repressors act epistatically to control flowering, and it is only when the repressors are downregulated that the meristem is able to switch from vegetative to floral growth (Fig 3.1; Boss et al. 2004).

While the genes of the autonomous pathway have been identified, their mechanism of FLC suppression is not fully understood (Veley and Michaels, 2008). The FLD protein of the 
autonomous pathway is thought to be a histone demethylase, as it is homologous to the human protein, LSD1, which has been shown to have histone H3 lysine 4 demethylase activity (Shi et al., 2004; Veley and Michaels, 2008). FVE has a human homolog which is suggested to be involved in histone deacetylation (He et al., 2003). Interestingly, fld and fve mutants have hyperacetylated histone $\mathrm{H} 4$ at FLC chromatin (although the magnitude of hyperacetylation is not as substantial in fve as in fld mutants). However, this hyperacetylation is absent in $f c a, f p a$, or ld mutants (He et al., 2003). He et al. (2003) identified a 295-bp region within the first intron of FLC, which, when deleted, mimics the hyperacetylated phenotype of fld mutants. The LD protein appears to be a nuclear protein and contains glutamine-rich domains characteristic of some transcription factors (Lee et al., 1994). FCA encodes a protein with two RNA-recognition motifs (RRMs) and a WW-repeat domain and is alternatively spliced with four splice variants (Fig. 3.2; FCA- $\alpha, F C A-\beta, F C A-\gamma$, and $F C A-\delta$ ) where correct variant processing occurs through interaction with FY using the WW-repeat domain (Macknight, 2002; Macknight et al., 1997; Page et al., 1999; Simpson et al., 2003). FCA- $\gamma$ is the only splice variant which encodes the active FCA protein which associates with FLC chromatin (Liu et al., 2007; Macknight et al., 1997). FCA also requires FLD for FLC downregulation (Liu et al., 2007) and interacts with the chromatin remodeling factors ATSWI3A and ATSWI3B (Sarnowski et al., 2002 ; Sarnowski et al., 2005). FPA and FCA are both important regulators in RNA-mediated chromatin silencing, both at the FLC locus and other loci genome-wide (Baurle et al., 2007). FY is important for correct FCA splicing and proper FCA function with null fy alleles being lethal (most likely due to FY being a necessary protein in the RNA $3^{\prime}$ end processing complex), while hypomorphic alleles are late flowering (Simpson et al., 2003). However, FY has been observed to affect FLC expression and polyadenylation in a manner independent of FCA (Feng et al., 2011). In sum, the proteins of the autonomous pathway act through independent and redundant mechanisms to modify the FLC chromatin in the promotion of flowering (Veley and Michaels, 2008).

The goal of this study was to identify the mechanism through which the autonomous pathway contributes to the regulation of AA biosynthesis in vtc mutants. In order to test this, $v t c f c a$ double mutants were generated and characterized. 

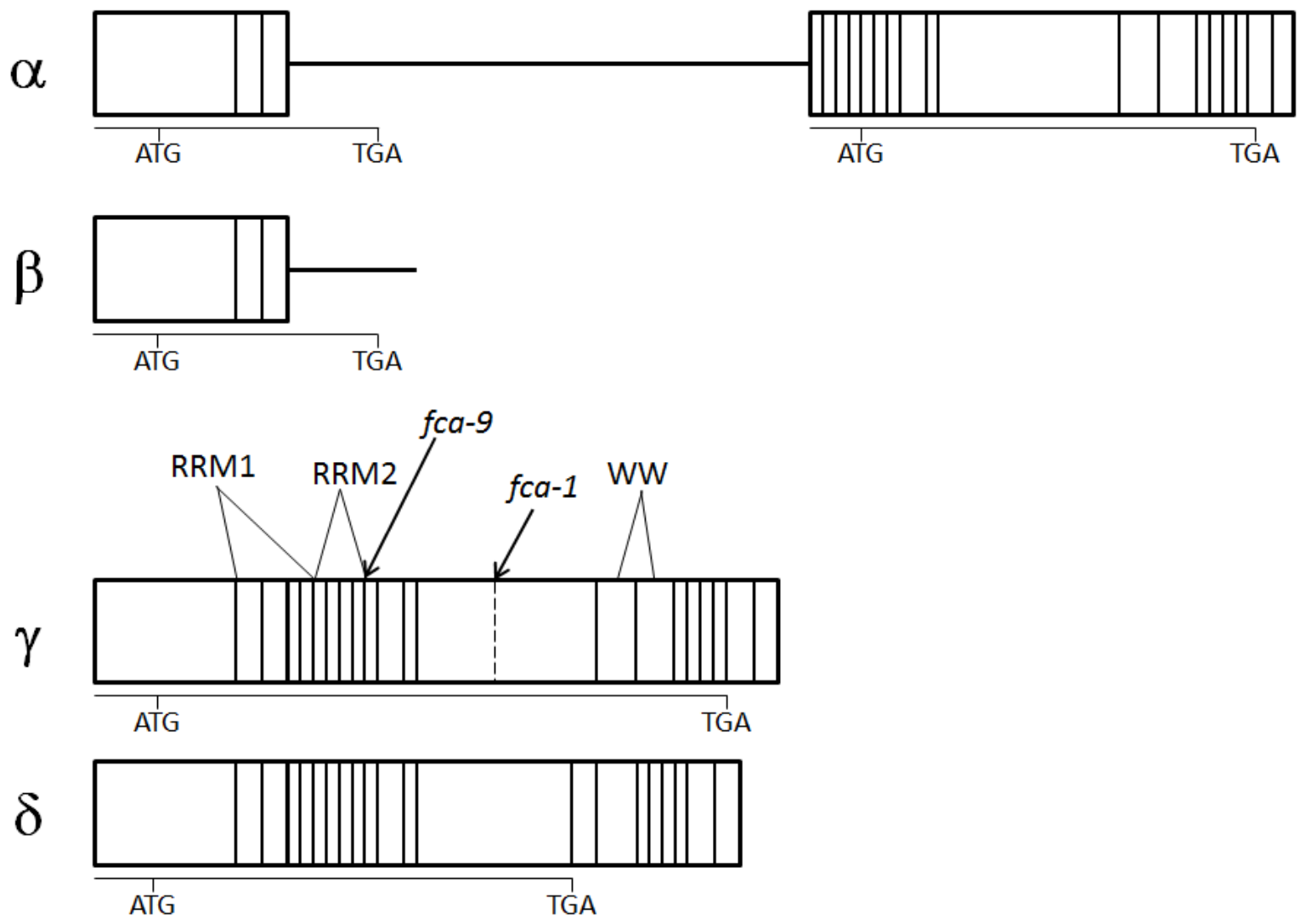

Figure 3.2 Diagram of the four alternative FCA transcripts after Macknight et al. (1997).

Boxes represent exons, the heavy horizontal line represents intron three. Horizontal lines below gene schematics represent possible ORFs within the above transcript. The exon regions encoding the two RRM and WW domains are indicated above the $\gamma$ transcript (Macknight et al., 1997). The approximate mutation locations for fca-9 (frame-shift mutation at the end of exon 9 encoding a truncated protein) and $\mathrm{fca}_{-1}$ ( $\mathrm{C}$ to $\mathrm{T}$ mutation introducing a premature stop codon within exon 13 ) are shown by arrows on the $\gamma$ transcript (Feng et al., 2011; Macknight et al., 1997; Page et al., 1999). 


\subsection{MATERIALS AND METHODS}

\subsubsection{Plant material and growth conditions}

Arabidopsis thaliana L. Heynh wild-type ecotype Columbia-0 (Col) and previously described Arabidopsis mutants vtc1-1, vtc2-1, vtc3-1, vtc4-1 kindly provided by P. Conklin (Conklin, 2001; Conklin et al., 2000; Conklin et al., 1996) were grown in a growth chamber (Percival, Perry, IA). Mutant plants were backcrossed to Col wild type four times (vtc1-1), three times (vtc3-1) or two times (vtc2-1, vtc4-1). The flowering time mutants fca-1 (CS167) and the wild type Landsberg erecta-0 (CS20; Ler) were obtained from the ABRC stock center. The flowering time mutant fca-9 (Page et al. 1999) was kindly donated by R. Macknight. The fpa-7 (Michaels and Amasino, 2001), fld-3 (He et al., 2003), and fpa-7 fld-3 (Veley and Michaels, 2008) flowering time mutants were kindly provided by $\mathrm{S}$. Michaels. Plants were grown on soil (Metromix 360, BFG Supplies, Burton, $\mathrm{OH}$ ) in replicate flats, containing 32 inserts with wild-type controls and mutants always present on the same flat. Seeds were suspended in $0.1 \%$ phytoblend agar (Caisson Laboratories, Inc.) and stratified at $4^{\circ} \mathrm{C}$ for 2 to 4 days before planting. Temperature in the chamber was $23^{\circ} \mathrm{C}$ at day and at night. Plants were grown under long-day (LD, $16 \mathrm{~h}$ light/8 $\mathrm{h}$ dark, growth chamber lights turned on at 6:00 AM and turned off at 10:00 PM) at a light intensity of $160 \mu \mathrm{mol}$ photons $\mathrm{m}^{-2} \mathrm{~s}^{-1}$ (fluorescent bulbs). Whole rosettes of threeweek-old plants were harvested for RNA extraction, $A A$ and ABA content measurements, shock frozen in liquid nitrogen, and stored at $-80^{\circ} \mathrm{C}$ until further analysis.

\subsubsection{Root length measurements}

For assessment of root growth, seeds were surface-sterilized and grown on $1 \mathrm{x}$ Murashige and Skoog (MS) medium in omni trays as described in (Barth et al., 2010). Trays were sealed with one layer of micropore tape (3M), put in vertical orientation, and placed in the growth chamber using the growth conditions described above. Each plate contained wild type and mutant seed. Root length was measured in seven-day-old seedlings using a ruler.

\subsubsection{Generation and identification of vtc and flowering time double mutants}

The vtc1-1 mutant (Col background; Conklin et al. 2000) was crossed with fca-1 (Ler background; Macknight et al., 1997), and fca-9 (Col background; Page et al., 1999), respectively. The vtc4-1 mutant (Col background; Conklin et al., 2000) was crossed to fca-9. $F_{1}$ progeny of the crosses were allowed to self. $F_{2}$ progeny were screened for AA deficiency using the nitroblue tetrazolium assay (Conklin et al., 2000) and DNA was extracted from progeny that scored as AAdeficient. Sequencing was conducted to determine plants homozygous for both mutations using primers listed in Table 3.1. $F_{3}$ seeds from homozygous double mutants were used for experiments. The individual Col and Ler wild types and Col/Ler crosses were used as controls. 
Table 3.1 Sequences of oligonucleotide primers used for qRT-PCR and sequencing.

\begin{tabular}{|c|c|c|}
\hline Primer Name & 5 & ATG Number \\
\hline VTC1-F & TCGCTTGAGACCATTGACT & \multirow{2}{*}{ AT2G39770 } \\
\hline VTC1-R & TCGCTAGAGCCAGAGGAC & \\
\hline VTC4-F & TGTAAGCCGCAACGCCTCAG & \multirow{2}{*}{ AT3G02870 } \\
\hline VTC4-R & AGCAGCTCTTTCCCAATCACA & \\
\hline TUB2-RT-F2 & CTCAAGAGGTTCTCAGCAGTA & \multirow{2}{*}{ AT5G62690 } \\
\hline TUB2-RT-R2 & TCACCTTCTTCATCCGCAGTT & \\
\hline FCA-9-F1 & ATGCGGGATGAATATAGACAGAG & \multirow{4}{*}{ AT4G16280 } \\
\hline FCA-9-R1 & CCAACAGGAGGTGCCATTTC & \\
\hline FCA-1-F1 & GCCTATGGGGTTTGCCTACGATGA & \\
\hline FCA-1-R1 & CTGACCGGAAAGAGGCTGCTGGAC & \\
\hline
\end{tabular}


To minimize genetic variability, resulting from crossing two different backgrounds, seeds were pooled from 12 different crossing events of the Col and Ler wild-type controls (Col/Ler; (Miller et al., 2007) and at least three independent double mutants were evaluated for flowering time.

\subsubsection{Qualitative AA content analysis in double mutants}

A total of $183 \mathrm{~F}_{2}$ plants vtc1-1 fca-1 from three independent crosses (Kotchoni et al., 2009) were assayed for AA content using the nitroblue tetrazolium assay (Conklin et al., 2000). Plants were scored as positive (+), i.e., wild-type content of AA, negative (-), i.e., AA-deficient, or positive/negative (+/-), i.e., intermediate $A A$ content. Recessive trait heredity was calculated using qualified $A A$ levels in crosses to see if they agreed with Mendelian inheritance laws. Statistical analysis was conducted using a $\mathrm{X}^{2}$-test $(\alpha=0.05)$.

\subsubsection{RNA isolation, cDNA synthesis, and gene expression analysis}

Total RNA was extracted from rosette leaf tissue collected and pooled from seven-dayold seedlings using the Tri-Reagent protocol (Molecular Research Center, Inc., Cincinnati, $\mathrm{OH}$ ). One microliter of total RNA was treated with $1 \mu \mathrm{L}$ of DNasel (Invitrogen, Carlsbad, CA) and subsequently used for reverse transcription using $10 \mathrm{pg}$ of oligo(dT) primers using the firststrand cDNA synthesis kit (Invitrogen). Quantitative RT-PCR reactions were set up using 2.5 pmole of gene specific primers and 1:10 dilutions of cDNA:DNase/RNase free water with the iQ SYBER Real-Time Master Mix (Bio-Rad, Hercules, CA) in a total volume of $10 \mu \mathrm{L}$. Negative controls contained water instead of reverse transcriptase. Reactions were run in a Bio-Rad iCycler for 40 cycles. The threshold cycles $\left(C_{T}\right)$ were calculated using iQ software (Bio-Rad) and relative transcripts (RT) were calculated using the formula: $R T=1 / 2^{C T}$. The RT values of the genes assessed were normalized to TUBULIN2 and mean values of biological replicates were calculated. Experiments were performed at least three times. PCR fragments were separated on a $1 \%$ agarose gel stained with ethidium bromide to check for correct fragment amplification. Gene-specific primer sequences are listed in Table 3.1.

\subsubsection{Ascorbic acid quantification}

Leaf AA content was determined in leaves from three-week-old rosettes using the iron reduction assay (Dowdle et al., 2007; Mukherjee et al., 2010).

\subsubsection{Abscisic acid quantification}

For abscisic acid (ABA) content measurements, tissue (0.1-0.15 g) was crushed in liquid nitrogen, extracted in $1 \mathrm{ml} 80 \%(\mathrm{v} / \mathrm{v})$ acetone, and incubated overnight in the dark at 4ㅇ. Samples were centrifuged at $14,000 \mathrm{rpm}$ at $4^{\circ} \mathrm{C}$ for $10 \mathrm{~min}$. The supernatant was diluted 1:10 with Tris-buffered saline $(\mathrm{pH} 7.5)$. Abscisic acid content was determined in diluted samples using the Phytodetek ABA kit (Agdia, Elkhart, IN) following the manufacturer's protocol. 


\subsubsection{Statistical analysis}

Data presented are mean values \pm standard errors (SE). Experiments were repeated at least three times. $P$ values were determined by Student's $t$-test or $X^{2}$-test analyses, as indicated.

\subsection{RESULTS}

\subsubsection{AA levels are partially recovered in vtc fca double mutants along with some but not all vtc pleiotropic phenotypes}

The vtc1-1 fca-1 double mutant, which is in the Col/Ler background, has a partially recovered AA content (Fig. 3.2). The total AA content increased more than twice in the double mutant compared to the vtc1-1 single mutant and is approximately $70 \%$ of the Col/Ler wildtype control and the $f c a-1$ single mutant. To test whether a similar recovery of AA content occured in the other vtc mutants and whether this effect is fca allele-specific, we crossed vtc1-1 and vtc4-1 mutants with the $f c a-9$ mutant. This also had the advantage that the double mutants were then entirely in the Col background. We then determined the AA content of the homozygous double mutants. The AA level of the vtc1-1 fca-9 and vtc4-1 fca-9 mutants is partially, but to a much lower extent, recovered compared to their respective AA deficient single mutants (Fig. 3.3).

Furthermore, we evaluated whether the high level of $A B A$ detected in vtc mutants would decrease to wild-type ABA levels in the vtc fca double mutants. As shown in Fig. 3.4, ABA content decreased dramatically in the vtc1-1 fca-1 double mutant, although it was still slightly higher in the Col/Ler wild-type control.

Compared to the respective wild-type controls, root development is partially recovered in the vtc1-1 fca-1 double mutant, but this is not the case in the vtc1-1 fca-9 double mutant when grown in the presence of ammonium (Fig. 3.5). These data suggest that fca does neither act in an allele- nor in a gene-specific manner. It is possible that combining two different backgrounds (vtc1-1 in Col-0, fca-1 in Ler-0 background) may be the reason for the elevated AA content in the vtc1-1 fca-1 double mutant and other restored phenotypes. However, strong effects in the Col/Ler wild-type control are not observed. Therefore, it is not clear what is causing the recovered phenotype in vtc1-1 in the presence of the $f c a-1$ allele. 


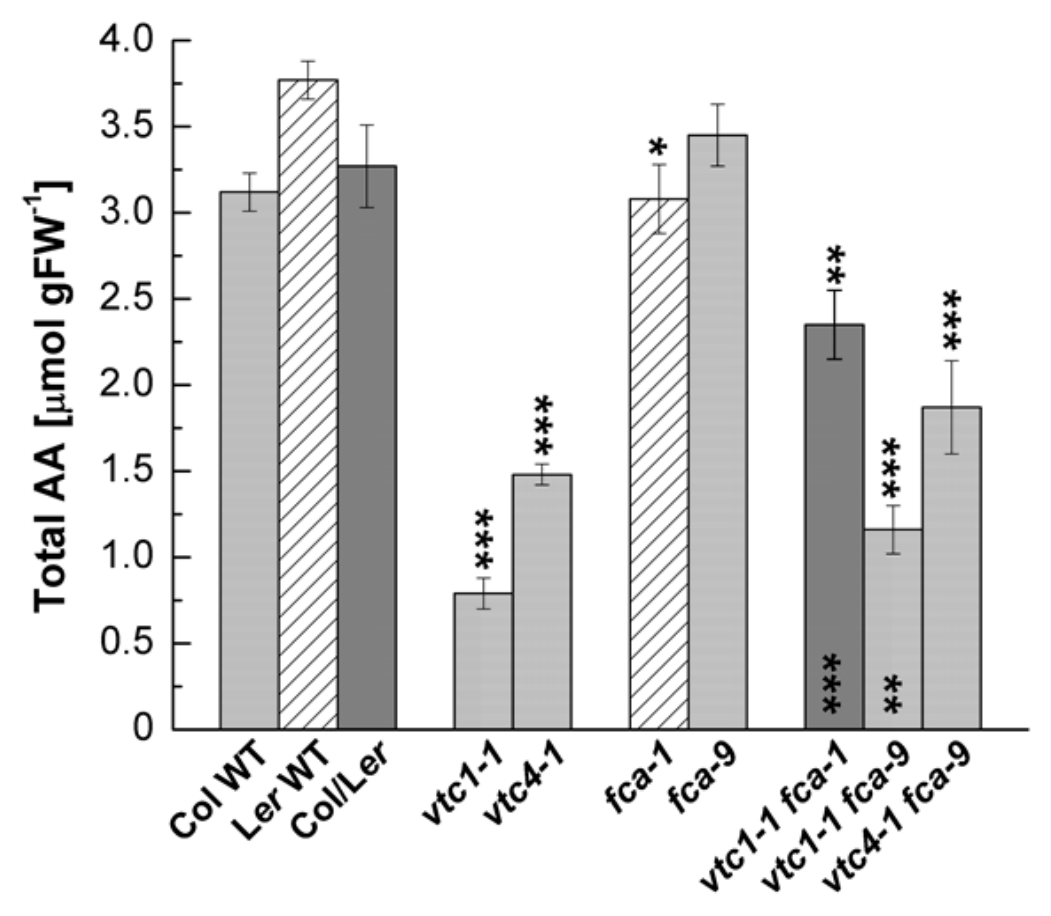

Figure 3.3 Mean ascorbic acid (AA) content in three-week-old rosette leaves of vtc and fca single and double mutants compared to Col, Ler and Col/Ler wild-type controls.

Bars represent means $\pm \mathrm{SE}$. Asterisks indicate ${ }^{*} P<0.05, * * P<0.01,{ }^{* * *} P<0.001$, Student's $t$-test. Statistical differences above bars represent difference from the respective WT, while statistical differences directly above the $x$-axis represent differences from the respective vtc single mutant. Bar shading indicates the lines of the same genetic background. 


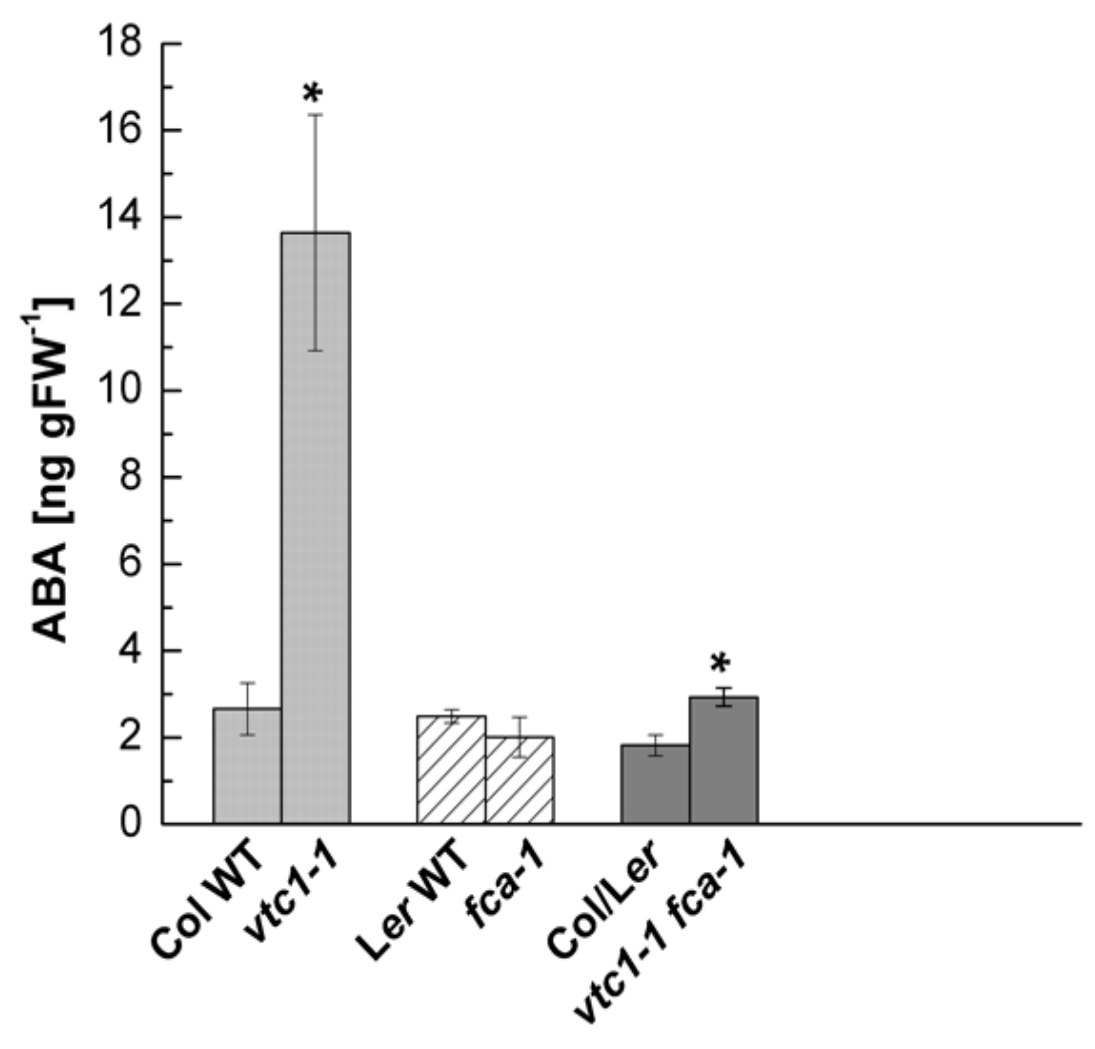

Figure 3.4 Total abscisic acid (ABA) content in Col, Ler and Col/Ler wild-type controls compared to vtc1-1 and fca-1 single mutants and the vtc1-1 fca-1 double mutant.

Bars represent means $\pm \mathrm{SE}$. Asterisks indicate significant differences compared to the respective wildtype controls. ${ }^{*} P$-value $<0.05$, Student's $t$-test. Bar shading represents lines of the same ecotype. 


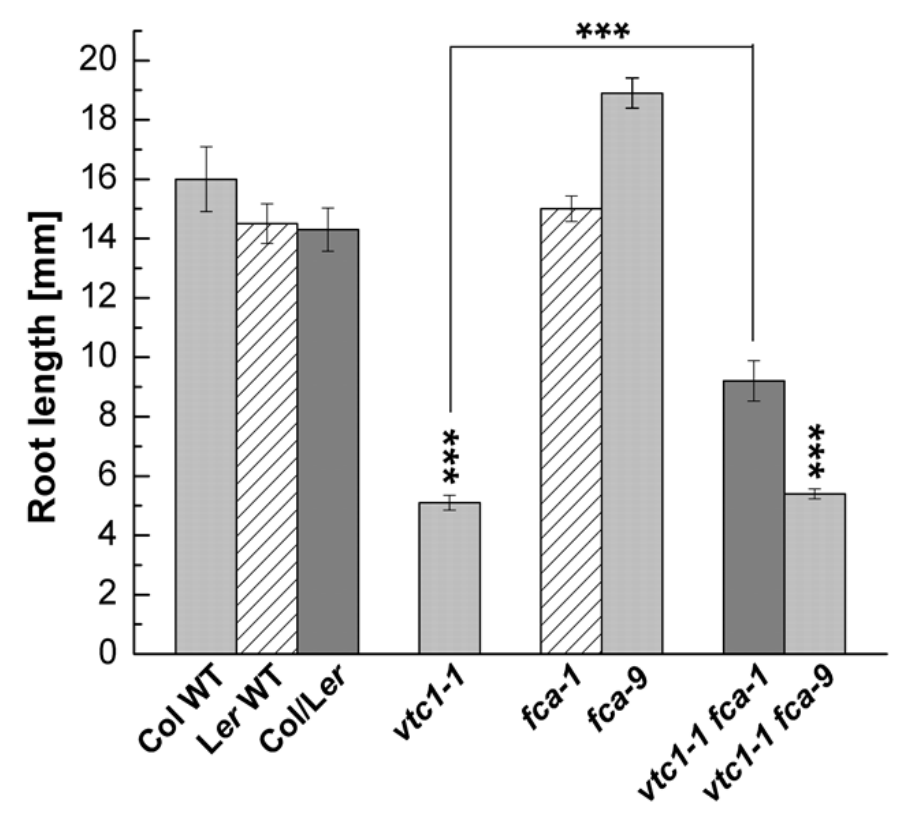

Figure 3.5 Primary root length in seven-day-old Col, Ler, Col/Ler wild-type controls, vtc1-1, fca-1, fca-9 single and vtc1-1 fca-1 and vtc1-1 fca-9 double mutants grown on 1x MS medium.

Bars represent means $\pm \mathrm{SE}$. Asterisks designate significant differences between mutants and respective wild-type controls, unless otherwise indicated. ${ }^{*} P$-value $<0.05,{ }^{* * *} P$-value $<0.005$ Student's $t$-test. Bar shading indicates lines of the same genotype. 


\subsubsection{VTC transcripts are not altered in vtc fca double mutants}

We hypothesized that suppression of AA deficiency occurs through increased transcription of the VTC genes in vtc fca double mutants (Fig. 3.8). Using quantitative real-time PCR (qRT-PCR) we analyzed VTC1 and VTC4 mRNA in vtc1-1 fca-1, vtc1-1 fca-9 and vtc4-1 fca-9 double mutants, respective single mutants, and wild-type controls. In vtc1-1, transcripts of VTC1 were expected to be approximately at the wild-type level since the mutation affects enzyme activity and not transcription (Conklin et al., 1999). This is indeed the case (Fig. 3.6a). Furthermore, VTC1 mRNA levels are similar in the double mutants and Col wild type. Interestingly though, VTC1 transcript levels are substantially lower in the Ler and Col/Ler wild types and the fca-1 single mutant (Fig. 3.6a). Transcript levels of VTC4 were similar in all genotypes, except in the Ler wild type, which contained somewhat higher VTC4 mRNA levels (Fig. 3.6b). This data suggests that in the presence of $f c a$ mutations, transcript levels of VTC1 or VTC4 are not affected.

\subsubsection{Ascorbic acid levels in autonomous pathway flowering time mutants fca-1, fca-9, fld-3, fpa-7, and fpa-7 fld-3 are unchanged}

Because FCA interacts with other proteins in the autonomous flowering pathway, we hypothesized that one or more of these interacting proteins may act at the VTC1 locus or other loci encoding enzymes in the D-mannose/L-galactose pathway to suppress AA biosynthesis. If this were the case, we would expect to see elevated AA amounts in mutants that are affected in the autonomous flowering pathway. As is illustrated in Fig. 3.7, the AA content in $f c a-1, f c a-9$, $f l d-3, f p a-7$, and $f p a-7 f l d-3$ is comparable to the wild type. This data suggest that mutations in these autonomous flowering pathway genes do not alter the AA content.

\subsection{DISCUSSION}

\subsubsection{The autonomous flowering pathway protein, FCA, does not appear to be involved in transcriptional regulation of the VTC1 and VTC4 genes}

Kotchoni et al. (2009) demonstrated that the vtc mutants have significantly reduced levels of $F L C$ mRNA during long days, but this was not directly attributable to the concentration of $A A$, as vtc1-1 fca-1 mutants displayed a delayed flowering phenotype despite having approximately $70 \%$ of wild-type AA. They also observed that double mutants between vtc1-1 and circadian clock and photoperiodic pathway genes exhibited delayed flowering and reduced AA content, and vtc mutants did not have increased mRNAs of gibberellin biosynthesis genes. These data indicate that AA does not directly appear to influence flowering directly through the defined flowering pathways. The data presented here do not suggest that the early flowering phenotype in the vtc mutants is caused by interaction of the examined autonomous 

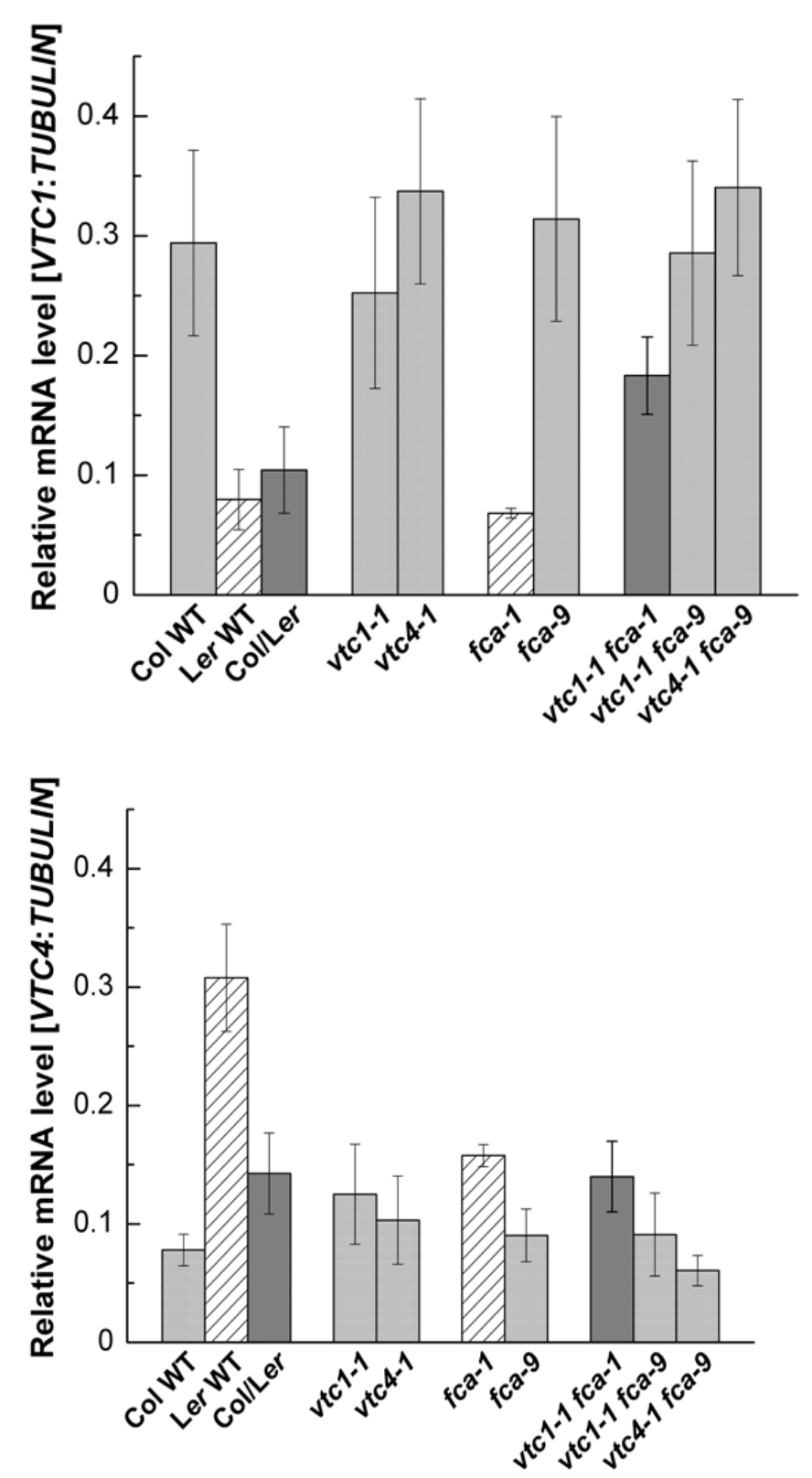

Figure 3.6 Relative transcript levels of VTC1 (a) and VTC4 (b) in mutants and respective controls normalized to TUBULIN mRNA.

Bars represent means $\pm \mathrm{SE}$. No statistical significance was observed, $n=3$ Student's $t$-test, $P<0.05$. Bars of the same shading represent lines of the same genotype. 


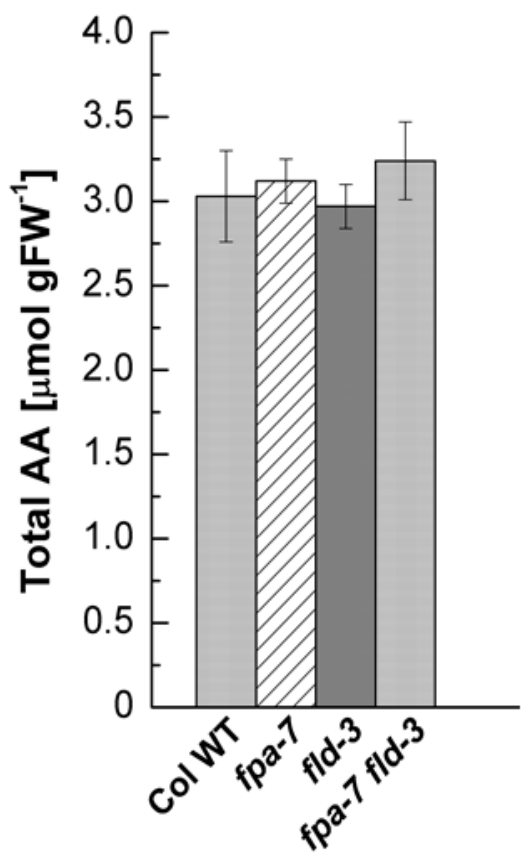

Figure 3.7 Total ascorbic acid (AA) content in three-week-old rosette leaves of autonomous flowering pathway mutants compared to Col wild type (Col WT).

Bars represent means $\pm \mathrm{SE}$. No statistical significance was observed, Student's $t$-test, $P<0.05$. 


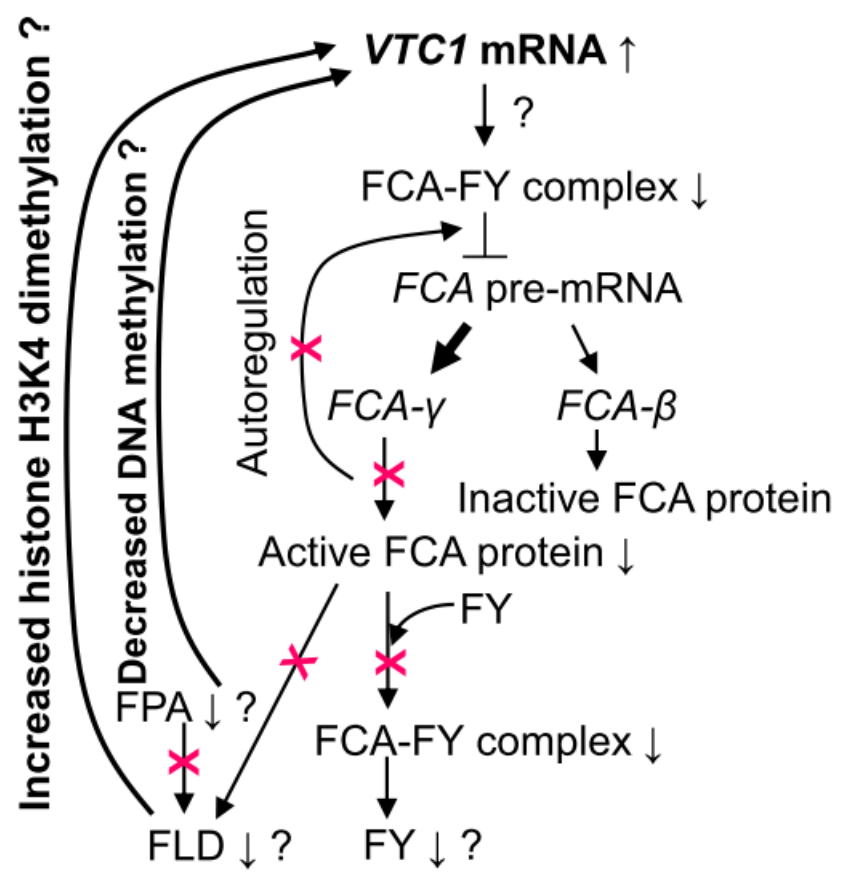

Figure 3.8A hypothetical model of the interaction between VTC1 and FCA in the vtc1-1 fca-1 double mutant.

Arrows pointing up or down illustrate an increase or decrease, respectively. Red crosses indicate dysfunction. Since FCA requires both FY and the demethylase FLD, which requires FPA, we propose that the defect in FCA results in decreased FLD and FPA activities. FLD is required for histone H3K4 demethylation. Thus, H3K4 dimethylation is increased in $f c a$ mutants, which is associated with overall increased transcriptional activity. In contrast, DNA methylation is compromised in fca and fpa mutants. Hence, we hypothesize that VTC1 transcription is enhanced in the double mutant through increased H3K4 dimethylation and/or decreased DNA methylation. It is not clear why fca-1 single mutants do not have higher than wild-type levels of AA. We suggest that there are additional factors acting in this regulation and that negative feedback control by AA itself (not indicated) is contributing to maintaining AA homeostasis. 
flowering pathway proteins at transcriptional regulation of the VTC1 or VTC4 loci. We do provide evidence that mutations in the FCA gene suppress AA deficiency in the vtc1-1 and the vtc4-1 mutants in a recessive manner (Fig. 3.3). This suggests that in the wild type, FCA functions to limit $A A$ accumulation, presumably in order to maintain AA homeostasis. This is most likely does not occur directly through FCA, but may be through one of its interacting partners by an unknown mechanism. Our initial hypothesis proposed that FCA and/or one of its interacting partners may affect chromatin modifications at the VTC loci as mutations in FCA and FPA suppress RNA-mediated chromatin silencing (Baurle et al., 2007). However, our qRT-PCR data do not support a role of FCA in the transcriptional regulation of VTC genes (Fig. 3.6). Since the FCA pre-mRNA is a target for alternative splicing (Macknight et al., 1997; Page et al., 1999; Simpson et al., 2004), it is possible that the VTC genes (or genes within other AA biosynthetic pathways) are also targets of the FCA-splicing complex (Fig. 3.8). Currently listed on The Arabidopsis Resource (http://arabidopsis.org) are two known VTC1 transcripts which have an alternatively spliced 3' UTR region and three possible alternative transcripts for VTC4. Interestingly, using the Arabidopsis Small RNA Project database (http://asrp.cgrb.oregonstate.edu/db/; Backman et al., 2008; Gustafson et al., 2005), we identified two small RNAs which match the VTC1 gene sequence. One of these matches a 20 base-pair region in the fourth exon and the other matches a 22 base-pair sequence near the $5^{\prime}$ region of the 3' UTR. Considering the RNA-binding properties of FCA and the importance of FY in RNA processing - null fy mutant alleles are embryo lethal (Henderson et al., 2005)-it seems plausible that the VTC genes may be regulated at the post-transcriptional level, but this needs further experimental evidence.

The two fca mutant alleles, $f c a-1$ (Ler-0 background) and fca-9 (Col-0 background), have varying effects on the suppression of vtc mutations. Mixing the Col and Ler backgrounds in the vtc1-1 fca-1 double mutant may complicate interpretations due to the presence of polymorphisms and modifier genes that may affect the AA phenotype (Koornneef et al., 2004). Supporting this idea are the results from a microarray experiment conducted by Marquardt et al. (2006) that aimed to find additional targets of FCA by comparing expression changes in Col-0, fca-9, Ler-0, and fca-1. The group observed many expression changes in an unexpected accession-specific manner. However, the authors speculated that the observed differences could be due to inter-experimental variation that could not be overcome through their analyses or that genome-sequence differences interfered with probe hybridization (Marquardt et al., 2006). The VTC1 gene does have polymorphisms between Col-0 and Ler-0, although they appear to neither affect VTC1 transcript accumulation (Fig. 3.6) nor AA biosynthesis (Fig. 3.3). Therefore, the question arises whether $f c a-1$ and $f c a-9$ mutant alleles differ in their strength. The fca-1 mutant contains a premature stop codon within exon 13, which leads to the loss of the WW domain (Fig. 3.2; Macknight et al., 1997). The fca-9 mutant is a splice mutant that 
produces a truncated protein even shorter than that in fca-1 (Fig. 3.2; Page et al. 1999). In respect to flowering, the relative strength of the $f c a-1$ and $f c a-9$ mutations cannot be compared, because the Col-0 ecotype contains dominant alleles at $F L C$, enhancing the late flowering phenotype of $f c a$ mutations (Sanda, 1996). Although, in support of accession-specific transcriptome differences, $f c a-9$ and vtc1-1 fca-9 double mutants flower much later than $f c a-1$ and vtc1-1 fca-1 double mutants (Kempinski and Barth, unpublished results).

\subsubsection{A wide variety of control mechanisms affect the autonomous and other flowering pathways in a combinatorial manner, making it difficult to elucidate the manner in which ascorbic acid biosynthesis is affected by flowering time}

Plants must incorporate both environmental and internal cues to switch from vegetative to floral growth. Multiple pathways (Fig. 3.1), which to some extent are reglated by epigenetic mechanisms, mediate the transition from the vegetative to the reproductive phase (Jack, 2004), requiring regulatory proteins. Proteins involved in the autonomous pathway can be divided into two broad groups: RNA-binding proteins (including FPA and FCA; Macknight et al., 1997; Schomburg et al., 2001) and chromatin-modifying proteins (Noh and Noh, 2006). In conjunction with regulating flowering through the autonomous pathway, several of these proteins also act redundantly to alter gene expression of non-flowering associated genes (Veley et al. 2008). Baurle et al. (2007) found that FCA and FPA act redundantly with each other, and in parallel with siRNA silencing machinery, to suppress many loci across the genome whose silencing is dependent on siRNAs and are not directly linked to floral induction. As stated above, it could be possible that the VTC genes are post-transcriptionally regulated or that flux through another AA biosynthetic pathway could be affected (at least, partially) by FCA and its partners. The study by Kotchoni et al. (2009) showed that AA does not appear to directly affect any specific flowering pathway and it seems likely that the pleiotropic phenotypes (Table 1.1) of the vtc mutants contribute in a complex manner to the early flowering phenotype. For example: elevated ABA is known to delay flowering, while elevated SA can suppress FLC under short days, but independently of FCA (Davis, 2009).

\subsubsection{Concluding remarks}

Taken together, it has been demonstrated that FCA has other targets beyond floral induction (Marquardt et al. 2006). We have found that FCA influences the accumulation of AA, a process that does not involve transcriptional regulation of VTC genes. It is possible that FCA and its partners act at one or more of the other AA biosynthetic pathways (Hancock and Viola, 2005a; Hancock and Viola, 2005b; Lorence et al., 2004). We speculate that FCA and its interacting partners are important for maintaining $A A$ homeostasis. Given the current literature, this may occur through multiple partners regulating post-transcriptional processes. 
This might also explain why it is difficult to elevate AA content in plants substantially through overexpression of AA biosynthetic genes (Ishikawa et al., 2006). It is clear that there is link between $A A$ accumulation and flowering time and this work provides additional groundwork for elucidating the role of $A A$ in flowering time.

\subsection{REFERENCES}

Abe M, Kobayashi Y, Yamamoto S, Daimon Y, Yamaguchi A, Ikeda Y, Ichinoki H, Notaguchi M, Goto K,Araki T (2005) FD, a bZIP protein mediating signals from the floral pathway integrator FT at the shoot apex. Science 309: 1052-1056

Backman TW, Sullivan CM, Cumbie JS, Miller ZA, Chapman EJ, Fahlgren N, Givan SA, Carrington JC,Kasschau KD (2008) Update of ASRP: the Arabidopsis Small RNA Project database. Nucleic Acids Res 36: D982-985

Barth C, Gouzd ZA, Steele HP,Imperio RM (2010) A mutation in GDP-mannose pyrophosphorylase causes conditional hypersensitivity to ammonium, resulting in Arabidopsis root growth inhibition, altered ammonium metabolism and hormone homeostasis. Journal of Experimental Botany 57: 1657-1665

Baurle I, Smith L, Baulcombe DC,Dean C (2007) Widespread role for the flowering-time regulators FCA and FPA in RNA-mediated chromatin silencing. Science 318: 109-112

Blazquez MA (2005) Plant science. The right time and place for making flowers. Science 309: 1024-1025

Boss PK, Bastow RM, Mylne JS,Dean C (2004) Multiple pathways in the decision to flower: enabling, promoting, and resetting. The Plant Cell 16 Suppl: S18-31

Conklin PL, Williams EH,Last RL (1996) Environmental stress sensitivity of an ascorbic acid-deficient Arabidopsis mutant. Proceedings of the National Academy of Sciences of the United States of America 93: 9970-9974

Conklin PL, Norris SR, Wheeler GL, Williams EH, Smirnoff N,Last RL (1999) Genetic evidence for the role of GDP-mannose in plant ascorbic acid (vitamin C) biosynthesis. Proceedings of the National Academy of Sciences of the United States of America 96: 4198-4203

Conklin PL, Saracco SA, Norris SR,Last RL (2000) Identification of ascorbic acid-deficient Arabidopsis thaliana mutants. Genetics 154: 847-856

Conklin PL (2001) Recent advances in the role and biosynthesis of ascorbic acid in plants. Plant, Cell and Environment 24: 383-394

Corbesier L,Coupland G (2005) Photoperiodic flowering of Arabidopsis: integrating genetic and physiological approaches to characterization of the floral stimulus. Plant, Cell and Environment 28: $54-66$

Davis SJ (2009) Integrating hormones into the floral-transition pathway of Arabidopsis thaliana. Plant, Cell \& Environment 32: 1201-1210

Dowdle J, Ishikawa T, Gatzek S, Rolinski S,Smirnoff N (2007) Two genes in Arabidopsis thaliana encoding GDP-L-galactose phosphorylase are required for ascorbate biosynthesis and seedling viability. The Plant Journal 52: 673-689

Feng W, Jacob Y, Veley KM, Ding L, Yu X, Choe G,Michaels SD (2011) Hypomorphic alleles reveal FCAindependent roles for FY in the regulation of FLOWERING LOCUS C. Plant Physiology 155: 14251434

Gustafson AM, Allen E, Givan S, Smith D, Carrington JC,Kasschau KD (2005) ASRP: the Arabidopsis Small RNA Project Database. Nucleic Acids Res 33: D637-640 
Hancock R,Viola R (2005a) Biosynthesis and Catabolism of L-Ascorbic Acid in Plants. Critical Reviews in Plant Sciences 24: 167-188

Hancock RD,Viola R (2005b) Biosynthesis and catabolism of L-ascorbic acid in plants. Critical Reviews in Plant Sciences 24: 167-188

He Y, Michaels SD,Amasino RM (2003) Regulation of flowering time by histone acetylation in Arabidopsis. Science 302: 1751-1754

Henderson IR, Liu F, Drea S, Simpson GG,Dean C (2005) An allelic series reveals essential roles for FY in plant development in addition to flowering-time control. Development 132: 3597-3607

Hepworth S, Valverde F, Ravenscroft D, Mouradov A,Coupland G (2002) Antagonistic regulation of flowering-time gene SOC1 by CONSTANS and FLC via separate promoter motifs. The EMBO Journal 21: 4327-4337

Huang T, Bohlenius H, Eriksson S, Parcy F,Nilsson O (2005) The mRNA of the Arabidopsis gene FT moves from leaf to shoot apex and induces flowering. Science 309: 1694-1696

Ishikawa T, Dowdle J,Smirnoff N (2006) Progress in manipulating ascorbic acid biosynthesis and accumulation in plants. Physiologia Plantarum 126: 343-355

Jack T (2004) Molecular and genetic mechanisms of floral control. The Plant Cell 16 Suppl: S1-17

Kobayashi Y,Weigel D (2007) Move on up, it's time for change--mobile signals controlling photoperioddependent flowering. Genes and Development 21: 2371-2384

Koornneef M, Alonso-Blanco C, Peeters AJ,Soppe W (1998) Genetic Control of Flowering Time in Arabidopsis. Annual Review of Plant Physiology and Plant Molecular Biology 49: 345-370

Koornneef M, Alonso-Blanco C,Vreugdenhil D (2004) Naturally occurring genetic variation in Arabidopsis thaliana. Annual review of plant biology 55: 141-172

Kotchoni SO, Larrimore KE, Mukherjee M, Kempinski CF,Barth C (2009) Alterations in the endogenous ascorbic acid content affect flowering time in Arabidopsis. Plant Physiology 149: 803-815

Lee I, Aukerman MJ, Gore SL, Lohman KN, Michaels SD, Weaver LM, John MC, Feldmann KA,Amasino RM (1994) Isolation of LUMINIDEPENDENS: a gene involved in the control of flowering time in Arabidopsis. The Plant Cell 6: 75-83

Lee J,Lee I (2010) Regulation and function of SOC1, a flowering pathway integrator. Journal of Experimental Botany 61: 2247-2254

Liu F, Quesada V, Crevillen P, Baurle I, Swiezewski S,Dean C (2007) The Arabidopsis RNA-binding protein FCA requires a lysine-specific demethylase 1 homolog to downregulate FLC. Molecular Cell 28: 398-407

Liu L, Zhang YC, Li QH, Sang Y, Mao J, Lian HL, Wang L,Yang HQ (2008) COP1-mediated ubiquitination of CONSTANS is implicated in cryptochrome regulation of flowering in Arabidopsis. The Plant Cell 20: 292-306

Lorence A, Chevone BI, Mendes P,Nessler CL (2004) myo-inositol oxygenase offers a possible entry point into plant ascorbate biosynthesis. Plant Physiology 134: 1200-1205

Macknight R, Bancroft I, Page T, Lister C, Schmidt R, Love K, Westphal L, Murphy G, Sherson S, Cobbett C,Dean C (1997) FCA, a gene controlling flowering time in Arabidopsis, encodes a protein containing RNA-binding domains. Cell 89: 737-745

Macknight R (2002) Functional Significance of the Alternative Transcript Processing of the Arabidopsis Floral Promoter FCA. The Plant Cell Online 14: 877-888

Marquardt S, Boss PK, Hadfield J,Dean C (2006) Additional targets of the Arabidopsis autonomous pathway members, FCA and FY. Journal of Experimental Botany 57: 3379-3386

Michaels SD,Amasino RM (1999a) FLOWERING LOCUS C encodes a novel MADS domain protein that acts as a repressor of flowering. The Plant Cell 11: 949-956 
Michaels SD,Amasino RM (1999b) The gibberellic acid biosynthesis mutant ga1-3 of Arabidopsis thaliana is responsive to vernalization. Developmental Genetics 25: 194-198

Michaels SD,Amasino RM (2001) Loss of FLOWERING LOCUS C activity eliminates the late-flowering phenotype of FRIGIDA and autonomous pathway mutations but not responsiveness to vernalization. The Plant Cell 13: 935-941

Michaels SD, Ditta G, Gustafson-Brown C, Pelaz S, Yanofsky M,Amasino RM (2003) AGL24 acts as a promoter of flowering in Arabidopsis and is positively regulated by vernalization. Plant Journal 33: 867-874

Miller G, Suzuki N, Rizhsky L, Hegie A, Koussevitzky S,Mittler R (2007) Double mutants deficient in cytosolic and thylakoid ascorbate peroxidase reveal a complex mode of interaction between reactive oxygen species, plant development, and response to abiotic stresses. Plant Physiology 144: 1777-1785

Mukherjee M, Larrimore KE, Ahmed NJ, Bedick TS, Barghouthi NT, Traw MB,Barth C (2010) Ascorbic acid deficiency in Arabidopsis induces constitutive priming that is dependent on hydrogen peroxide, salicylic acid and the NPR1 gene. Molecular Plant-Microbe Interactions 23: 340-351

Noh B,Noh Y-S (2006) Chromatin-mediated regulation of flowering time in Arabidopsis. Physiologia Plantarum 126: 484-493

Page T, Macknight R, Yang CH,Dean C (1999) Genetic interactions of the Arabidopsis flowering time gene FCA, with genes regulating floral initiation. The Plant Journal 17: 231-239

Putterill J, Robson F, Lee K, Simon R,Coupland G (1995) The CONSTANS gene of Arabidopsis promotes flowering and encodes a protein showing similarities to zinc finger transcription factors. Cell 80: 847-857

Quesada V, Macknight R, Dean C,Simpson GG (2003) Autoregulation of FCA pre-mRNA processing controls Arabidopsis flowering time. The EMBO Journal 22: 3142-3152

Sanda SL, Amasino, R. M. (1996) Ecotype-Specific Expression of a Flowering Mutant Phenotype in Arabidopsis thaliana. Plant Physiology 111: 641-644

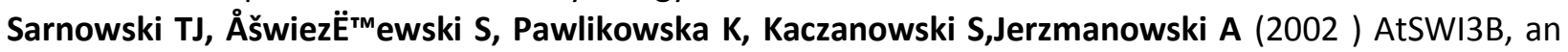
Arabidopsis homolog of SWI3, a core subunit of yeast Swi/Snf chromatin remodeling complex, interacts with FCA, a regulator of flowering time Nucleic Acids Research 30 3412-3421

Sarnowski TJ, RÃ-os G, JÃisik J, Swiezewski S, Kaczanowski S, Li Y, Kwiatkowska A, Pawlikowska K, Kozbial M, Kozbial P, Koncz C,Jerzmanowski A (2005) SWI3 Subunits of Putative SWI/SNF Chromatin-Remodeling Complexes Play Distinct Roles during Arabidopsis Development The Plant Cell Online 17 2454-2472

Schomburg FM, Patton DA, Meinke DW,Amasino RM (2001) FPA, a Gene Involved in Floral Induction in Arabidopsis, Encodes a Protein Containing RNA-Recognition Motifs The Plant Cell Online 13 1427-1436

Shi Y, Lan F, Matson C, Mulligan P, Whetstine JR, Cole PA,Casero RA (2004) Histone demethylation mediated by the nuclear amine oxidase homolog LSD1. Cell 119: 941-953

Simpson GG, Dijkwel PP, Quesada V, Henderson I,Dean C (2003) FY is an RNA 3' end-processing factor that interacts with FCA to control the Arabidopsis floral transition. Cell 113: 777-787

Simpson GG, Quesada V, Henderson IR, Dijkwel PP, Macknight R,Dean C (2004) RNA processing and Arabidopsis flowering time control. Biochem Soc Trans 32: 565-566

Valverde F, Mouradov A, Soppe W, Ravenscroft D, Samach A,Coupland G (2004) Photoreceptor regulation of CONSTANS protein in photoperiodic flowering. Science 303: 1003-1006

Veley KM,Michaels SD (2008) Functional redundancy and new roles for genes of the autonomous floralpromotion pathway. Plant Physiology 147: 682-695 
Wigge PA, Kim MC, Jaeger KE, Busch W, Schmid M, Lohmann JU,Weigel D (2005) Integration of spatial and temporal information during floral induction in Arabidopsis. Science 309: 1056-1059 